\title{
An evaluation of the effects of thermal insulation levels on the energy performance of New Zealand office buildings- exploring the impact of building attributes on the performance of thermal insulation
}

By

Brittany Grieve

A thesis submitted to the

School of Architecture, Victoria University of Wellington

In fulfilment of the requirements for the degree of

Master of Building Science

Victoria University of Wellington 



Author: Brittany Grieve

School of Architecture

Victoria University of Wellington

Email: grievebritt@gmail.com

Supervisor: Dr Nigel Isaacs

Senior Lecturer

School of Architecture

Victoria University of Wellington

Email: nigel.isaacs@vuw.ac.nz 
This thesis explored the impact of thermal insulation on the energy performance of New Zealand air-conditioned commercial office buildings. A sample of calibrated energy models constructed using real building performance data and construction information was used to ensure that the results produced were as realistic as possible to the actual building performance of New Zealand commercial office buildings. The aim was to assess how different climates and building attributes impact thermal insulation's ability to reduce energy consumption in New Zealand commercial office buildings.

Driven by the ever increasing demands for healthier, more comfortable, more sustainable buildings, building regulations have steadily increased the levels of insulation they require in new buildings over time. Improving the thermal properties of the building envelope with the addition of thermal insulation is normally used to reduce the amount of heating and cooling energy a building requires. Thermal insulation reduces the conductive heat transfer through the building envelope and with a higher level of thermal resistance, the less heat would transfer through the envelope. Consequently, the common expectation is that the addition of thermal insulation to the building envelope will always reduce energy consumption. However, this assumption is not always the case. For internal load dominated buildings located in certain climates, the presence of any or a higher level of thermal insulation may prevent heat loss through the wall, increasing the cooling energy required. This issue is thought to have not been directly examined in literature until 2008. However, an early study undertaken in New Zealand in 1996 found that for climates similar or warmer than Auckland, the addition of insulation could be detrimental to an office building's energy efficiency due to increased cooling energy requirements.

The energy performance of a sample of 13 real New Zealand office building energy models with varying levels of thermal insulation in 8 locations was examined under various scenarios. A parametric method of analysis using building energy modelling was used to assess the energy performance of the buildings. Buildings were modelled as built and standardised with the current NZS4243:2007 regulated and 
assumed internal load and operational values. The effect the cooling thermostat set point temperature had on the buildings' energy performance at varying levels of insulation was also tested.

The study concluded that the use of thermal insulation in New Zealand office buildings can cause an increase in cooling energy for certain types of buildings in any of the eight locations and thermal insulation levels explored in the study. The increase in cooling energy was significant enough to increase the total energy consumption of two buildings when modelled as built. These buildings were characterised by large internal loads, low performance windows with high window to wall ratios and low surface to volume ratios. The current minimum thermal resistance requirements were found to not be effective for a number of buildings in North Island locations. 


\section{Acknowledgements}

Firstly, I would like to thank my supervisor, Nigel Isaacs. Your kind support, encouragement and advice are greatly appreciated.

Thanks to my parents, friends and fellow MBSc students. 


\section{Table of Contents}

PREFACE.

ABSTRACT.

ACKNOWLEDGEMENTS IV

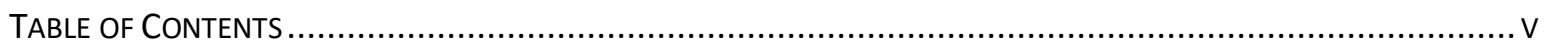

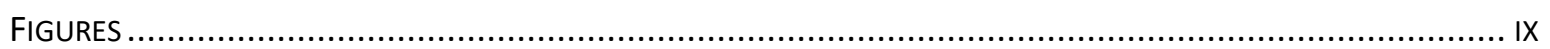

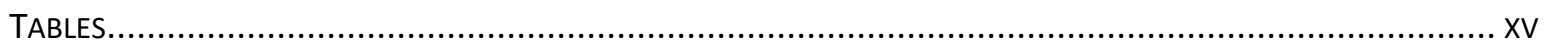

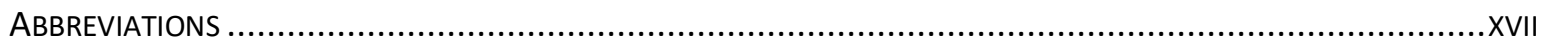

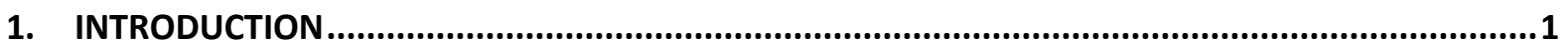

1.1. THERMAL INSULATION IN OfFICE BUILDINGS- THE ISSUE.................................................

1.1.1. Circumstances Remain Ambiguous.......................................................

1.2. RESEARCH AIM, HYPOTHESIS AND QUESTIONS ..........................................................

1.2.1. Research Hypothesis ..................................................................... 4

1.2.2. Research Questions........................................................................ 4

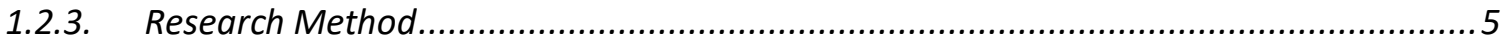

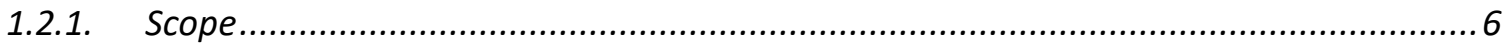

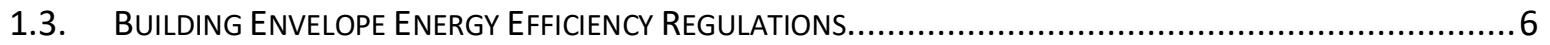

1.3.1. New Zealand Standard for Energy Efficiency: Current Minimum Thermal Resistance

Requirements ............................................................................................. 7

1.3.2. Development Findings: Thermal insulation sensitivity studies undertaken to test influence of internal load, window to wall ratio, operating schedule and HVAC system ..............8

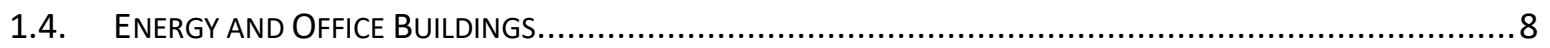

1.4.1. Energy End Uses in New Zealand Office Buildings............................................... 9

1.4.2. Factors that determine a buildings energy use cannot be viewed in isolation ................9

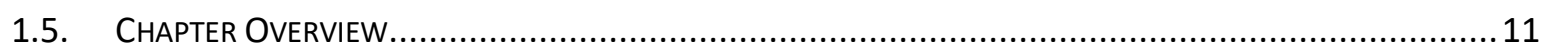

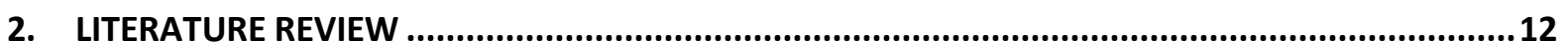

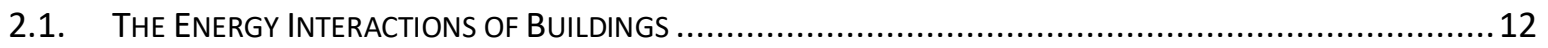

2.1.1. Space conditioning energy use translates to the building internal and external loads .. 13

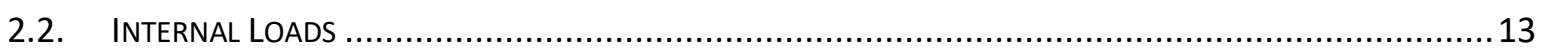

2.2.1. The impact of internal load level on energy consumption is dependent on climate and building attributes

2.2.2. High internal heat gains may contribute to increased or reduced energy consumption 16 
2.2.3. New Zealand Standard for Energy Efficiency: Lighting, Equipment and Occupancy Requirements

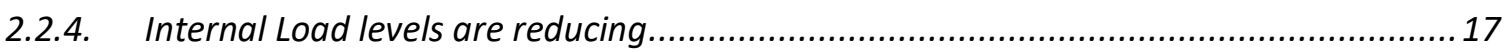

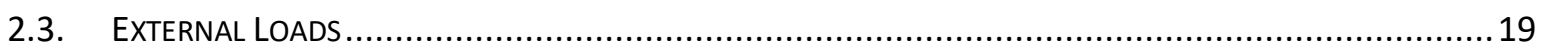

2.3.1. Mediterranean and Temperate Climates are the most susceptible to adverse energy behaviour

2.3.2. Climate Change: higher temperatures will decrease amount of time building spends warmer internally.

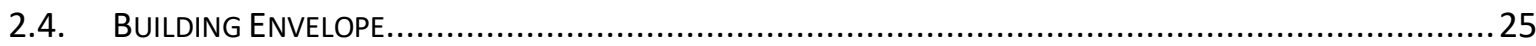

2.4.1. Shape and Orientation: Lower surface to volume ratio may increase internal load domination, higher ratio is expected to significantly improve energy savings from wall thermal

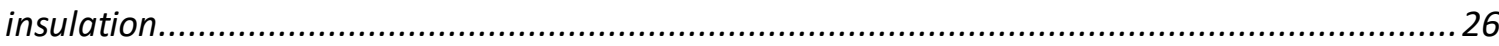

2.4.2. Building Materials: type and configuration effect energy use ...................................2

2.4.3. Windows: window design has a major impact on energy use in buildings.................... 30

2.4.4. Energy savings decrease as insulated wall area decreases......................................... 31

2.4.1. Low window to wall ratios benefit buildings in hot climates, high window to wall ratios

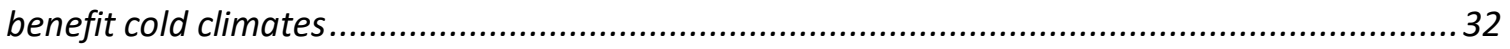

2.4.2. Higher distribution of glazing on north façade increases energy use.............................33

2.4.3. New Zealand: The colder the climate, the greater the increase in energy use for

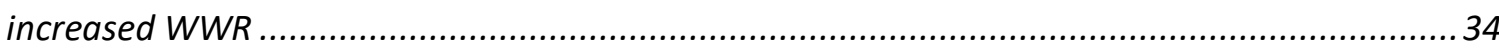

2.4.4. Shading reduces cooling load and can increase heating.............................................. 34

2.4.1. Natural Ventilation can reduce the internal heat load ................................................. 36

2.5. SPACE CONDITIONING SYSTEMS: DIFFERENT SYSTEMS AND DESIGN WILL HAVE DIFFERENT HEATING AND COOLING DEMANDS

2.5.1. The cooling set point can determine whether a building is susceptible to the adverse effect 37

2.5.1. Free-cooling can reduce or prevent an increase in energy use.

2.6. SUMMARY: DRIVERS OF THERMAL INSULATION RESULTING IN REDUCED AND INCREASED SPACE CONDITIONING ENERGY USE.

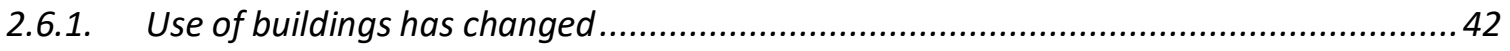

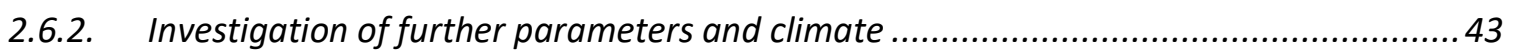

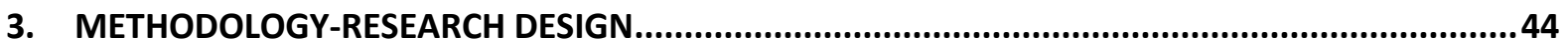

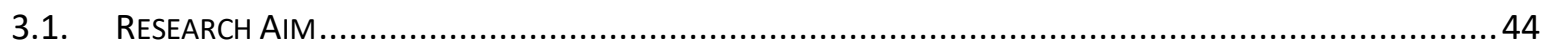

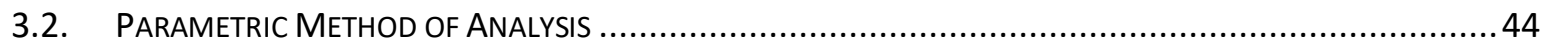


3.3. WhOlE BUILDING SIMULATION: USING ENERGYPLUS

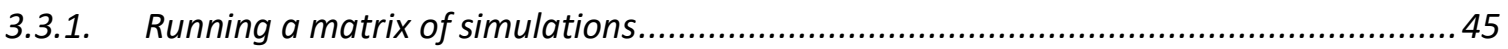

3.4. DESIGN OF PARAMETRIC STUDY: THREE SETS OF ENERGY MODELLING ............................................... 47

3.4.1. Thermal Insulation Levels: Used for all sets of modelling ........................................... 48

3.4.2. Climates: Selection process for study locations and weather data ..............................49

3.4.3. As-built: Exploring effect of climate and thermal resistance level of the calibrated

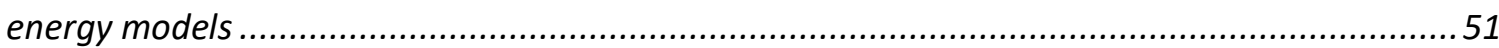

3.4.4. Energy Models Standardized to regulated and assumed NZS4243:2007 values............51

3.4.1. Exploration of Building Attribute: Cooling thermostat set point temperature................54

3.5. RELIABILITY AND REPRESENTATION OF SAMPLE OF REAL NEW OfFICE ZEALAND BUILDINGS....................54

3.5.1. Energy Performance of Real New Zealand Office Buildings........................................55

3.5.2. Benefit of using real building energy models over prototypical energy models.............55

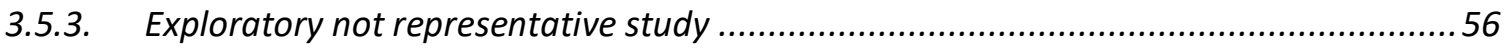

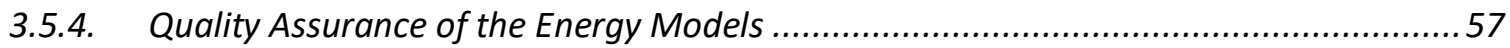

3.5.1. Construction of the Energy Models: Simplifications of the models and the limitations for

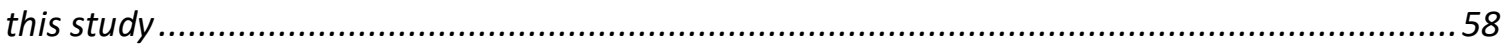

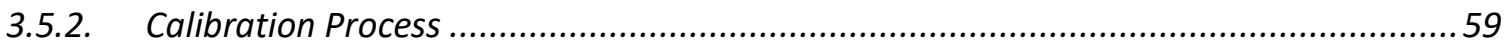

3.5.3. Energy Performance of the Energy Models: the performance varies greatly from how

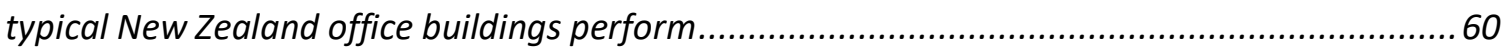

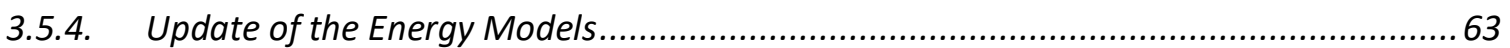

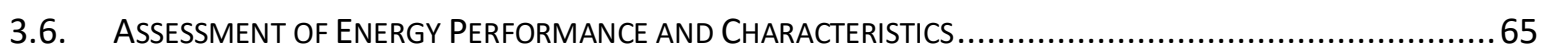

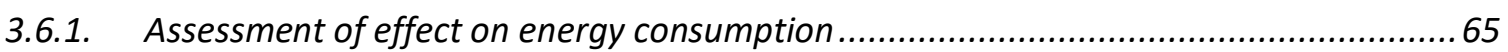

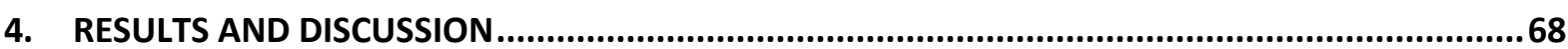

4.1. AS-BUILT: EXPLORING THE EFFECT OF INCREASING INSULATION LEVEL AND LOCATION ON AS-BUILT ENERGY

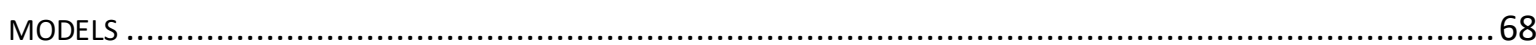

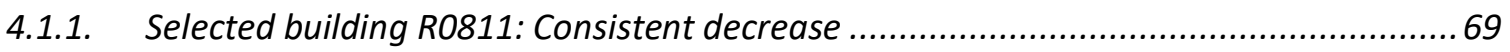

4.1.2. Selected building R0738: Increase cooling energy ................................................ 72

4.1.1. Selected building R1586: Increase total building energy ......................................... 77

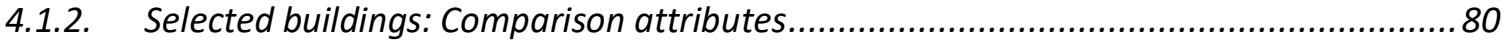

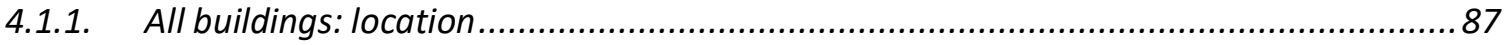

4.1.2. Effect on cooling energy consumption: All buildings ............................................. 90

4.1.3. Comparison of buildings energy performance: Total Energy .................................... 93

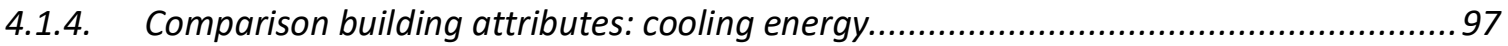

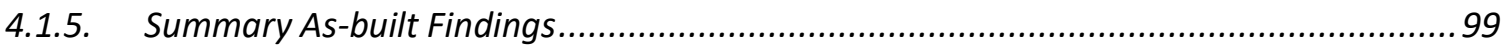


4.2. STANDARDIZED BUILDINGS: NZS4243 REGULATIONS AND ASSUMPTIONS .99

4.2.1. Comparison Energy Consumption of Selected Buildings ..........................................100

4.2.2. All Buildings Effect on Total Energy Consumption: Location ........................................ 102

4.2.1. All Buildings Effect on Cooling Energy Consumption: Location .................................. 104

4.2.2. Comparison Attributes: Total Energy Consumption................................................. 107

4.2.3. Cooling Energy Consumption: Comparison attributes ............................................ 109

4.2.4. Summary of Findings Standardised buildings........................................................ 112

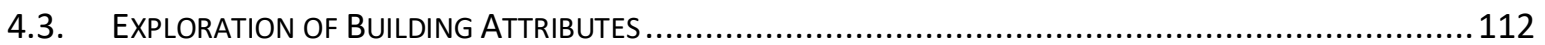

4.3.1. Cooling Set Point: Effect on cooling energy........................................................ 112

4.3.2. Cooling Set Point: effect on heating and cooling energy ......................................118

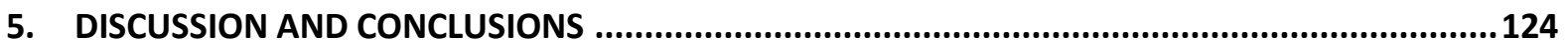

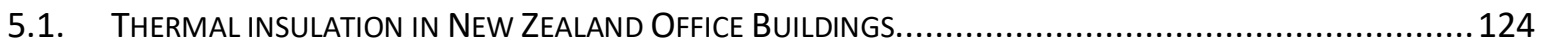

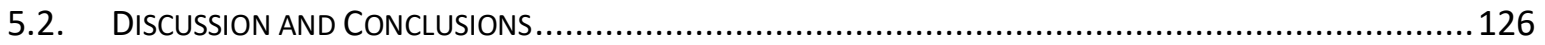

5.2.1. Can thermal insulation have a negative impact on total energy consumption in New

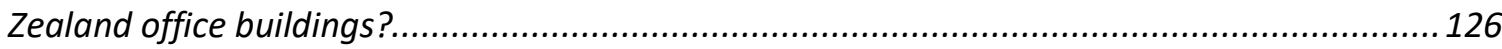

5.2.2. What are the characteristics of New Zealand office buildings that may lead to more

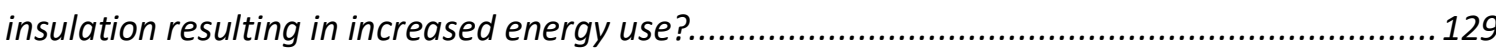

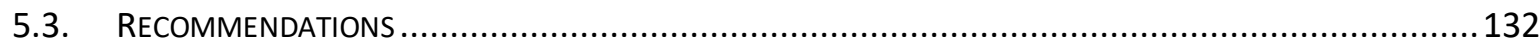

5.3.1. Current requirements found not to be effective: minimum thermal resistance requirements should be set for greater than two areas of New Zealand and for different size ranges of buildings.

5.3.2. Use of Building Energy Modelling should be mandatory to demonstrate compliance with the minimum requirements.

5.3.1. Re-evaluation should use a larger sample of real buildings and explore greater number of climates.

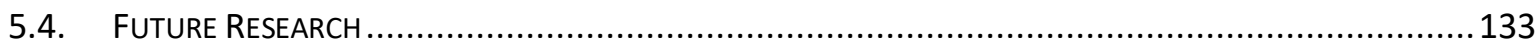

6. REFERENCES

7. APPENDIX.

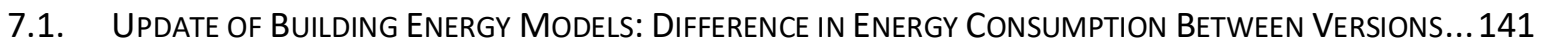

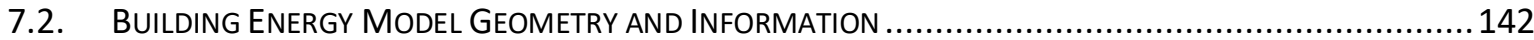

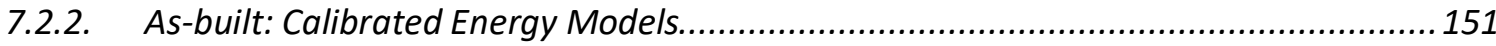

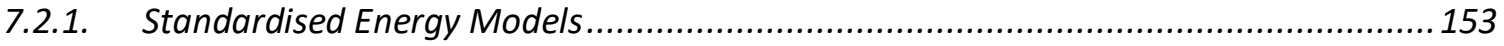

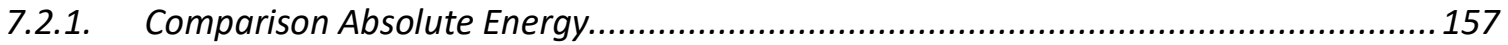


Figure 1 Energy use within a building -showing driving forces on the left, energy interactions are in the central portion and the desired result(user environment) is to the right (Reconstructed using image from (Isaacs, Lee, \& Donn, 1995) . 10

Figure 2 Milan annual primary energy requirements- effect of internal load and thermal insulation level (insulation in walls and roof). 15

Figure 3 Palermo annual primary energy requirements- effect of internal load and thermal insulation level (insulation in walls and roof)

Figure 4 Cairo annual primary energy requirements- effect of internal load and thermal insulation level (insulation in walls and roof)

Figure 5 Rome annual primary energy requirements- effect of internal load and thermal insulation level (insulation in walls and roof) .................................................. 15

Figure 6 Studied cities and effect on EUI (Friess et al., 2017). 20

Figure 7 Total building energy consumption ( $\mathrm{kWh} / \mathrm{m}^{2} / \mathrm{year}$ ) of a 5 storey office

building modelled with different urban density aspect ratios (Strømann-Andersen

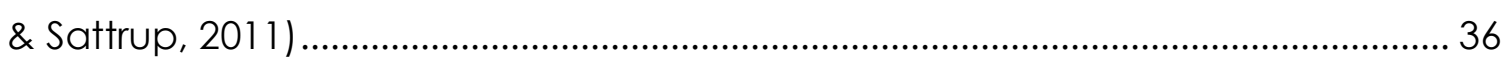

Figure 8 Locations the sample of buildings are simulated in and the NZBC zones ..... 50 Figure 9 Building R0811 Queenstown Annual Energy Use for Energy Use Types $\left(\mathrm{kWh} / \mathrm{m}^{2}\right)$. 70

Figure 10 Building R0811 Queenstown percentage reduction annual energy use types. 70

Figure 11 Building R0811 percentage reduction total energy consumption all locations.

Figure 12 Building R081 1 percentage reduction heating and cooling energy consumption all locations. 71

Figure 13 Building R081 1 percentage reduction annual heating energy consumption all locations. 72

Figure 14 Building R0811 percentage reduction annual cooling energy consumption all locations 72

Figure 15 Building R0738 Napier energy use for total, heating and cooling combined and individually. 74 
Figure 16 Building R0738 Napier percentage reduction annual energy use relative to uninsulated building for total and heating and cooling energy combined and individually

Figure 17 Building R0738 reduction annual total energy consumption relative to

building uninsulated in each of the eight locations.

Figure 18 Building reduction annual heating and cooling energy consumption

relative to building uninsulated in each of the eight locations 75

Figure 19 Building reduction annual heating energy consumption relative to building

uninsulated in each of the eight locations 76

Figure 20 Building reduction annual cooling energy consumption relative to building

uninsulated in each of the eight locations 76

Figure 21 Building R1586 Paraparaumu annual Energy Use (kWh/m2) 78

Figure 22 Building R1586 Paraparaumu percentage reduction annual energy consumption 78

Figure 23 Building R1586 percentage effect annual total energy consumption 79

Figure 24 Building R1586 percentage effect heating and cooling energy 79

Figure 25 Building R1586 percentage effect annual heating energy. 80

Figure 26 Building R1586 percentage effect annual cooling energy 80

Figure 27 Selected buildings Auckland annual total energy consumption $(\mathrm{kWh} / \mathrm{m} 2 / \mathrm{yr})$

Figure 28 Selected buildings Dunedin annual total energy consumption ( $\mathrm{kWh} / \mathrm{m} 2 / \mathrm{yr}$ )

Figure 29 Building R081 1 84

Figure 30 Building R0738 84

Figure 31 Building R1586 84

Figure 32 Selected buildings Auckland annual heating energy consumption

$(\mathrm{kWh} / \mathrm{m} 2 / \mathrm{yr})$

Figure 33 Selected buildings Auckland annual cooling energy consumption

$(\mathrm{kWh} / \mathrm{m} 2 / \mathrm{yr})$

Figure 34 Selected buildings Dunedin annual heating energy consumption $\left(\mathrm{kWh} / \mathrm{m}^{2} / \mathrm{yr}\right)$

Figure 35 Selected buildings Dunedin annual cooling energy consumption (kWh/m²/yr) 
Figure 36 Insulation Case 2: Effect types on total energy consumption that occur across sample of buildings in each location- Z1 minimum required level.

Figure 37 Insulation Case 3: Effect types on total energy consumption that occur

across sample of buildings in each location

Figure 38 Insulation Case 4: Effect types on total energy consumption that occur

across sample of buildings in each location- $Z 2$ and $Z 3$ minimum required level 89

Figure 39 Insulation Case 5: Effect types on total energy consumption that occur

across sample of buildings in each location

Figure 40 Insulation Case 6: Effect types on total energy consumption that occur

across sample of buildings in each location 90

Figure 41 Auckland cooling energy $\mathrm{kWh} / \mathrm{m}^{2} / \mathrm{yr}$ 91

Figure 42 Hamilton cooling energy $\mathrm{kWh} / \mathrm{m}^{2} / \mathrm{yr}$ 91

Figure 43 Napier cooling energy $\mathrm{kWh} / \mathrm{m}^{2} / \mathrm{yr}$ 92

Figure 44 Paraparaumu cooling energy $\mathrm{kWh} / \mathrm{m}^{2} / \mathrm{yr}$ 92

Figure 45 Wellington cooling energy $\mathrm{kWh} / \mathrm{m}^{2} / \mathrm{yr}$ 92

Figure 46 Christchurch cooling energy $\mathrm{kWh} / \mathrm{m}^{2} / \mathrm{yr}$. 92

Figure 47 Queenstown cooling energy $\mathrm{kWh} / \mathrm{m}^{2} / \mathrm{yr}$ 93

Figure 48 Dunedin cooling energy $\mathrm{kWh} / \mathrm{m}^{2} / \mathrm{yr}$ 93

Figure 49 Building R0811 Percentage Reduction Annual Energy Consumption........ 100

Figure 50 Building R0738 Percentage Reduction Annual Energy Consumption ........ 100

Figure 51 Building R1586 Percentage Reduction Annual Energy Consumption ........ 100

Figure 52 Building R081 1 Heating Energy Consumption ................................................... 101

Figure 53 Building R0738 Heating Energy Consumption ................................................ 101

Figure 54 Building R1586 Heating Energy Consumption .............................................. 101

Figure 55 Building R081 1 Cooling Energy Consumption ............................................... 101

Figure 56 Building R0738 Cooling Energy Consumption ................................................. 101

Figure 57 Building R1586 Cooling Energy Consumption ............................................... 101

Figure 58 Number of buildings at case 2 effect types occur in each location.......... 103

Figure 59 Number of buildings at case 3 effect types occur in each location.......... 103

Figure 60 Number of buildings at case 4 effect types occur in each location.......... 103

Figure 61 Number of buildings at case 5 effect types occur in each location.......... 103

Figure 62 Number of buildings at case 6 effect types occur in each location.......... 104

Figure 63 Auckland cooling energy percentage effect type ...................................... 105

Figure 64 Hamilton cooling energy percentage effect type....................................... 105 
Figure 65 Napier cooling energy percentage effect type.

Figure 66 Paraparaumu cooling energy percentage effect type .............................. 106

Figure 67 Wellington cooling energy percentage effect type...................................... 106

Figure 68 Christchurch cooling energy percentage effect type................................... 106

Figure 69 Queenstown cooling energy percentage effect type .................................. 107

Figure 70 Dunedin cooling energy percentage effect type ......................................... 107

Figure 71 R1017 Wellington heating and cooling energy (kWh) at each case ......... 111

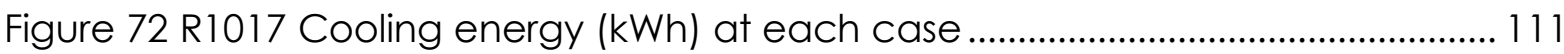

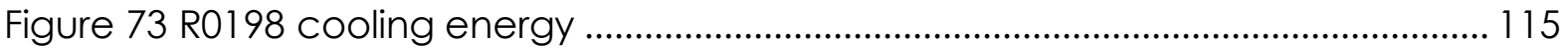

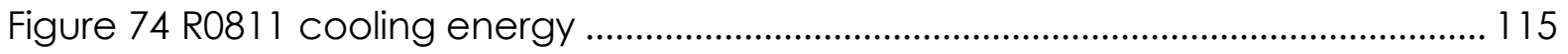

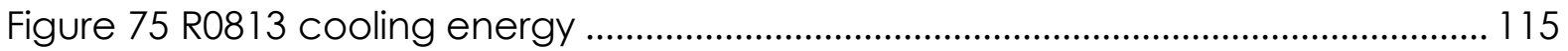

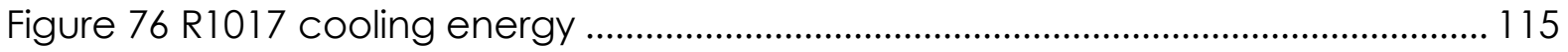

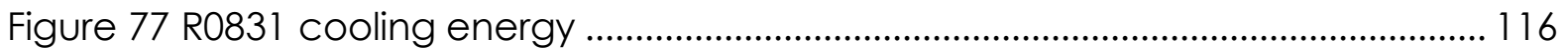

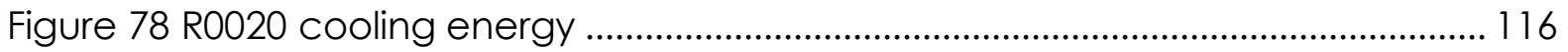

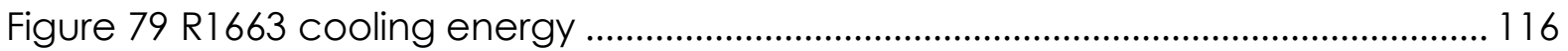

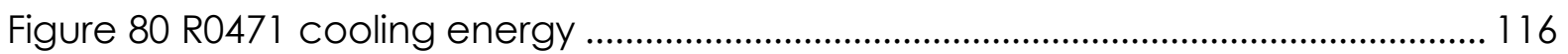

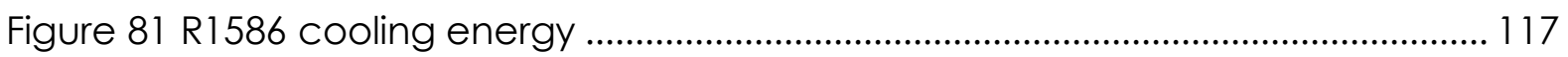

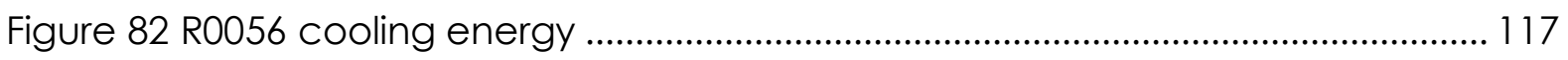

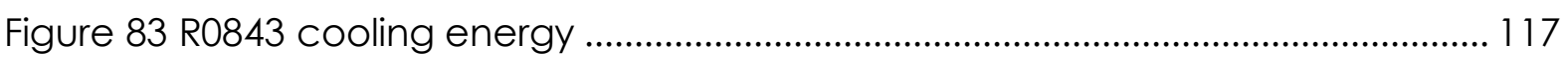

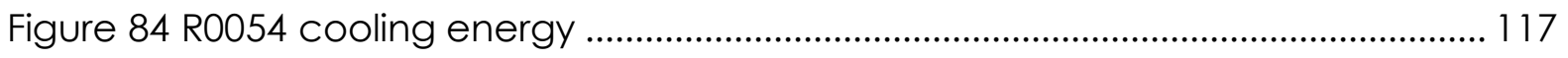

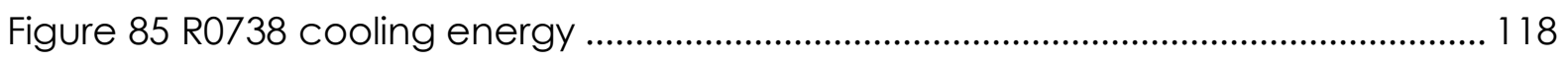

Figure 86 R1017 heating and cooling energy .............................................................. 120

Figure 87 R0813 heating and cooling energy ............................................................. 120

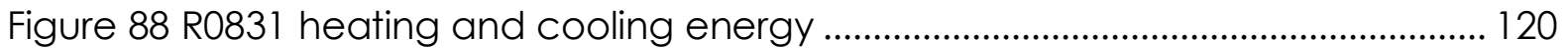

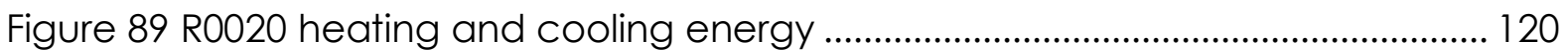

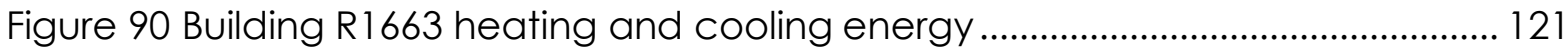

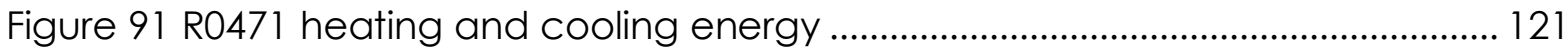

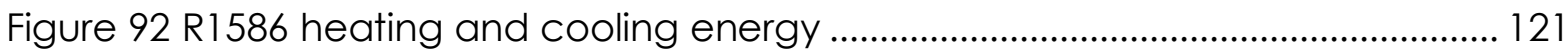

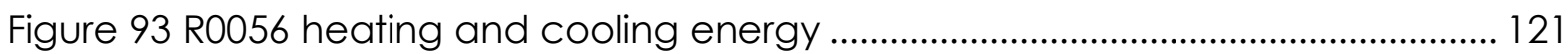

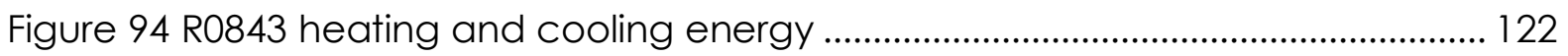

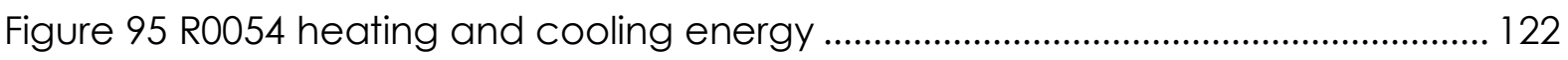

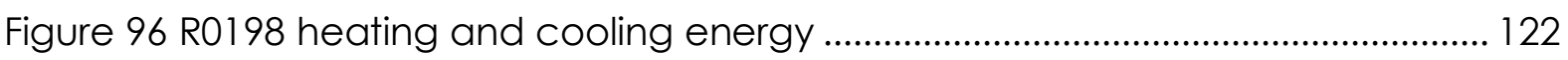

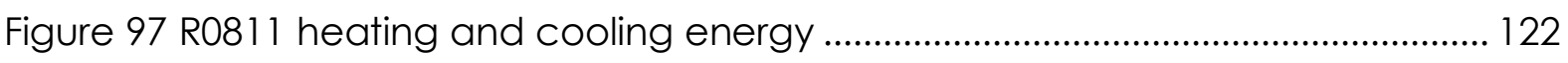

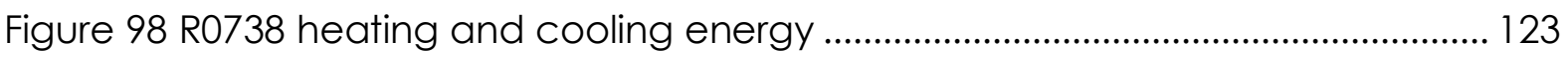


Figure 99 Illustrations obtained through Sketchup. North is represented by the green axis line and shading from adjacent buildings is represented by the purple.

Figure 100 Percentage Reduction Total Energy Consumption of all buildings at each insulation case- Auckland

Figure 101 Percentage Reduction Total Energy Consumption of all buildings at each insulation case- Hamilton

Figure 102 Percentage Reduction Total Energy Consumption of all buildings at each insulation case- Napier.

Figure 103 Percentage Reduction Total Energy Consumption of all buildings at each

insulation case- Paraparaumu

Figure 104 Percentage Reduction Total Energy Consumption of all buildings at each insulation case- Wellington.

Figure 105 Percentage Reduction Total Energy Consumption of all buildings at each insulation case- Christchurch

Figure 106- Percentage Reduction Total Energy Consumption of all buildings at each insulation case- Queenstown.

Figure 107 Percentage Reduction Total Energy Consumption of all buildings at each insulation case- Dunedin.

Figure 108 Percentage Reduction Total Energy Consumption of all buildings at each insulation case- Auckland 153

Figure 109 Percentage Reduction Total Energy Consumption of all buildings at each

insulation case- Hamilton 153

Figure 110 Percentage Reduction Total Energy Consumption of all buildings at each insulation case- Napier.

Figure 111 Percentage Reduction Total Energy Consumption of all buildings at each insulation case- Paraparaumu

Figure 112 Percentage Reduction Total Energy Consumption of all buildings at each insulation case- Wellington.

Figure 113 Percentage Reduction Total Energy Consumption of all buildings at each insulation case- Christchurch

Figure 114- Percentage Reduction Total Energy Consumption of all buildings at each insulation case- Queenstown.

Figure 115 Percentage Reduction Total Energy Consumption of all buildings at each insulation case- Dunedin. 
Figure 116 Effect on total energy consumption for building and case- Auckland ... 155 Figure 117 Effect on total energy consumption for building and case- Hamilton..... 155 Figure 118 Effect on total energy consumption for building and case- Napier......... 155 Figure 119 Effect on total energy consumption for building and case- Paraparaumu 155

Figure 120 Effect on total energy consumption for building and case- Wellington.. 156 Figure 121 Effect on total energy consumption for building and case- Christchurch

Figure 122 Effect on total energy consumption for building and case- Queenstown 156

Figure 123 Effect on total energy consumption for building and case- Dunedin ..... 156 
Table 1 NZS4243: Part 1 Thermal Envelope Requirements. .8

Table 2 Recreated findings of (Friess et al., 2017) identifying correlation between effects of insulation on energy consumption and climate attributes

Table 3 Mean monthly air temperature values for the 1981-2010 period (locations

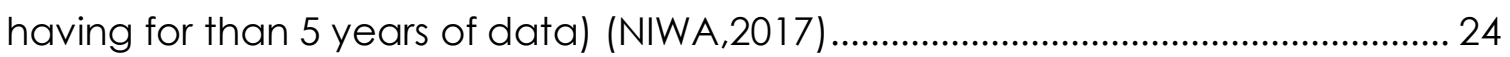

Table 4 Heating and cooling degree days with $18^{\circ} \mathrm{C}$ base source (NIWA, 2017) ....... 24

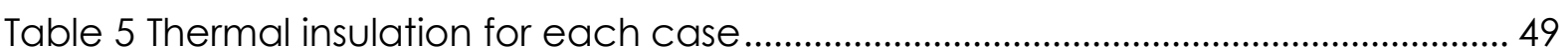

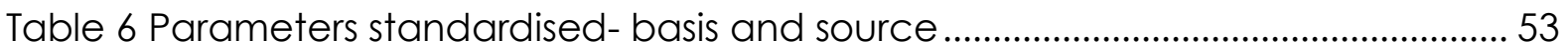

Table 7 Cooling set point values explored in the study ...................................................... 54

Table 8 Number of office buildings included in the sample of BEES commercial energy models

Table 9 Real and calibrated EUI's and percentage difference. Detailed monitoring period and meter data and building location information ....

Table 10 Energy type of each building and comparison to BEES Strata mean Enl for relevant energy type

Table 11 Mean commercial office building EnPI for each fuel type and strata group

Table 12 Internal load power and occupant densities for each of the buildings.

Table 13 Influence changing concrete to material no mass has on energy

consumption of building R0054 with and without thermal insulation added

Table 14 Terms used to describe amount percentage reduction in energy consumption

Table 15 Prevailing effect types for each building across all cases in each locationtotal energy consumption

Table 16 Prevailing effect types for each building across all cases in each locationcooling energy.

Table 17 Prevailing effect type of each building in each location - total energy consumption

Table 18 Prevailing effect type of each building in each location - cooling energy consumption

Table 19 Difference in energy consumption between version 7.2 and 8.6 141

Table 20 Details of buildings R0020, R0831, R0056 and R0471 construction 144 
Table 21 Details of buildings R0813, R0054, R0738 and R0811 construction

Table 22 Details of buildings R0843, R0198, R1017, R1586 and R1663 construction ... 146

Table 23 Details of buildings R0020, R0831, R0056 and R0471 shading

Table 24 Details of buildings R0813, R0054, R0738 and R081 1 shading 148

Table 25 Details of buildings R0843, R0198, R1017, R1586, R1663 shading..... 149

Table 26 Selected Buildings Comparison building attributes

Table 27 Calibrated energy models- minimum, maximum and average $\mathrm{kWh} / \mathrm{m}^{2} / \mathrm{yr}$ for each location and Case

Table 28 NZS4243 Standardised energy models- minimum, maximum and average $\mathrm{kWh} / \mathrm{m}^{2} / \mathrm{yr}$ for each location and Case. 


\section{Abbreviations}

${ }^{\circ} \mathrm{C}$ Degrees Celsius

ACH Air Changes Per Hour

BEES Building Energy End-Use Study

BRANZ Building Research Association of New Zealand

CIBSE Chartered Institution of Building Services Engineers

COP Coefficient of Performance

EECA Energy Efficiency Conservation Authority

EPD Equipment Power Density

NZBC New Zealand Building Code

NZGBC New Zealand Green Building Council

R-Value Thermal Resistance

EnPI Energy Performance Indicator: measured in $\mathrm{kWh} / \mathrm{m}^{2} \cdot \mathrm{yr}$ (final energy)

EUI Energy Use Intensity: energy per metres squared of floor area ( $\left.\mathrm{kWh} / \mathrm{m}^{2} \cdot \mathrm{yr}\right)$

HVAC Heating, Ventilation and Air-conditioning

ILD Internal Load Dominated

kWh kilowatt-hours

LPD Lighting Power Density

$\mathrm{m}^{2}$ square metres

NIWA National Institute for Weather and Atmospheric Research

NZBC New Zealand Building Code

NZS New Zealand Standard

People $/ \mathrm{m}^{2}$ People per square metre

PTI Point of Thermal Inflexion

SLD Skin Load Dominated

TMY Typical Meteorological Year

W Watt

$\mathrm{W} / \mathrm{m}^{2}$ Watts per square metre of floor area

WWR Window to Wall Ratio 



\section{Introduction}

\subsection{Thermal Insulation in Office Buildings- The Issue}

Driven by the ever increasing demands for healthier, more comfortable, more sustainable buildings, building regulations have steadily increased the levels of insulation they require in new buildings over time. Buildings are responsible for over $40 \%$ of the global energy demand and $35-40 \%$ of all energy related $\mathrm{CO} 2$ emissions (Cory, 2016). This creates a large opportunity for energy savings- and for policy to enforce energy efficiency measures for new and existing buildings that assist in this. The largest energy-use in both residential and non-residential buildings is typically HVAC (heating, ventilation, and air conditioning) (PérezLombard, Ortiz, \& Pout, 2008). The addition of thermal insulation to the building envelope is believed to be an effective measure to reduce HVAC energy requirements.

A building's heating and cooling load is the product of its internal gains (e.g. equipment, lights, and people), solar gains (through fenestration) and transmission loads (conduction of heat through the envelope opaque components). The addition of thermal insulation to a building's envelope will always reduce the transmission load. Consequently, the common perception is that this will always be favourable as the heating and cooling loads will be reduced-and therefore, it is a guaranteed energy saving strategy (Masoso \& Grobler, 2008)(Guan, 2015). This belief has been found to be conveyed through legislation and by construction professionals (Idris \& Mae, 2017).

However, analysis shows this is not the case- in certain buildings, there are times when it would be better for the internal heat and stored heat in the building's envelope to dissipate passively to the outside of the building (Guan, 2015). The problem is that thermal insulation can inhibit this, and as a result an increased amount of cooling energy would be required, 


\subsubsection{Circumstances Remain Ambiguous}

The buildings in which the dissipation of heat through the envelope is favourable, are those that are located in extreme climates- as the transmission loads will be dominant (Friess, Rakhshan, \& Davis, 2017). Friess et al. summarises that past research identifies that the counterintuitive behaviour occurs in internal load dominated buildings with a pronounced cooling need. However, the particular circumstances that lead to the occurrence of the behaviour are not well determined in literature and are thought to remain ambiguous (Idris \& Mae, 2017) (Masoso \& Grobler, 2008).

There is an increasing amount of literature that acknowledges that the "more is better" thermal insulation approach is not always the case. This issue is thought to have not been directly examined in literature until 2008 by Massaso and Grobler (Idris \& Mae, 2017). However, an early study undertaken in New Zealand by (Bannister \& Guan, 1996) found that for climates similar or warmer than Auckland, the addition of insulation could be detrimental to an office building's energy efficiency. It was found that the presence of a low level of wall insulation in a prototypical building energy model simulated in Auckland caused the cooling energy to increase so greatly that the total building energy consumption increased.

(Masoso \& Grobler, 2008) carried out an extensive literature survey to validate the theory that increased levels of wall insulation could increase energy consumption. No mention of the prospect of wall insulation causing an increase in energy consumption was found- only the reoccurring message of wall insulation resulting in a reduction of energy. Included in their survey, was the latest research work, journals, conference papers and other up to date publications. Through simulating a new energy model, (Masoso \& Grobler, 2008) were able to confirm that there are instances where insulation will directly increase energy consumption. As the findings were thought to not have been documented before, the opinion of several experts in the building energy field were sought. Each suspected the outcome to be due to a software error. Through reviewing studies that used different simulation tools and where an increase in cooling energy had been observed, but not attributed to insulation, 
(Masoso \& Grobler, 2008) determined that it was unlikely that the results were due to a software error. It was thought that the reason for the researchers failing to notice the adverse effect caused by insulation, was due to it only occurring in summer cooling (Masoso \& Grobler, 2008). Given that the majority of studies simulate buildings in North America and Europe where the winter heating requirements would be dominant-the decreases in heating energy would likely outweigh the increase in cooling energy due to the additional thermal insulation.

Similarly, (de' Rossi, Marigliano, Marino, \& Minichiello, 2016) identified that although a building may be compliant with local energy efficiency regulations, the thermal insulation level may be excessive and have a counterproductive effect. This was observed for a building simulated with high internal loads in a Mediterranean climate (characterised by warm summers and mild winters). (de' Rossi et al., 2016) simulated an existing office building in four locations (Milan, Italy, Rome and Cairo) with varying insulation and internal load levels. In two locations, it was observed that the optimal insulation value (considering primary energy requirements and discounted payback period) was lower than the value required to meet the local energy saving regulations.

Researchers such as (Friess et al., 2017; Guan, 2015; Pan, Chan, Deng, \& Lin, 2012) have explored how the effectiveness of thermal insulation in office buildings is influenced by parameters such as internal load level, thermal mass, window to wall ratio and cooling thermostat set point temperature. Each parameter was found to contribute to whether a building experienced an increase in cooling energy. A review of the literature suggests that other parameters that effect a building's heat gains and losses (and therefore, energy use) do not appear to have been explored directly in relation to this issue. However, it must be noted that the performance of thermal insulation is thought to be strongly affected by internal load and climate, and more weakly by other factors such as building size and window to wall ratio (Bannister \& Guan, 1996).

\subsection{Research Aim, Hypothesis and Questions}

Internationally there is limited knowledge regarding thermal insulation's influence on the energy performance of office buildings. The New Zealand Building Code 
Clause H1 Acceptable Solution (H1/AS1) references Standard NZS4243: Part 1 2007 which provides minimum acceptable energy efficiency performance requirements that new large buildings, including offices, must meet. Requirements for the building envelope were not revised from the preceding NZS4243:1996 (Standards New Zealand, 2007). When developing the standard, it was established that thermal insulation in roofs has good potential for economic returns throughout New Zealand, however wall insulation only produced significant energy savings south of Auckland. It is expected that due to the change in use of commercial buildings over the past 20 years, thermal insulations' potential to reduce energy consumption will have changed also.

This research aims to contribute to the current re-evaluation of NZS4243: Part 1 through extending the understanding of air conditioned office buildings' sensitivity to various levels of thermal insulation. Also, to identify the New Zealand climates which may contribute to insulation increasing energy use. The research also assesses how air conditioned office buildings' overall energy consumption is influenced by levels of thermal insulation, internal loads, building occupant behaviour, operational, design and construction factors.

\subsubsection{Research Hypothesis}

The research objective was to test the hypothesis that:

- The addition of thermal insulation to commercial office buildings in New Zealand results in increased energy use

$$
\text { 1.2.2. Research Questions }
$$

The following questions were investigated in the research. In order to answer the questions, firstly the drivers for thermal insulation causing space conditioning energy use to increase and decrease were identified.

- Can insulation have a negative impact on the total energy consumption of New Zealand office buildings? 
While it was established when developing NZS4243:1 that wall insulation could increase cooling energy in locations throughout New Zealand, it was only found to increase the total energy consumption in Auckland and expected to result in increases in locations north of Auckland. Therefore, this question sought to establish whether this earlier finding was true for New Zealand office buildings currently.

- What are the characteristics of New Zealand office buildings that may lead to insulation resulting in increased energy use?

The final question sought to establish how the drivers for increased energy use (identified in the literature review) are applicable to New Zealand.

\subsubsection{Research Method}

Building energy simulation was used in this research to assess the energy performance of New Zealand air conditioned office buildings and their sensitivity to various levels of thermal insulation and other parameters. To ensure the research results were representative of the performance of New Zealand office buildings, results from the BRANZ Building Energy End Use-Study (BEES) were used (Amitrano et al., 2014).These included operational and internal energy load data, as well a series of 13 office building energy models created as part of a VUW PhD using the BEES monitored data (Cory, 2016).

The building energy modelling undertaken was divided into three steps:

- Firstly, the office building energy models were simulated as-built and asused with varying levels of thermal insulation and in eight locations

- Secondly, the buildings internal loads etc were standardized to match NZS4243 requirements and then simulated with varying levels of thermal insulation and in eight locations

- Lastly, the sample of buildings (with NZS4243 standardised values) sensitivity to an operational parameter was tested as the thermal insulation level was increased in the eight locations 
The research undertaken in this thesis focusses on the energy performance of New Zealand office buildings. It does not undertake a cost analysis of the thermal insulation levels explored or assess the implications on thermal performance.

It is important to note that the maximum optimal level of thermal insulation is recognised by many studies to be when the material and installation cost exceed the energy return over the lifetime of a building (Friess et al., 2017). Therefore, this means that generally thermal insulation levels are not too high as there is a non-linear relationship between the heat flow rate through the building envelope and the R-value (Guan, 2010).

\subsection{Building Envelope Energy Efficiency Regulations}

Internationally, building codes and standards regulate the energy efficiency of the building envelope. Many factors influence the energy performance of a building and building codes tend to address only the most integrated elements (International Energy Agency, 2008). Historically, the building envelope is the first element of a building to influence its energy performance to have been regulated. It is considered an essential part of nearly all regulation for energy efficiency in new buildings (International Energy Agency, 2008).

Energy efficiency requirements should be reviewed and updated regularly. Over time, the feasibility and rationale for minimum energy efficiency requirements set in any Building Code will change. This is due to the construction market continuously developing with new products, improved existing products and changes in energy prices. The European Directive on Energy Performance in Buildings states that building standards must be reviewed at regular intervals (no longer than 5 years) in order to reflect technical progress in the building industry (International Energy Agency, 2008). The New Zealand Building Code energy efficiency Clause (as with all NZBC clauses) is subject to a five-year review (Isaacs, 1999). 


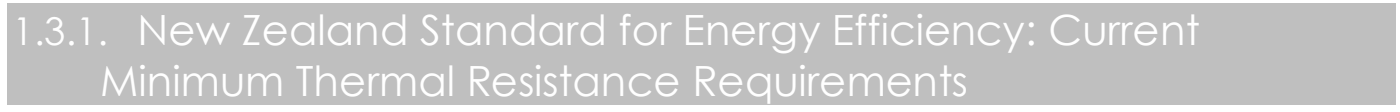

The New Zealand Building Code Standard NZS4243:Part 1:2007 provides minimum acceptable energy efficiency performance requirements that new large (over $300 \mathrm{~m}^{2}$ ) buildings must meet. These are the same levels as in the preceding NZS4243:1996. The given level of thermal resistance for the building envelope was based on an economic cost benefit analysis, being the least cost option for the building owner (Standards New Zealand, 2007). The Standard is not a code of good practice and increased levels of energy efficiency are thought to achieve improved results (Standards New Zealand, 2007).

Compliance can be through either the Schedule, Calculation or Modelling methods. The table below provides the Schedule Method minimum R-values required for all large buildings that have a window to wall ratio of less than or equal to $50 \%$. Compliance is demonstrated by calculating the total R-value (thermal resistance) of building elements (Elink, 2012). If the window to wall ratio is greater than 50\%, the Calculation or Modelling methods must be used. Building envelope components do not need to comply with the Schedule Method if using the Modelling Method- providing that the energy use of the proposed building design is not greater than the energy use of the reference building. The reference building is required to be modelled the same as the proposed building, however its thermal characteristics must be according to the Schedule Method requirements.

The NZBC divides New Zealand into three zones. Zone 1 includes Auckland and all northward land, Zone 2 includes the remaining area of the North Island except the central plateau, and Zone 3 is the South Island and North Island central plateau. The Schedule Method requirements for Zone 2 and 3 buildings are the same, and greater than the requirements for Zone 1 (refer to table below). Buildings are not required to achieve any minimum glazing thermal requirement. The issue of thermal insulation potentially causing an increase in energy consumption is not mentioned in the Standard. 


\begin{tabular}{|l|c|c|}
\hline \multicolumn{3}{|c|}{ Building Thermal Envelope Component } \\
\hline & \multicolumn{2}{|c|}{ Minimum R-values } \\
\hline & $\mathbf{Z 1}$ & Z2 \& Z3 \\
\hline Roof & 1.9 & 1.9 \\
Wall & 0.3 & 1.2 \\
Floor & No requirement & 1.3 \\
Glazing & No requirement & No requirement \\
\hline
\end{tabular}

Table 1 NZS4243: Part 1Thermal Envelope Requirements

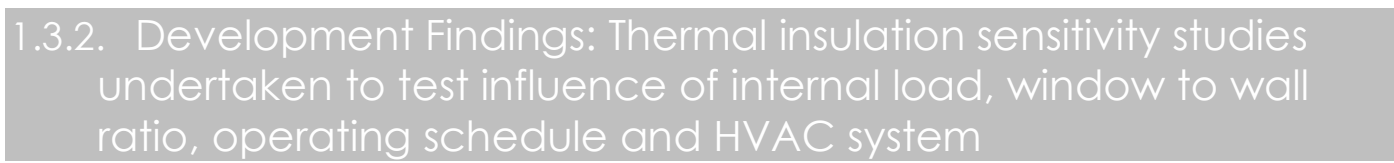

The Building Industry Authority (BIA - now MBIE Building System Performance (BSP) branch) and the Energy Efficiency and Conservation Authority (EECA) funded a number of studies from 1994 to support the development of NZS4243:1996 Part 1 which in turn is used as the Acceptable Solution for NZBC Clause H1 (Bannister \& Guan, 1996). The development of the Standard followed the process of developing prototypical commercial buildings, modelling their energy use in various climates for a range of energy efficiency options, evaluating the lifecycle cost of each option and selecting the most suitable option to be included in the code (Isaacs, 1999). Two prototypical buildings of $3,000 \mathrm{~m}^{2}$ and $15,000 \mathrm{~m}^{2}$ were modelled with a range of construction types and thermal efficiency levels in four locations (Auckland, Wellington, Christchurch and Invercargill). To determine the minimum required thermal resistance levels, a number of sensitivity studies were undertaken. The parameters tested included internal load, window to wall ratio, operating schedule and HVAC. It was expected that all new buildings constructed to meet the requirements would achieve a higher reduction in energy use than found in the studies.

\subsection{Energy and Office Buildings}

The original development of NZS 4243:1996 was not developed using data on real office or other building types. This changed with the Building Energy End-Use Study (BEES). This makes it now possible to test the energy performance of a sample of calibrated models. 


\subsubsection{Energy End Uses in New Zealand Office Buildings}

Commercial office buildings were classified by the Building Energy End-Use Study (BEES) to be buildings where clerical, administrative and office work is carried out. Activities are generally carried out at designated work stations (Amitrano et al., 2014). Office buildings must be comfortable for their occupants and allow the users to carry out various tasks to be performed. To achieve this, energy is relied upon for heating and cooling from space conditioning systems to provide comfortable temperatures, lighting and office equipment (Amitrano et al., 2014).

HVAC (heating, ventilation and air- conditioning) is typically the largest energyend use for commercial buildings (Pérez-Lombard et al., 2008). Typically, an inverse correlation exists between the efficiency of the building envelope and the need for air conditioning- a highly efficient building envelope will reduce the need for energy to provide heating and cooling.

1.4.2. Factors that determine a buildings energy use cannot be viewed in isolation

Overall; energy use is determined by the use of energy for lighting, equipment and the interaction of internal heat gains (from occupants, lights and equipment) with the external climate (both temperature and sunlight). The building envelope mediates these influences by controlling how energy is gained and lost by the building and the temperature is controlled by the space conditioning system (Bannister \& Guan, 1997).

It became recognised in the 1970's (after the 1972/1973 oil shock which led to increased prices for energy) that buildings had mostly been constructed to be heavily dependent on external sources of energy (for lighting, equipment and HVAC systems) due to electricity, gas and oil being cheap and readily available (Isaacs, Donn, \& Baird, 1994). Research carried out in the 1970's found that commercial building energy use was not solely related to the climate (Isaacs et al., 1994). Factors identified included the exterior envelope of the building, fixed building services, equipment and controls, provision of hot water throughout the building, lighting equipment and controls and tenant controlled equipment used 
inside the building (Isaacs et al., 1994). Each cannot be viewed in isolation, given that the interactions can multiply the consequences of wasteful energy use.

The following diagram illustrates the numerous variables that contribute to the energy use in a building. Factors on the left are the driving forces- the climate, fuel, user needs and purpose of the building. The product of all the driving forces and energy interactions (central portion of image) is to the right- the user environment.

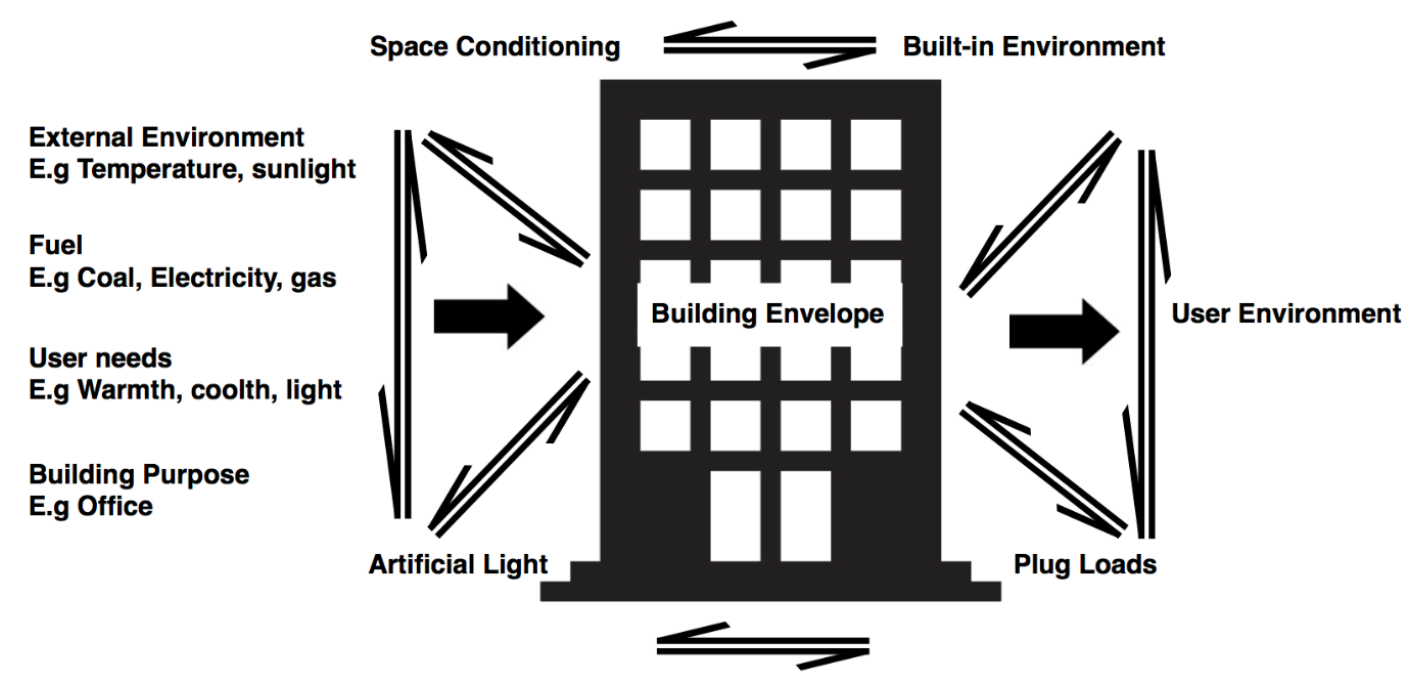

Figure 1 Energy use within a building -showing driving forces on the left, energy interactions are in the central portion and the desired result(user environment) is to the right (Reconstructed using image from (Isaacs, Lee, \& Donn, 1995) 
This thesis consists of five chapters as noted below:

\section{Chapter 1: Introduction}

Chapter One introduces the thesis topic, the aim of the research and the question to be answered. It also provides background to the development to the current NZBC Clause $\mathrm{H} 1$ requirements.

\section{Chapter 2: Literature Review}

Chapter Two discusses the energy interactions in buildings and the drivers for increased energy use as a result of added thermal insulation

\section{Chapter 3: Methodology}

Chapter Three provides details of the parametric building simulation method chosen, the design of the study, the parametric process undertaken, the relevance of the building energy models selected for the study, the construction of the energy models and relevance of the parameters explored

\section{Chapter 4: Results}

Chapter Four discusses the results of each of the three sets of simulations undertaken, including the as-built models, standardised NZS4243 models and exploration of an operational building attribute

\section{Chapter 5: Discussion and Conclusions}

Chapter Five summarises the findings from previous chapters and provides recommendations based on these 


\section{Literature Review}

\subsection{The Energy Interactions of Buildings}

The effectiveness of insulation is determined by the laws of thermodynamics.

The first law of thermodynamics is the principle of conservation of energy. Energy cannot be created or destroyed, but only converted from one form to another. The second law states that heat transfer can take place spontaneously in one direction only- from a hotter to a cooler body (Szokolay, 2014). Therefore, when the outdoor temperature is higher than the indoor temperature of a building, the building envelope then acts as a source of heat gain. Conversely, when the internal gains of a building are high and the outdoor temperature lower than the indoor temperature, the presence of insulation can reduce the dissipation of heat through the envelope. Consequently, an increased amount of energy consumption (relative to building with less or no added insulation) can be required in order to remove the extra thermal load.

Office buildings are generally air conditioned to maintain comfortable temperatures. To stabilise the heat balance at the desired thermal environment, equipment of a specified cooling capacity will control and counteract the thermal load of a building

A building has a series of heat inputs and outputs. For a specified hour, the total thermal load (Q) of a building can be described by the equation:

$$
Q=Q s+Q i+Q c+Q a
$$

Where, Qs is solar heat gain, Qi is internal heat gain, Qc is conduction heat and $Q a$ is heat transfer. If $Q$ is equal to 0 , then no heating or cooling is required to maintain a given temperature. When the building thermal load (Q) is negative, heating will be required and cooling when is $Q$ is positive. 
The heating and cooling loads of a building translate to the internal and external loads. The load is calculated as the amount of energy that is required to be removed from or moved into a space to maintain a specified temperature set point.

A building is either internal or external load dominated. Internal load dominated can be defined as a building in a cool climate requiring no or very little additional heating energy, due to the heat gains already present (Isaacs et al., 1995). An external load dominated building has a small internal load level in comparison to the heat gained or lost through the building envelope. In most office buildings, the amount of heat energy given off by people, equipment, and lights is usually greater than the energy lost through the building envelope (Guan, 2010). Therefore, a building that has a net cooling load will have greater heat gains than its envelope and ventilation losses, while a building that has a net heating load will have greater heat losses than its internal gains.

The following sections discuss the drivers for thermal insulation resulting in reduced and increased space conditioning energy use. The applicability of the drivers to New Zealand office buildings is examined.

\subsection{Internal Loads}

Internal heat gain is the combination of sensible and latent heat emitted from lighting, equipment and occupants within a building. The heat produced by these sources increases the temperature within a space. Increased internal loads will increase cooling energy requirements and decrease heating energy requirements (Bannister \& Guan, 1995). Removal of heat by either air conditioning or ventilation may be required to maintain a comfortable temperature. For intensely used buildings such as offices, the internal gains will generally offset a buildings envelope and ventilation heat losses (CIBSE, 2012). 
The importance of internal heat gain in terms of required energy consumption varies depending on a building's location, size and specific building processes within the building. (Guan, 2006) found that a decrease in internal load density of a typical Australian office building significantly reduced the building's total and cooling energy load in eight Australian cities. However, a reduction of the internal load of an office building, will not always result in a significant reduction of total heating and cooling energy requirements.

The study by (de' Rossi et. al., 2016) demonstrated how the same varying thermal load and thermal insulation levels modelled for one building can produce very different trends when simulated in different climates They simulated an existing building with three insulation cases and three separate internal loads in four locations- Palermo, Italy (warm summers and mild winters), Rome, Italy (warm summer and cold winters), Milan, Italy (warm summers and very cold winters) and Cairo, Egypt (very warm climate). The internal loads were 10,20 and $30 \mathrm{~W} / \mathrm{m}^{2}$. For each insulation case (different locations for insulation), the insulation thickness was increased in $2 \mathrm{~cm}$ increments from 0 to $12 \mathrm{~cm}$. The trends displayed related to the difference in total annual heating and cooling energy between thermal load levels and whether as insulation increases, energy consumption increases/decreases.

When modelled in Milan (cold winters), the annual energy consumption was about the same for any thermal load level at each insulation level. This was identified to be due to the higher heating requirements than cooling the building has (no matter what load level) (de' Rossi et al., 2016). This suggests that even at the highest thermal load level, the building is still skin load dominatedconsequently, insulation increases are beneficial.

However, when modelled in Palermo (warm summer, mild winters), the annual energy consumption for each insulation thickness was shown to significantly increase as the thermal load level increased (Figure 3). 


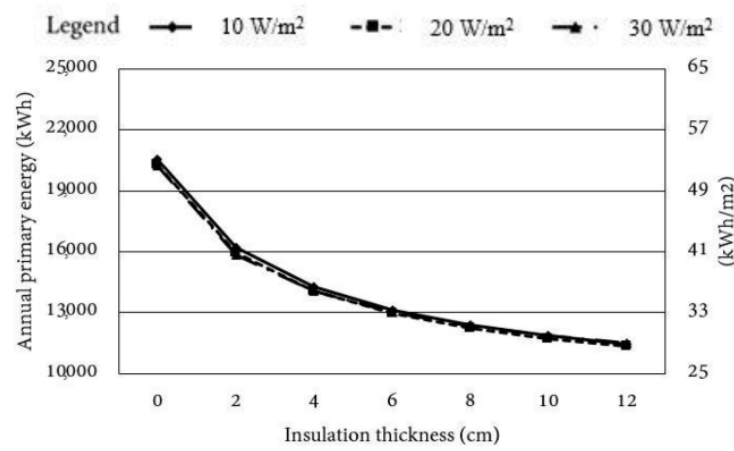

Figure 2 Milan annual primary energy requirementseffect of internal load and thermal insulation level (insulation in walls and roof)

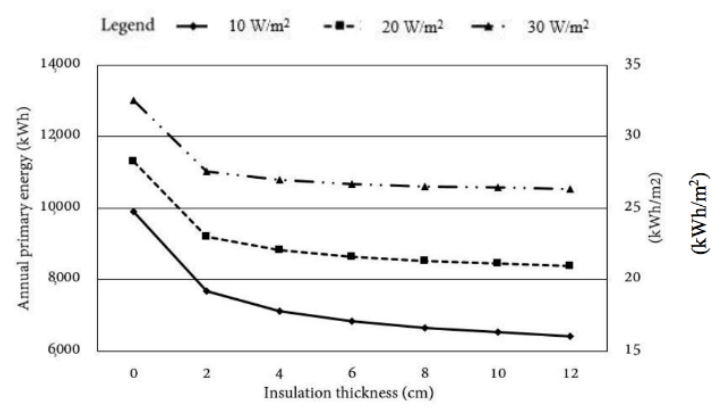

Figure 3 Palermo annual primary energy requirementseffect of internal load and thermal insulation level (insulation in walls and roof)

When modelled in Cairo (mild winter, very warm summer) and Rome, Italy (warm summer and cold winters), increased thermal insulation levels have opposing effects on the heating and cooling energy behaviour. The summer energy demand is greater than for the winter for the building in Cairo, while heating is dominant for Rome (de' Rossi et al., 2016). Results for the Cairo location show that the total energy consumption increased for each insulation case (beyond $2 \mathrm{~cm}$ thickness), and load level (de' Rossi et al., 2016). As heating is dominant in Rome, the higher reduction in transmission load is beneficial.

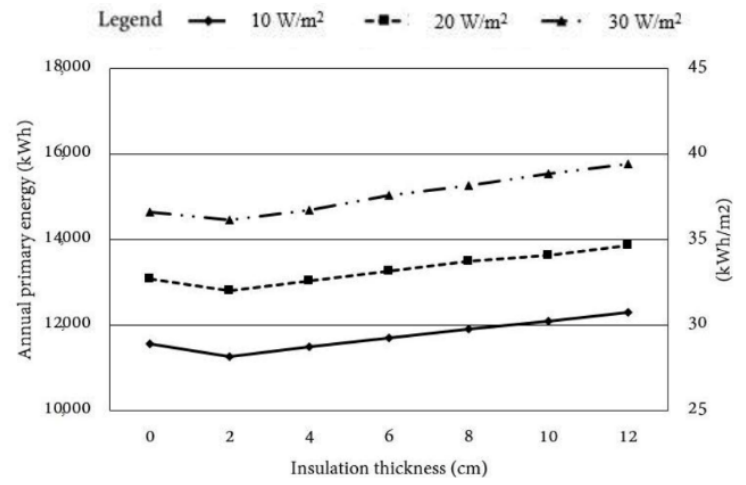

Figure 4 Cairo annual primary energy requirementseffect of internal load and thermal insulation level (insulation in walls and roof)

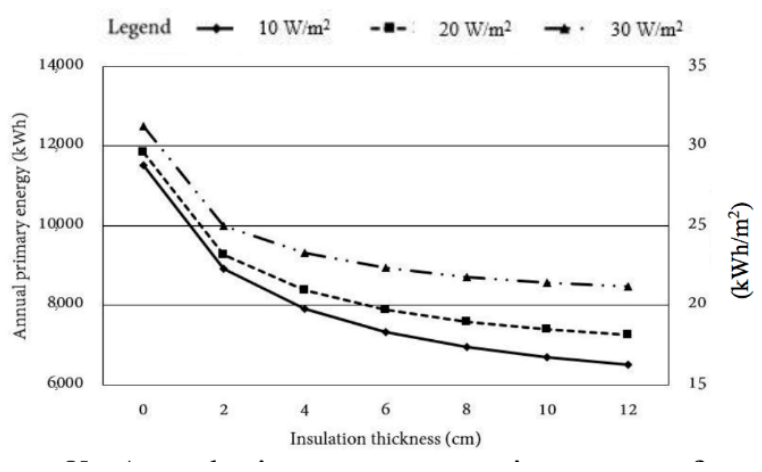

Figure 5 Rome annual primary energy requirements- effect of internal load and thermal insulation level (insulation in walls and roof) 


\subsubsection{High internal heat gains may contribute to increased or reduced energy consumption}

As shown above, the impact internal load has on the energy performance of a building is dependent on climate. Internal heat gains provide a source of heat within a building, reducing the heating requirements during winter. The addition of thermal insulation can provide benefits in winter through trapping this heat within the building. However, high internal gains can lead to insulation causing an adverse effect (Masoso \& Grobler, 2008). For internal load dominated buildings that have higher temperatures indoors than outside, insulated external walls would trap the heat inside rather than release it to the outside (Guan, 2010). Therefore, in New Zealand locations extra insulation in internal load dominated buildings is not likely to greatly improve the energy performance (Isaacs et al., 1995).

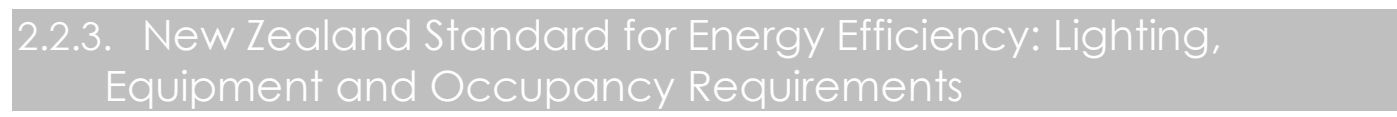

Standard internal loads are provided in NZS4243:Part 2, with artificial lighting power density in office buildings not to exceed $12 \mathrm{~W} / \mathrm{m}^{2}$. The NZS 4243,1 does not set a maximum for the power density of equipment. However, equipment and occupancy maximum values (2.7 and $8.1 \mathrm{~W} / \mathrm{m}^{2}$ respectively) are provided in NZS4243:Part 1 under the "Modelling Method". These are provided so that energy use can be compared between a reference model and a proposed design to prove minimum thermal performance requirements have been met. Two schedules for both lighting and plug loads, and building occupancy are also included to provide default values for heat release at different times of day (Standards New Zealand, 2007).

(Cory, Donn, \& Pollard, 2015a) used data obtained through the BEES study to identify lighting and equipment power densities and pattern of use, that is typical of New Zealand commercial buildings. The data was obtained over 6 years, beginning in 2007. It was determined that the NZS4243 regulated and assumed values were reasonably representative of the typical lighting and equipment load densities of office buildings. However, substantial differences between the measured typical and assumed equipment load schedules were found. 
The typical lighting power density (LPD) for office buildings was found to be $11 \mathrm{~W} /$ $\mathrm{m}^{2}$, slightly lower than the value set by NZS 4243.22007 of $12 \mathrm{~W} / \mathrm{m}^{2}$. As the NZS4243.2 value is similar to that of existing buildings, this suggests that buildings are being designed to meet the code requirements- and not to be more energy efficient than required (Cory, Donn, \& Pollard, 2015b). The typical office equipment power density (EPD) was $8 \mathrm{~W} / \mathrm{m}^{2}$-almost identical to the NZS 4243 assumption of $8.1 \mathrm{~W} / \mathrm{m}^{2}$. The measured low and high values for lighting and equipment were: $3 \mathrm{~W} / \mathrm{m}^{2}$ and $21 \mathrm{~W} / \mathrm{m}^{2}$, and $4.5 \mathrm{~W} / \mathrm{m}^{2}$ and $24 \mathrm{~W} / \mathrm{m}^{2}$ respectively. The sample was determined to be representative of the energy use in New Zealand commercial buildings and included 35 office buildings for the lighting load, and 28 for equipment. The data was obtained through measuring the energy use of each building at one minute intervals for a 2-3 week's period (Cory et al., 2015b). The weekly period monitoring was spread throughout the year for different buildings and energy results could be for a period in summer or winter. The typical scenario is the Median (50th percentile) load and pattern of use found from the representative sample of buildings. Low and high values were also identified using the $10^{\text {th }}$ percentile of the measured load and pattern use across the sample, and the $90^{\text {th }}$ percentile (high scenario). Power densities were calculated by dividing the maximum measured load (for lighting and equipment), by the monitored floor area. Operation patterns were divided by the maximum measured level load to establish the percentage load "on" during that 10 minute interval.

\subsubsection{Internal Load levels are reducing}

The changing LPD and EPD over time suggests the energy use of buildings is changing- due to both advances in technology and changes in occupant behaviour.

While load densities in office buildings have soared in the past, recent technological advancements and the increase in use of laptops (which consume a fraction of the energy of desk top computers), has resulted in load densities being driven down (Menezes, Cripps, Buswell, Wright, \& Bouchlaghem, 
2014). This change in load density will have a significant impact on the longer term energy behaviour of office buildings- as it significantly impacts the heating and cooling energy requirements to maintain comfortable temperatures.

While (Masoso \& Grobler, 2008) state that it is due to the increasing use of equipment that load densities have risen and consequently caused insulation to perform unexpectedly- the opposite trend in load density can be observed since the New Zealand Standard for energy efficiency was implemented.

NZS4243:1996 had a maximum lighting load density of $18 \mathrm{~W} / \mathrm{m}^{2}$. This value was reduced when the Standard was updated in 2007 to $12 \mathrm{~W} / \mathrm{m}^{2}$ to reflect current practice. In December of 2017, the lighting power density limit of between 7-9 $\mathrm{W} / \mathrm{m}^{2}$ (depending on space type) was proposed as an amendment, although at the time of writing the final version has yet to be released (EECA, 2017). The NZS4243:1996 value was recommended as having industry acceptability at the time. It was derived from a survey determining the provisional average lighting density (by GFA) in 1994/1995. 30 Wellington business district buildings were included in the survey by Victoria University of Wellington. The power density range of 10-15 W/ $\mathrm{m}^{2}$ was thought at the time to be achievable through careful design and the use of standard fittings (Bannister \& Guan, 1996).

As previously mentioned, the BEES study identified the typical load density to be about the same as NZS 4243.2:2007 $11 \mathrm{~W} / \mathrm{m}^{2}$. However, newly constructed or refurbished New Zealand buildings that aim to achieve a higher energy efficiency are found to have significantly lower power densities. The Geyser building constructed in 2011 in Auckland (first 6 star rated Green Star-Office Design building) was designed to require 6W/ m²(Samson Corporation, 2017). Green Star New Zealand awards 1 pt for buildings that achieve $2.5 \mathrm{~W} / \mathrm{m}^{2}$ per 100 lux, 2 pt for $2.0 \mathrm{~W} / \mathrm{m}^{2}$ per 100 lux and 3 pts for $1.5 \mathrm{~W} / \mathrm{m}^{2}$ per 100 lux. Two Wellington Green Star rated buildings achieve the $2.5 \mathrm{~W} / \mathrm{m}^{2}$. Seven Green Star Rated buildings in Wellington achieve the $2.0 \mathrm{~W} / \mathrm{m}^{2}$ per 100 lux target (Baird \& Prins, 2013).

The Colliers International New Zealand Workplace 2016 Report identified that the national CBD average office density was $16.4 \mathrm{~m}^{2}$ per person. This is a reduced 
density in comparison to the identified value in the 2014 survey, of $17.2 \mathrm{~m}^{2}$. Note that a higher density per person, results in less space per person and therefore a higher amount of heat gain.

Typical densities for different sectors were identified to be- $22.2 \mathrm{~m}^{2}$ for legal, 18.1 $\mathrm{m}^{2}$ for private and the lowest of $16 \mathrm{~m}^{2}$ for public offices. Average density by CBD location were determined to be, $18.1 \mathrm{~m}^{2}$ in Auckland, $16.2 \mathrm{~m}^{2}$ in Wellington, 18.5 $\mathrm{m}^{2}$ in Christchurch, and $18.3 \mathrm{~m}^{2}$ in Dunedin. The survey results are obtained from Colliers leases nationally (Auckland, Wellington, Christchurch, Hamilton and Dunedin) with an effective date between August 2014-July 2016. Over 430 leases were used and those with fewer than 5 employees were excluded. The sample size covered $234,530 \mathrm{~m}^{2}$ and 13,867 employees.

\subsection{External Loads}

(Masoso \& Grobler, 2008) and (Friess et al., 2017) explored the effect of climate, construction and use factors on an office building's energy consumption and found that while each of the locations used in the study had higher cooling requirements, each location responded differently to increased insulation levels.

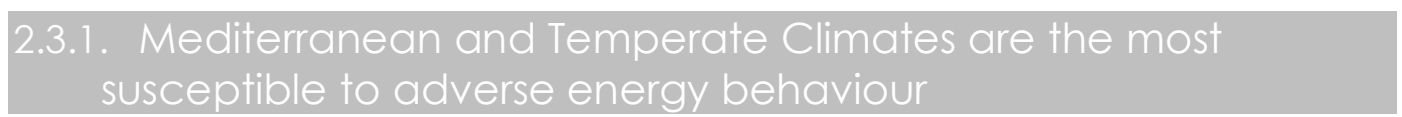

Studies have identified that the addition of thermal insulation can cause an increase in energy consumption in locations in Australia, Europe, Botswana, Italy and China (Guan, 2010)(Masoso \& Grobler, 2008) (Boyano, Hernandez, \& Wolf, 2013, de' Rossi et al., 2016). While (Masoso \& Grobler, 2008) state that the adverse energy behaviour could be expected to occur in both hot and cold climates due to the fact that office buildings tend to require cooling throughout the year in mid zones- (Friess et al., 2017) found that the behaviour did not occur in extreme climates, however can be expected to occur in locations with balanced heating and cooling needs. For the particular office building modelled by (Friess et al., 2017), thermal insulation was found to be beneficial in reducing energy use in heating dominated locations, however a negligible or no benefit was found to occur for buildings that were cooling dominated. 
Prior to the study by (Friess et al., 2017) the geographic areas and building attributes that contribute to increased cooling energy due to increased thermal insulation had not been identified. In order to identify the specific geographic areas, a generic office building with varying levels of insulation was simulated in 132 global locations. The Koppen climate classification was chosen to identify representative locations that could then identify susceptible climate zones (Friess et al., 2017). This classification system uses average annual temperatures and precipitation to categorise climates into groups ranging from "A" (tropical) to " $E$ " (alpine and polar). Each group has subgroups based on precipitation and seasonal temperature extremes.

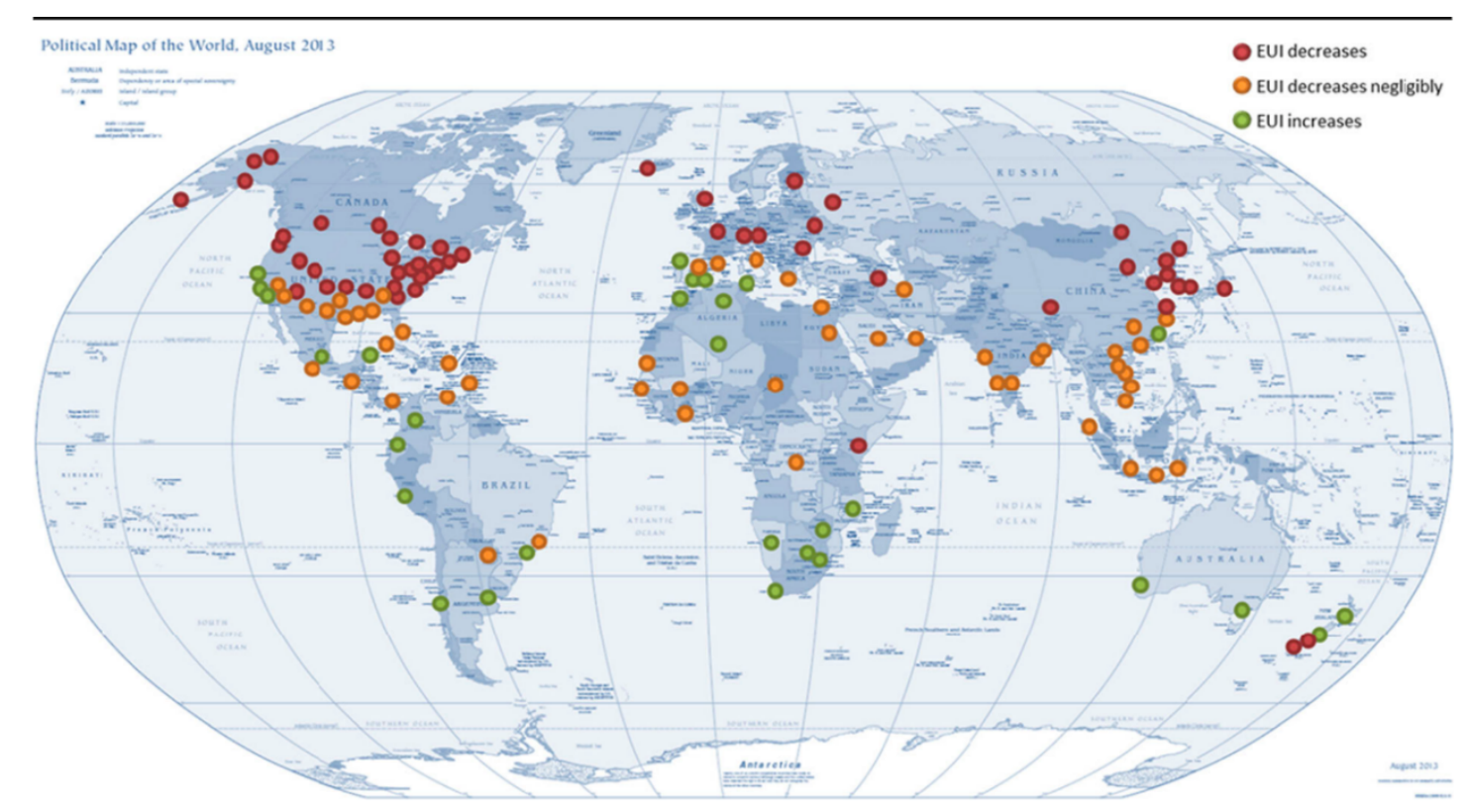

Figure 6 Studied cities and effect on EUI (Friess et al., 2017)

The performance of each building was either classified as having a positive correlation between increased insulation benefiting energy consumption (decreased EUI), a small benefit (less than 1\%) to the EUI or a negative correlation, where an increase in energy consumption is observed (Friess et al., 2017). A negative correlation was found in most cities located in Koppen climate classification C. Climate classification Csa (Mediterranean with mild winters and hot summers) was particularly high, with all four locations displaying a negative correlation. In colder climates (i.e. heating dominant), insulation is observed as resulting in decreased energy consumption. 
The trends identified from simulating the single building indicated the following beneficial/adverse/insensitive relationships between locations and insulation increases, given in Table 2:

\section{Negative Effect}

\section{Beneficial Effect} Insenstivie/ Negligable Positive Effect

Average yearly temperature between $13^{\circ} \mathrm{C}$ to $21^{\circ} \mathrm{C}$ than $13^{\circ} \mathrm{C}$ (progressively more beneficial as average Average temperatures above $21^{\circ} \mathrm{C}$

Moderate and balanced climates with low and moderate seasonal swings (e.g. Mediterranean climate, which is identified as most susceptible)

Less than 2000 HDD (base

temperature $18^{\circ} \mathrm{C}$ )

Extreme environments that are heating dominant

Between 2000-5000 CDD,

indicative of a temperate climate (base temperature $10^{\circ} \mathrm{C}$ )

Balanced heating and cooling needs and cooling needs up to an order of magnitude higher than the heating needs

Ratio of HDD/CDD of between 1 to 0.1

Low seasonal temperature swings (low heating and cooling needs)

Low TDD (indicates low seasonal swings), between 3000 to 5500

TDD, majority not exceeding 4000 TDD

Table 2 Recreated findings of (Friess et al., 2017) identifying correlation between effects of insulation on energy consumption and climate attributes

While the study conducted by (Friess et al., 2017) identified global trends between adverse effects and climate attributes, the validity of the results are limited. As only a single building with fixed parameters (aside from insulation 
level) has been simulated in each location to allow for quantitative comparative results, locations where the adverse effect has been identified to not occur, do not necessarily mean it could not occur under different conditions. This is evident where the tested building in Dubai had a positive correlation (energy decreases), however when the same building was simulated in Dubai prior to the global study but with a greater number of parameters changed (window to wall ratio, cooling set point temperature and insulation level), an adverse effect was observed beyond a certain internal temperature set point.

(Idris \& Mae, 2017) also examined the correlation between the presence of an adverse effect and climate zones. A range of climates in the USA and Canada were explored. The most severe adverse effect was found to only occur in the Marine climates (San Francisco, Salem and Vancouver)- these locations had the least cooling degree days (CDDs), therefore required the least cooling. These locations while described as marine by (Idris \& Mae, 2017), fit into the Koppen climate classification of Csb, Csb and Cfb respectively. These climates had the second and third highest frequency of a negative effect ( out of the number of locations within climate zone) in the global study conducted by (Friess et al., 2017).

Hot dry arid climates (Phoenix, Riyadh and El Paso) were determined to be the least susceptible to the adverse effect or where an adverse effect did not occur. This type of climate requires a high amount of cooling (could be proven given the locations with this type of climate had the highest PTI (Point of Thermal Inflexion) values). Friess et al. (2017) and Masoso \& Grobler (2008) have identified this as a climate where an adverse effect does occur, although it had a low frequency of occurrence in the study. However, the differences in findings can be attributed to the fact that the global study did not explore multiple set points in the same way as Idris \& Mae (2017).

The climate attributes identified by (Friess et al., 2017) discussed in the previous section, to be an indicator of the adverse effect occurring were used to assess 
New Zealand locations. Four New Zealand locations were included in the study by (Friess et al., 2017). The two northern locations (Wellington and Christchurch) were found to have a positive correlation, while the two most southern locations were negative.

When assessing the attributes of a larger number of NZ locations, it was found that the average annual temperatures for Auckland, Hamilton and Napier fell within the range of $13-21^{\circ} \mathrm{C}$. Locations south of Napier have an average yearly temperature below $13^{\circ} \mathrm{C}$, therefore it would be expected that thermal insulation would be beneficial in these locations. Auckland, Hamilton, Napier, Paraparaumu and Wellington all have HDD less than 2000 (same base temperature of $18^{\circ} \mathrm{C}$ as used in the study). Note that the indicators were established in the study by linking climate attributes to an increase in total energy consumption when additional insulation was added. These findings are similar to those of (Bannister \& Guan, 1996), who found that thermal insulation caused the total energy consumption of an office building simulated in Auckland to increase. Hamilton, Napier and Paraparaumu were not included in that study, however it was thought that the addition of thermal insulation would always bring energy savings in locations south of Auckland.

New Zealand has the Koppen Climate Classification of "Cfb", meaning it has a temperate oceanic climate. This classification had the third highest frequency of "anti-insulation behaviour" in (Friess et al., 2017). Cfb locations have the coldest month averaging above $0{ }^{\circ} \mathrm{C}$, all months averaging below $22^{\circ} \mathrm{C}$, and at least four months averaging above $10^{\circ} \mathrm{C}$.

The average monthly temperatures, heating degree days and cooling degree days for each month and annually are shown below for seven New Zealand locations. NIWA average annual temperature data for between 1981 and 2010 shows that Auckland, Hamilton and Napier have an average annual temperature within the rage of $13^{\circ} \mathrm{C}-21^{\circ} \mathrm{C}$. The other New Zealand locations (Wellington, Christchurch, Queenstown and Dunedin) listed in the table below have an average yearly temperature below $13^{\circ} \mathrm{C}$. 


\begin{tabular}{|l|r|r|r|r|r|r|r|r|r|r|r|r|r|r|r|r|r|r|r|r|}
\hline LOCATION & JAN & FEB & MAR & APR & MAY & JUN & JUL & AUG & SEP & OCT & NOV & DEC & YEAR \\
\hline Auckland & 19.1 & 19.7 & 18.4 & 16.1 & 14 & 11.8 & 10.9 & 11.3 & 12.7 & 14.2 & 15.7 & 17.8 & 15.2 \\
\hline Hamilton & 18.4 & 18.8 & 17.1 & 14.5 & 11.9 & 9.5 & 8.9 & 9.8 & 11.6 & 13.2 & 14.9 & 16.9 & 13.8 \\
\hline Napier & 19.5 & 19.4 & 17.7 & 15 & 12.4 & 10 & 9.4 & 10.3 & 12.3 & 14.3 & 16.1 & 18.4 & 14.6 \\
\hline Wellington & 16.9 & 17.2 & 15.8 & 13.7 & 11.7 & 9.7 & 8.9 & 9.4 & 10.8 & 12 & 13.5 & 15.4 & 12.9 \\
\hline Christchurch & 17.5 & 17.2 & 15.5 & 12.7 & 9.8 & 7.1 & 6.6 & 7.9 & 10.3 & 12.2 & 14.1 & 16.1 & 12.2 \\
\hline Queenstown & 15.8 & 15.6 & 13 & 9.7 & 7 & 4.1 & 3 & 5 & 7.7 & 9.8 & 11.6 & 14 & 9.7 \\
\hline Dunedin & 15.3 & 15 & 13.7 & 11.7 & 9.3 & 7.3 & 6.6 & 7.7 & 9.5 & 10.9 & 12.4 & 13.9 & 11.1 \\
\hline
\end{tabular}

Table 3 Mean monthly air temperature values for the 1981-2010 period (locations having for than 5 years of data) (NIWA, 2017)

The table below displays the heating and cooling degree days (base $18^{\circ} \mathrm{C}$ ) for selected NZ locations. As mentioned in the previous section, locations with less than 2000 heating degrees days were found to be an indicator of the adverse behaviour. Auckland, Hamilton, Napier, Paraparaumu and Wellington have heating degree days less than 2000. Christchurch, Queenstown and Dunedin all have over 2000 heating and degree days. The number of CDD and TDD (HDD and CDD combined) a location had was also determined to be an idicator of the adverse effect occurring. However, no comparison between the NIWA CDD data and the findings of (Friess et al., 2017) were made as the base temperature is not consistent.

\begin{tabular}{|c|l|c|c|c|c|c|c|c|c|c|c|c|c|c|}
\hline Location & (Base 18 $\mathbf{~}^{\circ} \mathbf{C}$ & Jan & Feb & Mar & Apr & May & Jun & Jul & Aug & Sep & Oct & Nov & Dec & Ann \\
\hline \multirow{2}{*}{ Auckland } & CDD & 63 & 63 & 32 & 8 & 1 & 0 & 0 & 0 & 0 & 1 & 6 & 31 & 205 \\
& HDD & 8 & 4 & 21 & 69 & 137 & 205 & 237 & 214 & 157 & 111 & 63 & 23 & 1250 \\
\hline \multirow{2}{*}{ Hamilton } & CDD & 28 & 32 & 17 & 3 & 0 & 0 & 0 & 0 & 0 & 0 & 2 & 11 & 94 \\
& HDD & 31 & 23 & 53 & 118 & 206 & 266 & 296 & 261 & 206 & 159 & 103 & 59 & 1780 \\
\hline \multirow{2}{*}{ Napier } & CDD & 64 & 52 & 29 & 7 & 1 & 0 & 0 & 0 & 1 & 5 & 14 & 44 & 218 \\
& HDD & 17 & 14 & 38 & 97 & 175 & 240 & 266 & 240 & 171 & 120 & 72 & 31 & 1482 \\
\hline \multirow{2}{*}{ Paraparaumu } & CDD & 17 & 19 & 9 & 1 & 0 & 0 & 0 & 0 & 0 & 0 & 1 & 6 & 52 \\
& HDD & 39 & 35 & 72 & 136 & 198 & 248 & 289 & 265 & 208 & 173 & 23 & 68 & 1854 \\
\hline \multirow{2}{*}{ Wellington } & CDD & 28 & 26 & 14 & 1 & 0 & 0 & 0 & 0 & 0 & 0 & 1 & 11 & 80 \\
& HDD & 29 & 26 & 55 & 109 & 172 & 224 & 261 & 242 & 190 & 158 & 105 & 54 & 1625 \\
\hline \multirow{2}{*}{ Christchurch } & CDD & 23 & 18 & 8 & 1 & 0 & 0 & 0 & 0 & 0 & 1 & 4 & 14 & 68 \\
& HDD & 60 & 59 & 103 & 173 & 275 & 345 & 370 & 332 & 249 & 188 & 130 & 84 & 2370 \\
\hline \multirow{2}{*}{ Queenstown } & CDD & 16 & 13 & 2 & 0 & 0 & 0 & 0 & 0 & 0 & 0 & 1 & 6 & 37 \\
& HDD & 73 & 66 & 123 & 214 & 331 & 404 & 438 & 383 & 290 & 228 & 162 & 100 & 2813 \\
\hline \multirow{2}{*}{ Dunedin } & CDD & 7 & 7 & 3 & 0 & 0 & 0 & 0 & 0 & 0 & 0 & 1 & 3 & 22 \\
& HDD & 96 & 91 & 131 & 189 & 273 & 328 & 355 & 323 & 258 & 218 & 168 & 129 & 2259 \\
\hline
\end{tabular}

Table 4 Heating and cooling degree days with $18^{\circ} \mathrm{C}$ base source (NIWA, 2017) 
The earth's climate is unmistakably warming up and therefore the cooling load of buildings is expected to increase. The Ministry for the Environment projects that in New Zealand the average temperature will rise by $0.4^{\circ} \mathrm{C}$ by 2040 and 2 to $2.1^{\circ} \mathrm{C}$ by 2090. The strongest warming is expected to occur during the winter months and possibly will be the greatest in the eastern and northern parts of New Zealand. The number of days that are above $25^{\circ} \mathrm{C}$ is expected to rise especially in northern locations (Ministry for the Environment, 2017).

(Guan, 2006) explored the implications of thermal insulation in Australian office buildings using a 2070 high climate scenario. It was found that with a higher outdoor temperature, there would be less time a building would spend warmer inside than outside and therefore a higher level of thermal insulation may be beneficial. The proposed thermal insulation level was shown to reduce the overheating hours per annum for Darwin by up to $7.44 \%$ or 175 hours per annum in comparison to the base case.

\subsection{Building Envelope}

The building envelope's main function in different weather conditions is to:

- Cold weather: reduce heat loss through the envelope, maximise solar and internal heat gains and reduce heat loss by uncontrolled air infiltration

- Warm weather: minimise solar heat gain to avoid overheating, and reduce heat gain with the use of shading and thermal mass (CIBSE, 2012)

Solar heat gain on opaque surfaces is influenced by surface properties, shape and orientation. Solar heat gain through the windows is affected by window size, orientation, glazing material and shading devices. A building's surrounding vegetation and adjacent buildings can have a large influence on the solar gain admitted to a building. The thermal mass of a building will affect the retention and release of the heat gain admitted into the building (Szokolay, 2014). 


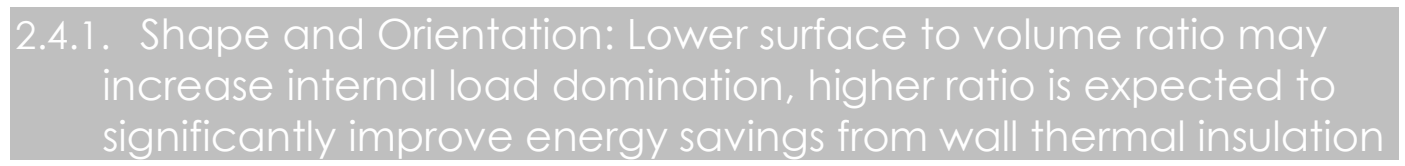

The number of storeys and the shape of a building will determine its ratio of perimeter area to floor area. The orientation will determine the level of solar heat gain. The shape of an office building can have a significant impact on energy use as it determines the amount of conduction heat gain and loss (Ourghi, AlAnzi, \& Krarti, 2007).

A larger building that is otherwise identical to a small building, will have higher cooling loads and less heating (Bannister \& Guan, 1995). This is due to the smaller surface area to volume of the larger building- less area to lose heat externally. Therefore, a lower surface to volume ratio will increase internal load domination as the external environment has a reduced influence. A higher surface to volume ratio would be expected to significantly improve wall thermal insulations ability to decrease energy requirements (Bannister \& Guan, 1995).

It would be expected that a more compact building would perform better thermally. However, the study by (Creswell-Wells, 2014) demonstrates that this is not necessarily true. The pattern observed indicated that building height has a negligible effect on energy consumption and is not proportional to energy performance. An office building was modelled with various heights $(4,6$ and 8 floors) and with 2 and $6 \mathrm{~m}$ gaps (between building and adjacent buildings). As the building height increased, the total energy consumption was shown to increase. However, the impact was very negligible- around $2 \mathrm{kWh} / \mathrm{m}^{2} /$ year between heights. A reduction in energy consumption was observed for buildings between 4 and 6 floors when modelled with a 6 m gap.

The orientation of a building can have a significant impact on energy efficiency (CIBSE, 2012). An optimum orientation will maximise daylight and minimise summer heat gain and winter heat loss. In most cases, it is optimal for the north and south walls of a building to be longer than the east and west- with a ratio of 1.3 to 2.0 (depending on temperature and radiant conditions). Refer to the Window section for discussion of how window placement will affect solar gain. 


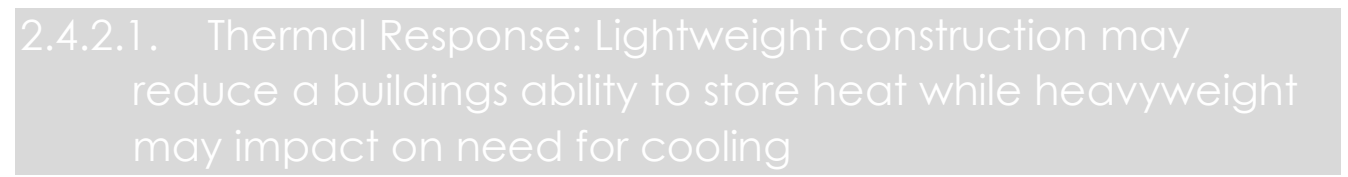

The thermal response of a building can be used to reduce energy consumption. Energy can be reduced by smoothing out transient temperature variations and reducing maximum summer time temperatures (CIBSE, 2012). A range of factors effect thermal mass such as temperature, occupancy pattern and wall construction. Lighter construction methods will decrease a building's ability to store heat, requiring more heating energy than if it had heavyweight (high mass) construction. However, high mass does not guarantee reduced energy consumption. For office buildings where overheating is an issue, using concrete as a passive heat source is not beneficial, however its thermal inertia qualities may be useful. Therefore, the cooling load of buildings with high internal heat gains can be reduced by using high thermal mass to slow down swings in temperature (CIBSE, 2012) (Bannister \& Guan, 1995). However, if a building does not use natural ventilation strategies a lower thermal mass may be appropriate (to allow for heat to be released externally).

While NZS 4243.1 Energy Efficiency- Large Buildings sets minimum requirements for building components thermal resistance levels, there is no requirement for thermal mass.

Different mass and insulation configurations will differently impact both heating and cooling energy (Stazi, Bonfigli, Tomassoni, Di Perna, \& Munafò, 2015). The benefits of concrete (high thermal mass material) will be maximised when thermal insulation is placed on the exterior side of the wall (Creswell-Wells, 2014). It is more cost effective to apply insulation to the inside of the wall, however the thermal inertia qualities of concrete would be reduced. 
While the thermal mass benefits of concrete may be maximised when insulation in placed externally, when it is placed internally the potential to increase cooling energy use could be mitigated or eliminated (Idris \& Mae, 2017).

Creswell-Wells (2014) modelled an office building in Christchurch with concrete construction by placing insulation internally and externally. It was found that the concrete with external insulation provided the best result in terms of total energy use. The appropriate configuration and level of thermal resistance and mass would however depend on the specific building.

An adequate thermal insulation level will vary between building types and climate. Increasing the insulation value is intended to save energy consumption through reducing the heat transfer. For external load dominated buildings in cold climates, a higher level of insulation may be required. However, a lower level may be required in internal load dominated buildings in temperate climate.

Higher levels of insulation are thought to be unlikely to greatly improve the energy performance of a building that is dominated by its internal energy loads. Studies carried out by Ballarini \& Corrado (2012); Boyano et al. (2013); de' Rossi et al. (2016); Friess et al. (2017); Idris \& Mae (2017); Masoso \& Grobler (2008); and Pan et al. (2012) all identify that thermal insulation beyond a certain level can cause heat to trap inside a building, and therefore increase the cooling energy consumption.

(Boyano et al., 2013) explored the effects of levels of thermal insulation higher than those required as the minimum in European national building codes. It was found that in two (Tallin and London) of the three locations (Tallin, London, Madrid) used in the study, increased insulation levels considerably reduced annual energy consumption, and in the other, insulation had a decreasing effectiveness (Madrid location). The office buildings were simulated with varying parameters at three locations- each representative of the principal climate 
zones in Europe). Where cooling energy was observed to increase, the decreases in heating energy outweighed the increase- and so an overall decrease in energy consumption still occurred. While the reduction in energy consumption was still significant, the overall annual energy cost reductions were not (-8\% savings). This is due to the simulated building using expensive electricity for cooling energy and lower cost natural gas for heating (Boyano et al., 2013).

(Guan, 2010) found that a higher level of insulation caused both the cooling and total energy use to increase for a building modelled in Australia. (Guan, 2010) modelled a typical Australian office building (as found in the central business districts of the capital cities or major regional centres in Australia), with either a low (no added insulation), medium (R2.0 roof, R1.5 wall) or high level (R3.5 roof, R3.0 wall) of insulation in each of the eight capital cities of Australia. Relative to the mid case of insulation, the increase in annual energy consumption was shown to be a maximum of $0.5 \%$ (Hobart). The low level of insulation was found to be the most beneficial in all cities except Darwin.

It was established when developing NZS 4243;1996 that the benefits of thermal insulation in office buildings located in Auckland and northward may be counteracted by increased cooling energy (Paul Bannister \& Lisa Guan, 1995). South of Auckland, the decreases in heating energy were thought to be significant enough to outweigh any increase. (Bannister \& Guan, 1995) found that added roof insulation had potential for energy savings throughout $\mathrm{New}$ Zealand, however wall insulation will only produce savings south of Auckland. While wall and roof thermal insulation was found to achieve significant decreases in energy consumption in Auckland, the increase in cooling energy was great enough that the total energy consumption was increased (relative to the simulation model with only roof insulation (Roof R1.9 and wall R.0)). When the same energy model was simulated in Christchurch, any level of added insulation caused the cooling energy to increase. However, as the Christchurch climate is cooler than Auckland, the reduction in heating energy always outweighed the 
increase significantly enough for wall insulation to be recommended (Paul Bannister \& Lisa Guan, 1995). (Bannister \& Guan, 1996) recommended values similar to those that are included in NZS 4243:!996, and found together the measures resulted in a maximum of $18 \%$ reduction in total energy consumption.

A later study by Creswell-Wells, (2014) found that any added level of insulation (to that required by NZS 4243) to the roof or wall of an office building modelled in Christchurch, caused the energy consumption to increase. This was observed for a building with no natural ventilation. The highest level of thermal insulation used in the study resulted in the greatest reduction in energy consumption for all models simulated with passive ventilation. The highest thermal insulation levels were R5.7 in the roof and R3.6 in the wall. While the addition of R3.6 to the walls resulted in the greatest total energy reduction, it was only decreased very negligibly by less than $1 \%$ for each case.

Only visible materials were recorded during BEES and therefore no information is known about the typical thermal insulation levels of New Zealand office buildings.

2.4.3. Windows: window design has a major impact on energy use in buildings

The heat gain and loss of windows can occur in four ways- conduction, convection, radiation and/or air leakage. Typically, the conductive heat losses during winter will add to energy requirements and radiant heat gains in the summer (Guan, 2011 ). Glazing can be defined by three material properties, visible light transmittance (VLT), solar heat gain coefficient (SHGC) and thermal resistance (U-value). VLT represents the percentage of a light-wave that is able to pass through. SHGC is the measure of the total solar energy transmittance and the U-value describes the glazing's ability slow down heat escaping from a space and incoming heat transfer. A high U-value indicates poor thermal resistance, while a lower SHGC will better restrict heat energy transmission. As the VLT of glass increases, the depth of daylight penetration will be increased. 
The thermal properties of glass can have a significant impact on the amount of solar energy that enters a building envelope. Guan (2011) demonstrated that like wall thermal insulation, glazing with higher thermal resistance can cause cooling energy requirements to increase in certain locations. Gazing with a higher Uvalue and solar reflectance, but lower shading coefficient was found to have the greatest reduction in cooling and total building energy consumption. Single and double reflective glass had these qualities and resulted in the greatest reduction in energy use for each of the locations used in the study. Guan (2011) simulated a typical office building in the eight capital cities of Australia with different glazing types. Single clear glass was used as a reference base case to show the relative performance of other glazing types. It was found that typically, single pane glass (lower thermal resistance) had better energy performance than double pane glass (higher thermal resistance). An increase in total energy consumption of up to $3.5 \%$ was shown to occur.

(Creswell-Wells, 2014) observed a similar result when modelling an office building in Christchurch. At a WWR of $25 \%$ translucency, not higher thermal properties, was the better characteristic. However, at a higher WWR of $75 \%$, the findings reversed.

\subsubsection{Energy savings decrease as insulated wall area decreases}

The overall performance of a building is largely affected by the relative area of window to the total area of a building façade (WWR). The WWR gives a measure to the window heat loss and solar radiation heat gains (Bannister \& Guan, 1996; Friess et al., 2017; Bannister \& Guan, 1997) speculated that there is a level of window to wall ratio at which wall insulation is no longer viable. This was determined to be likely at a WWR ratio higher than 50\%. This was established from simulating an office building in New Zealand with different levels of thermal insulation and window to wall ratios. It was found that as the insulated area decreased, the savings per unit area also decreased. (Friess et al., 2017) also found that a higher window to wall ratio heavily reduces the thermal insulation's ability to decrease energy consumption. 


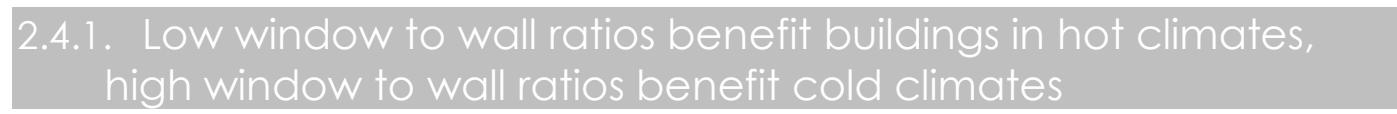

A lower window to wall ratio in a NZ climate would generally result in lower solar heat gain and conduction heat flow through the window. As a result, both heating and cooling loads would decrease (Guan, 2006). It is important to note that the influence of area of glazing on each façade may not be the same. For example, in New Zealand glazing on the south façade would be expected to have less influence than on the east.

For internal load dominated buildings, smaller windows may then result in a reduced loss of unwanted heat. (Guan, 2006) found that the relationship between reduced WWR and the change in total and cooling energy decreases in a non- linear manner. This was observed when modelling a typical Australian office building in the eight capital cities of Australia.

(Bannister \& Guan, 1996) found that increased window to wall ratios causes both the heating and cooling loads to increase- due to the additional solar gains and conduction heat transfer. Low window to wall ratios will be beneficial in very hot climates, while high ratios are more beneficial in climates where heating loads are dominant (Szokolay, 2014). This is demonstrated in the study by (Friess et al., 2017) who simulated an office building with three different cooling set points, varying thermal insulation levels and four WWR's in 3 different climates. It was found that the WWR that produced the lowest EUI in each location varied for each location and a higher window to wall ratio reduced the impact that wall insulation had on the energy consumption of building in all climates.

Beyond a certain insulation level (which varied depending on location), the insulation increases had almost no effect at all - as energy consumption remained constant. The locations (Malaga, Dubai, El Dorado) included in the study were selected at random to reflect a range of climate extremes while also remaining in a predominantly cooling environment (previously identified as susceptible to an adverse effect). 
The optimum WWR (where annual energy consumption is lowest) was found to be different for each location included in the study-40\% Dubai (hot climate), Malaga (balanced climate) 60\% and El Dorado (cool climate) $80 \%$ (at the $24{ }^{\circ} \mathrm{C}$ set point) (Friess et al., 2017). These findings are consistent with the common perception that a low WWR is optimal in very hot climates such as Dubai- due to reduced solar gains. In cooler climates with higher heating requirements (like El Dorado), a higher WWR is optimal- this will reduce heating requirements. Malaga, the more balanced climate, was observed to be less affected by WWR changes (EUI varies between 1-2\% across the $40-80 \%$ WWR changes) (Friess et al., 2017). In El Dorado and Malaga, the energy behaviour of each building did not change as the WWR increased. A consistent decrease in energy consumption was observed for the El Dorado location, and a consistent increase for Malaga. However, for Dubai, the window to wall ratio had a greater effect- as it is shown to influence whether the building experiences a positive or negative effect. Insulation increases at the lowest set point $(21 \circ \mathrm{C})$ are shown to always have a positive effect-although beyond $40 \%$ WWR, any increase above $30 \mathrm{~mm}$ insulation thickness appeared to have no effect, and energy consumption was constant. The effect of insulation increases at the mid set point $(25 \circ \mathrm{C})$ at $20 \%$ is positive, at $40 \%$ a negligible decrease and a negligible increase at $60 \%$ and $80 \%$. At the highest set point $(27 \circ \mathrm{C})$, the EUI is consistently just below $160 \mathrm{kWh} / \mathrm{m}^{2} / \mathrm{yr}$ for every insulation level, very negligibly increasing.

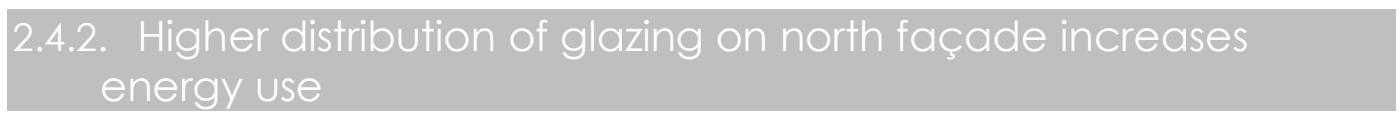

While the overall WWR will have a large effect on the building's energy consumption, the distribution of glazing on each wall will also have an effect. A building with a higher distribution of glazing on the northern and west walls and lower distribution on the south and east is expected to require greater amounts of energy than one with a lower distribution on the north and west walls (Bannister \& Guan, 1995). 


\subsubsection{New Zealand: The colder the climate, the greater the increase in energy use for increased WWR}

To use the Schedule Method of NZS4243 requires the building to have a WWR of 0.5 or lower. However, if a proposed building has a WWR higher than this, the Calculation or Modelling Method must be used. No glazing requirement is set in NZS 4243:1996. The impact of double glazing in commercial buildings was explored when first developing the code, however it was found to not be costeffective in any situation at the time and so was not further explored (Bannister \& Guan, 1995).

(Bannister \& Guan, 1996) modelled WWR of $0.2,0.5$ and 0.9 for the two buildings with thermal insulation levels about same as required by NZS4243:1996. A maximum window to wall ratio of 0.5 was suggested by (Bannister \& Guan, 1996) as an optimised value when considering the energy savings with small windows against decreased potential for the replacement of artificial light by natural daylighting. Annual energy results for each building and varying WWR demonstrated that the colder the climate, the greater the increase in energy use for an increased WWR.

\subsubsection{Shading reduces cooling load and can increase heating}

Office buildings often have large glazed areas. This can result in large cooling demands and can also reduce heating demands when its cooler. Solar shading can be used to minimise the cooling load through reduced solar gain during the summer. (Grynning, Time, \& Matusiak, 2014) state that shading measures are vital for reducing the cooling demand of office buildings. However, shading systems may contribute to higher heating demands as well as higher artificial lighting energy requirements. (Creswell-Wells, 2014) found that all office building scenarios modelled with a low WWR ratio of $25 \%$ had the best energy performance with no external shading. With larger windows (WWR 75\%), shading achieved energy savings. However, small sized overhangs $(750 \mathrm{~mm})$ were more efficient. The appropriate type of shading, size and positioning for a building will be dependent on climate, use and the angle of sun to be excluded (CIBSE, 2012). 
Just as external shading systems applied to a building can impact energy demand, surrounding vegetation and adjacent buildings will as well. Office buildings typically are constructed in high density areas. The void space or "urban canyon" between buildings is a significant source of solar energy to buildings (Creswell-Wells, 2014). It affects both the outdoor and indoor microclimates (Ali-Toudert \& Mayer, 2006).

The aspect ratio (ratio between heights of buildings to width of street) will determine the effectiveness of the void. Strømann-Andersen \& Sattrup (2011) found the aspect ratio can significantly impact the total energy demand of an office building by up to $+30 \%$ with an aspect ratio of 3.0 , and by $2 \%$ at a low ratio of 0.5. A ratio of 1:1 was found to create shade across an entire street at a certain time, while a ratio of 0.5:1 will shade only half the street (StrømannAndersen \& Sattrup, 2011).

Strømann-Andersen \& Sattrup (2011) suggest that high density ratios of 3.0 will severely limit solar radiations ability to enter the canyon in comparison to a low density of 0.5 . It was observed when modelling an office building with aspect ratios of $0.5,0.75,1,1.5,2$ and 3 , a general increase in total energy consumption occurred as the ratio increased. The cooling demand decreased with increased density due to overshadowing, while heating energy increased due to reduced solar gains.

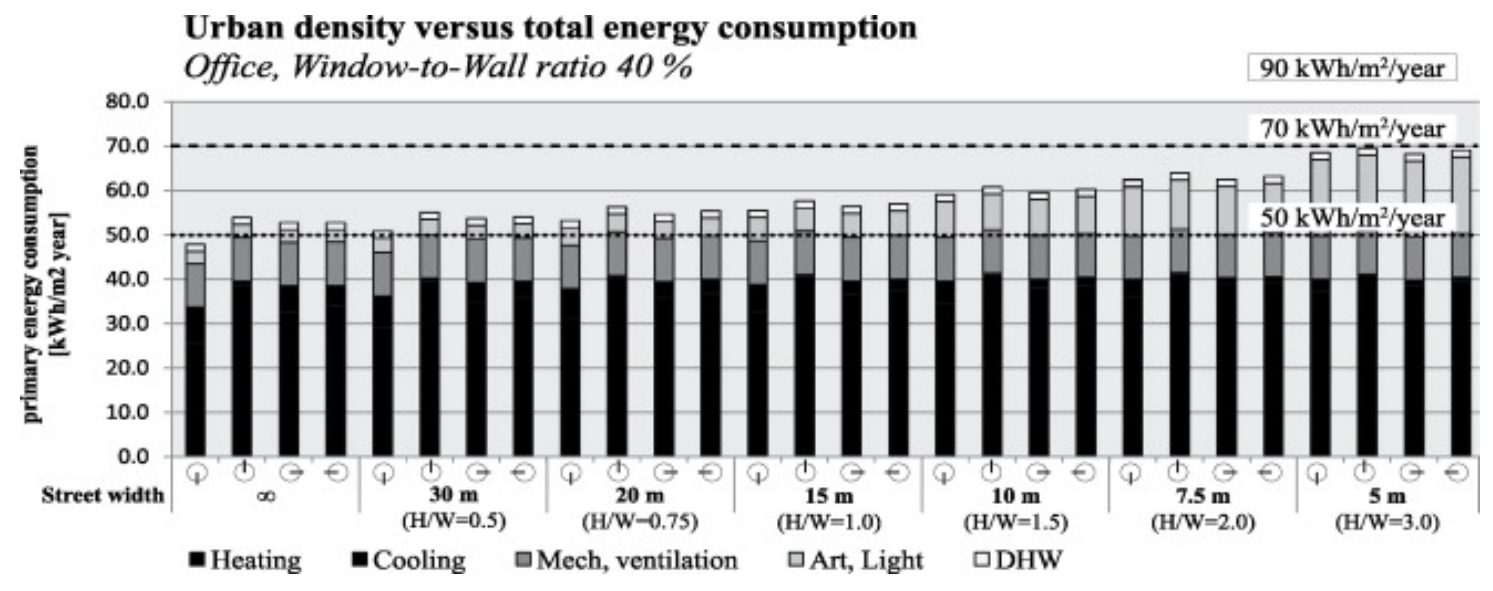


Figure 7 Total building energy consumption ( $\mathrm{kWh} / \mathrm{m}^{2} /$ year) of a 5 storey office building modelled with different urban density aspect ratios (Strømann-Andersen \& Sattrup, 201 1)

\subsubsection{Natural Ventilation can reduce the internal heat load}

Natural ventilation is the passive flow of air into a building through planned openings or system settings, or through unintentional openings. It is needed to supply air to a space and extract polluted air. Airtight construction which reduces air infiltration is important in air conditioned buildings, and specifically for buildings in extreme climates to prevent unwanted ventilation and heat gains or losses. However, airtight construction can also contribute to the trapping of heat which may result in increased energy use. Natural ventilation through a building's fenestrations can provide a reliable source to dissipate unwanted heat gains. However, thermal insulation in an office building that is naturally ventilated with no air conditioning system may have overheating issues even in cooler climates (Paul Bannister \& Lisa Guan, 1995).

\subsection{Space Conditioning Systems: Different systems and design will have different heating and cooling demands}

The use of space conditioning systems in buildings is to maintain desired environmental conditions. Systems are either centralized (a large central plant) or de-centralized (smaller plants located around the building).

The design of a system will have a significant impact on a buildings energy efficiency, and heating and cooling demands. Design influences include the type of pump, fan etc. and their efficiency and the control strategy (temperature schedule).

(Korolija, Marjanovic-Halburd, Zhang, \& Hanby, 2011) explored the relationship between building heating and cooling load and the energy consumption required for different HVAC systems. A large difference between energy demand and type of air conditioning system was found. Two common HVAC systems (Fan Coil Unit (FCU) and variable air volume (VAV)) were simulated in two office buildings (open plan and cellular) energy models in the UK. For both 
buildings, the VAV system had over $40 \%$ less cooling demand in comparison to the cooling load. The FCU system required $30 \%$ more cooling energy than the building demand. The increase in energy required would be due to the excess heat gains produced by the fans and pumps, while the VAV system required less energy as it used free cooling.

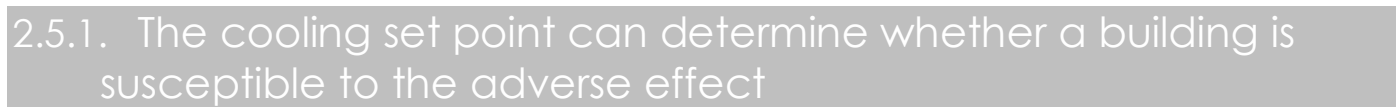

Whether the presence of insulation in a building reduces or increases a building's cooling load, has also been found to be dependent on the cooling set-point temperature of the HVAC system. Air conditioning systems typically have a both a heating and cooling thermostat set point, either at a fixed temperature throughout the year or on a schedule. In temperate climates, reducing the room temperature by $1^{\circ} \mathrm{C}$ can reduce the total energy consumption by around $10 \%$ (CIBSE, 2012).

(Friess et al., 2017; Idris \& Mae, 2017; Masoso \& Grobler, 2008) demonstrated that at a certain set point temperature, thermal insulation can switch from causing a decrease in cooling energy to an increase- and the increase can become more pronounced as the set point increases or decreases. The temperature at which the building switches is termed "the point of inflexion" (PTI). Note that when the outdoor temperature is higher than the indoor temperature, the building envelope would then act as source of heat gain (not loss). (Friess et al., 2017). This is demonstrated in the study by (Guan, 2010) which found that when simulating a prototypical office in all capital cities of Australia, both the total energy and cooling load generally increased as the insulation level increased in all cities expect Darwin. The building was simulated with a cooling set point temperature of $24{ }^{\circ} \mathrm{C}$. Guan attributed the increase in energy to the fact that each location except Darwin had more than $80 \%$ of hours where the outdoor temperature was lower than $25^{\circ} \mathrm{C}$. Therefore, a higher level of insulation would be likely to trap heat inside, and consequently a greater amount of cooling energy would be required to remove the extra heat load. 
Idris \& Mae (2017) identified eight behaviours of cooling energy consumption that can occur as insulation levels and cooling set point are increased within a building. The results were obtained through simulating a building with five different insulation levels at five varying cooling set points in 13 locations with varying climates in America and Canada. The annual cooling energy consumption at each insulation level was plotted for each cooling set point. Five groups can be used to describe the energy behaviour that occurs as the insulation level of a building is increased (Idris \& Mae, 2017):

- Pro-Insulation Behaviour: increasing set point always results in positive effect (reduction of energy use)

- Negative PTI: Where higher cooling set points are prone to increased energy use.

- Inverted PTI: Where lower set-points have negative values, higher set points were found to save energy

- Ranged PTI: Where two PTI's are found within the set point ranges simulated. Between the PTI's a negative or positive effect on energy savings can occur

- Severe Adverse effect: cases where there is always an increase in energy consumption regardless of set point temperature. The PTI can then be expected to fall below the lowest set point used in the study. Only when adding the sum of heating and cooling energy, can it be identified whether the increase in cooling energy will result in overall increased energy consumption

The following studies carried out by other researchers demonstrate the findings of (Idris \& Mae, 2017), that depending on the location of a building, either a lower or higher cooling set point may cause increased energy use.

Masoso \& Grobler (2008) demonstrate that a higher set point in an office building in Botswana may cause an adverse effect. An office building was modelled with varying set points, to find the point of thermal inflexion. Six sets of simulations were carried out- each set involved simulating a range of wall insulation levels at one cooling set point temperature. The mid insulation level (80 $\mathrm{mm}$ XPS insulation) used in the study was shown to achieve a $3.5 \%$ reduction in annual energy 
consumption at a cooling set point of $18{ }^{\circ} \mathrm{C}$. As the set point rises the energy savings decrease up until $25.72 \circ \mathrm{C}$, where the decrease in cooling energy consumption switches to an increase. Beyond this temperature, negative savings start to increase.

Friess et al. (2017) (described in 2.3.1) simulated a generic office building in three global cities (Dubai, Malaga and El Dorado) and assessed the effect of increasing wall insulation levels and the cooling set point temperature. It was found that in each of the locations, the set point had a contrasting effect. Varying insulation levels $(0,20,60,90,120$ and $150 \mathrm{~mm})$ were simulated for each building. For each step, a range of window to wall ratios $(20,40,60,80 \%)$ were modelled at each cooling set point temperature $(21,25,27 \circ \mathrm{C})$. The heating set point remained at $20 \circ \mathrm{C}$ for each case.

For all cases in Malaga (small heating and larger cooling requirement), an adverse effect was observed for all set points, El Dorado (mixed heating and cooling, but cooling dominated) had a consistent positive effect where increased insulation decreases energy consumption for all set points. For Dubai (cooling dominated), after the first step in insulation $(30 \mathrm{~mm})$, the annual energy consumption is seen to not be significantly affected by any increase in insulation. The effect is positive for the lowest set point and negative for the highest, while the mid set point displays both effects for different WWR (although very negligibly).

At the lowest set point temperature, the outdoor temperature will rarely be below the internal set point for the Dubai case. Therefore, there will be more thermal gains through the envelope and so insulation is an efficient way to decrease the energy consumption (although no additional energy savings occur beyond lowest level). Conversely, at the higher set points the building spends less time cooler outside than inside. Consequently, heat is trapped.

The results for the Malaga location, displayed a consistent negative effect for all set points. Malaga has a Mediterranean climate, requiring a small amount of heating and larger amount of cooling. This means that winter temperatures 
outdoors were low enough to require heating, and the summer months were warm enough that cooling was still required at the lowest set point. The consistent increase of energy consumption at every set point was due to the building not being able to shed enough heat through the walls. The heating requirements are not significant enough to outweigh the cooling requirements, therefore in this case insulation was not beneficial.

The El Dorado results show insulation increases were beneficial at every set point. While the climate is similar to Malaga and requires a similar amount of coolingthe climate is more extreme with stronger seasonal swings, requiring a higher amount of heating. This factor appears to be the reason why the results are the opposite to Malaga.

The effect the cooling set point has on insulation or energy consumption was not explored by (Bannister \& Guan, 1996) or (Isaacs et al., 1994) when developing the energy efficiency requirements for large office buildings. Fixed heating and cooling set points were modelled $-20.5^{\circ} \mathrm{C}, 23.5^{\circ} \mathrm{C}$ and $19 \mathrm{C}, 22^{\circ} \mathrm{C}$ respectively. NZS4243.1 recommends temperatures within the range of $19-24^{\circ} \mathrm{C}$ to be used when using the modelling method.

2.5.1. Free- cooling can reduce or prevent an increase in energy use

While there appear to be no studies that directly explore the effect of economiser control (the direct use of external air when at an acceptable temperature) on the effectiveness of thermal insulation, it would be expected that the use of it could prevent an increase in cooling energy use- due to the reduction in energy use. Air conditioning systems can incorporate the use of economiser control to provide free cooling. Free cooling works similar to the use of windows in residential buildings, as they take advantage of the outdoor air conditions. When the conditions are favourable, the chiller plant can be shut down and "free" cooling from outdoors can be used to cool a space (CIBSE, 2012). This therefore, would save a great deal of cooling energy for buildings that 
have an outdoor temperature below the cooling set point temperature for a large amount of time during the year. A reduced amount of energy is required as the compressor is run less when using free cooling. (Guan, 2010) found that all capital cities of Australia had more than $80 \%$ of hours when the outdoor temperature is lower than $25^{\circ} \mathrm{C}$. This means that for an office building in these cities with a cooling set point of $24^{\circ} \mathrm{C}$, the use of free cooling could save a significant amount of cooling energy. Various types of economiser control exist. The optimal control type for a building is dependent on the location of a building (Marion Camelin \& Adrien Destrez, 2011).

2.6. Summary: Drivers of thermal insulation resulting in reduced and increased space conditioning energy use

The literature review identified the drivers for thermal insulation resulting in reduced and increased space conditioning energy use. The climate and internal load are expected to have the greatest impact on the effectiveness of thermal insulation. Buildings located in Mediterranean and Temperate climates are expected to be the most susceptible to the presence of thermal insulation leading to increased energy use. The susceptible locations have balanced heating and cooling energy requirements and the effect primarily occurs in locations with low temperature swings. For buildings that are susceptible to an increase in cooling energy, reducing the amount of time the building spends warmer inside and cooler outside (overheating) in summer would allow for thermal insulation to either achieve greater energy savings or prohibit an increase from occurring.

The external and internal loads of an office building will determine the amount of heating and cooling energy a building requires to maintain the specified heating and cooling set points. The adverse energy behaviour only affects cooling energy and excludes heating. While some researchers suggest that the adverse effect only occurs in buildings with a pronounced cooling need, others have found that it occurs in heating dominated buildings. The increase in energy is likely to be greatly outweighed by the reduction in heating energy use of a heating dominated building. 
Reducing the time a building spends overheated will reduce its cooling load. While the adverse energy behaviour will occur in buildings that are warmer inside than outside, it will occur at the time when cooling energy is required. Both fixed and operational parameters at certain levels or values can reduce a buildings cooling load. Factors that can reduce a buildings cooling load include reduced internal gains, shading, natural ventilation, additional building mass and smaller window to wall ratios.

Studies undertaken to directly explore the adverse energy behaviour have previously assessed the impact of higher levels of thermal insulation, internal load, window to wall ratio, thermal mass and cooling set point. The studies undertaken to develop the New Zealand Standard for energy efficiency did not explore thermal insulation sensitivity to thermostat set point, shading, ventilation, thermal mass or different air conditioning systems. Consideration of these factors would ensure that the minimum required levels of thermal resistance for the building envelope were robust in terms of expected energy performance.

Thermal insulation was thought to be beneficial for buildings south of Auckland when developing the New Zealand Standard for energy efficiency. While an increase in cooling energy is expected for southern locations, the reduction in heating energy found to outweigh and increase significantly. However, indicators established by (Friess et al., 2017) suggest that thermal insulation in locations south of Auckland may cause increased total energy consumption.

\subsubsection{Use of buildings has changed}

NZS4243:1:2007 superseded NZS4243:1996, however the thermal performance requirements have not been altered since the 1996 version. The use of buildings has changed over the past 20 years with the advancement of technology and change in occupant behaviour and use. As previously identified, the regulated and typical values used when carrying out modelling for the development of the Standard are no longer relevant to office buildings currently. Therefore, it would be expected that the influence of thermal insulation on the energy performance of buildings would vary from how it has in the past. 


\subsubsection{Investigation of further parameters and climate}

The research in this thesis explores the influence of a range of New Zealand climates on the energy performance of buildings and thermal insulations sensitivity to various parameters. Parameters include building construction materials, window design, internal load level and cooling set point. The research uses building energy simulation to assess the following:

- How current real New Zealand office buildings perform with increased levels of thermal insulation

- How the climate influences current real New Zealand office buildings to perform with increased levels of thermal insulation

- How real New Zealand office buildings perform when complying with the regulated and assumed values set out in NZS4243.1:2007

- How the sensitivity of thermal insulation to a selected parameter varies throughout a sample of real New Zealand office buildings (complying with the regulated and assumed values of NZS243.1:2007) 


\section{Methodology-Research Design}

This chapter details the methodology followed in the research of this thesis.

\subsection{Research Aim}

The aim of this research is to identify whether the addition of thermal insulation to New Zealand office buildings could lead to increased energy use. Also to identify the characteristics of New Zealand Commercial Office buildings and climates that might lead to thermal insulation resulting in increased space conditioning energy use. Energy performance data and analysis will be used to test the hypothesis- that the addition of thermal insulation to commercial office buildings in New Zealand results in increased energy use. The following sections outline the selected method of analysis, the computer programs used to assist in the process and the design of the study.

\subsection{Parametric Method of Analysis}

This research is a quantitative study investigating the energy performance of a sample of New Zealand office buildings under varying scenarios. Building energy modelling (BEM) is essential to allow for the estimation of building energy consumption. A parametric method of analysis was used to understand how the energy performance of each building is affected by thermal insulation in combination with climate and various building attributes. This type of method allows for systematic analysis of a range of variations in design. Through altering one or a combination of parameters of a building energy model at a time, the effect of the parameter/s are able to be determined. Patterns of effect are able to be found when changing the characteristics of selected parameters a number of times. It is important to note that if more than two or three parameters are varied, it will be difficult to understand the interaction of the system parameters (Wetter, 2004). 


\subsection{Whole Building Simulation: Using EnergyPlus}

BEM is a well-established method to represent the energy performance of a building. BEM uses physics-based software that calculates building energy use. The database and algorithms used by a program are crucial for the prediction of building energy performance. Therefore, the selection of a suitable program is important. Selection factors considered to be important include; the reputation of program developer, features and capacity, the validation process and popularity (Guan, 2006).

A range of computer programs for building energy modelling exist. Major building energy simulation programs include TAS, ESP II, ESP-r, TRACE 700, IES Virtual Environment, TRYNSYS and EnergyPlus (Guan, 2011). Energy modelling in this study was carried out using EnergyPlus version 8.6. Where necessary, the geometry of the sample of buildings was altered using the OpenStudio Version 2.4.0 plugin for Sketchup. EnergyPlus and Openstudio were initially used by the BEES team to create the commercial office building energy models used in this study. EnergyPlus was developed by LBNL (Lawrence Berkley National Laboratory) and NREL (National Renewable Energy Laboratory) and is funded by the US Department of Energy. The program is tested to international standards (International Energy Agency (IEA)) building energy simulation test (BESTEST)).

"EnergyPlus is an energy analysis and thermal load simulation program. Based on a user's description of a building from the perspective of the building's physical make-up, associated mechanical systems, etc., EnergyPlus will calculate the heating and cooling loads necessary to maintain thermal control set-points, and the energy consumption of primary plant equipment; as well as many other simulation details that are necessary to verify that the simulation is performing as the actual building would." (Lawrence Berkeley National Laboratory, 2013).

\subsubsection{Running a matrix of simulations}

This research required thousands of different energy models to be simulated. For all variations of the base calibrated energy models that were explored, an 
individual IDF file was required to be generated for each. In order to efficiently generate and run the files for each building, a matrix system based on Excel was used. The system involved writing macros to generate the model files and to extract the results from multiple output files once each model had been run using EnergyPlus. An Excel macro can be defined as a set of programming instructions that can be used to eliminate the need for repetitive tasks.

It is important to note that plugins for Rhino such as Ladybug and Honeybee exist to facilitate the generation of hundreds of EnergyPlus IDF files with varying parameters. However, these were not utilised as the selected process was thought to be less time consuming. Programs such as GenOpt can be used to automatically run through options between defined minimum and maximum values of a parameter- to find the option that achieves the greatest reduction in energy use. While this type of program may have been more efficient to identify the best performing option, it does not allow for the type of analysis that this research required (Cory, 2016).

Excel macros were used to generate the individual files with various design changes for each building. Firstly, the program "R" was used to generate a string of numbers to represent each combination of various design changes (relevant to a simulation set). For example, the numbers 1 and 8 represent Auckland and Dunedin. While, 1_9 represents the building simulated in Auckland with Case 1 values applied. A series of three numbers (for example, 2_7_11) was used to explore the effects of both climate, thermal insulation and one parameter. The relevant string of numbers for the set of modelling were placed into Excel for the macro to read. For each building, the text from the IDF file of each base building (see section 3.5 for more information on how the base models were created) was then placed into another Excel sheet. The relevant lines of text that related to the design changes were copied into another Excel sheet and edited as required. Reference to the line of text within the base model and the number representing the design change was documented by the text. A macro was then written to automate the process of extracting lines of code from the base model text and replacing the lines with the relevant text for each variation. After successfully copying and pasting each of the lines of text for one variation, the 
macro would save the "base model" text as an IDF file to the specified location with the specified name referencing the changes made. Each batch of files for the buildings was then run in EnergyPlus using the feature to simulate a group of input files. The relevant TMY weather files were used (see further sections for more information).

As discussed in further sections, the commercial office building energy models were detailed models with every floor modelled. Several of the buildings simulated had between 10 -20 floors with multiple zones on each, therefore to create the Excel files for each building to run the Macro and then run the IDF files through EnergyPlus was a time-consuming process. For example, when changing all internal load (occupancy, equipment and lighting) levels of the 20 storey building with 5 zones per floor, a minimum of 100 lines of text for each internal load type had to be extracted from the base model file and changed to suit the relevant variation.

To efficiently extract the results produced by the simulations, another Excel macro was used. The base IDF files were set up to generate the desired output results in a particular order into a.csv file. The macro was written to extract the data from the output.csv files for all variations of one building at a time. The results were pasted into one separate workbook for analysis.

\subsection{Design of Parametric Study: Three sets of energy modelling}

Separate parametric investigations were undertaken to assess the energy performance of the sample of buildings. The approach varied for each set of energy modelling. However, the thermal insulation levels were kept consistent throughout each set of modelling. Locations used in the study were consistent in the as-built and NZS4243 modelling sets. Three of the locations (Auckland, Wellington and Dunedin) were used when exploring the effect of the cooling thermostat set point temperature on the performance of thermal insulation. The design of the parametric study included the three following sets of modelling: 
1. As-built: exploring impact of different levels of added thermal insulation and climate on the energy consumption of buildings of the calibrated energy models

2. NZS4243 Standardised Models: the energy models were simulated with the regulated and assumed NZS4243 values for thermal insulation, operations, internal loads, etc.

3. Building Attributes: standardised base models were used to explore the sensitivity of thermal insulation to an operational building parameter.

\subsubsection{Thermal Insulation Levels: Used for all sets of modelling}

The buildings were modelled with six different insulation cases. This included one case with no added insulation (case 1) and 5 cases with added insulation. Essentially, beyond case 2, only the wall thermal insulation was increased for each case. Thermal insulation was modelled to be on the external side of the wall for each building.

Energy models simulated with Cases 2 and 4 values met the minimum thermal resistance requirements for Zone 1, and Zone 2 and 3 respectively. As previously discussed in Chapter 1, the minimum thermal resistance requirements include the total thermal resistance level of all construction materials for each building components. For example, R1.9 insulation was not just added to the roof of each of the energy models, but enough insulation so the overall roof achieved R.19. Within the sample, the buildings had varying roof construction types and so had different base thermal resistance levels. This means that for each case and component, the sample had different amounts of insulation added.

In some cases, added insulation was not required for the building component to meet or even exceed the minimum required level. The thermal resistance of each wall without added insulation was high enough that it didn't require added insulation for case 2. The thermal resistance of each of the building's floors was great enough that no added insulation was required to meet the requirements of any Case. 


\begin{tabular}{|c|c|c|c|}
\hline \multicolumn{1}{|c|}{ Insulation Case } & Roof & Wall & Floor \\
\hline 1 & & & \\
& No added insulation & No added insulation & No added insulation \\
\hline 2 (Z1 minimum requirement) & 1.9 & 0.3 & No requirement \\
\hline 3 & 1.9 & 0.8 & - \\
\hline 4 (Z2 \& 3 min requirement) & 1.9 & 1.2 & 1.3 \\
\hline 5 & 1.9 & 2.4 & 1.3 \\
\hline 6 & 1.9 & 3.8 & 1.3 \\
\hline
\end{tabular}

Table 5 Thermal insulation for each case

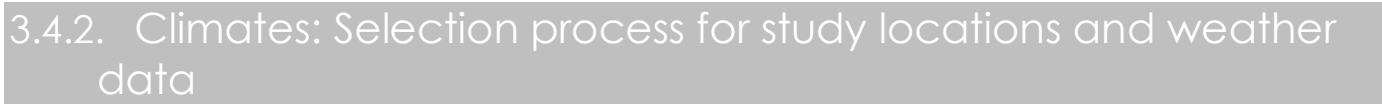

The locations used in the study included eight New Zealand cities and towns (as given in Table 3). As was previously identified in the literature review that locations south of Auckland in the North Island could be susceptible to an increase in total energy consumption- this study aimed to model a greater number of locations than the main cities of New Zealand (Auckland, Wellington, Christchurch and Invercargill). These locations were used when exploring the effect of thermal insulation on energy use for the development of NZS4243:1:1996.

The chosen locations were selected based on the findings of (Cory, 2016). Cory determined eight locations were representative of New Zealand's climate archetypes. The selected locations not only capture a range of different climate conditions, but also possess the majority of New Zealand commercial buildings. The weather files used to represent each climate location included (from north to south- as can be seen in Figure 8) Auckland (Z1), Hamilton (Z2), Napier (Z2), Paraparaumu (Z2), Wellington (Z2), Christchurch (Z3), Queenstown (Z3) and Dunedin (Z3). The selected locations include locations in each of the three climate zones of New Zealand as determined by the NZBC. 


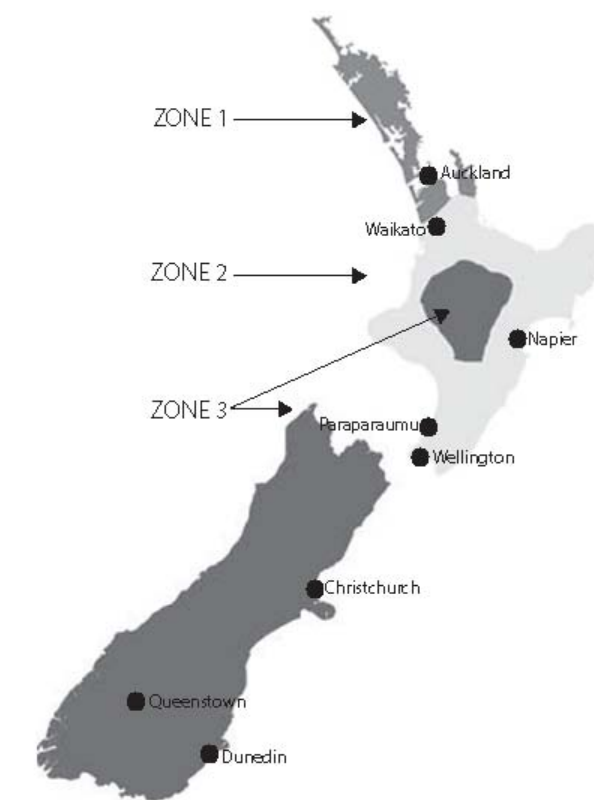

Figure 8 Locations the sample of buildings are simulated in and the NZBC zones

A total of eighteen Typical Meteorological Year (TMY) New Zealand weather files existed from Cory's research (Cory, 2016). EECA funded the development of these weather data files for the Home Energy Rating Scheme (HERS)- each location's TMY (Typical Meteorological Year) file represents a typical year's weather based on data collected over 30 years (Cory et al., 2015a).

As Cory simulated commercial buildings (generally not solely influenced by their external climate conditions), it was established that the use of all the weather files was likely excessive for the purposes of representing the entire New Zealand commercial building stock. An aggregation process was used to eliminate climates of similar qualities and where the amount of commercial floor area was not significant (Cory, 2016). If a climate location represented greater than $5 \%$ of the whole commercial building stock's floor area it was used in the poststratification process. If the representation of a location was less, it was aggregated to another similar location if 5 or fewer of the Climate indicators had less than a $20 \%$ difference. If the difference was greater, the location was kept split if the impact on the results was considered to be very different.

Building Climate Classification was used to identify whether climates had similarities. The classification uses thermal simulation of a reference building (in 
accordance to NZBC requirements) to identify the predominant design challenges of a climate- using the climate indicators that assess both the external conditions of a location and the internal building activity and thermal performance. The indicators include temperature, humidity, solar radiation, daylight, wind and comfort hours (Cory, 2016).

Note that Cory's thesis documents that while 7 climates are representative, a preliminary report authored by Cory concluded that eight locations were adequate (Shaan Cory, 2013). The report was used to base the selection of locations for this thesis. The additional climate region was Southland which is represented by a Queenstown weather file.

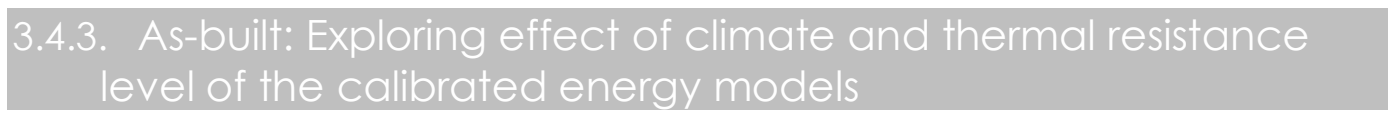

The models were simulated as-built to determine the impact the thermal insulation level and climate had on the energy performance. Each of the energy models was simulated as-built in the eight locations. The only building parameter that varied was the thermal insulation level (refer to following section for information of the levels). All other building parameters were kept consistent with the original calibrated energy models. This set of simulations consisted of creating 624 (13 buildings $\times 8$ locations $\times 6$ insulation cases) energy models.

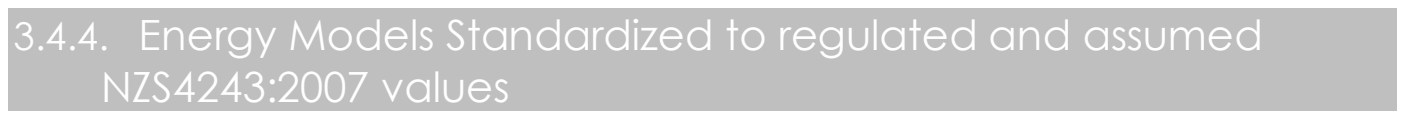

Each of the 13 calibrated energy models were simulated with the regulated and assumed NZS4243:2007 values. Each of the standardised buildings were modelled with the same 6 thermal insulation cases and in the eight locations. As with the previous set of simulations, this involved generating 624 IDF files- 48 for each of the thirteen buildings.

Figure 7 summarises each of the standardized parameters and the basis for each value(s). While not defined in NZS4243.1:2007, the occupant density was 
standardised so that the internal load level was equal among the sample. The HVAC pattern of use was adjusted so that it fitted within the standardised occupancy hours. The typical annual operational hours for HVAC from CIBSE Guide F: Energy Efficiency 2012 was used(CIBSE, 2012). While NZS4243 does not mandate minimum or maximum thermostat set point temperatures, it provides the set point temperature range often used in air conditioned buildings. The set points were standardized across the sample as many of the buildings' set points fell outside of this range. 


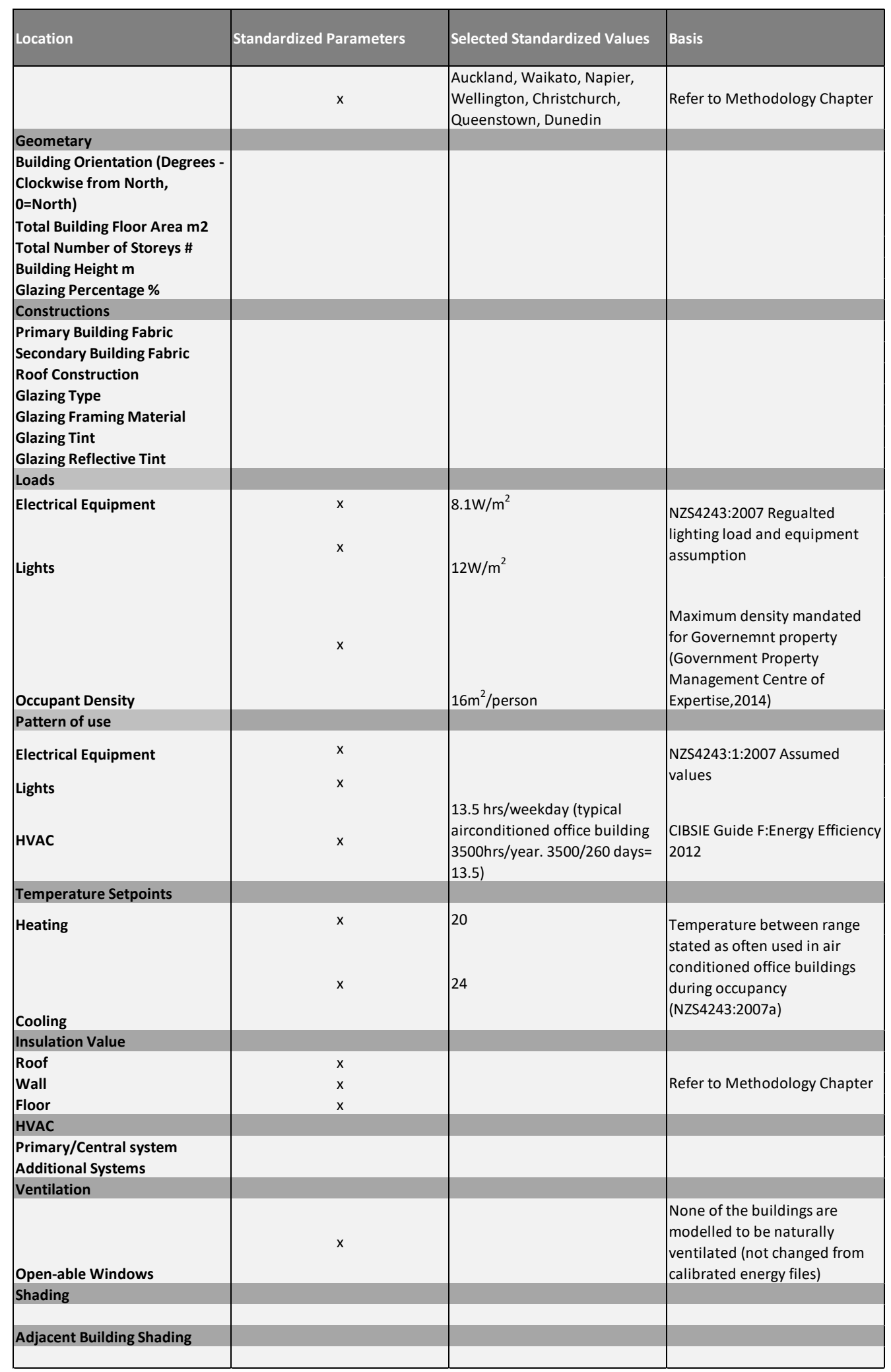

Table 6 Parameters standardised-basis and source 
All parameters not standardized were kept the same as the original calibrated energy files for all buildings except R0198. For this building, the HVAC heating supply temperature needed to be raised as the standardized heating set point temperature was the same as the HVAC heating supply temperature (both 20 $\left.{ }^{\circ} \mathrm{C}\right)$. The thermostat heating set point in the calibrated energy file is very low at 14 ${ }^{\circ} \mathrm{C}$. Therefore, the file terminates when processing- as would be expected given that the supply temperature needs to be higher than the set point.

\subsubsection{Exploration of Building Attribute: Cooling thermostat set point temperature}

The standardized building energy models were used to explore the influence of the cooling set point temperature on the energy performance of the buildings as the thermal insulation level is increased. Standardized parameters rather than the original calibrated values were used as they comply with the requirements of NZS4243:2007. The energy impact of varying levels and types of parameters such as HVAC type, surface to volume ratio, and WWR were not explored in each building, although the sample buildings include a range of these attributes. Each of the buildings were simulated in one location from each building code zoneAuckland (Z1), Wellington (Z2), Dunedin (Z3). The exploration of the influence the cooling thermostat temperature had on the effectiveness of thermal insulation involved simulating 702 IDF files in total ( 13 buildings $\times$ ( 3 locations $\times 6$ climates $\times 3$ set points). Table 7 provides details of the varying cooling thermostat set points explored.

\begin{tabular}{|l|l|l|}
\cline { 2 - 3 } \multicolumn{1}{c|}{} & \multicolumn{2}{c|}{ Cooling Set Point } \\
\hline Location & Heating set Point & Cooling Set Point \\
\cline { 3 - 3 } Auckland & & $22^{\circ} \mathrm{C}$ \\
\cline { 3 - 3 } Wellington & $20^{\circ} \mathrm{C}$ & $24^{\circ} \mathrm{C}$ \\
\cline { 3 - 3 } Dunedin & & $26^{\circ} \mathrm{C}$ \\
\hline
\end{tabular}

Table 7 Cooling set point values explored in the study

\subsection{Reliability and Representation of Sample of Real New} Office Zealand Buildings

To ensure the energy results obtained in this thesis were reliable and valid, the following measures were undertaken. 


\subsubsection{Energy Performance of Real New Zealand Office Buildings}

To test how the energy performance of New Zealand commercial office buildings are impacted by thermal insulation, the buildings and parameters used to test this must be representative of New Zealand conditions. To achieve this, a sample of calibrated New Zealand office building energy models and real building data collected during the BEES study was used. The energy models were constructed in 2013 and data to create the models was collected over a 5 year period between 2007 and 2013.

\subsubsection{Benefit of using real building energy models over prototypical energy models}

"Computer simulations are only as useful as the accuracy of the simulations" (Cory, 2016).

Prototypical energy models allow for representation of the energy performance of an entire building stock (Guang Yang, Zhengwei Li, \& Godfried Augenbroe, n.d.). Generally, this type of model is used in studies and to develop energy codes. Prototypical models represent a hypothetical average building and have many assumptions about the way a building is operated. The size, envelope construction, window area, HVAC system type, operating schedules etc. are typically selected based on the mean or prevailing condition among a statistical sample. As they are typically based on opinions, experiences or guesses the models could be considered unreliable and inaccurate (Cory, 2016). Therefore, to understand how the energy performance of New Zealand office buildings is impacted by thermal insulation- a sample of real office building calibrated energy models was used. The parameters of the building energy models were constructed or input to match the counterpart of an existing building. The sample also captures a large variation in building attributes and the buildings are modelled to represent real urban environments with surrounding buildings. These aspects are not able to be captured using prototypical energy models. 
Prototypical energy models of two office buildings were used in the studies to develop NZS4243:1:1996. They used an HVAC system intended to represent the operation of a moderately well designed system (variable speed fans, use of fresh air cooling) and schedules were selected as being representative of standard office buildings operating under a five day schedule. As previously discussed, what was common or representative of office buildings 20 years ago, is not representative of buildings currently- therefore the findings of the studies using these models do not necessarily represent the performance of the current commercial office building stock.

The calibrated New Zealand office building energy models were developed by BEES in 2013 (Cory, 2016). However, it is important to note that the energy data used to match the real performance of the buildings with the energy models was collected between 2009 and 2013 -therefore the results of the energy models are not particularly reflective of the most modern building stock. Monthly meter data and 10 minute monitoring data collected over several weeks by BEES and annual EnPl's were used to ensure that the energy models performed similarly to the real building (Cory, 2016). The models were developed as part of a group of forty-eight calibrated energy models that were selected as a representative sample of New Zealand commercial buildings (Cory, 2016). The aggregate energy consumption of the sample of real buildings was used to calculate the energy consumption of the entire commercial building stock population.

\subsubsection{Exploratory not representative study}

While the office building energy models were a part of a representative sample of commercial buildings, the use of the models in this study is exploratory rather than fully representative. Through assessing in detail each of the building's attributes, it was found that certain attributes the buildings were intended to have did not match to the actual attributes. For example, a number of buildings were categorised as being within a strata size group- but the floor area of the energy model and building was that of a different strata size group. Note that BEES divided total floor area results into five approximately equal area groups (strata) (Amitrano et al., 2014). Strata 1 ranged from $5 m^{2}-649 m^{2}, 650-1,4999 m^{2}$ for 
strata $2,1,500-3,499 \mathrm{~m}^{2}$ for strata $3,3,500-8,999 \mathrm{~m}^{2}$ for strata 4 and over $9,000 \mathrm{~m}^{2}$ for strata 5.

The BEES sample of commercial buildings was a random statistical sample, aimed to capture the variation of building attributes in New Zealand in a representative way. Cory did not model all of the 101 monitored BEES buildings due to time constraints. Ten buildings with monitored data were selected in each of the first four BEES strata size groups, but as monitored data was collected for only eight Strata 5 buildings, there are 48 buildings in total (Cory, 2016).

The distribution of building type, building height, number of occupants and the number of occupied hours across the larger sample of BEES buildings was considered. The distribution of attributes was broken down for each BEES dataset within the Strata size groups. Therefore, the number of office buildings selected to be modelled within each strata size group (maximum 10) is reflective of the proportion of office buildings within this size range of the datasets. 17 office buildings were included in the total sub-sample.13 of the 17 commercial office building energy models included in the sub-sample were used in this thesis.

\begin{tabular}{|l|c|c|c|c|}
\hline \multicolumn{2}{|c|}{ Building Type } & Office & \% of Total & All \\
\hline & 1 & 3 & $30 \%$ & 10 \\
& 2 & 2 & $20 \%$ & 10 \\
Size Group & 3 & 3 & $30 \%$ & 10 \\
& 4 & 5 & $50 \%$ & 10 \\
& 5 & 4 & $50 \%$ & 8 \\
\hline Totals & & $\mathbf{1 7}$ & & $\mathbf{4 8}$ \\
\hline
\end{tabular}

Table 8 Number of office buildings included in the sample of BEES commercial energy models

\subsubsection{Quality Assurance of the Energy Models}

Quality Assurance of an energy model involves systematic evaluation to minimise risk of error and to ensure simulations are accurate (Cory, 2016). Quality Assurance of the models developed by BEES was considered to be achieved when the performance of an energy model matched that of the real building. 
The use of standardised template energy models and a calibration technique created by Cory was used to improve the QA.

Template models are simplified versions of a real building. The template files have NZ relevant materials, constructions, loads and HVAC systems. Each calibrated energy model was constructed using a standardised model creation method, limiting only measured data to be input. The process allowed for a reduced amount of time to model a real building and prevented inputs of data that had no relevance to the real building attributes (Cory, 2016). The potential for human error was also minimised as the number of user inputs was reduced.

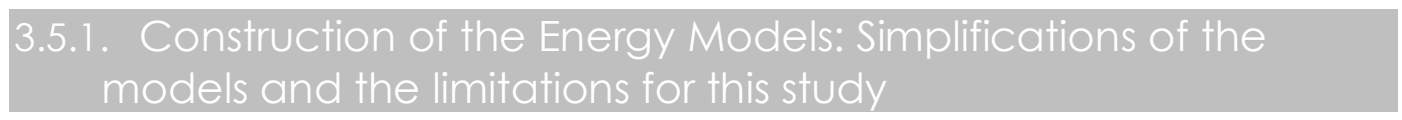

Due to the available information and desire to reduce modelling and simulation time, the energy models developed by Cory required a number of simplifications and assumptions. The most relevant simplification to this research was that only materials that were visible for each real building were recorded. This meant that the actual thermal insulation levels in each building were unknown. An initial aim of this study was to assess how the buildings performed with their real thermal insulation levels, however this was not able to be undertaken due to the lack of data on the buildings' thermal insulation levels. Many of the office buildings had thermal insulation added to the walls and roof, however the basis for the level added is unknown, or whether it meets the requirements of NZS4243:1997. The recording of only visible materials also meant that the modelled materials were selected assuming they were or were close to the available common constructions used in the template model files. The glazing of each building was recorded as either single or double glazing, along with the tint, framing and reflective properties.

The main limitation of the energy models is that all zones are operated and controlled equally. This was due to the total load calculation of the models and not having available equipment load breakdowns per room. Due to this, the research undertaken in this study does not identify how individual zones within a building perform. Monitored energy data collected over two weeks at 10 minute 
intervals of the lighting, equipment, domestic hot water, air conditioning and miscellaneous equipment was used to construct the models. Monitored data was not available for all the office energy models, therefore averaged values of the relevant strata are used. The same method used to determine the load levels of each zone was used for occupancy. In addition to this, a simple on/off schedule was applied to the buildings as the daily variance of building occupancy was unknown.

Several template built forms were created by BEES. The appropriate form was selected for each building. The forms were kept square for each building to reduce modelling time. Building and site shading was modelled. For simplicity, the site shading was modelled as the same width as the modelled building.

Detailed information of the HVAC systems was also not recorded. It was determined by Cory that the ideal EnergyPlus air load system was not capable of matching the true performance of complex HVAC systems (Shaan Cory, Anothony Gates, \& Michael Donn, 2011 1). Standardised HVAC templates for common NZ systems were created by (Anthony Gates, 2013) to address this issue. The files were created using EnergyPlus version 6.0.

\subsubsection{Calibration Process}

A calibrated energy model is defined as when the simulation results closely match the real energy consumption of the building (Cory, 2016). A simulation match of $\pm 5 \%$ monthly or $\pm 1 \%$ hourly compared to the real energy consumption was aimed for as recommended in ASHRAE Guideline 14:2002(ASHRAE, 2002). For models that were difficult to calibrate to this level, the acceptable tolerance was increased based on the known level of error in the data used to construct the model. To match the simulation to the energy consumption, the modeller calibrates the parameters of a simulation model.

The calibration process used to create the models was developed by (Cory, 2016). The method uses as-built building information and a standardised procedure to identify inaccurate model inputs to be corrected. The process 
involved ensuring the models were matched as closely as possible to the materiality, construction, window size, building loads, patterns of use and HVAC system of the real building. Monitored data obtained through BEES was used to inform how the building operated and the load uses.

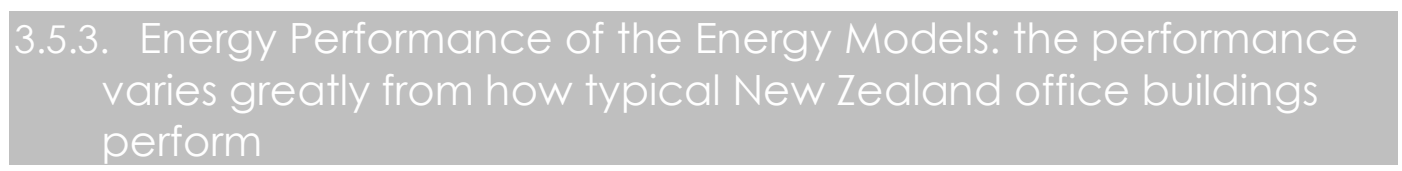

As mentioned previously, 13 of the 17 calibrated office energy models were used in the study. Refer to Appendix Section 7.2 for images of each of the energy models- the green axis line represents north. The attributes of each of the buildings is also provided in the Appendix. The information was collated by the research as the available information for each of energy models did not match the construction of the models.

All three of the Strata 1 buildings were not used due to the small size of the buildings and one having no centralised HVAC system. The Strata 1 buildings R0031 and R0037 have total building floor areas of $188 \mathrm{~m}^{2}$ and $209 \mathrm{~m}^{2}$. Therefore, they are too small for NZS4243:1 to apply to them. One of the Strata 4 buildings (R0173) was not used due to the large number of underground floors it had.

Table 9 below displays the EUI of the real building and calibrated energy models, and the percentage difference. The location and the detailed monitoring periods and meter data years are also provided. As previously mentioned, the $5 \%$ calibration tolerance was extended for buildings that had a limited amount of data available. Three of the buildings did not have any meter data available and so the models were constructed using average Strata data. It can be seen that 6 of the 13 buildings either have a percentage difference greater than $5 \%$ or no real building EUI. For each of the buildings with no meter data available, averages for the relevant strata were used. 


\begin{tabular}{|c|c|c|c|c|c|c|c|}
\hline Cory ID & BEES ID & Real & Calibrated & Difference to Real & Detailed Monitoring Period & Meter Data & Location \\
\hline S1-0-1 & R0017 & 51.04 & 51.49 & $1 \%$ & $22 / 01 / 2010-15 / 02 / 2010$ & 2009 & Hamilton \\
\hline $\mathrm{S} 1-\mathrm{O}-2$ & R0031 & - & 196.14 & - & 20/04/2010-04/05/2010 & Averages of Strata 1 & Auckland \\
\hline $\mathrm{S} 1-0-3$ & R0037 & 13.11 & 17.12 & $31 \%$ & $23 / 06 / 2010-16 / 07 / 2010$ & 2009 (3 months missing) & Napier \\
\hline S2-O-1 & R0020 & 21.13 & 20.57 & $-3 \%$ & $15 / 04 / 2010-04 / 05 / 2010$ & 2009 & Auckland \\
\hline $\mathrm{S} 2-\mathrm{O}-2$ & R0831 & 131.35 & 134.05 & $2 \%$ & $08 / 12 / 2010-22 / 12 / 2010$ & 2010 & Hamilton \\
\hline S3-O-1 & R0056 & 247.04 & 238.00 & $-4 \%$ & 10/01/2011-24/01/2011 & 2010 & Auckland \\
\hline S3-O-2 & R0471 & - & 164.73 & - & 02/02/2011-06/03/2011 & Averages of Strata 3 & Queenstown \\
\hline S3-0-3 & R0813 & 28.65 & 28.58 & $0 \%$ & $04 / 11 / 2010-18 / 11 / 2010$ & 2009 & Auckland \\
\hline S4-0-1 & R0054 & 168.59 & 163.04 & $-3 \%$ & $17 / 02 / 2010-03 / 04 / 2010$ & 2009 (only 2 months) & Auckland \\
\hline S4-0-2 & R0173 & 71.31 & 88.76 & $24 \%$ & 24/03/2010-07/04/2010 & 2010 & Auckland \\
\hline S4-O-3 & R0738 & 118.79 & 121.73 & $2 \%$ & 2/05/2011-16/05/2011 & 2010 & Wellington \\
\hline S4-0-4 & R0811 & 76.53 & 74.19 & $-3 \%$ & 21/06/2011-13/08/2011 & 2010 & Wellington \\
\hline S4-0-5 & R0843 & 3.79 & 3.66 & $-3 \%$ & 01/11/2011-23/11/2011 & 2010 (combined premises) & Napier \\
\hline S5-O-1 & R0198 & 68.47 & 140.71 & $106 \%$ & $24 / 08 / 2011-14 / 09 / 2011$ & 2011 and 2012 Jan and Feb & Auckland \\
\hline $\mathrm{S} 5-\mathrm{O}-2$ & R1017 & - & 77.86 & - & $07 / 08 / 2012-28 / 08 / 2012$ & Averages of Strata 5 & Auckland \\
\hline S5-O-3 & R1586 & 182.19 & 189.09 & $4 \%$ & 02/05/2012-19/05/2012 & 2011 & Auckland \\
\hline S5-O-4 & R1663 & 99.74 & 94.39 & $-5 \%$ & $13 / 07 / 2012-27 / 07 / 2012$ & 2011 & Hamilton \\
\hline
\end{tabular}

Table 9 Real and calibrated EUI's and percentage difference. Detailed monitoring period and meter data and building location information

Table 10 documents the fuel type each building uses, it's calibrated and real EUI. The mean strata EnPI for each of the buildings (relevant to strata size and fuel type) is listed and a comparison is made between the mean values identified by BEES and the values of the energy models. The comparison was made to assess how similarly the buildings performed compared to commercial office buildings of the same size and fuel type. Refer to Table 11 for the EnPI for each fuel and strata group. The values of most of the energy models are shown to greatly differ to the mean values- up to $4436 \%$. The energy performance of building R0054 is the closest to the identified mean EnPI (9\%).

\begin{tabular}{|c|c|c|c|c|c|c|}
\hline Cory ID & BEES ID & elec/gas/e+g & Calibrated EUI $\left(\mathbf{k W h} / \mathbf{m}^{2}\right)$ & Real EUI $\left(\mathbf{k W h} / \mathbf{m}^{2}\right)$ & BEES Strata Mean EnPI & Percentage Difference \\
\hline S1-O-1 & R0017 & elec & 51.49 & 51.04 & 94.3 & $85 \%$ \\
S1-O-2 & R0031 & elec & 196.14 & - & 94.3 & \\
S1-O-3 & R0037 & None & 17.12 & 13.11 & - & 170 \\
\hline S2-O-1 & R0020 & elec & 20.57 & 21.13 & 170 & $705 \%$ \\
S2-O-2 & R0831 & elec & 134.05 & 131.35 & 0 & $29 \%$ \\
\hline S3-O-1 & R0056 & e+g & 238.00 & 247.04 & 0 & \\
S3-O-2 & R0471 & e+g & 164.73 & - & 243.6 & $750 \%$ \\
S3-O-3 & R0813 & elec & 28.58 & 28.65 & 183.8 & $15 \%$ \\
\hline S4-O-1 & R0054 & e+g & 163.04 & 168.59 & 183.8 & $45 \%$ \\
S4-O-2 & R0173 & e+g & 88.76 & 71.31 & 171.9 & $140 \%$ \\
S4-O-3 & R0738 & elec & 121.73 & 118.79 & 183.8 & $4436 \%$ \\
S4-O-4 & R0811 & e+g & 74.19 & 76.53 & 260.4 & $280 \%$ \\
S4-O-5 & R0843 & elec & 3.66 & 3.79 & 252.7 & \\
\hline S5-O-1 & R0198 & e+g & 140.71 & 68.47 & 260.4 & $43 \%$ \\
S5-O-2 & R1017 & elec & 77.86 & - & 260.4 & $161 \%$ \\
\hline S5-O-3 & R1586 & e+g & 189.09 & 182.19 & 99.74 & \\
S5-O-4 & R1663 & e+g & 94.39 & & & \\
\hline
\end{tabular}




\begin{tabular}{|l|r|r|r|}
\hline Strata & $\begin{array}{c}\text { BEES CO Mean EnPI } \\
\text { elec }\end{array}$ & $\begin{array}{r}\text { Mean CO } \\
\text { EnPI gas }\end{array}$ & $\begin{array}{r}\text { Mean CO } \\
\text { EnPI e+g }\end{array}$ \\
\hline Strata 1 & 94.3 & 0 & 94.3 \\
\hline Strata 2 & 170 & 0 & 170 \\
\hline Strata 3 & 243.60 & 0 & 243.60 \\
\hline Strata 4 & 171.9 & 42.8 & 183.8 \\
\hline Strata 5 & 252.7 & 53.8 & 260.4 \\
\hline
\end{tabular}

Table 11 Mean commercial office building EnPI for each fuel type and strata group

Table 12 displays the load power densities and occupant density for each of the building energy models. Power densities included lighting, equipment, miscellaneous, district hot water and lift. The power densities vary greatly between the buildings and to the established typical load power densities as identified in the literature review. This is important to consider as only internal dominated buildings are identified as being susceptible to the adverse effect. The identified typical internal load levels for New Zealand office buildings also create a benchmark for what can be considered a low or high value in New Zealand. It would be expected that the buildings with the very high load levels in relation to the typical values would be susceptible to the adverse effect in certain locations. Many of the buildings have very low load densities and would not be expected to be internal load dominated.

\begin{tabular}{|c|c|c|c|c|c|c|c|}
\hline \multicolumn{7}{|c|}{ Load Power Density for each of the 17 BEES Office Buildings } \\
\hline CORY ID & BEES ID & LPD & EPD & MPD & DHW & LIFTPD & OPD (person/m ${ }^{2}$ ) \\
\hline S1-O-1 & R0017 & 9.37 & 4.07 & 0 & 1.22 & - & 0.0278 \\
S1-O-2 & R0031 & 7.61 & 20.12 & 16.93 & - & - & 1.2148 \\
S1-O-3 & R0037 & 1.58 & 9.11 & - & - & - & 0.0239 \\
\hline S2-O-1 & R0020 & 4.9 & 5.5 & 0.06 & - & - & 0.2706 \\
S2-O-2 & R0831 & 18.34 & 8.13 & 3.51 & 0.7 & - & 0.0545 \\
\hline S3-O-1 & R0056 & 14.5 & 8.35 & 9.56 & - & 2.28 & 0.0661 \\
S3-O-2 & R0471 & 6.78 & 2.04 & 7.06 & 1.84 & - & 0.1712 \\
S3-O-3 & R0813 & 3.17 & 1.46 & - & - & - & 0.0142 \\
\hline S4-O-1 & R0054 & 10 & 6.98 & 10.99 & - & - & 0.1599 \\
S4-O-2 & R0173 & 3.16 & 2.25 & 3.18 & 0.43 & 0.38 & 0.129 \\
S4-O-3 & R0738 & 8.5 & 7.42 & 11.41 & - & - & 0.0466 \\
S4-O-4 & R0811 & 3.04 & 1.35 & 0.17 & - & - & 0.0941 \\
S4-O-5 & R0843 & 0.48 & 0.15 & 0.13 & 0.11 & - & 0.0025 \\
\hline S5-O-1 & R0198 & 5.56 & 2.6 & - & 0.86 & 14.39 & 0.0124 \\
S5-O-2 & R1017 & 5.85 & 3.15 & 0.19 & - & - & 0.0278 \\
S5-O-3 & R1586 & 18.45 & 12.91 & 1.08 & 1.27 & & 0.0556 \\
S5-O-4 & R1663 & 5.95 & 2.86 & 0.0046 & 0.63 & 3.04 & 0.0069 \\
\hline
\end{tabular}

Table 12 Internal load power and occupant densities for each of the buildings 
The energy models were created in version 7.2 of EnergyPlus. For use in this study, each of the models was updated to the current version of EnergyPlus (8.6) at the time of beginning the modelling process. The update was made using the EnergyPlus IDFVersionUpdater. Prior to updating the models, each energy model was simulated in version 7.2 and the annual energy consumption for lighting, equipment, heating, cooling and total building energy consumption was documented. This was also done for the buildings when updated so that the results could be compared (refer to Appendix Section 7.1). This comparison between the versions was necessary as major updates had been made since version 7.2. Updates were made to the way in which EnergyPlus runs and the inputs that are available to model features (EnergyPlus, 2015). Therefore, it was expected that the energy performance of each of the buildings might be different between versions.

As can be seen in the Appendix the differences in heating or cooling energy was up to $6 \%$ in some cases. The expanded IDF files for each of the buildings were analysed and compared to identify how the buildings were modelled differently between versions. It was found that extra fans were modelled for the version 8.6 FCU (fan coil unit) HVAC system. However, no changes were made to the way the HVAC systems were user modelled for any of the buildings.

The material "Concrete $100 \mathrm{~mm}$ " is input into all of the original energy model files as a no mass material. It is used in the construction of the roof and walls in the majority of the building energy models. The material was updated for this research to be modelled as a "Material" with mass and this change was expected to have an impact on the energy performance of the buildings.

EnergyPlus allows materials to be modelled as either a "Material" with a full set of thermal properties (including roughness, thickness, conductivity, density, specific heat and thermal, solar and visible absorptance) or as a "Material:NoMass" with regular material properties but described with the principal description of thermal resistance (properties include thermal resistance, thermal, solar and 
visible absorptance). The properties for the updated material were obtained from CIBSE Guide A (CIBSE Guide A-Chapter Three Thermal Properties) (CIBSE, 2015).

To determine the impact on energy consumption the different material input types have on the energy consumption of the building, a building was simulated with each material type. Building R0054 was simulated in Auckland with the added insulation levels required to meet the minimum requirements of Zone 1. The "Concrete100mm" material is used in the construction of the building in both the roof and walls. As displayed in Table 12 below, modelling the material as a material with mass has a very small impact on the energy performance. The total energy consumption (includes lighting, equipment, fans, pumps) increased by $0.33 \%$, heating energy increased by $2.45 \%$ and cooling energy decreased by $0.42 \%$.

\begin{tabular}{|l|c|c|c|}
\multicolumn{1}{c}{} & Total Energy & Heating & Cooling \\
\hline R0054 Auckland Z2/3 & & & \\
\hline Concrete Nomass Material & 925042 & 155977 & 134224 \\
\hline Concrete Mass Material & 928060 & 159796 & 133659 \\
\hline $\begin{array}{l}\text { Difference } \\
\text { R0054 Auckland No added insulation }\end{array}$ & $\mathbf{0 . 3 3 \%}$ & $\mathbf{2 . 4 5 \%}$ & $\mathbf{- 0 . 4 2 \%}$ \\
\hline Concrete Nomass Material & 948315 & 187001 & 126437 \\
\hline Concrete Mass Material & 953314 & 195427 & 123496 \\
\hline Difference & $\mathbf{0 . 5 3 \%}$ & $\mathbf{4 . 5 1 \%}$ & $\mathbf{- 2 . 3 3 \%}$ \\
\hline Overall Difference & $\mathbf{- 0 . 2 0 \%}$ & $\mathbf{- 2 . 0 6 \%}$ & $\mathbf{1 . 9 1 \%}$ \\
\hline
\end{tabular}

Table 13 Influence changing concrete to material no mass has on energy consumption of building R0054 with and without thermal insulation added

The impact that the different material input types had on the effectiveness of insulation was tested. The impact was identified through comparing the difference of the models with Z2/Z3 thermal resistance requirements and the energy models with no added insulation. An overall difference was found- a $0.20 \%$ difference for the total energy consumption, $2 \%$ difference for heating and $1.9 \%$ difference for cooling.

Overall, while there is a difference in energy consumption, the change in material type is not expected to alter the energy performance of the buildings 
greatly and the impact on how efficient insulation performs is identified to be small.

The modelling of the concrete floor slabs was also altered. The ground floor temperatures which are required to model the floor type are all input into the energy models to be relevant for Wellington. The temperatures were updated for each location using the relevant NIWA EPW weather information.

\subsection{Assessment of Energy Performance and Characteristics}

The intent of the research is not to find the maximum optimal thermal insulation level for each building in each scenario, but rather to assess the energy impact as the thermal insulation level is increased under different scenarios. For each set of simulations, the buildings were grouped by their general energy behaviour. The groups were then used to assess the general characteristics causing each to perform differently. Using both the findings of the buildings energy behaviour as the thermal insulation level is increased and the findings of the characteristics between buildings recommendations are made for a future re-evaluation of NZS4243:1.

\subsubsection{Assessment of effect on energy consumption}

The common metric to measure energy consumption in buildings is the kilowatt hour ( $\mathrm{kWh}$ ). This measures a buildings absolute energy consumption- therefore it cannot be used to compare the energy consumption of different sized buildings. The $\mathrm{kWh} / \mathrm{m}^{2} / \mathrm{yr}$ (EUI) metric was used to enable the energy consumption of buildings to be compared. This metric was used for all energy end uses (heating, cooling, combined heating and cooling, total energy).

To assess the energy performance of the buildings and scenarios, a combination of absolute values and percentage differences are used. Four terms were used throughout the study to describe the percentage differences that occurred for a particular scenario: "Decrease", "Negligible Decrease", "Negligible Increase" or "Increase". The terms are used to describe the percentage change in energy consumption that occurs between added insulation levels relative to the building 
uninsulated (in one location). The different terms apply to certain ranges in percentage change and are different between energy end use types. The following sections assess the impact on total building energy consumption (includes heating, cooling, lighting, equipment, fans, pumps), heating and cooling energy combined, and cooling energy individually. The percentage difference and effect type for each building and scenario was generated using Excel formulas.

Table 14 below displays the ranges in percentage increase or decrease that apply to the terms. A percentage decrease in total energy consumption below $5 \%$ is and decrease in heating and cooling energy (combined and individually) below $-10 \%$ is termed "decrease". Where the energy performance of a building with a certain scenario is described as "decrease", the building at the particular insulation level and location is considered to be beneficial. For the energy consumption to not be decreased beyond 5 or $10 \%$ (negligible decrease, negligible increase or increase), the impact on energy consumption a scenario has is considered to not be beneficial.

Total Building Energy Heating and Cooling Energy Heating Energy Cooling Energy

\begin{tabular}{|l|c|c|c|c|}
\hline Decrease & below $-5 \%$ & below $-10 \%$ & below $-10 \%$ \\
Negligable Decrease & $-5 \%$ to $0 \%$ & $-10 \%$ to $0 \%$ & $-10 \%$ to $0 \%$ \\
Negligable Increase & $0 \%$ to $5 \%$ & $0 \%$ to $10 \%$ & $0 \%$ to $10 \%$ & $0 \%$ to $10 \%$ \\
Increase & above $5 \%$ & above $10 \%$ & above $10 \%$ & above $10 \%$ \\
\hline
\end{tabular}

Table 14 Terms used to describe amount percentage reduction in energy consumption

The terms allow for clear identification of the effect at each insulation level (relative to uninsulated case). However, it is important to note that it does allow for analysis of the most optimum insulation level or for the amount of reduction in energy use to be known. For example, all insulation levels modelled in building R0020 in Queenstown may cause the total energy consumption to decrease beyond $-5 \%$ relative to the uninsulated buildings and therefore, each building is labelled as a "decrease".

The effect terms also do not allow for a clear representation of the reduction or increase in energy use- due to the fact that a small number will provide a larger percentage increase or decrease. Therefore, while the percentage increase 
may be the greatest in a colder climate that requires less cooling than a warmer climate- the increase in absolute cooling energy would be expected to be greater for the warmer location. The difference in energy use between locations and at each thermal insulation level are displayed in the appendix. The tables document the minimum, maximum and average normalised $\left(\mathrm{kWh} / \mathrm{m}^{2} / \mathrm{yr}\right)$ absolute total, heating and cooling energy for each location and insulation level for both the as built and the standardised sets of modelling.

To address the second question ("What are the characteristics of New Zealand office buildings that may lead to an increase in energy use?") this thesis aimed to explore, the buildings were grouped by their energy behaviour as the thermal insulation level increased in each location. The groups were based on the effect types as outlined in the section above.

It was observed that most building's percentage reduction/increase in total energy consumption for each Case fell within one category across all levels of insulation. For buildings that had multiple effect types across different Cases, the appended graphs (section 7.2.2) showing percentage reduction in energy use were used to determine the most suited group. If a negligible increase or increase in energy consumption occurred for any number of cases for a building, it was categorised by this. The additional category "Greatest Decrease" applies to all scenarios where the total energy consumption is reduced beyond $-10 \%$. The findings of the literature review were used to only assess the most relevant building parameters. The literature review identified the parameters/factors that influence thermal insulation to lead to increased or decreased energy consumption. The information for each building was tabulated to allow for comparison. 


\section{Results and Discussion}

This section consists of three subsections that present the simulation results. It overviews the interrelation between the design of New Zealand office buildings and energy behaviour as the thermal insulation level is increased in various locations. The regions of New Zealand where an increase in energy use is possible and the most substantial is identified for each set of simulations. Based on the findings, recommendations for the design and use of office buildings are made to ensure the use of additional thermal insulations reduces energy consumption.

\subsection{As-built: Exploring the effect of increasing insulation level and location on as-built energy models}

The as-built set of simulations assessed the impact of increasing levels of thermal insulation in each of the building energy models in a range of climates. Each building was simulated in eight locations and with six levels of thermal insulation. The aim was to assess how the building energy models performed at the minimum required (relevant to location and zone) and increased levels of thermal insulation, and to identify any trends between locations and energy performance at each insulation level. Lastly, the analysis looks to identify any trends between building attributes and energy performance.

The following sections discuss the effect insulation level and location have on the energy performance of the buildings. Detailed analysis was undertaken for three selected buildings. Each selected building displays a different behaviour in energy performance across all scenarios. Analysis of each of the buildings was then undertaken to identify the specific attributes of the buildings which cause them to perform so differently. The selected buildings were R081 1, R0738 and R1586.

R0811 was selected as for every scenario, the energy consumption is reduced for all types. R0738 was observed to have an increase in cooling energy in the majority of locations (for all levels of insulation in some, and higher levels for others), however the increase was never significant enough that heating and 
cooling energy combined or the total energy consumption of the building was increased. For every scenario building R 1586 was modelled with, the required cooling energy was increased relative to the building uninsulated in each location. In all North Island locations, the increase in cooling energy was significant enough that the heating and cooling energy combined and total building energy requirements were increased at certain insulation levels.

\subsubsection{Selected building R0811: Consistent decrease}

When simulated in each location and at each insulation level, the required energy consumption for building R0811 with each scenario modelled was reduced (relative to building uninsulated in each location). Building R081 1 is a Strata 4 building (area of 5,389 $\mathrm{m}^{2}$ ). It is $29 \mathrm{~m}$ in height, with 8 levels. The glazing percentage on the north, east, south and west facades are $80 \%, 80 \%, 30 \%$ and $80 \%$ respectively. The primary construction material of the roof is concrete, concrete fibre cement and exposed concrete for the walls and concrete slab for the floor. The windows are single glazed aluminium, with a light tint. The primary HVAC system is VAV and secondary is heat pump. The VAV system utilises the economiser control function. Heating for the building is fuelled by gas. The load power densities of the buildings are very low relative to the values identified by BEES to be typical of New Zealand office buildings. The building has a lighting power density of $3.04 \mathrm{~W} / \mathrm{m}^{2}$, equipment power density of $1.35 \mathrm{~W} / \mathrm{m}^{2}$ and miscellaneous load power density of $0.17 \mathrm{~W} / \mathrm{m}^{2}$. The occupant density is 0.0094 people/ $\mathrm{m}^{2}$. The building is modelled to be occupied between 08:00-17:00pm during weekdays only. It has fixed heating and cooling thermostat set points of $15.7^{\circ} \mathrm{C}$ and $26.0^{\circ} \mathrm{C}$. The building is not heavily shaded by adjacent buildings. Shading $15 \mathrm{~m}$ in height and $10 \mathrm{~m}$ from the south façade is modelled to account for a building roughly half the height of R0811. Low level retail buildings surround the building to the east, west and north.

Detailed analysis of the building located in Queenstown was undertaken. The graphs below display each energy use type at each insulation level in $\mathrm{kWh} / \mathrm{m}^{2} / \mathrm{yr}$ and the percentage reduction of energy consumption at each insulation level relative to the building uninsulated. 
The building's total energy consumption is $105.6 \mathrm{kWh} / \mathrm{m}^{2} / \mathrm{yr}$ uninsulated (Figure 9). At the highest insulation level, the total energy consumption is reduced by $13.7 \%$ to $91.1 \mathrm{kWh} / \mathrm{m}^{2} / \mathrm{yr}$ (Figure 10). The building is heating dominated, with very low cooling energy requirements at all levels of insulation. The cooling energy requirements of the building decrease as the insulation level increases (although very negligibly, never beyond $-5 \%)$. Heating requirements are decreased up to $24.8 \%$ at the highest insulation level. Due to the very dominant heating requirements, the combined heating and cooling requirements have a similar reduction in energy use at each level.

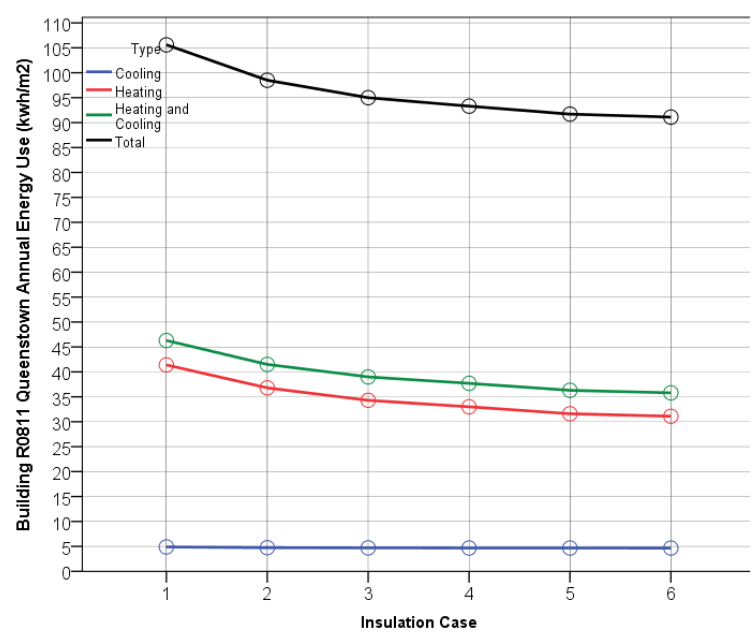

Figure 9 Building R0811 Queenstown Annual Energy Use for Energy Use Types $\left(\mathrm{kWh} / \mathrm{m}^{2}\right)$

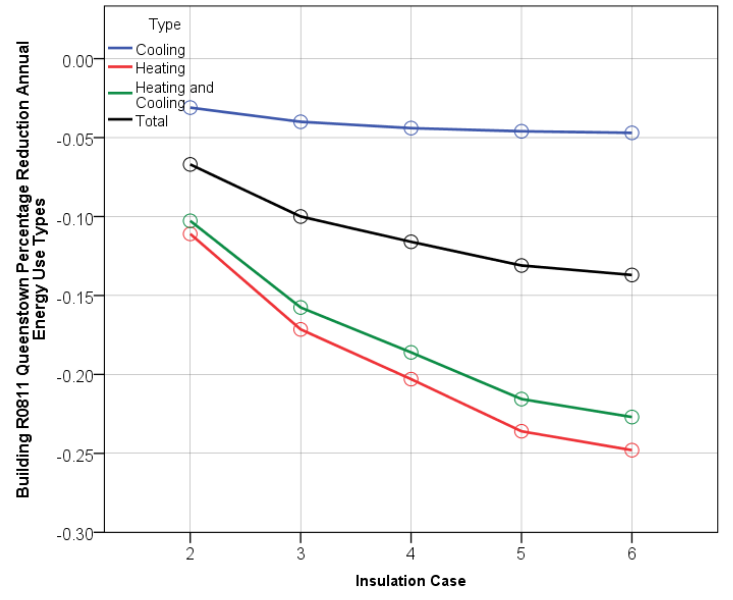

Figure 10 Building R0811 Queenstown percentage reduction annual energy use types

The graphs below display the percentage reduction in energy consumption types for the building located in all locations and each added insulation level. The reduction for each Case is relative to the building uninsulated in each location.

The total energy consumption of the building is reduced beyond $5 \%$ at all levels when located in Christchurch, Queenstown and Dunedin (Figure 11). At the minimum required thermal insulation level for buildings located in zone 2 and 3(Case 4), energy consumption is reduced for all relevant locations. The energy consumption at each insulation level in Auckland is negligibly decreased. At the 
minimum required level for the Auckland location, the total energy consumption is decreased by $2.1 \%$.

The heating and cooling energy is decreased beyond $10 \%$ in all South Island locations at Case 2 (Figure 12). It is negligibly decreased in Auckland at all added insulation levels. The largest reduction in energy at each insulation level occurs for the building located in Wellington and Dunedin.

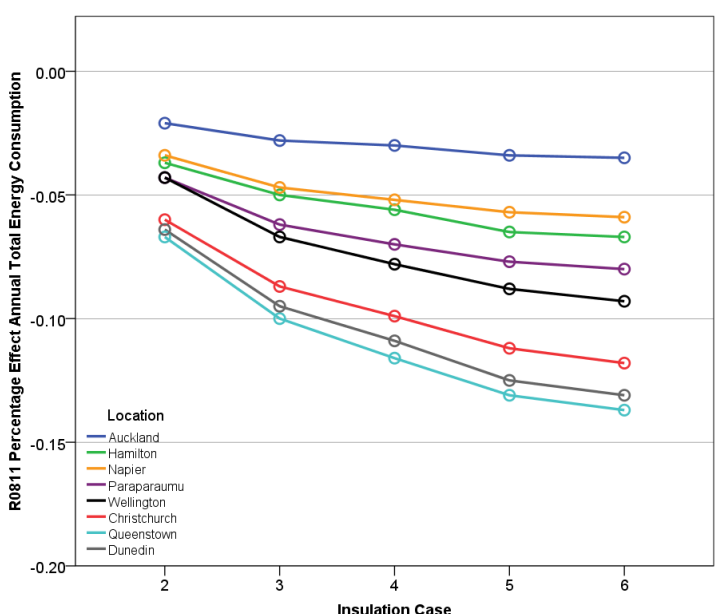

Figure 11 Building R0811 percentage reduction total energy consumption all locations

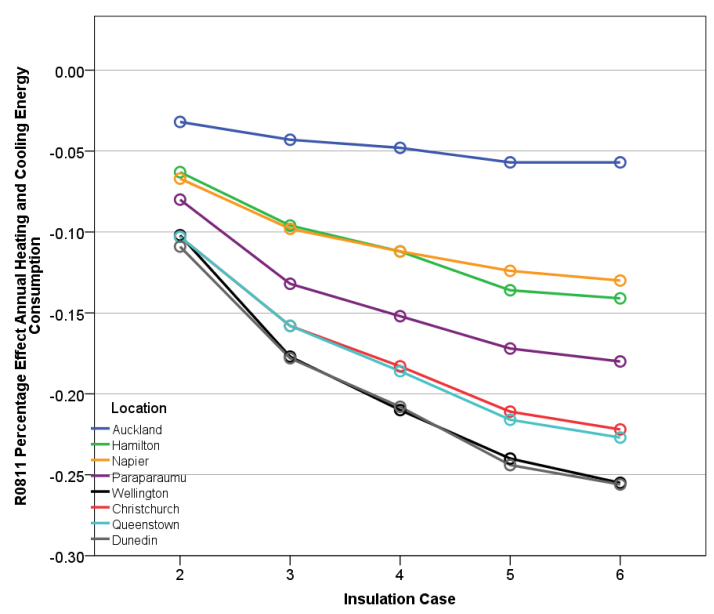

Figure 12 Building R081 1 percentage reduction heating and cooling energy consumption all locations

Heating is shown to be decreased beyond $10 \%$ in all locations (Figure 13). The largest reductions occurred for the building located in Auckland at all levels, and the lowest- in all South Island locations. However, the reduction in kWh between the building uninsulated and at the highest level of insulation is the greatest in Queenstown (for Queenstown the reduction is $59,976 \mathrm{kWh}$ and $8,867 \mathrm{kWh}$ for Auckland). This is due to the significantly higher heating requirements in Queenstown- a higher percentage occurs between the differences of lower numbers.

Cooling energy is always reduced at every level in each location relative to the building uninsulated (Figure 12). However, for Paraparaumu, Christchurch and Dunedin the reduction in heating energy is slightly higher at lower levels of added insulation than it is at higher levels. The reduction in cooling energy for all 
scenarios is never greater than $10 \%$ (maximum decrease is $4.7 \%$ ), therefore the cooling energy is always negligibly decreased

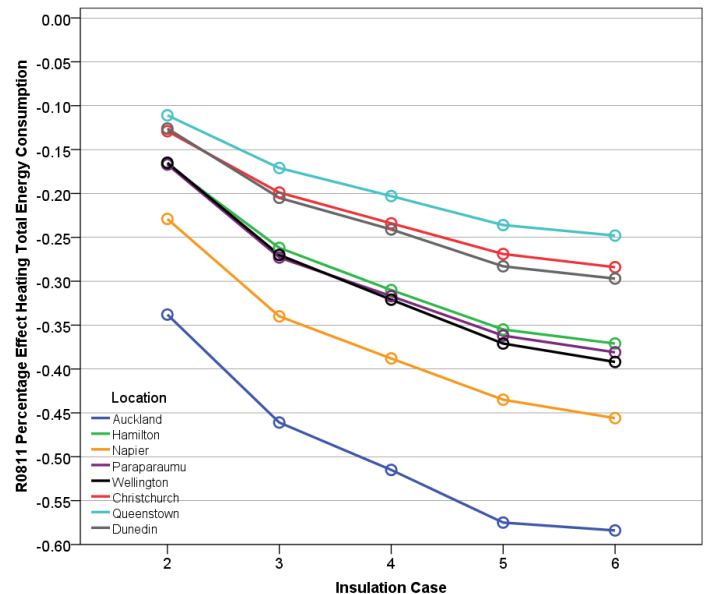

Figure 13 Building R0811 percentage reduction annual heating energy consumption all locations

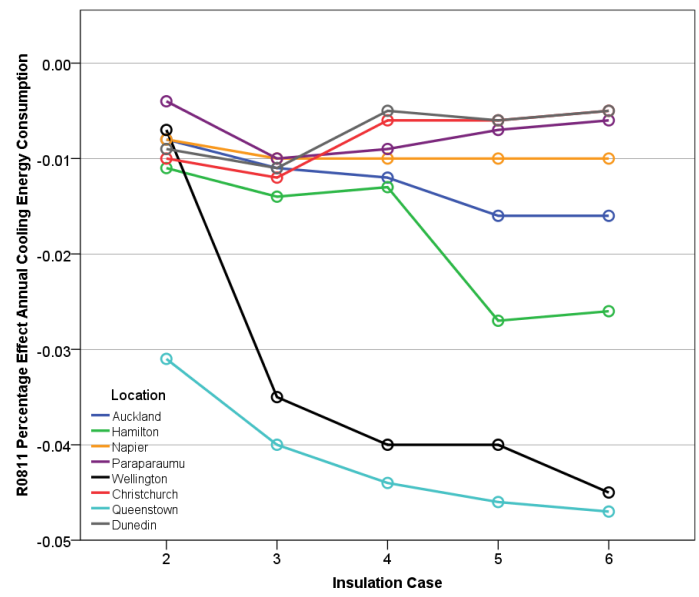

Figure 14 Building R081 1 percentage reduction annual cooling energy consumption all locations

\subsubsection{Selected building R0738: Increase cooling energy}

Detailed analysis was undertaken for the building R0738. The cooling energy requirements were increased for this building in most locations. However, the increase was never significant enough that the building's total or heating and cooling energy consumption was increased.

R0738 has an area of $9439 \mathrm{~m}^{2}$ (strata 4), 9 levels and a height of $22 \mathrm{~m}$. The building has $100 \%$ glazing on the north façade. Glazing on the east, south and west is $10 \%, 20 \%$, and $30 \%$ respectively. The building is heavily shaded to the east and west by two adjacent buildings of roughly the same height. The building is of concrete construction with single glazed aluminium windows. The north façade glazing is heavily tinted while the east and south have no tint. The west is lightly tinted. The load level of the building is $7.42 \mathrm{~W} / \mathrm{m}^{2}$ for equipment, lighting is $8.5 \mathrm{~W} / \mathrm{m}^{2}$. A high miscellaneous load level of $11.41 \mathrm{~W} / \mathrm{m}^{2}$ was applied to all zones. Occupants are scheduled to use the building between 0:800am-17:00pm during weekdays only. The occupant density is 0.0466 people $/ \mathrm{m}^{2}$. The primary HVAC system of the buildings is VAV electric heat pump system and heat pump as the 
secondary system. Heating is gas fuelled. The thermostat set point temperatures vary throughout the year. From 01/01 the heating and cooling set point is 18 and $24^{\circ} \mathrm{C}$ respectively until $31 / 04,19.6$ and $22.2^{\circ} \mathrm{C}$ until $31 / 10,23$ and $23.5^{\circ} \mathrm{C}$ until $31 / 11$ and 18 and $25^{\circ} \mathrm{C}$ until $31 / 12$.

The graphs below display the building's energy performance at each insulation level when simulated in Napier. Results are displayed for the total and heating and cooling energy combined and individually. Figure 16 below displays the building's energy use per building area ( $\left.\mathrm{kWh} / \mathrm{m}^{2} / \mathrm{yr}\right)$ for each energy type at each insulation level. It can be seen that as the insulation level increases, the building's total building energy consumption decreases. The building's EUI reduced from 126.8 to 116.6 . The figure below displays the percentage effect on energy use types relative to the building uninsulated. It can be seen that the total energy consumption is reduced just below 5\% (negligible decrease) at the first insulation Case. For the remaining cases, insulation is decreased beyond $5 \%$ (decrease) - between $6.2 \%$ at the $3^{\text {rd }}$ Case and $8.1 \%$ at the highest Case. The heating and cooling energy combined decreases as the insulation level increases.

The required cooling energy increases for every level beyond Case 3. At Case 3, the cooling energy is negligibly increased by $1.2 \%$, but by $3.8 \%$ at Case 6 . As the graph below demonstrates, the reduction in heating energy requirements decreases significantly as the insulation level increases. The decreases in heating energy are far greater than any increase of cooling energy consumption, therefore the heating and cooling energy combined is never increased.

As can be seen the graph below (Figure 15), the heating and cooling energy requirements of the building is mixed-while heating requirements are slightly more dominant at the lower level and cooling at the higher level. The energy required for HVAC is roughly $25 \%$ of the total energy required for the building. 


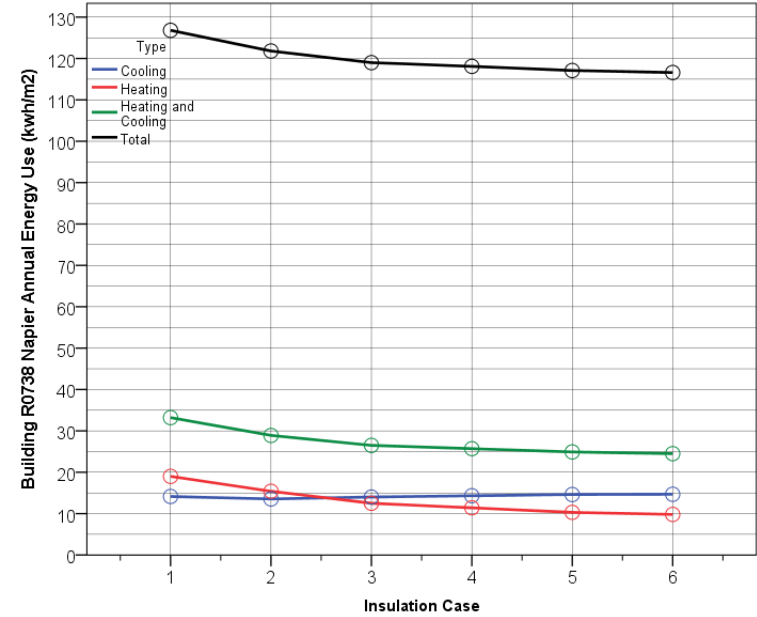

Figure 15 Building R0738 Napier energy use for total, heating and cooling combined and individually

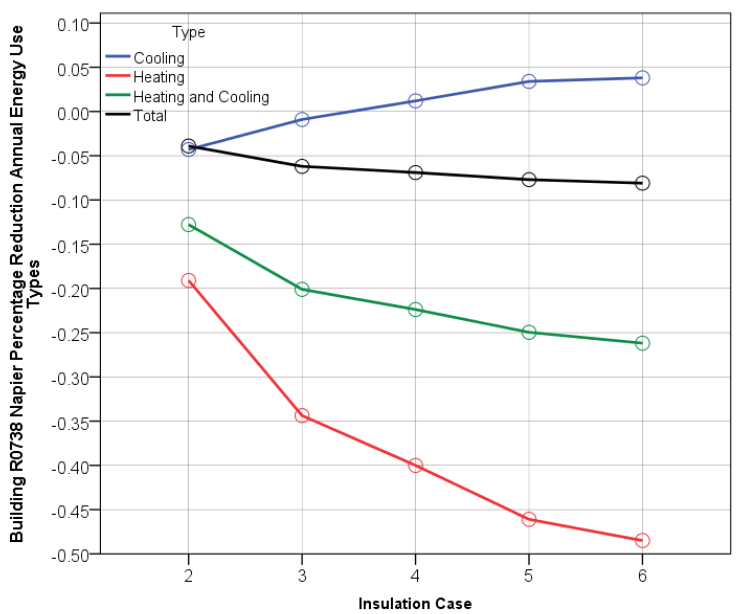

Figure 16 Building R0738 Napier percentage reduction annual energy use relative to uninsulated building for total and heating and cooling energy combined and individually

The graph below displays the reduction in annual total building energy use at each insulation level and location. In all buildings, increasing the insulation level reduces the energy consumption. Only in Queenstown the building has a decrease in energy consumption for Case 2- in all other locations the energy consumption is negligibly decreased. For all Cases, the added insulation level is most effective in Queenstown. It is the least effective in Auckland for all Cases.

The building energy consumption is negligibly decreased (-2.8\%) meeting the minimum thermal resistance requirements for Auckland, the only Zone 1 location. A decrease beyond -5\% occurred in the buildings in all Zone 2 and 3 locations, when insulation is added.

The graphs below display the percentage reduction in heating and cooling energy requirements relative to the building uninsulated in each location. The building in each location at each insulation level has a reduction beyond $10 \%$ (decrease), aside from the lowest insulation Case in Auckland (-9.6\%). The energy consumption reduces in all Cases as the insulation level increases. As would be expected, the first step in insulation results in the largest reduction in energy use. Beyond the first level, the amount the energy consumption is reduced between 
levels is decreased. For each Case, the insulation's effect on energy consumption becomes increasingly beneficial as the further south the building is located.

It can be seen that the largest percentage reduction in energy consumption at all levels occurs for the building in Dunedin. This is unlike what can be seen for the building's total annual energy consumption, where the largest reduction occurs in Queenstown.
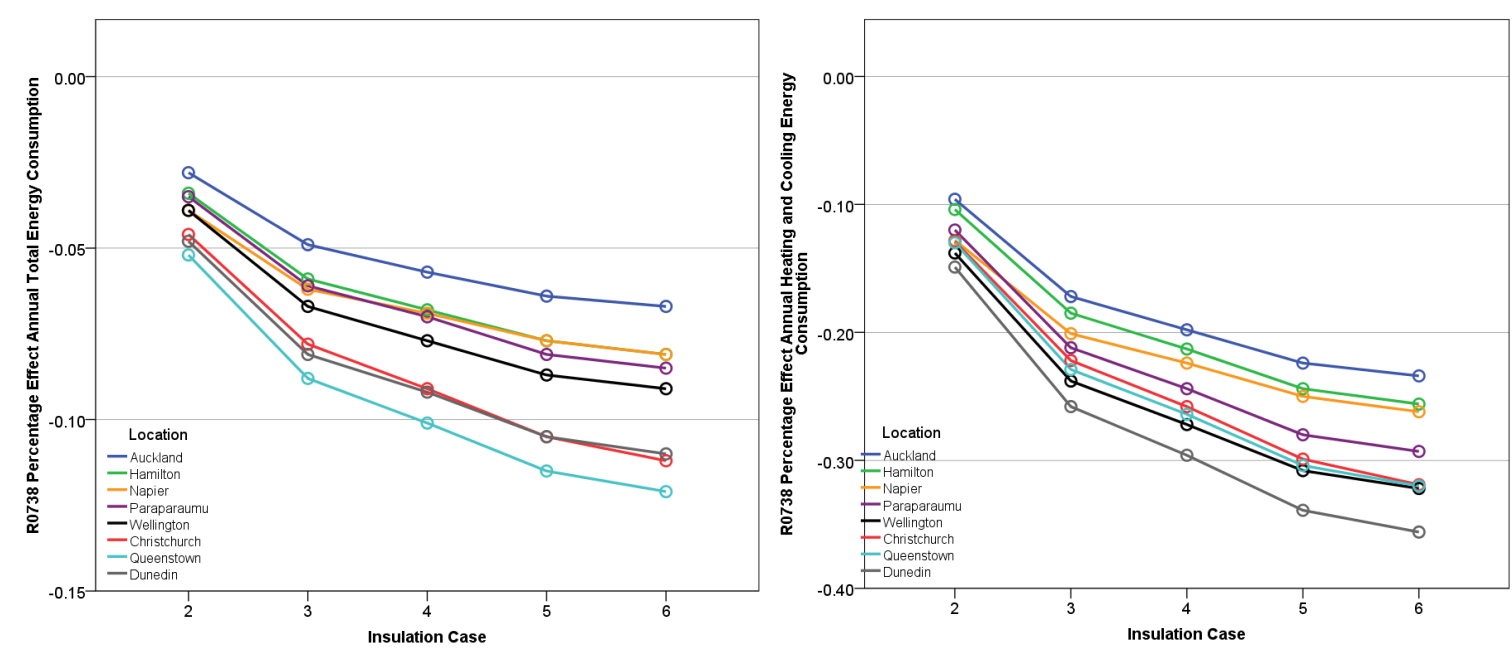

Figure 17 Building R0738 reduction annual total Figure 18 Building reduction annual heating and energy consumption relative to building uninsulated in each of the eight locations cooling energy consumption relative to building uninsulated in each of the eight locations

The graph below (Figure 19) displays reduction in annual heating energy consumption requirements for the building in each of the locations and insulation Case. The building in all locations except Queenstown, and all insulation Cases achieves a reduction in energy consumption beyond $10 \%$. It can be seen in the graph below that the largest reduction in heating energy occurs for the building in Auckland. The building located in the South Island locations (coolest during winter) have the lowest decrease in heating energy. However, it must be noted that while they have the lowest percentage decrease relative to the building uninsulated in each location- the amount in $\mathrm{kWh}$ that is reduced for southern locations is far greater than the north. For example, between the uninsulated and highest insulation level, the required heating energy is reduced by 75,546 kWh in Auckland and 151,635 in Queenstown. The reduction in kWh for Queenstown is over double the reduction for Auckland. As the insulation level 
increases in Queenstown, the percentage of reduction in energy consumption declines. For all other location the reduction increases as the insulation level is decreased.

Only in Christchurch and Dunedin is the required cooling energy at every insulation level below that required of the building uninsulated. An increase in required cooling energy beyond $10 \%$ relative to the building uninsulated is observed in the Wellington location. A reduction in energy consumption beyond $-10 \%$ only occurred in Queenstown at the two lowest levels of insulation. Any added insulation to the building located in Auckland, Wellington and Paraparaumu causes the cooling energy to increase (Figure 20). The increase is only beyond $10 \%$ in Wellington at the two highest levels of insulation, as it is negligibly increased in all other locations. The cooling energy is negligibly decreased at the lowest levels of insulation in Dunedin, Hamilton and Napier. Higher levels of insulation in these locations cause the cooling energy to increase. However, as previously mentioned, the required heating and cooling energy requirements always reduce energy consumption for all scenarios. Increasing the insulation level was observed to always reduce the required energy further. Therefore, the reduction in heating energy requirements significantly outweighs the increases in cooling energy.

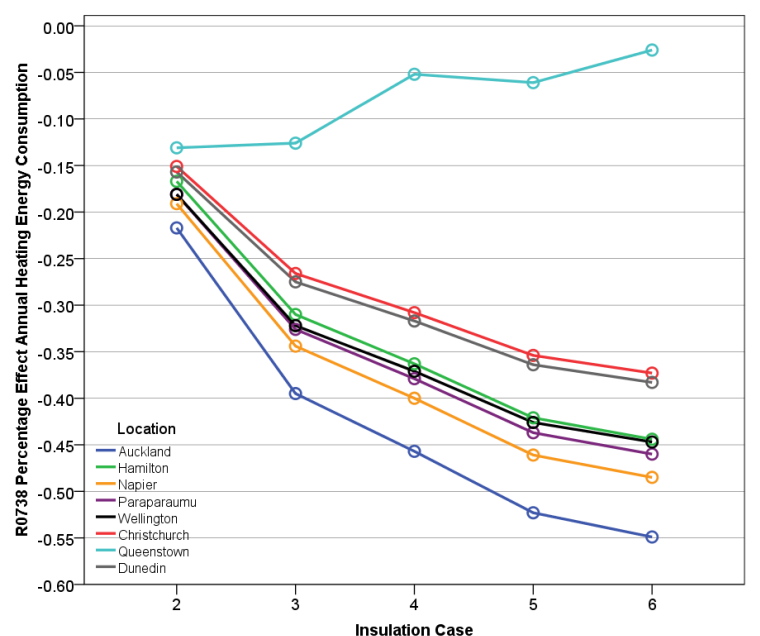

Figure 19 Building reduction annual heating energy consumption relative to building uninsulated in each of the eight locations

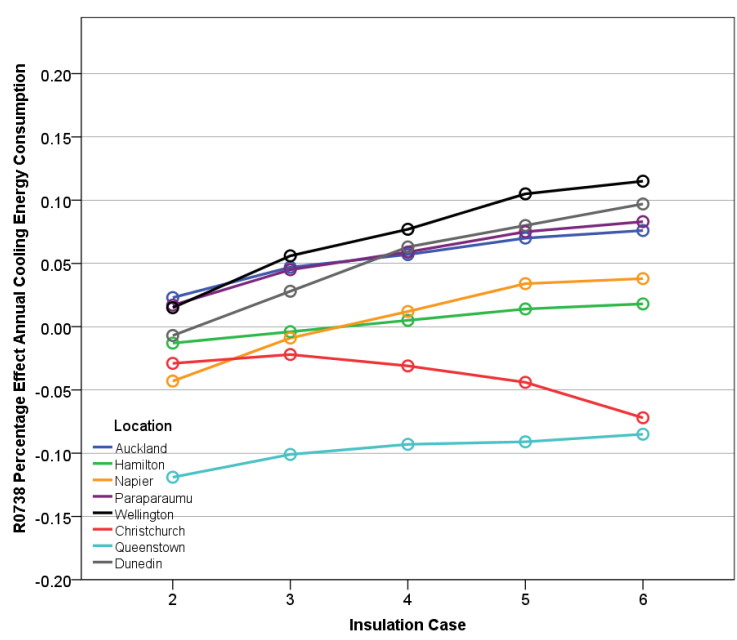

Figure 20 Building reduction annual cooling energy consumption relative to building uninsulated in each of the eight locations 
The cooling energy requirements for building R 1586 was so great that in some scenarios, the total building energy consumption was increased relative to the building with no added insulation. Building R 1586 is a strata 5 building of $6,029 \mathrm{~m}^{2}$. It is $15.5 \mathrm{~m}$ in height with 4 stories. The construction of the building is of concrete for the roof, exposed concrete for the exterior walls and concrete slab for the floor. The windows are single glazed aluminium, with a light tint. The façade glazing ratio is very high- from north to south the ratios are $90 \%, 90 \%, 90 \%$ and $95 \%$. The primary HVAC system is FCU. Heating is fuelled by gas. The load level of the building is high in comparison to the typical load level of New Zealand office buildings determined by BEES. The lighting power density is $18.45 \mathrm{~W} / \mathrm{m}^{2}$, equipment is $12.91 \mathrm{~W} / \mathrm{m}^{2}, \mathrm{DHW}$ is $1.27 \mathrm{~W} / \mathrm{m}^{2}$ and a miscellaneous load level of $1.081 \mathrm{~W} / \mathrm{m}^{2}$ is applied to all zones. Occupants are scheduled to occupy the building from 08:00am-18:00pm during weekdays only. The occupant density is 0.0556 people $/ \mathrm{m}^{2}$. The building has a fixed heating and cooling thermostat set points of $20.3^{\circ} \mathrm{C}$ and $23^{\circ} \mathrm{C}$. It is shaded by adjacent low level buildings to the north, south and west. Shading a third of the height of the building is placed $5 \mathrm{~m}$ in height, $8 \mathrm{~m}$ from the north façade and $9.5 \mathrm{~m}$ in height, $6.5 \mathrm{~m}$ from the south façade. To the west, shading is $9.5 \mathrm{~m}$ in height and $30 \mathrm{~m}$ from the façade.

The energy use of the building simulated in Paraparaumu at each insulation level is displayed in the graphs below. The total energy consumption of the building uninsulated is $180.2 \mathrm{kWh} / \mathrm{m}^{2} / \mathrm{yr}$. At the highest insulation level, the total energy consumption is increased by $1.6 \%$ to $183.6 \mathrm{kWh} / \mathrm{m}^{2} / \mathrm{yr}$. Total energy consumption requirements are decreased negligibly at the first added insulation level by $0.8 \%$. Added insulation beyond this level negligibly increases the total building energy consumption. Cooling energy is dominant at every insulation level and is up to 20 times greater than the heating requirements (at highest level). The cooling energy requirements of the building increases at every added insulation level. At the lowest level it is increased by $6.1 \%$ and at the highest, $12.6 \%$. The increases in cooling energy at the two lowest levels of added insulation are not significant enough to outweigh the decreases in heating energy consumption. Therefore, the combined heating and cooling requirements of the building are reducedalthough negligibly, only a $1 \%$ reduction occurs at Case 2 (Figure 22). The heating 
and cooling energy requirements are increased by $2.5 \%$ at case $4,5.8 \%$ at Case 5 and $7.3 \%$ at Case 6. Heating energy is decreased beyond $10 \%$ at each insulation level. The reduction in heating energy is up to $75 \%$ at the highest insulation level- the $\mathrm{kWh} / \mathrm{m}^{2} / \mathrm{yr}$ reduces from 7.0 uninsulated to 1.7 (Figure 21). The percentage reduction is so great for heating as the required kWh are low. Therefore, while there is a significant reduction in heating energy, the impact on total energy consumption it has is not significant.

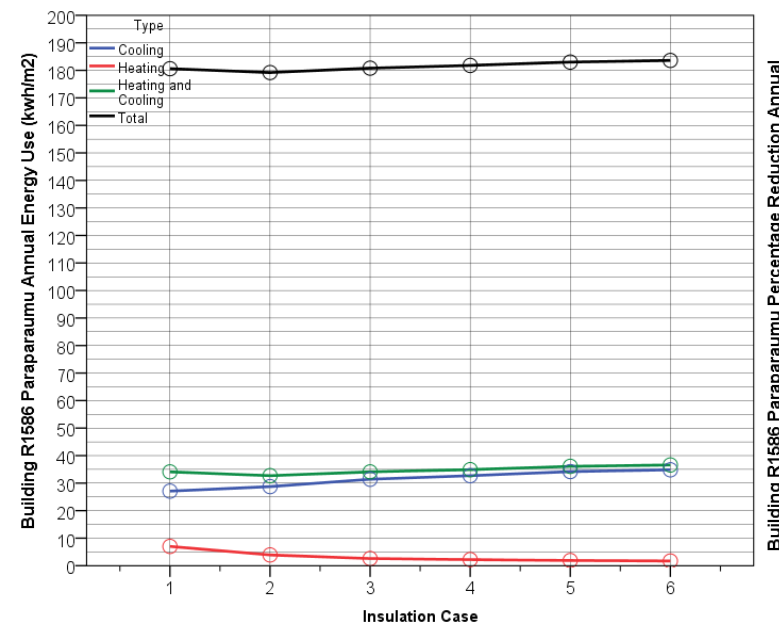

Figure 21 Building R1586 Paraparaumu annual Energy Use (kWh/m2)

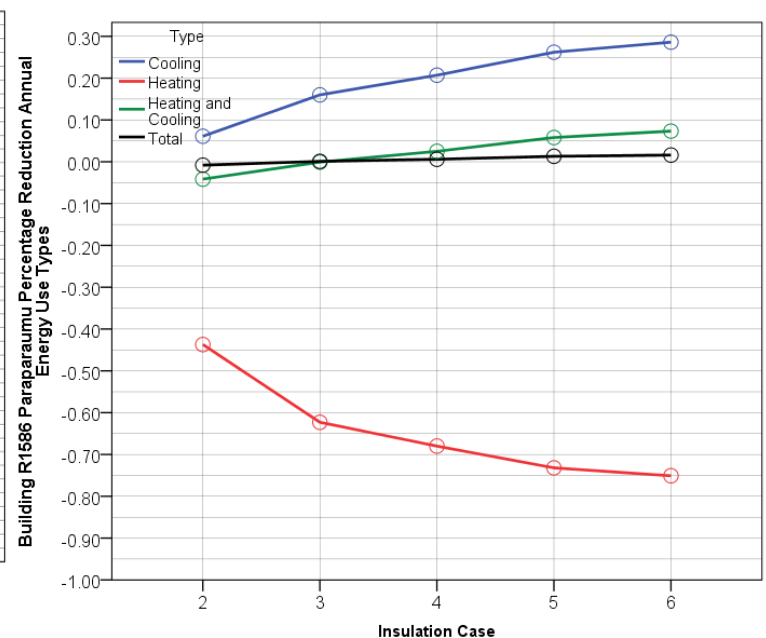

Figure 22 Building R 1586 Paraparaumu percentage reduction annual energy consumption

The graphs below display the percentage reduction or increase in energy consumption that occurs for each energy type- for each insulation level and location. Only in the South Island locations (Christchurch, Queenstown and Dunedin), the building's total energy consumption is decreased at all levels of added insulation. However, at higher levels the percentage decreased is reduced.The building in all North Island locations has increased total energy consumption levels above case 2 . The location with the highest increase in energy consumption for each level is Auckland- a negligible increase of $3 \%$ (negligible increase occurs at all levels). The building located in Hamilton, Napier and Paraparaumu performs almost identically. Lower insulation levels in these locations cause the energy consumption to negligibly decrease, and negligibly increase at higher levels. Therefore, it is demonstrated that insulation at the 
minimum required level (and relevant location) is never beneficial to the building- it negligibly decreases energy consumption in the southern locations and negligibly increases in the northern.

The behaviour of the heating and cooling energy at each level and location is very similar to the total energy- energy is decreased relative to building uninsulated at every level in South Island locations and energy increases relative to building uninsulated in all North Island locations at higher levels. The decreases in energy consumption for South Island location are beyond $10 \%$ except in Christchurch for the two highest levels of insulation. The highest levels of insulation in Auckland and highest in Napier cause the heating and cooling energy to increase beyond $10 \%$.

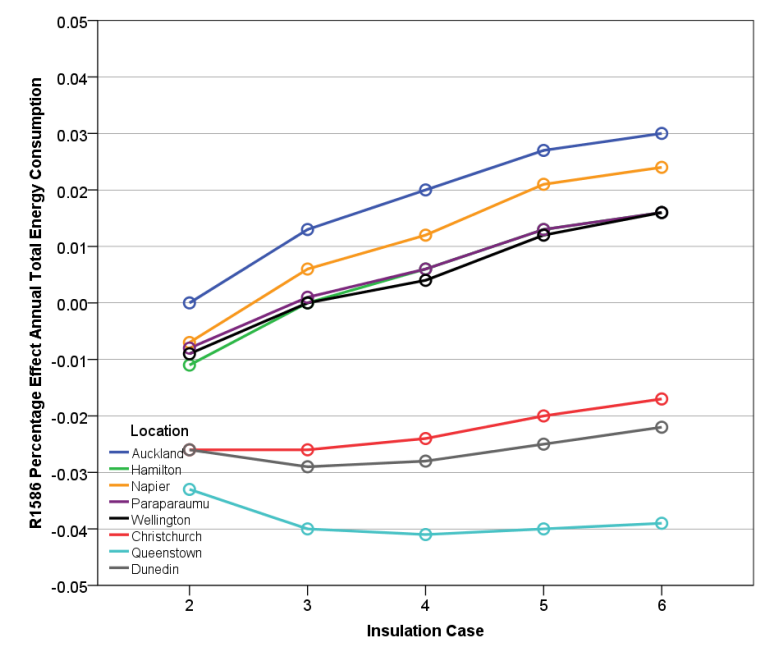

Figure 23 Building R1586 percentage effect annual total energy consumption

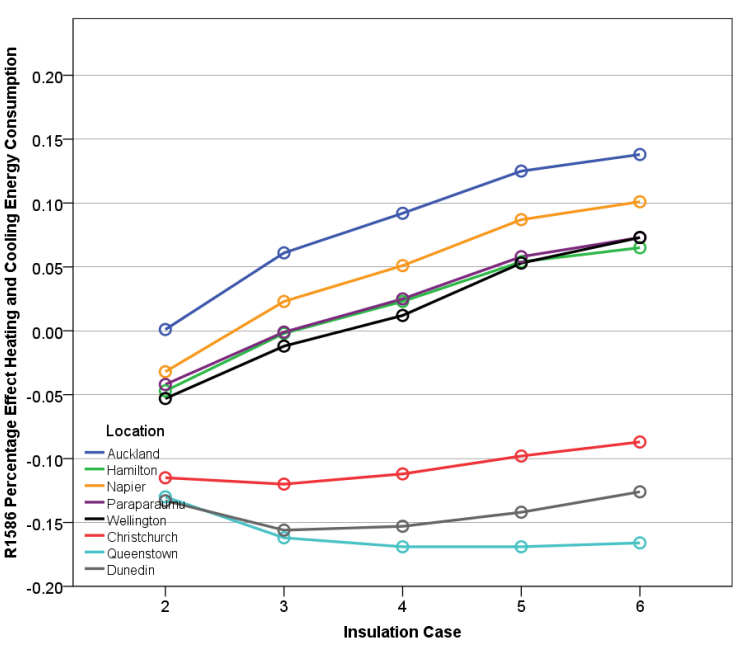

Figure 24 Building R1586 percentage effect heating and cooling energy

Heating energy is very significantly decreased in all locations and for every location- the reduction becomes greater as the insulation level increases (Figure 25). As mentioned previously for the building when simulated in Paraparaumu, the percentage reduction in heating energy consumption is so large due to the low amount of heating. The least amount of heating is required in the Auckland building, and greatest amount in the Queenstown location at all insulation levels. The biggest decreases in heating energy occur in Auckland, and the least in Queenstown- however, the amount of kWh that was reduced between the building uninsulated and with the highest level of insulation is far greater in the building simulated in Queenstown (reduction in kWh for Queenstown is 100,587 and 10,762kWh for Auckland). 
Cooling energy is shown (Figure 26) to be higher at every level than the required cooling energy for the building uninsulated. Similar to what was observed for the heating requirements, the locations where the cooling energy requirements are the lowest the largest percentage increase occurs, and where it is the greatest, the percentage increase is the lowest. However, the difference of kWh between the building uninsulated and at the highest level is far greater for the location that has the lowest increase for all levels. At the lowest insulation level, energy consumption is negligibly increased in all locations except Dunedin. Energy use is increased beyond $10 \%$ in all locations for the remaining added insulation levels. The increase is the greatest in Dunedin at all levels, however due to the significant reduction in heating requirements the total, and heating and cooling energy requirements are shown to always decrease energy consumption at all levels. Cooling energy is dominant in all locations with added insulation (Figure 26).

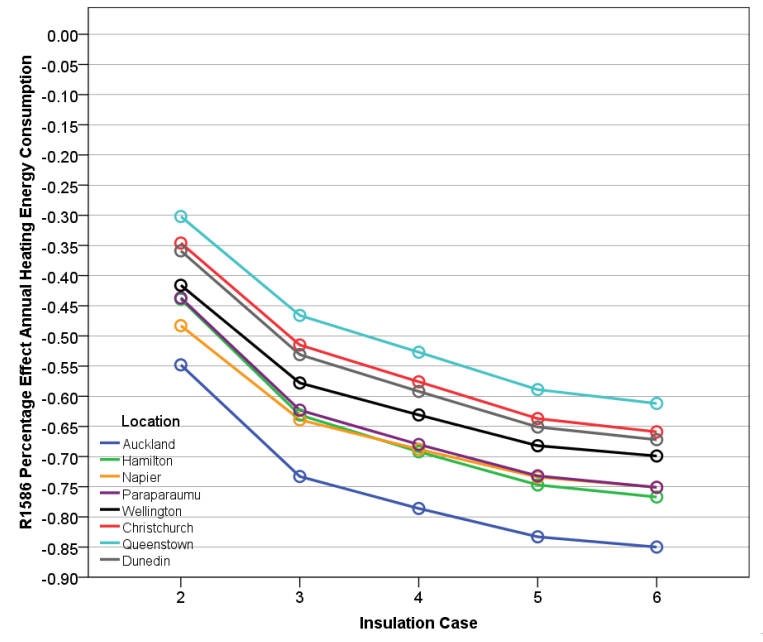

Figure 25 Building R1586 percentage effect annual heating energy

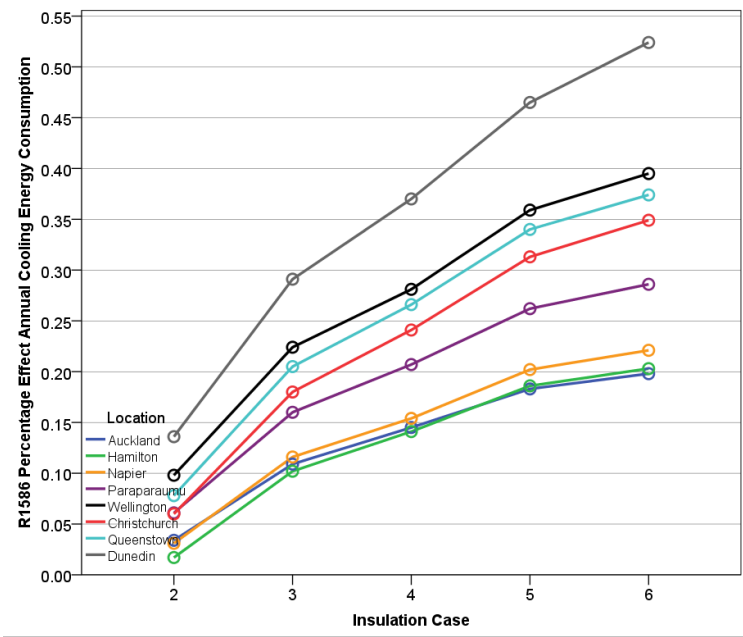

Figure 26 Building R1586 percentage effect annual cooling energy

\subsubsection{Selected buildings: Comparison attributes}

Analysis of the three selected building's attributes was undertaken. The purpose was to identify the differences between the attributes as they influence each of the buildings to perform differently when simulated in the same location and with the same level of added insulation. While it is the attributes collectively that 
cause the buildings to perform as they do, the analysis is intended to identify any trends of the individual attributes.

\section{Energy Use- Heating/Cooling Dominated}

Uninsulated, buildings R 1586 and R0811 are cooling energy dominated while R0738 has mixed heating and cooling requirements (14.6 and $14.8 \mathrm{kWh} / \mathrm{m}^{2} / \mathrm{yr}$ ). At the highest energy use case, all buildings are cooling energy dominated. Between Case 1 and 6, the greatest difference in HVAC absolute energy is R0738 (6.9kWh/m²/yr). R1586 has an increase in energy of $5.1 \mathrm{kWh} / \mathrm{m}^{2} / \mathrm{yr}$. Building R081 1 has a reduction in energy use of only $0.8 \mathrm{kWh} / \mathrm{m}^{2} / \mathrm{yr}\left(13.74-13.53 \mathrm{kWh} / \mathrm{m}^{2} / \mathrm{yr}\right)$. The minimal reduction in energy use is largely due to the large set point deadband of the building.

R1586 had an increase in cooling energy for all scenarios and the total energy consumption was increased in all North Island locations. Buildings that have a pronounced cooling energy need have been identified to be susceptible to an increase in cooling energy when thermal insulation is added. The building R1586, where added insulation has greatest adverse effect, is cooling dominated in all locations and has the highest cooling energy $/ \mathrm{m}^{2}$ of all the buildings for all scenarios.

Building R0738 had mixed heating and cooling requirements in all locations north of Wellington, and was heating dominated south of Paraparaumu. The cooling energy was increased in the North Island locations where cooling energy was the greatest. The building was heating dominated in all southern locations, however an increase in cooling energy still occurred for the building in Dunedin.

Interestingly, Building R081 1, which showed a decrease all energy use types for all scenarios, was cooling energy dominated in locations from Auckland to Paraparaumu. The heating energy required (Auckland to Paraparaumu) was very low at all added insulation levels- ranged between 0. 4-7kWh/m², while cooling energy was between $14-19 \mathrm{kWh} / \mathrm{m}^{2}$. The cooling energy requirements in Building R 1586 were significantly higher for these locations, between 27-43 $\mathrm{kWh} / \mathrm{m}^{2}$. 
Figure 27 and Figure 28 display the selected building's EUI ( $\mathrm{kWh} / \mathrm{m}^{2} / \mathrm{yr}$ ) at each insulation level in Auckland and Dunedin- the most northern and southern simulation locations. Building R081 1 (decrease occurs for all energy types as added insulation level increases) has the lowest energy consumption at each level. The building R1586 was selected as its total energy consumption increased in some locations at higher levels of added insulation, has the highest EUI in both Auckland and Dunedin. It can be seen that added insulation to the highest level in Dunedin has the greatest impact for building R0738 (14.7 kWh/m²/yr), and the least in Building 1586 (4 kWh/m²/yr). When simulated in Auckland, added insulation to the highest level has the greatest impact in building R0738 also. The EUI is increased by $5.5 \mathrm{kWh} / \mathrm{m}^{2} / \mathrm{yr}$ in building R 1586 between case 1 and 6 .

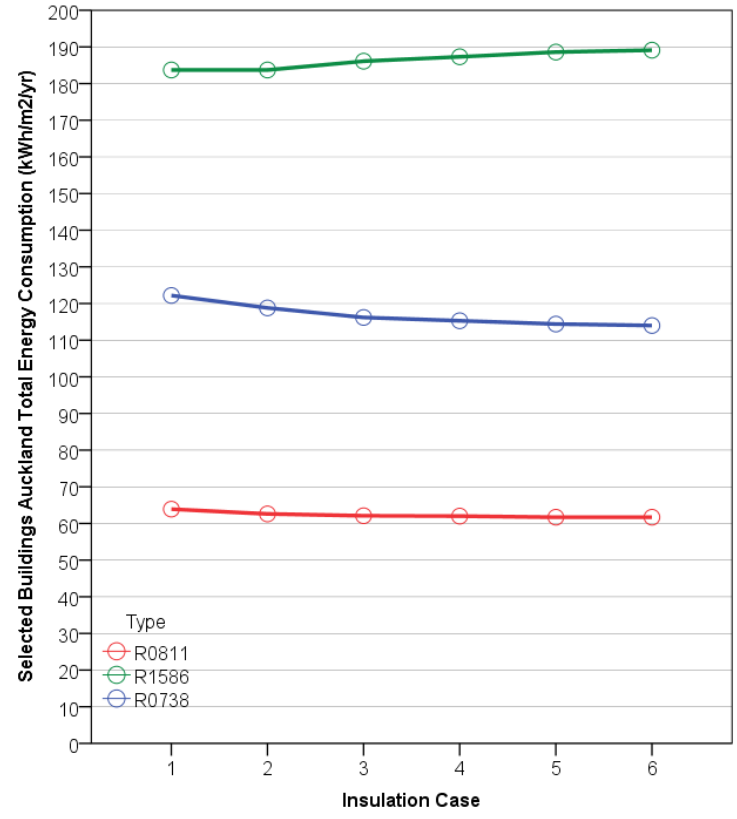

Figure 27 Selected buildings Auckland annual total energy consumption ( $k W h / m 2 / y r)$

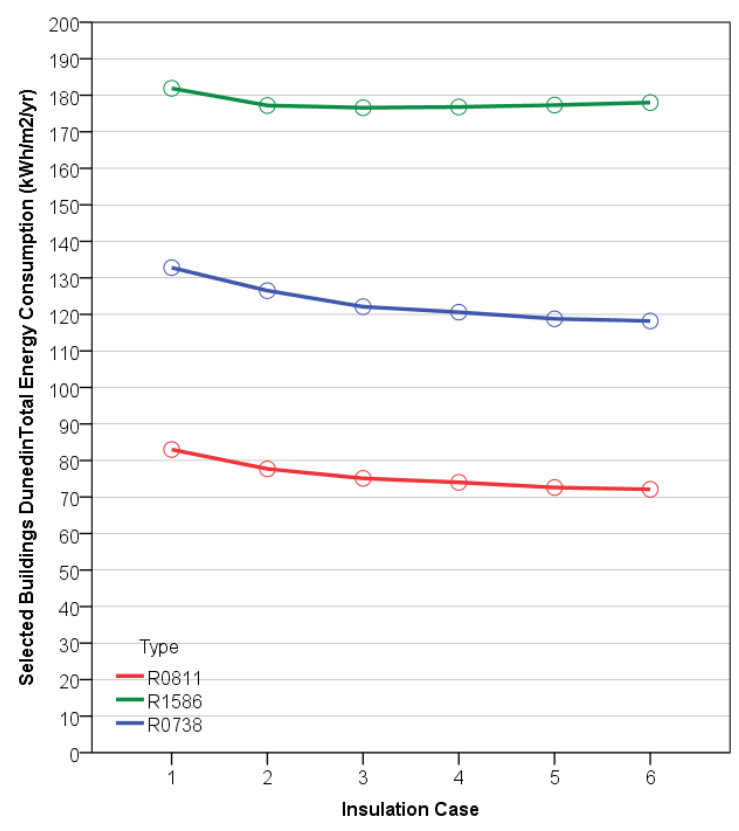

Figure 28 Selected buildings Dunedin annual total energy consumption ( $\mathrm{kWh} / \mathrm{m} 2 / \mathrm{yr}$ )

\section{Internal Load Level}

The performance of insulation is known to be strongly affected by the internal load level-which also greatly determines the amount of heating and cooling energy a building requires. The internal load levels of the buildings vary greatly and is reflective of their energy performance. 
The building with a decrease in all energy use types with additional thermal insulation has the lowest internal load level- the sum of all loads (includes electrical equipment, lights, dhw, lifts, miscellaneous loads and occupant density) is $4.65 \mathrm{~W} / \mathrm{m}^{2}$. The building with the highest sum $\left(33.77 \mathrm{~W} / \mathrm{m}^{2}\right)$ of all loads had an increase in total energy consumption with additional thermal insulation. Building R0738, which had an increase in cooling energy consumption with increased insulation, had a total internal load level of $27.38 \mathrm{~W} / \mathrm{m}^{2}$. Each of the buildings were simulated to have the same occupancy and HVAC pattern of use.

\section{Surface to Volume Ratio}

Building R0811 and R1586 are Strata 4, $5839 \mathrm{~m}^{2}$ and $6029 \mathrm{~m}^{2}$ respectively. Building R0738 is Strata 5 with a floor area of $9439 \mathrm{~m}^{2}$. Although they have different floor areas, their surface to volume ratios are very similar, $0.22,0.21$ and 0.23 for Building R081 1, R0738 and R1586 respectively. This means each building has a relatively similar amount of surface area for thermal gains and losses. Building R0738 is only slightly more able to be internally load dominated due to its lower surface to volume ratio. Therefore, as the buildings ratios are similar, the material properties of the walls will have a greater impact- the amount of glazing will determine the area available for thermal insulation.

\section{Construction Materials}

The construction materials the buildings were modelled to have were very similar. The buildings are all modelled with the same roof and floor constructions (trafficable concrete roofs and concrete floor slabs). The exteriors walls are exposed concrete for each of the buildings- except one façade for R0811 is constructed as concrete fibre cement. Each of the buildings had single glazing, with aluminium framing. The thermal properties of the windows for Building R081 1 and R1586 are the same as they both had lightly tinted glazing, while R0738 had light tint windows on the west façade, mirror glass on the north and clear on the east and south. 


\section{Window to Wall Ratio and Shading}

The building (R1586) with the largest increase in cooling energy consumption and total energy, is very heavily glazed and has minimal shading from adjacent buildings. While R1586 has the least amount of wall area available for thermal insulation, the addition of thermal insulation has a significant effect on the energy performance on the building. This is thought to be due to the very high internal load level and glazing of the building- overheating is likely an issue.

$35 \%$ of building R1586's exterior walls is unglazed. Building R0738 has a total glazing ratio of $27 \%$ and $16 \%$ for R081 1 . Note that only R0811 has a WWR that would allow for the NZS4243.1:2007 Schedule Method of compliance to be used.

As the images below show, building R0738 is the most heavily shaded-adjacent buildings to the east and west (same height and higher than R0738) are within 6m. Both R0738 and R0811 have buildings within 10m and over half the height.

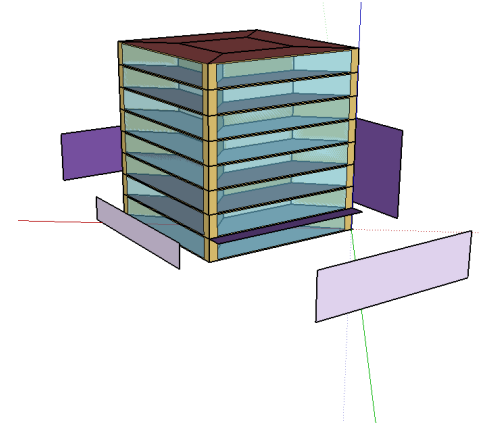

Figure 29 Building R0811

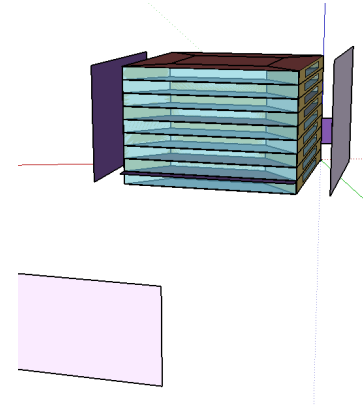

Figure 30 Building R0738

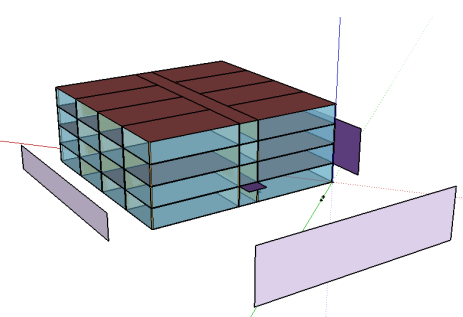

Figure 31 Building R1586

\section{Thermostat Set Point Temperature}

As identified by Friess et al. (2017) and Idris \& Mae (2017), the thermostat set point can determine whether thermal insulation performs beneficially or adversely. This is due to the set points determining how much heating and cooling energy a building requires to maintain comfortable temperatures. Also, when an office building is internal load dominated, allowing the building to cool naturally by conduction through the walls is beneficial- this occurs when the buildings internal temperature is below the set point temperature. The more time a building is cooler inside than outside, there will be more thermal gains through the 
envelope- thermal insulation will likely be more important. This is due to the restriction of heat flow through the envelope when the building is warmer internally.

In use, buildings R081 1 and R1586 are modelled with fixed set points, while R0738 has a schedule. Building R0811 has the lowest and highest heating and cooling set points of $15.7^{\circ} \mathrm{C}$ and $26.0^{\circ} \mathrm{C}$ - also the largest band. R1586 has set points of $20.3^{\circ} \mathrm{C}$ and $23.0^{\circ} \mathrm{C}$. The set points throughout the year for building R0738 include $18,19.6,23,19.6,18^{\circ} \mathrm{C}$ and $24,22.2,23.5,22.2$, and $25^{\circ} \mathrm{C}$. As displayed in Table 3 , the Auckland average annual temperature is $15.2^{\circ} \mathrm{C}$. The average minimum temperature during January is $17^{\circ} \mathrm{C}$ and maximum is $23.0^{\circ} \mathrm{C}$. For July, it is $15^{\circ} \mathrm{C}$ and $21^{\circ} \mathrm{C}$. The maximum temperature is $34.4^{\circ} \mathrm{C}$ and minimum $-3.9^{\circ} \mathrm{C}$.

Building R0811 required the lowest amount of cooling energy in Auckland and had very minimal heating requirements. Overall the building has very low HVAC energy requirements and this can be attributed to the fact that the minimum and maximum summer and winter temperatures largely fall within the set point range $\left(15.7^{\circ} \mathrm{C}\right.$ and $\left.26.0^{\circ} \mathrm{C}\right)$. The average minimum temperature during July $\left(15^{\circ} \mathrm{C}\right)$ is such that it would be expected the building had low heating requirements. While the average maximum January temperature is lower than the cooling set point, the maximum temperature is higher.

Building R 1586 has the same cooling set point as the average maximum January temperature. Given the very high internal load levels of the building, it would be expected that the building would spend a large amount of time requiring cooling (as is reflected in the graph below (Figure 33)). The building has very minimal heating requirements (Figure 32). While the buildings set point temperature is higher than the average minimum January and July temperatures, the high heat gains would be expected to cause the building to require cooling instead.

Building R0738 requires the largest amount of heating of the buildings and slightly more cooling than R0811. In contrast, to building R0811 the dead band is a lot smaller and so there is greater chance for heating energy to be required. The 
average minimum July temperature and heating set points during this time of year allow for heating.

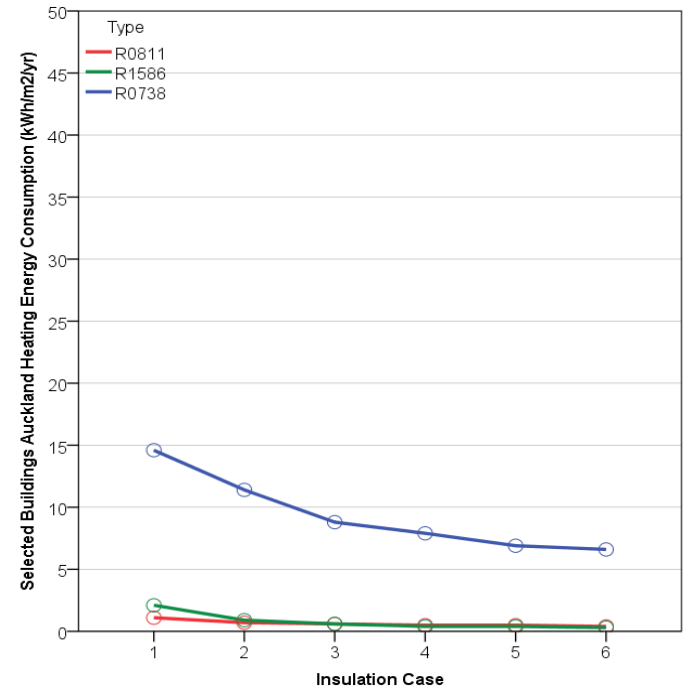

Figure 32 Selected buildings Auckland annual heating energy consumption ( $\mathrm{kWh} / \mathrm{m} 2 / \mathrm{yr}$ )

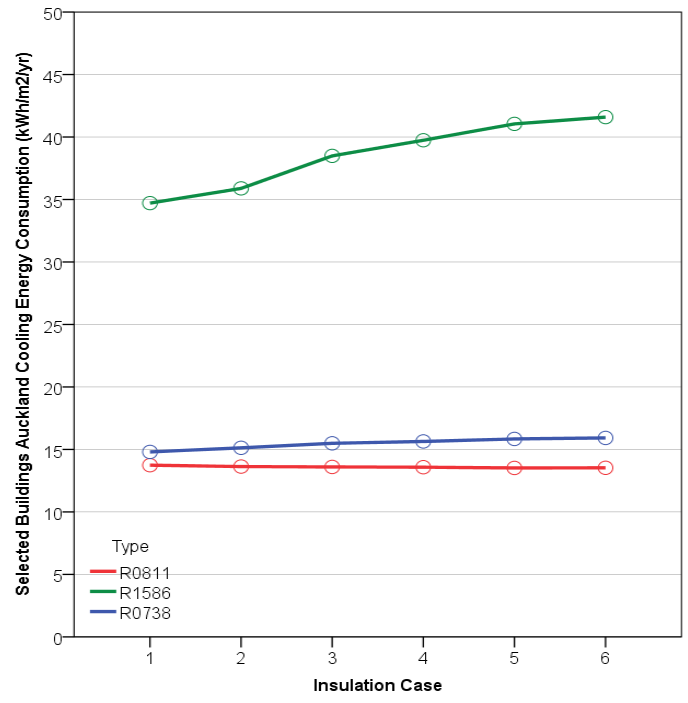

Figure 33 Selected buildings Auckland annual cooling energy consumption ( $\mathrm{kWh} / \mathrm{m} 2 / \mathrm{yr}$ )

Analysis for the buildings in Dunedin was undertaken to demonstrate how the set points would affect energy use in a southern location. The average minimum Dunedin temperature during January is $12^{\circ} \mathrm{C}$ and maximum is $17.0^{\circ} \mathrm{C}$. For July, it is $6^{\circ} \mathrm{C}$ and $9^{\circ} \mathrm{C}$.

When simulated in Dunedin, building R1586 (heating and cooling set points $20.3^{\circ} \mathrm{C}$ and $23.0^{\circ} \mathrm{C}$ ) when uninsulated has higher heating energy requirements than cooling. However, as the thermal insulation level increases, cooling is dominant. The heating set point is higher than both the July and January maximum average temperature. While, the average temperature is always significantly below the cooling set point temperature, it is the high internal load level that would be expected to be causing the higher amount of cooling energy to be required. Therefore, during this time the temperature is cooler outside and warmer inside and the presence of added thermal insulation is trapping the heat. The greater heating requirements are therefore why an increase in total energy consumption does not occur (as opposed to Auckland).

Note that building R1586 has the highest heating set point (greater chance building requires heating), yet it has the lowest energy requirements. Conversely, 
building R081 1 which has the lowest internal load level and heating set point has the highest heating requirements.

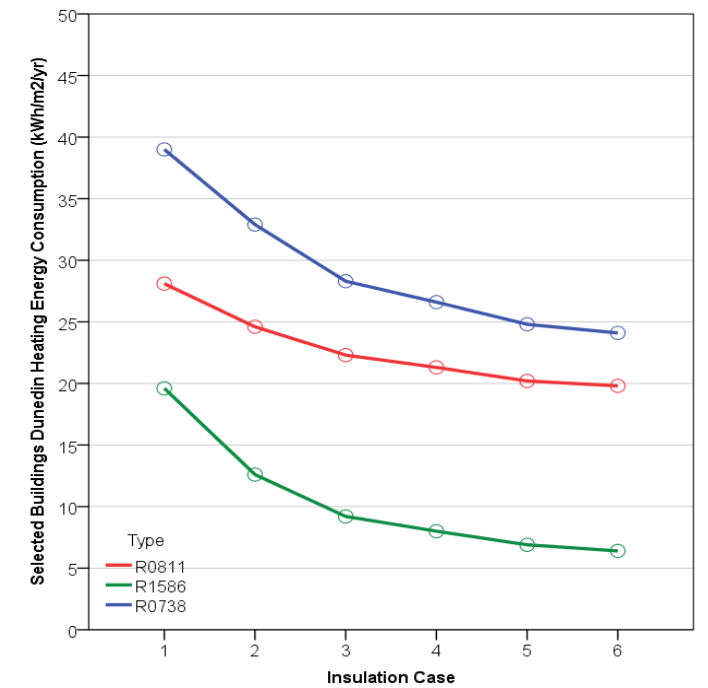

Figure 34 Selected buildings Dunedin annual heating energy consumption ( $\mathrm{kWh} / \mathrm{m}^{2} / \mathrm{yr}$ )

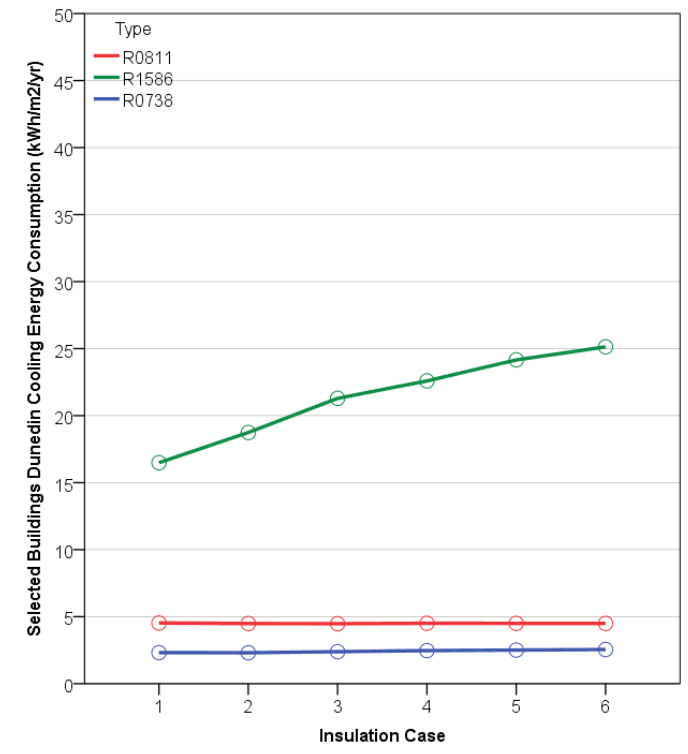

Figure 35 Selected buildings Dunedin annual cooling energy consumption $\left(\mathrm{kWh} / \mathrm{m}^{2} / \mathrm{yr}\right)$

\section{Economiser Control}

The use of economiser control in building R0811 may be the cause of it not experiencing an increase in cooling energy for any location and thermal insulation level. As identified previously, this would be due to the building requiring a reduced amount of energy when utilising economiser controltherefore, to remove any additional thermal load caused by the presence of thermal insulation, a greater amount of cooling energy would not be required as opposed to the buildings HVAC systems without economiser control.

\subsubsection{All buildings: location}

The graphs below (Figure 36-Figure 40) display the effect types on total energy consumption that occur across the sample of buildings in each location. The minimum, maximum and average total energy use of the sample of buildings for each location is displayed on the graphs. As 13 buildings in total were simulated, a maximum of 13 effect types can occur in each location. The aim was to 
identify how the buildings perform as the added insulation level is increased. It is found that the minimum level of thermal resistance required by the building code is not beneficial in the majority of buildings located in Zone 1 and several in zone 2. In Zone 3, the minimum required thermal insulation level achieves a 5\% reduction in energy use in most buildings.

Overall, added insulation at any level is shown to not be beneficial in the majority of the sample of buildings in Auckland. Beyond case 3, the effect on total energy consumption is the same for the sample of buildings located in Auckland (Z1) - 5 buildings have a decrease, 6 a negligible decrease and 2 have a negligible increase. At lower levels of insulation, the number of buildings that the added insulation is beneficial in, is reduced- 3 buildings at case 2 and 4 at case 3 . The sample of buildings simulated with case 2 levels of thermal resistance meet the minimum required level for Zone 1. At this level, in the majority of the buildings (9) the total energy consumption is negligibly decreased and in one building the energy consumption is negligibly increased. Only in 3 buildings, is the heating energy consumption reduced beyond $5 \%$.

For all Zone 2 locations, the highest number of decreases occur at the highest level of insulation. However- the number of buildings that have a decrease reduces by 1 from case 4 to 5 in Napier, Paraparaumu and Wellington. Case 4 is the minimum required level for all Zone 2 locations (Hamilton, Napier, Paraparaumu and wellington). At this level, added insulation is shown not to benefit several buildings in each of the zone 2 locations.

The number of buildings in which the added insulation reduces the total energy consumption below 5\% relative to the building uninsulated, is 8 in Hamilton, 7 in Napier, 9 in Paraparaumu and Wellington. The total energy consumption is negligibly increased in one building in each of the locations, and a negligible decrease occurs in the remaining buildings.

As the insulation level increases, the number of decreases that the sample has in all South Island (Z3) locations increases. At the highest level of insulation, all buildings except one (R1586) have their energy consumption decrease by $5 \%$. Case 4 is also the minimum required level for all buildings located in Zone 3 
locations. This level of added insulation is beneficial to most buildings- 10 buildings located in Christchurch have a decrease beyond 5\%, 11 in Queenstown and Dunedin. For the remaining buildings in each location, the energy consumption is negligibly decreased. As the insulation level is increased beyond the minimum required level, the effect on energy consumption is the same at case 5 . At the highest level, all but one building has a decrease.

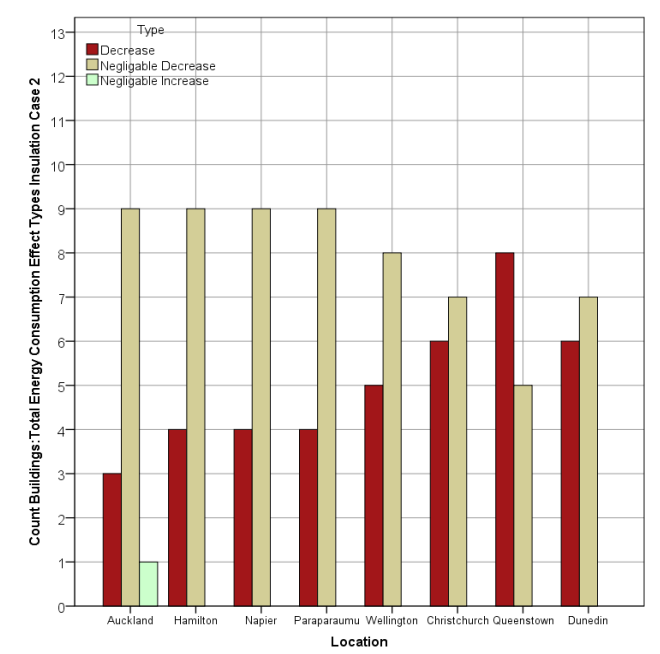

Figure 36 Insulation Case 2: Effect types on total energy consumption that occur across sample of buildings in each location- $Z 1$ minimum required level

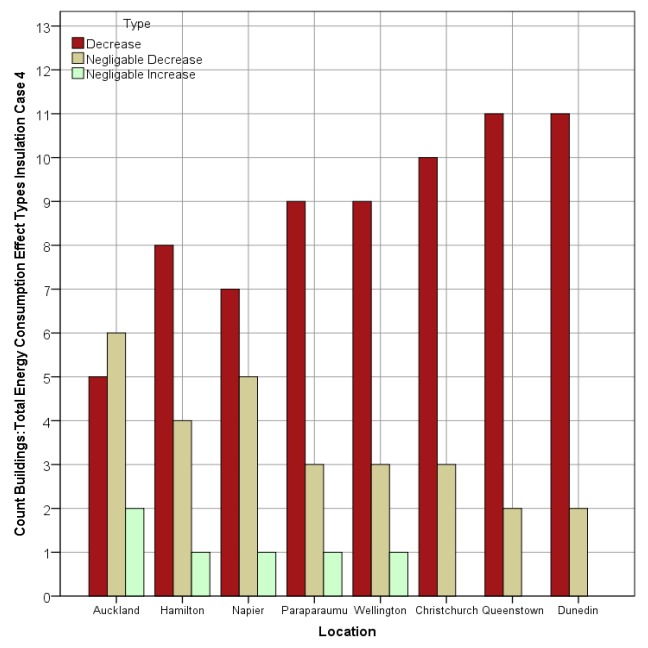

Figure 38 Insulation Case 4: Effect types on total energy consumption that occur across sample of buildings in each location- Z2 and Z3 minimum required level

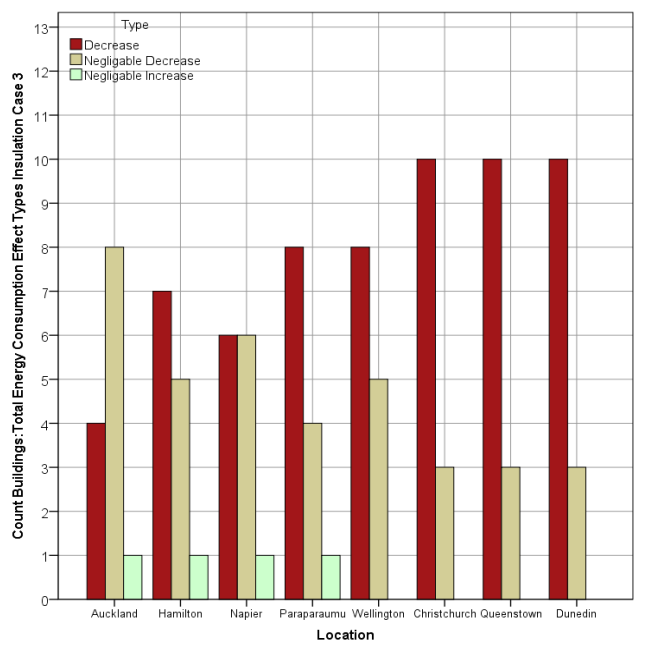

Figure 37 Insulation Case 3: Effect types on total energy consumption that occur across sample of buildings in each location

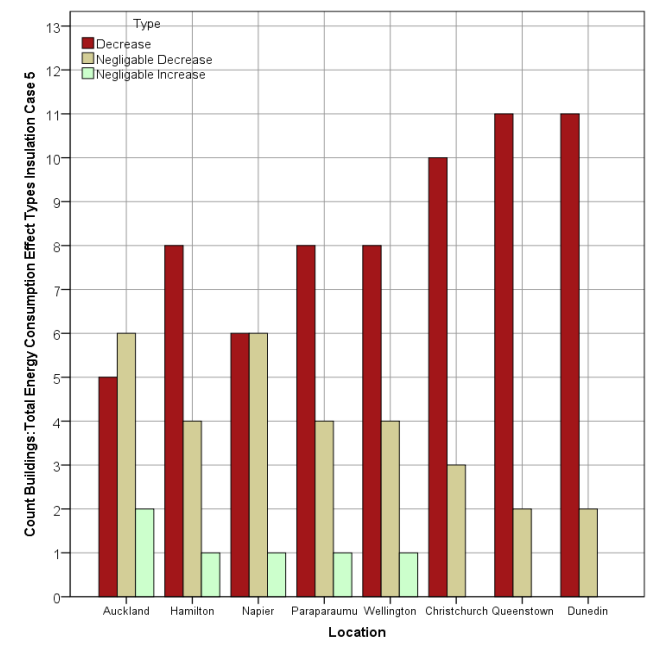

Figure 39 Insulation Case 5: Effect types on total energy consumption that occur across sample of buildings in each location 


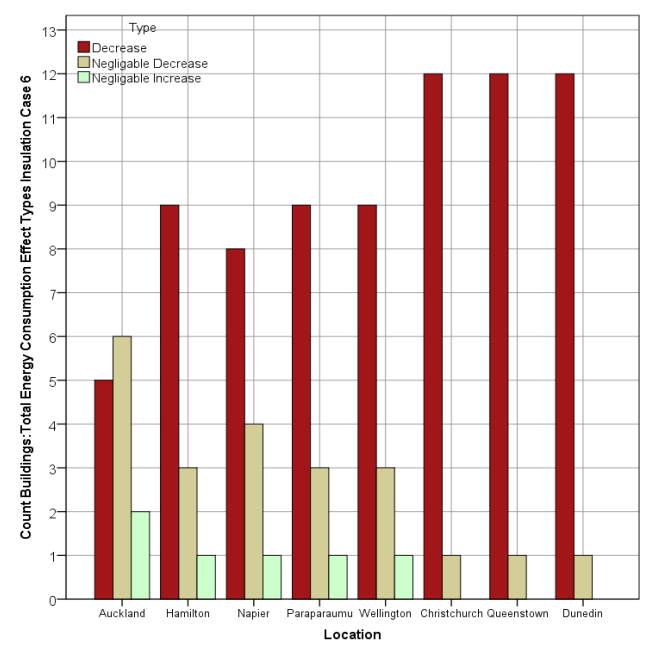

Figure 40 Insulation Case 6: Effect types on total energy consumption that occur across sample of buildings in each location

\subsubsection{Effect on cooling energy consumption: All buildings}

This section identifies the frequency of an increase in cooling energy by location and thermal insulation level. It can be seen whether higher levels of insulation encourages the adverse energy behaviour as the thermal insulation level is increased. As identified in the previous section, in a large number of buildings the total energy consumption is negligibly decreased in the northern locations at all Cases. This suggests that the cooling energy consumption of these buildings is increased relative to the building uninsulated. However, the reduction in heating energy consumption is great enough that the buildings total energy consumption is reduced. It is important to note that in the cooler locations the requirement for cooling energy will be lower than in the warmer locations. Therefore, it can be expected that the difference in cooling energy for the southern locations will results in a larger percentage increase or decrease. Refer to the appendices (section 7.2.1) for the difference in cooling energy requirements between locations. The minimum, maximum and average cooling energy requirements for the sample of buildings at each thermal insulation level are listed.

As can be seen in the graphs below (Figure 41-Figure 48), an increase in cooling energy is not limited to a few locations. The number of buildings with an increase in cooling energy use (any increase) generally increases in all locations as the 
thermal insulation level increases. Even for Dunedin, which has the lowest temperatures during summer, a higher level of thermal insulation is shown to increase the number of buildings that have an increase in cooling energy. Case 2 represents the addition of only roof insulation. It can be seen that in every location, the addition of roof insulation causes at least two buildings to require additional cooling energy in comparison to the building uninsulated. The addition of wall insulation (Case 3) increases the number of buildings that require an increased amount of cooling energy in all location except Auckland.

The number of buildings that had a Negligible Increase or Increase in cooling energy use was the greatest in Auckland at all thermal insulation levels. 6 had a Negligible Increase at Case 2 and 8 had either a Negligible Increase or Increase at Case 6. At the highest Case, the number of buildings that had an increase in cooling energy use did not increase beyond 8 for any other location (always stayed between 6-8). Dunedin and Christchurch had the greatest number of buildings with an increase in cooling energy use over 10\%. As previously established, this is due to the small cooling requirements of these cooler locations.

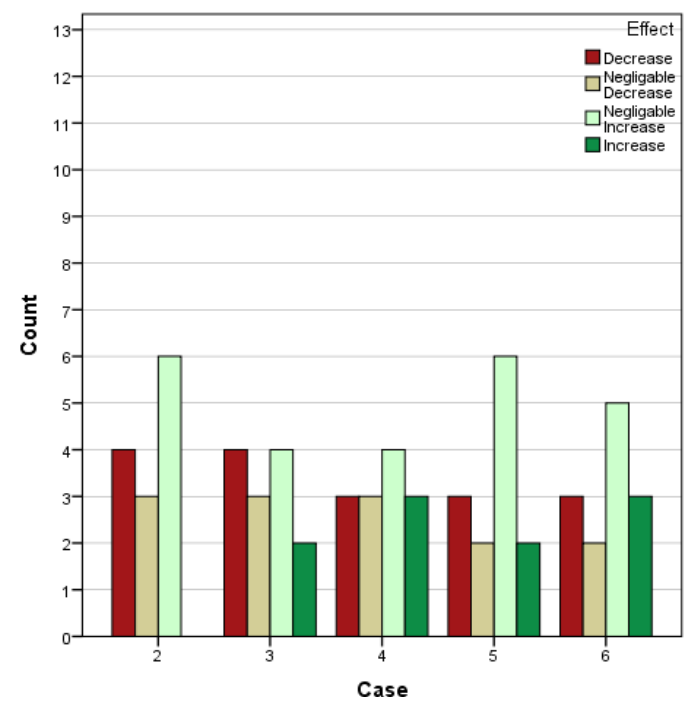

Figure 41 Auckland cooling energy $\mathrm{kWh} / \mathrm{m}^{2} / \mathrm{yr}$

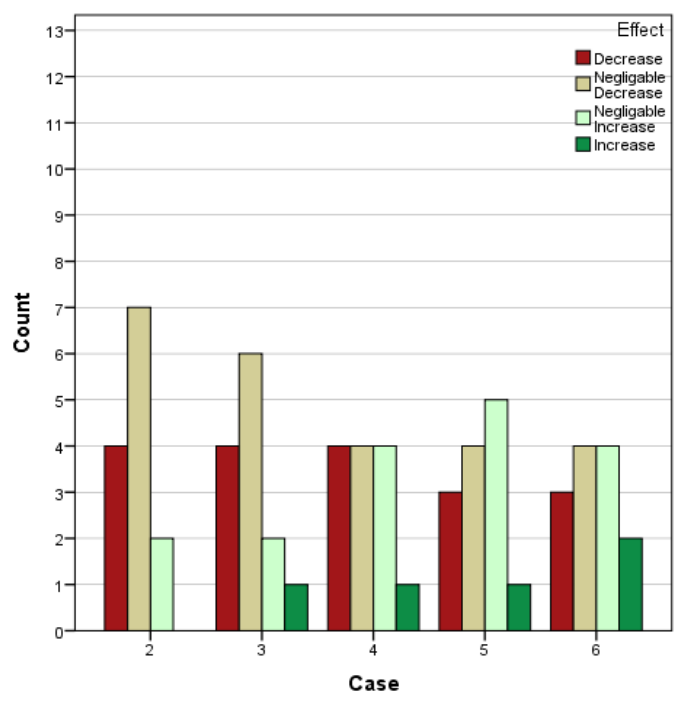

Figure 42 Hamilton cooling energy $\mathrm{kWh} / \mathrm{m}^{2} / \mathrm{yr}$ 


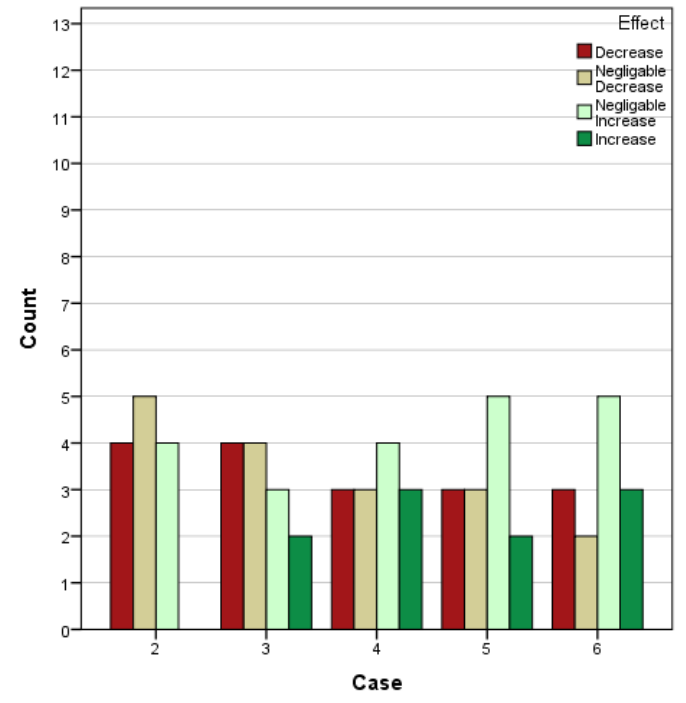

Figure 43 Napier cooling energy $\mathrm{kWh} / \mathrm{m}^{2} / \mathrm{yr}$

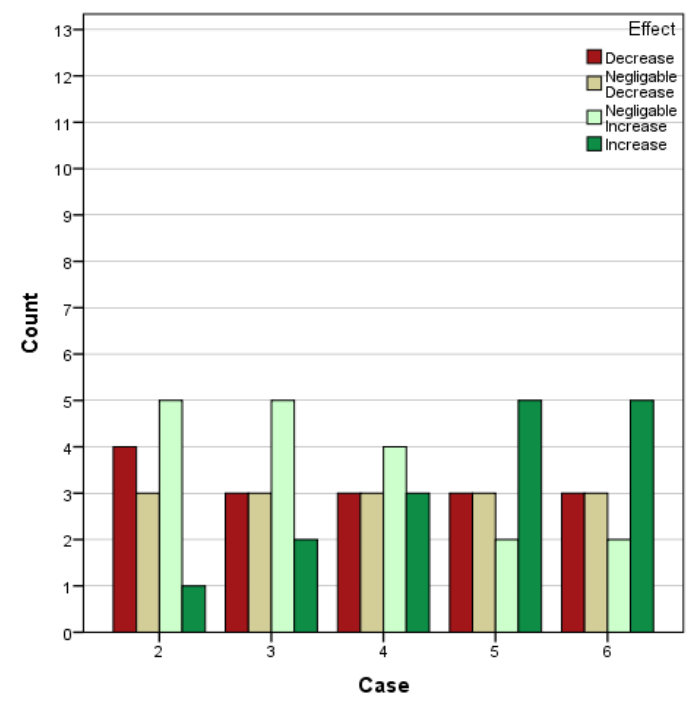

Figure 45 Wellington cooling energy $\mathrm{kWh} / \mathrm{m}^{2} / \mathrm{yr}$

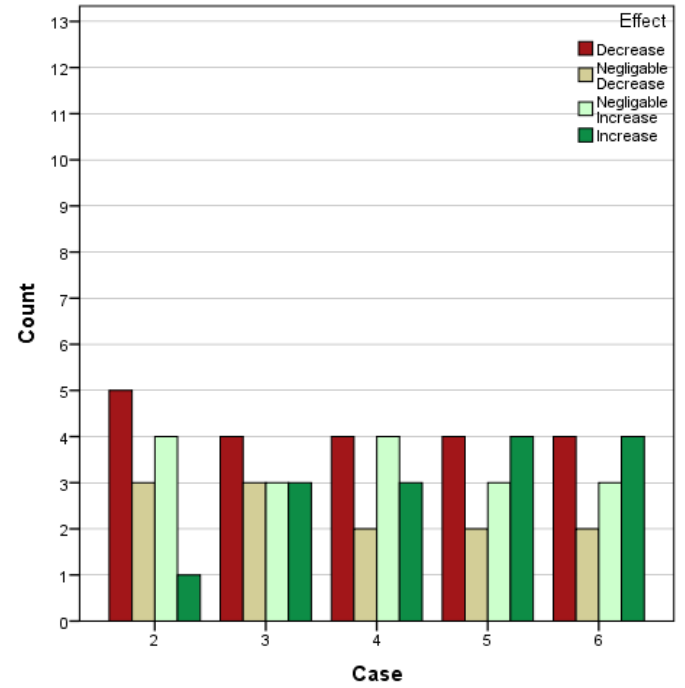

Figure 44 Paraparaumu cooling energy $\mathrm{kWh} / \mathrm{m}^{2} / \mathrm{yr}$

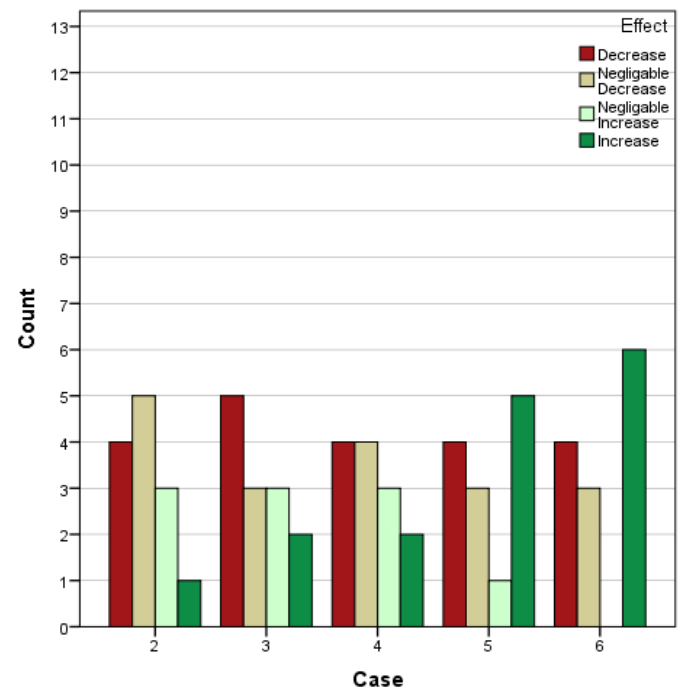

Figure 46 Christchurch cooling energy $\mathrm{kWh} / \mathrm{m}^{2} / \mathrm{yr}$ 


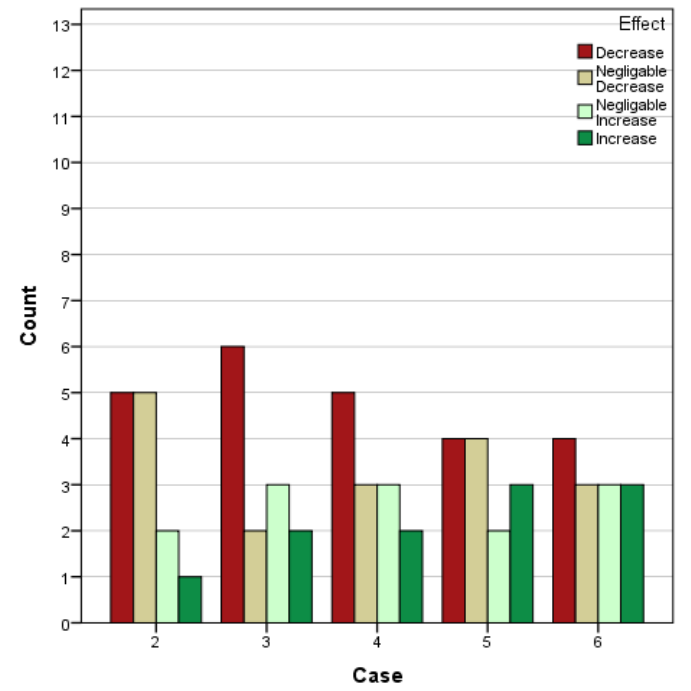

Figure 47 Queenstown cooling energy $\mathrm{kWh} / \mathrm{m}^{2} / \mathrm{yr}$

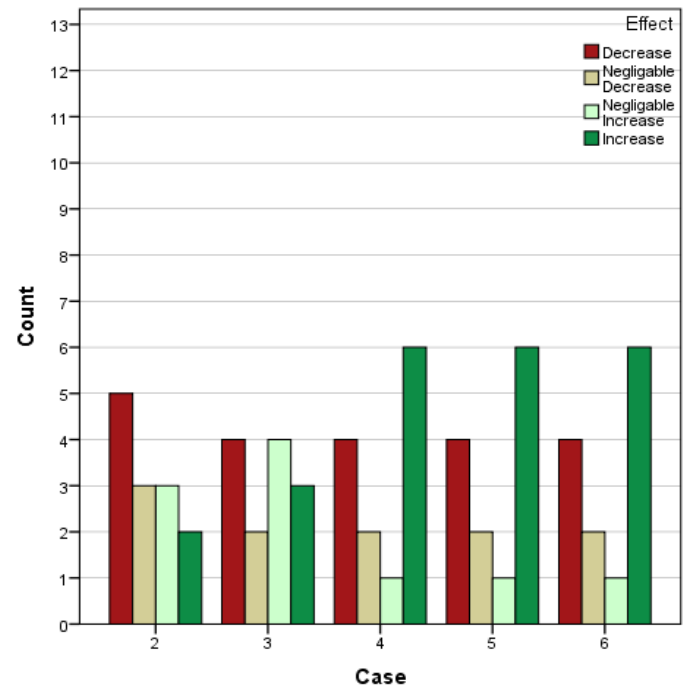

Figure 48 Dunedin cooling energy $\mathrm{kWh} / \mathrm{m}^{2} / \mathrm{yr}$

\subsubsection{Comparison of buildings energy performance: Total Energy}

The following section discusses the differences between the buildings in each energy groups. Building R0020, R0813 and R0843 have the greatest reduction in energy use across all locations with increasing thermal insulation. As expected, the buildings are shown to perform better in the southern locations. Therefore, the number of buildings that fall into the Decrease and Greatest Decrease categories becomes larger in the South Island locations. Buildings R081 1, R0831 and R0054 fall within the Greatest Decrease category in Queenstown while in the Decrease category for all other locations. This is expected to be due to the temperatures during the winter in Queenstown being the coolest of the locations- therefore the heating load is the greatest and the buildings are dominated by their envelopes. Except in Auckland and Queenstown, the majority of buildings in each location fall into the Decrease category.

As identified previously, the total energy consumption in most buildings when simulated in Auckland, was negligibly decreased. Added insulation in buildings R1586 and R0198 is the least beneficial as the energy consumption is increased negligibly in North Island locations (only at certain levels of added insulation). 
\begin{tabular}{|l|l|l|l|l|l|l|l|l|}
\hline Auckland & Hamiltion & Napier & Paraparaumu & Wellington & Christchurch Queenstown & Dunedin \\
\hline
\end{tabular}

\begin{tabular}{|c|c|c|c|c|c|c|c|c|}
\hline Negligable Increase & $\begin{array}{l}\text { R1586 } \\
\text { R0198 }\end{array}$ & R1586 & R1586 & R1586 & R1586 & & & \\
\hline Negligable Decrease & $\begin{array}{l}\text { R0056 } \\
\text { R0471 } \\
\text { R1017 } \\
\text { R0811 } \\
\text { R0831 } \\
\text { R1663 }\end{array}$ & $\begin{array}{l}\text { R0198 } \\
\text { R0471 } \\
\text { R1017 } \\
\text { R1663 }\end{array}$ & $\begin{array}{l}\text { R0198 } \\
\text { R0471 } \\
\text { R1017 } \\
\text { R1663 }\end{array}$ & $\begin{array}{l}\text { R0198 } \\
\text { R0471 } \\
\text { R1017 }\end{array}$ & $\begin{array}{l}\text { R0198 } \\
\text { R0471 } \\
\text { R1017 }\end{array}$ & $\begin{array}{l}\text { R1586 } \\
\text { R0198 } \\
\text { R1017 }\end{array}$ & $\begin{array}{l}\text { R1586 } \\
\text { R0198 } \\
\text { R1017 }\end{array}$ & $\begin{array}{l}\text { R1586 } \\
\text { R0198 } \\
\text { R1017 }\end{array}$ \\
\hline Decrease & $\begin{array}{l}\text { R0054 } \\
\text { R0738 }\end{array}$ & $\begin{array}{l}\text { R0054 } \\
\text { R0056 } \\
\text { R0831 } \\
\text { R0738 } \\
\text { R081 1 }\end{array}$ & $\begin{array}{l}\text { R0054 } \\
\text { R0056 } \\
\text { R0738 } \\
\text { R081 } \\
\text { R0831 }\end{array}$ & $\begin{array}{l}\text { R0054 } \\
\text { R0056 } \\
\text { R0738 } \\
\text { R0811 } \\
\text { R0831 } \\
\text { R1663 }\end{array}$ & $\begin{array}{l}\text { R0054 } \\
\text { R0056 } \\
\text { R0738 } \\
\text { R0811 } \\
\text { R0831 } \\
\text { R1663 }\end{array}$ & $\begin{array}{l}\text { R0056 } \\
\text { R0054 } \\
\text { R0831 } \\
\text { R0738 } \\
\text { R081 1 } \\
\text { R0471 } \\
\text { R1663 }\end{array}$ & $\begin{array}{l}\text { R1663 } \\
\text { R0738 } \\
\text { R0056 } \\
\text { R0471 }\end{array}$ & $\begin{array}{l}\text { R0056 } \\
\text { R0471 } \\
\text { R1663 } \\
\text { R0831 } \\
\text { R0054 } \\
\text { R0738 }\end{array}$ \\
\hline Greatest Decrease & $\begin{array}{l}\text { R0020 } \\
\text { R0813 } \\
\text { R0843 }\end{array}$ & $\begin{array}{l}\text { R0020 } \\
\text { R0813 } \\
\text { R0843 }\end{array}$ & $\begin{array}{l}\text { R0020 } \\
\text { R0813 } \\
\text { R0843 }\end{array}$ & $\begin{array}{l}\text { R0020 } \\
\text { R0813 } \\
\text { R0843 }\end{array}$ & $\begin{array}{l}\text { R0020 } \\
\text { R0813 } \\
\text { R0843 }\end{array}$ & $\begin{array}{l}\text { R0020 } \\
\text { R0813 } \\
\text { R0843 }\end{array}$ & $\begin{array}{l}\text { R0020 } \\
\text { R0054 } \\
\text { R0811 } \\
\text { R0813 } \\
\text { R0843 } \\
\text { R0831 }\end{array}$ & $\begin{array}{l}\text { R0020 } \\
\text { R081 1 } \\
\text { R0813 } \\
\text { R0843 }\end{array}$ \\
\hline
\end{tabular}

Table 15 Prevailing effect types for each building across all cases in each location-total energy consumption

The groupings were then used to compare the attributes of the buildings. A comparison of the buildings was undertaken for the Auckland groups and comparison to other location groups was made where relevant.

\section{Energy Use- Heating/Cooling Dominated}

Uninsulated, the buildings which a negligible increase or decrease in total energy consumption occurred in, had higher cooling requirements. Building R0198 required no heating energy while the other negligible increase building had a very low requirement of $2.1 \mathrm{kWh} / \mathrm{m}^{2} / \mathrm{yr}$.

Not all buildings that were within the Greatest Decrease category were heating dominated, although they all had the lowest heating and cooling energy requirements of the sample. Therefore, any change in energy required would result in a large percentage difference.

Buildings in the Decrease category had mixed heating and cooling requirements. Buildings in the negligible decrease category had higher cooling energy requirements, with most having very minimal heating requirements. 


\section{Internal Load Level}

While the buildings in the Greatest Decrease category generally had the lowest load levels of the sample, a higher load level did not necessarily mean that the building performed negligibly. The buildings in which a negligible increase in total energy consumption occurred in did not have the highest load levels of all buildings. Building R0198 had a total load level of $8.17 \mathrm{~W} / \mathrm{m}^{2}$. Among the sample, this is the fifth lowest. The building with the highest $\left(35 \mathrm{~W} / \mathrm{m}^{2}\right)$ load level was categorised in to the Decrease group. The buildings with the greatest decrease in energy performance had load levels amongst the lowest of the sample.

\section{Window to Wall Ratio}

When comparing the buildings in the highest and lowest performing groups, the lowest performing group has some of the highest total WWR's and glazing distribution on the north façade. The buildings in the highest performing group have some of the lowest ratios. Four of the buildings (R0054, R0811, R0198, R1586) in the sample had WWR greater than $50 \%$ (Schedule Method maximum allowance for window to wall ratio). Three of these buildings are placed within negligible categories.

\section{Surface to Volume Ratio}

The buildings which a negligible increase occurred in had low surface to volume ratios. The ratio for building R1098 is the lowest among the sample. The buildings in the decrease and greatest decrease categories generally have higher surface to volume ratios than the buildings within the negligible increase category. However, no clear trends between the groups exist. It is expected that the operational parameters of the buildings will have a greater effect on the energy performance of the buildings as these vary greatly among the sample.

\section{Thermostat Set Point Temperature}

The buildings with very low heating requirements had the lowest heating set points. Generally, buildings with set points below $20^{\circ} \mathrm{C}$ during the winter months have very minimal heating loads. While buildings with low heating loads were spread across all groups, both buildings that had a negligible increase in energy consumption had no and very low heating requirements. 
As mentioned previously, buildings that had a negligible increase or decrease in energy consumption were cooling dominant. Given that the internal load level has a great effect on the cooling requirements of buildings, there is no general trend across the sample. However, buildings that a negligible effect occurred in that didn't have the highest loads, did have high cooling set points. With a higher cooling set point temperature, it is more likely that the building will spend more time warmer inside than cooler outside (average Auckland maximum January temperature is $17^{\circ} \mathrm{C}$ ). For example, building R0198 which has a cooling set point of $28 \mathrm{C}$. Building R1017, R0811 have internal load levels of $4.6 \mathrm{~W} / \mathrm{m} 2$ and set points of $26 \mathrm{C}$ during the summer months and are within the negligible decrease category.

\section{Economiser Control}

Buildings R1098, R1017 and R0811 are modelled with economiser control. The economizer type for each building is differential dry bulb, and each has an upper and lower temperature limit of $19^{\circ} \mathrm{C}$ and $4^{\circ} \mathrm{C}$. This means that when the outdoor air temperature is higher than the dry-bulb temperature of the return airthe outdoor airflow will be set to the minimum. When the outdoor temperature falls outside of the limits, heat recovery is enabled and the outdoor air-flow is set to the minimum.

Each of these buildings fall within the Negligible Decrease category- expect for R0198 which falls within the Negligible Increase category in Auckland.

\section{Construction Materials}

Across the groups, there appears to be no clear trend between construction types of the buildings between groups. All buildings are single glazed. The majority are lightly tinted with aluminium framing. All buildings had thermal insulation placed on the internal side of the wall. Other attributes would be expected to have a greater influence on energy performance of the buildings. 
The table below (Table 16) groups the buildings in each location by their prevailing effect type on cooling energy. All buildings that have an increase in cooling energy in Dunedin fall within the Increase category. This is expected to be due to the cooling energy requirements for all buildings will be very lowtherefore any increase will result in a large percentage increase.

The Auckland group of buildings was used to assess the differences of the buildings across the groups. Comparison to other location groups was made where relevant.

\begin{tabular}{|c|c|c|c|c|c|c|c|c|}
\hline & Auckland & Hamiltion & Napier & Paraparaumu & Wellington & Christchurch & Queenstown & Dunedin \\
\hline Increase & $\begin{array}{l}\text { R0054 } \\
\text { R0056 } \\
\text { R1586 }\end{array}$ & R1586 & \begin{tabular}{|l|} 
R0054 \\
R1586
\end{tabular} & \begin{tabular}{|l|l|}
$R 0054$ \\
$R 0056$ \\
$R 1586$
\end{tabular} & \begin{tabular}{|l|} 
R0056 \\
R0831 \\
R1586
\end{tabular} & $\begin{array}{l}\text { R0054 } \\
\text { R0056 } \\
\text { R1586 }\end{array}$ & $\begin{array}{l}\text { R0054 } \\
\text { R0056 } \\
\text { R1586 }\end{array}$ & $\begin{array}{l}\text { R0054 } \\
\text { R0056 } \\
\text { R0471 } \\
\text { R0831 } \\
\text { R1586 } \\
\text { R1663 }\end{array}$ \\
\hline Negligable Increase & $\begin{array}{l}\text { R0056 } \\
\text { R0198 } \\
\text { R0471 } \\
\text { R0738 } \\
\text { R0831 } \\
\text { R1663 }\end{array}$ & $\begin{array}{l}\text { R0056 } \\
\text { R0471 } \\
\text { R0738 } \\
\text { R1663 }\end{array}$ & $\begin{array}{l}\text { R0198 } \\
\text { R0471 } \\
\text { R0738 } \\
\text { R1663 }\end{array}$ & $\begin{array}{l}\text { R0471 } \\
\text { R0738 } \\
\text { R0831 } \\
\text { R1663 }\end{array}$ & $\begin{array}{l}\text { R0054 } \\
\text { R0471 } \\
\text { R0738 } \\
\text { R1663 }\end{array}$ & $\begin{array}{l}\text { R0471 } \\
\text { R0831 } \\
\text { R1663 }\end{array}$ & $\begin{array}{l}\text { R0471 } \\
\text { R1663 }\end{array}$ & \\
\hline Negligablel Decrease & $\begin{array}{l}\text { R0811 } \\
\text { R } 1017\end{array}$ & $\begin{array}{l}\text { R0054 } \\
\text { R0198 } \\
\text { R0811 } \\
\text { R } 1017\end{array}$ & \begin{tabular}{|l|}
$R 0811$ \\
$R 0831$ \\
$R 1017$
\end{tabular} & $\begin{array}{l}\text { R0811 } \\
\text { R1017 }\end{array}$ & $\begin{array}{l}\text { R0198 } \\
\text { R0811 } \\
\text { R1017 }\end{array}$ & $\begin{array}{l}\text { R0738 } \\
\text { R0811 } \\
\text { R } 1017\end{array}$ & $\begin{array}{l}\text { R0198 } \\
\text { R0738 } \\
\text { R0811 } \\
\text { R1017 }\end{array}$ & $\begin{array}{l}\text { R0738 } \\
\text { R0811 } \\
\text { R } 1017\end{array}$ \\
\hline Decrease & $\begin{array}{l}\text { R0020 } \\
\text { R0813 } \\
\text { R0843 }\end{array}$ & $\begin{array}{l}\text { R0020 } \\
R 0813 \\
R 0831 \\
R 0843\end{array}$ & \begin{tabular}{|l|}
$R 0020$ \\
$R 0813$ \\
$R 0843$ \\
\end{tabular} & $\begin{array}{l}\text { R0020 } \\
R 0198 \\
R 0813 \\
R 0843\end{array}$ & $\begin{array}{l}\text { R0020 } \\
\text { R0813 } \\
\text { R0843 }\end{array}$ & $\begin{array}{l}\text { R0020 } \\
R 0198 \\
R 0813 \\
\text { R0843 }\end{array}$ & $\begin{array}{l}\text { R0020 } \\
R 0813 \\
R 0831 \\
\text { R0843 }\end{array}$ & $\begin{array}{l}\text { R0020 } \\
R 0198 \\
R 0813 \\
\text { R0843 }\end{array}$ \\
\hline
\end{tabular}

Table 16 Prevailing effect types for each building across all cases in each location- cooling energy

\section{Energy Use- Heating/cooling Dominated}

The buildings within the Increase or Negligible Increase category were either cooling dominated or had mixed heating and cooling needs (only one of the nine buildings) at the lowest Cases. Two of the buildings within the Decrease category were heating dominated and the other required only cooling (at all Cases above 2). These buildings have very low energy requirements. All buildings within the Negligible Decrease category were cooling dominated with very low heating requirements for all Cases. Many of the buildings are heating dominated in locations south of Auckland and have an increase in cooling energy. 


\section{Window to Wall Ratio, Placement and Shading}

Buildings within the Increase category generally have high WWR among the sample. However, while R0054 and R1586 have a large amount of glazing on the north façade, building R0056 has only $40 \%$ glazing and $10 \%$ to the east. The three buildings within the greatest decrease category have some of the lowest load levels among the sample.

\section{Size, Area and surface to Volume Ratio}

No trends exist between the groups' surface to volume ratios. However, as mentioned in the previous section, the ratio appears to collectively have influence on buildings such as R0198 that do not have high internal load levels. Factors such as the set point, high glazing and low surface to volume ratios are expected to increase the internal heat gain within the buildings.

\section{Internal Load Level}

The buildings within the Increase category had the highest load levels of the sample. All of these buildings are not operated for longer periods of time in comparison to the others- however R0056 is occupied and the HVAC system runs on both days of the weekend.

As, expected, buildings within the Decrease category had the lower load levels among the sample. Two had the lowest among the sample, while building R0020 had a moderate load level of $10.73 \mathrm{~W} / \mathrm{m}^{2}$ - higher than building R0198 that is placed in the negligible increase category.

\section{Heating and Cooling Thermostat Set Point}

As identified previously the Auckland average annual temperature is $15.2^{\circ} \mathrm{C}$. The average minimum temperature during January is $17^{\circ} \mathrm{C}$ and maximum is $23.0^{\circ} \mathrm{C}$. For July, it is $15^{\circ} \mathrm{C}$ and $21^{\circ} \mathrm{C}$. The maximum temperature is $34.4^{\circ} \mathrm{C}$ and minimum $3.9^{\circ} \mathrm{C}$.

The very high internal load levels of the buildings within the Increase category are thought to have the most influence on the performance of the buildings. These buildings have low cooling set points among the sample $\left(23^{\circ} \mathrm{C}\right.$ for two of the buildings) during the summer months. Therefore, while the buildings have less of 
an ability to be warmer inside than other buildings- as the maximum average outdoor temperature is $23^{\circ} \mathrm{C}$, the building is still likely to spend a great amount of time warmer inside than outside (the internal heat gains will be trapped).

Buildings such as R0198 and R1663 have an increase in cooling energy however do not have significant total internal load levels among the sample. It is thought that this is due to the buildings' both very large and very small temperature deadbands.

\subsubsection{Summary As-built Findings}

The calibrated, as-built, energy models were modelled in eight locations with 6 Cases of thermal insulation. The minimum required level of thermal resistance for buildings located in Zone 3 was found to have a beneficial impact on the energy use in most of the buildings modelled in all Zone 3 locations. However, this was not the case for buildings located in Zone 1 and Zone 2 with the relevant minimum required level. This suggests that separate requirements for buildings located in Zone 2 would be more appropriate. To meet the minimum thermal resistance requirements for Zone 1, thermal insulation was only added to the roof of each building.

Many of the buildings were heating dominated and an increase in cooling energy occurred. It was found that a higher load level did not necessarily relate to a building's total energy performance as the thermal insulation level was increased. For example, the total load level of a building that had an increase in total energy consumption, was one of the lower total load values of the sample.

\section{2. $\quad$ Standardized Buildings: NZS4243 Regulations and Assumptions}

The sample of buildings was investigated with the operational parameters of the buildings standardized to the regulated and assumed NZS4243 values. 


\subsubsection{Comparison Energy Consumption of Selected Buildings}

The graphs below (Figure 49-Figure 51) display the energy required for each of the three selected buildings. When simulated with a typical pattern of use, none of the buildings for any of the insulation cases have an increase in total energy consumption. This is unlike when the buildings were simulated as built, as the total energy consumption for building R1586 increased in Auckland and Napier, the thermal insulation has a reduced effectiveness. Added insulation to building R0738 has the greatest impact on energy consumption. The building responds almost identically in Paraparaumu, Wellington, Christchurch and Queenstown and separately for Napier and Christchurch.

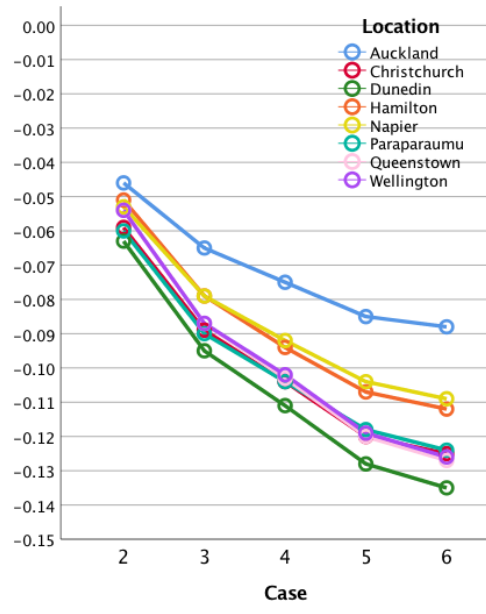

Figure 49 Building R081 1 Percentage Reduction Annual Energy Consumption

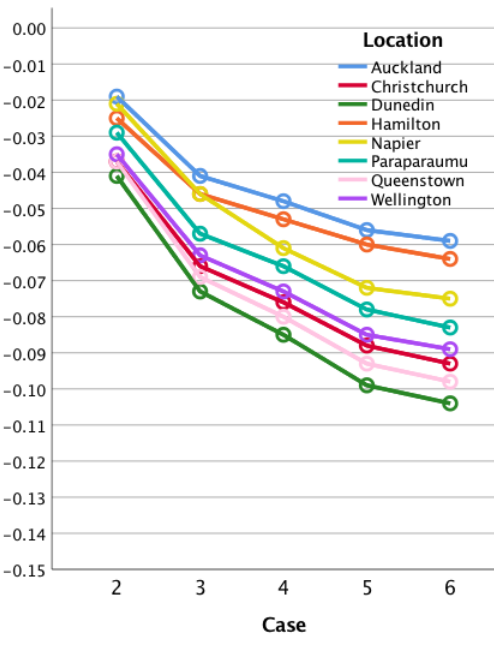

Figure 50 Building R0738 Percentage Reduction Annual Energy Consumption

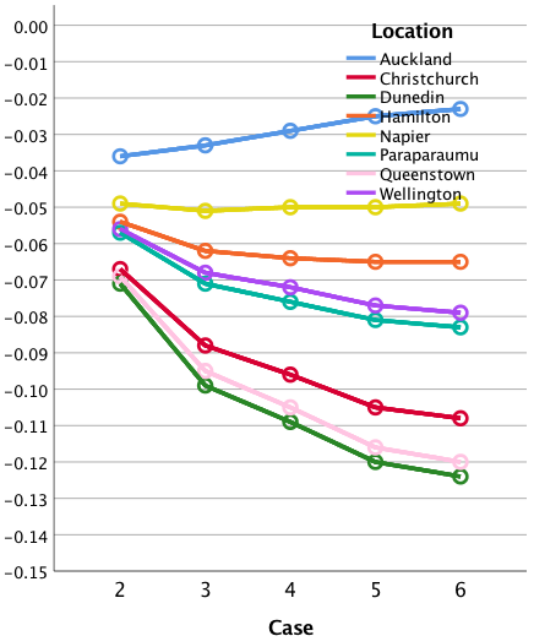

Figure 51 Building R 1586 Percentage Reduction Annual Energy Consumption

The following graphs (Figure 52-Figure 57) display the normalised annual heating energy requirements for each building ( $\mathrm{kWh} / \mathrm{m}^{2} / \mathrm{yr}$.). The set of graphs below display the normalised cooling energy requirements. An increase in cooling occurs for buildings R0738 and R1586- the same as when the buildings were simulated as-built.

Any level of added insulation causes the cooling energy requirements to increase in Auckland, Wellington and Dunedin for building R1586. The increase occurs in locations where the building is heating dominated. This can be seen for Dunedin, where the annual heating energy requirements are between $64.4-54$ 
$\mathrm{kWh} / \mathrm{m}^{2} / \mathrm{yr}$ (lowest to highest insulation Case) and the annual cooling requirements are far less- between $4.04-7.98 \mathrm{kWh} / \mathrm{m}^{2} / \mathrm{yr}$. The cooling energy requirements are only greater (very slightly) in Napier at the highest Cases.

For each building, the order of higher to lower heating requirements follows the same pattern, while for cooling energy it is different for each building. Hamilton and Napier have the highest cooling energy requirements for building R0811 and R0738.

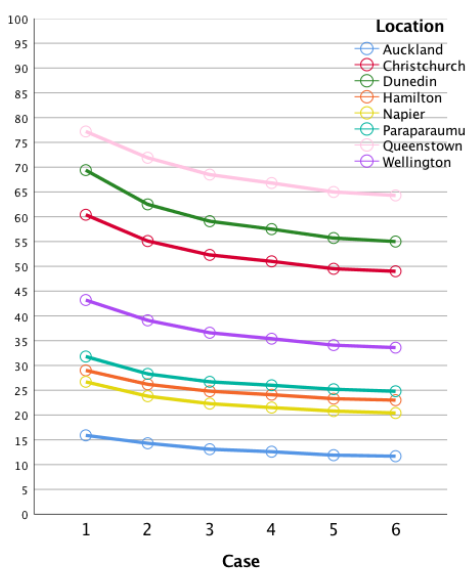

Figure 52 Building R081 1 Heating Energy Consumption

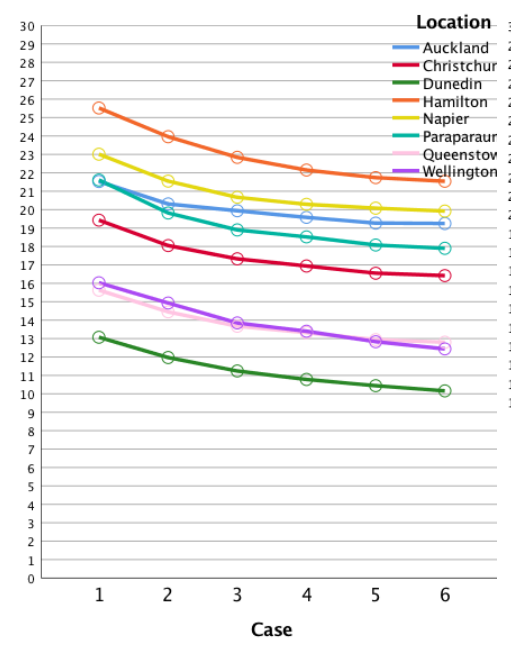

Figure 55 Building R081 1 Cooling Energy Consumption

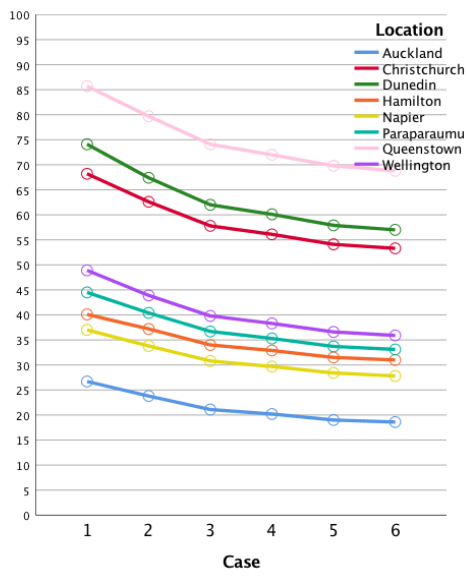

Figure 53 Building R0738 Heating Energy Consumption

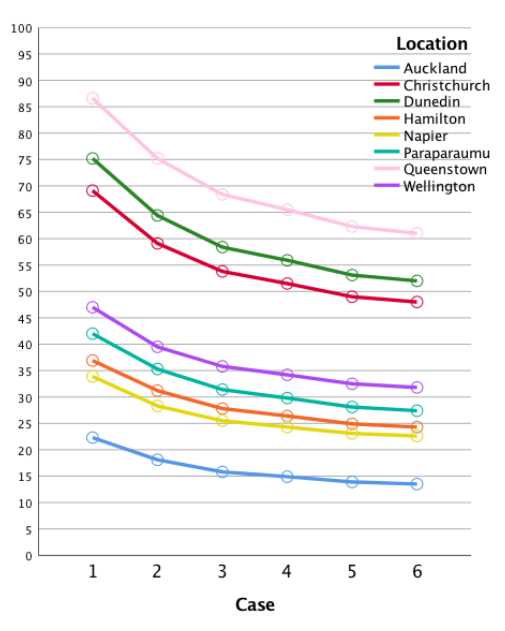

Figure 54 Building R 1586 Heating Energy Consumption

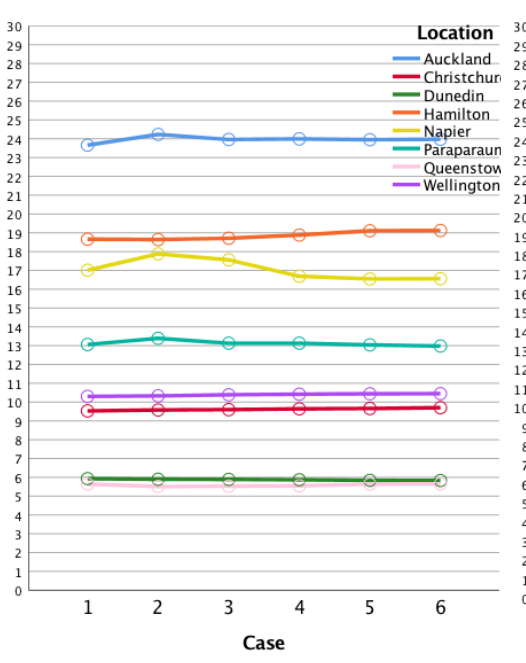

Figure 56 Building R0738 Cooling Energy Consumption

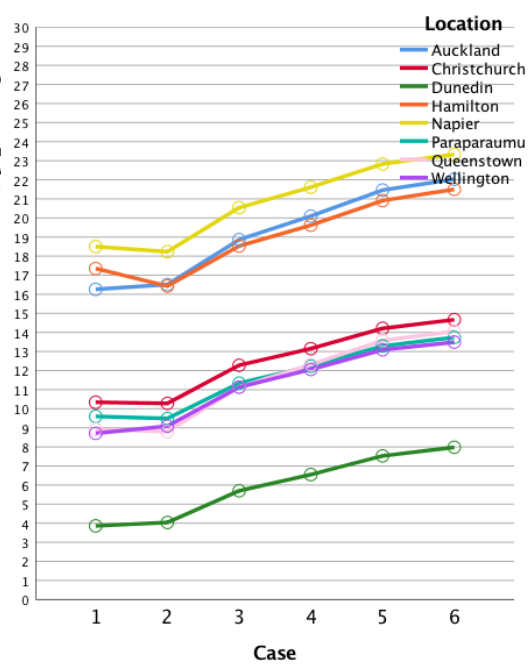

Figure 57 Building R 1586 Cooling Energy Consumption 


\subsubsection{All Buildings Effect on Total Energy Consumption: Location}

The purpose of this section was to identify how the buildings performed in each of the locations as the insulation level increased. The following graphs (Figure 58Figure 62) display the effect types on total energy consumption that occur for each building in each location and at each case. The effect types are based on the percentage increase or decrease the buildings had relative to the buildings uninsulated (represented by Case 1).

Overall, it can be seen that the number of buildings the energy consumption is decreased over $5 \%$ in, increases as the thermal insulation level is increased. Therefore, a higher level of thermal insulation is beneficial for a number of buildings. Beyond Case 3, the number of effect types for all buildings is the same for every location except Auckland. For Napier, two buildings have a negligible increase beyond Case 3. While for the rest of the locations, only one building has a negligible increase in energy consumption.

There is a great difference with the number of buildings which have a negligible decrease in energy consumption between Cases 2 and 3, and Cases 3 and 4 . Beyond Case 4 the number of buildings with a negligible decrease in energy consumption is the same. This would be expected, as case 3 signifies the addition of wall insulation. Refer to the appendix (section 7.2.1) for information on the difference in energy decrease between each insulation Case.

As the thermal insulation level is increased, the number of buildings in Auckland (Z1) with a negligible increase in energy consumption decreases. At Case 2 (minimum required level for Zone 1 buildings), most (10) buildings' energy consumption is negligibly decreased. At Case 3, the number of buildings which a Negligible Decrease occurs in reduces to 7, although 6 buildings have a Decrease in energy consumption. At the highest thermal insulation level, 8 buildings have a decrease in energy consumption and 5 have a negligible decrease. This suggests that while the total energy consumption is always decreased for every Case, any level of thermal insulation may not be an effective energy efficiency measure for buildings in Auckland. 
At Case 4 (minimum required thermal resistance level for zone 2 and 3), the energy consumption is decreased in most (11 Napier and rest 12) buildings located in the zone 2 and 3 locations. This suggests that the current minimum required thermal insulation value is beneficial for buildings with the regulated and assumed power density, pattern of use and recommended heating and cooling set points.

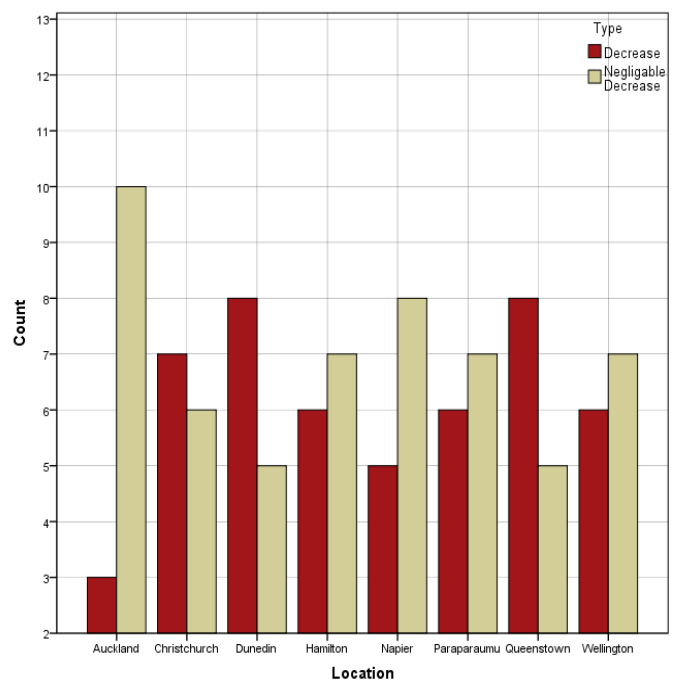

Figure 58 Number of buildings at case 2 effect types occur in each location

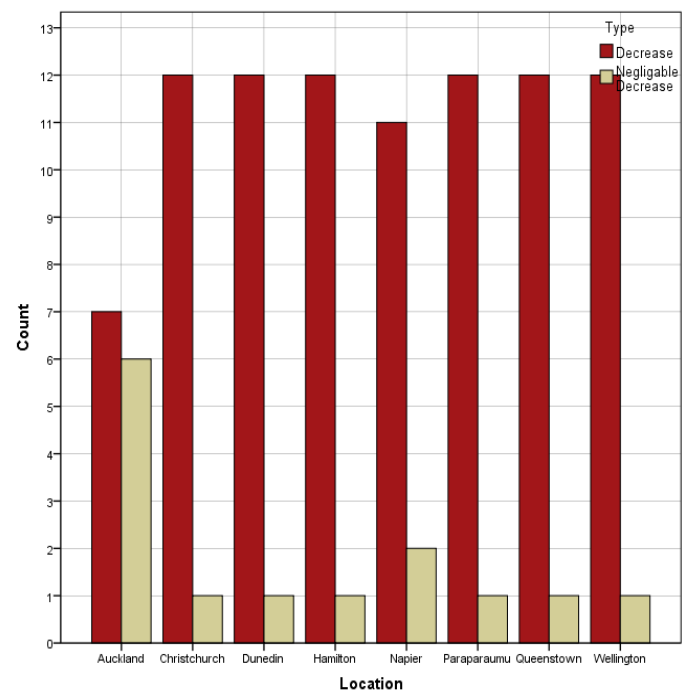

Figure 60 Number of buildings at case 4 effect types occur in each location

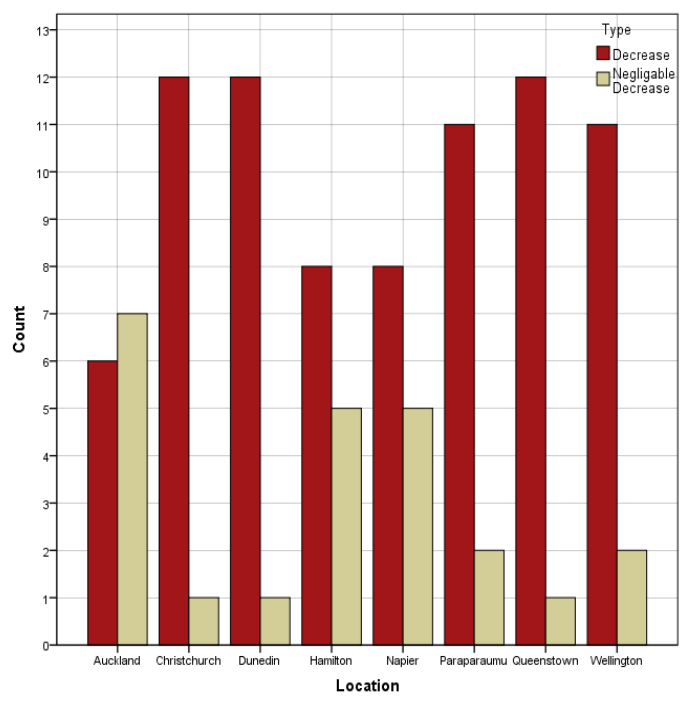

Figure 59 Number of buildings at case 3 effect types occur in each location

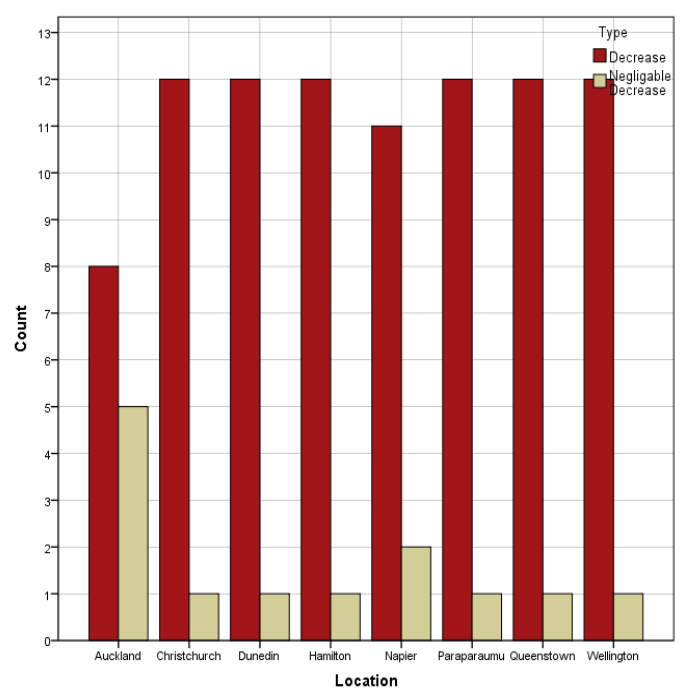

Figure 61 Number of buildings at case 5 effect types occur in each location 


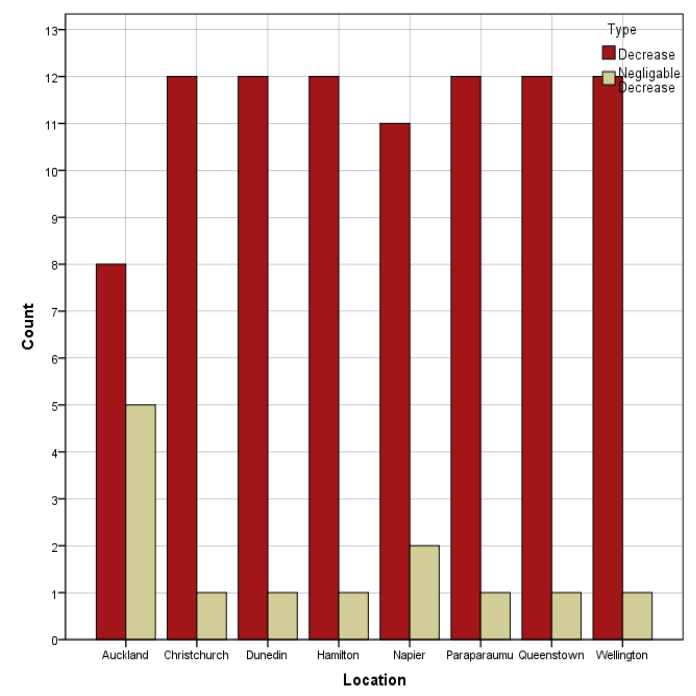

Figure 62 Number of buildings at case 6 effect types occur in each location

\subsubsection{All Buildings Effect on Cooling Energy Consumption: Location}

This section identifies the number of buildings at each insulation level and location that have either a Decrease, Negligible Decrease, Negligible Increase or Increase in cooling energy use. The purpose was to identify the locations and thermal insulation levels that result in the greatest number of increases in energy use. Therefore, the locations and the particular level at which buildings are the most susceptible to the adverse energy behaviour will be known.

As previously mentioned, the difference between smaller amounts of cooling energy (in $\mathrm{kWh} / \mathrm{m} 2 / \mathrm{yr}$ ) will result in a larger percentage increase or decrease. Therefore, it is due to the smaller cooling requirements in Dunedin and Queenstown in comparison to the warmer North Island locations, that a greater number of buildings in the south have an increase in cooling energy.

An increase (any type) in energy consumption is shown to occur in all locations and thermal insulation levels except Case 2 in Hamilton. It can be seen that for each location, as the thermal insulation level is increased, the number of buildings that have an Increase or Negligible Increase in energy use increases. As a result, the number of buildings with a Negligible Decrease or Decrease, 
reduces as the thermal insulation level is increased. When modelled in Auckland, the buildings had the greatest number of increases (any type) in cooling energy for all thermal insulation levels. Conversely, when located in Queenstown, the sample of buildings had the highest number of decreases in energy use at all levels.

For all locations at Case 2, the number of buildings that have a reduction in energy use significantly outweighs the number of buildings that have an increase. While at the highest Case, the number of buildings that have an increase is about the same as the number of buildings that have an increase. For example, 9 buildings have reduction in energy use and 4 have an increase at Case 2 in Auckland, while 6 have a reduction and 7 have an increase at Case 6. In Dunedin, the number of buildings that had a reduction in energy use at Case 2 was 10, while 3 had an increase at Case 6.

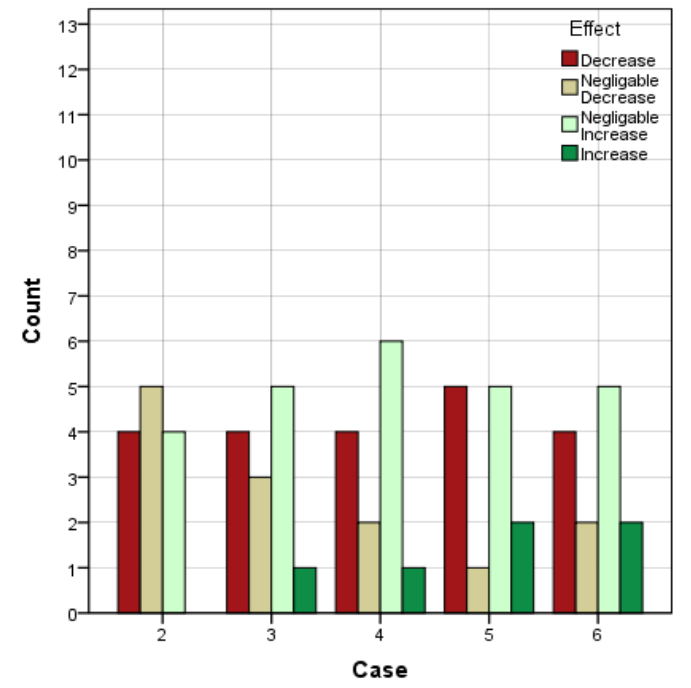

Figure 63 Auckland cooling energy percentage effect type

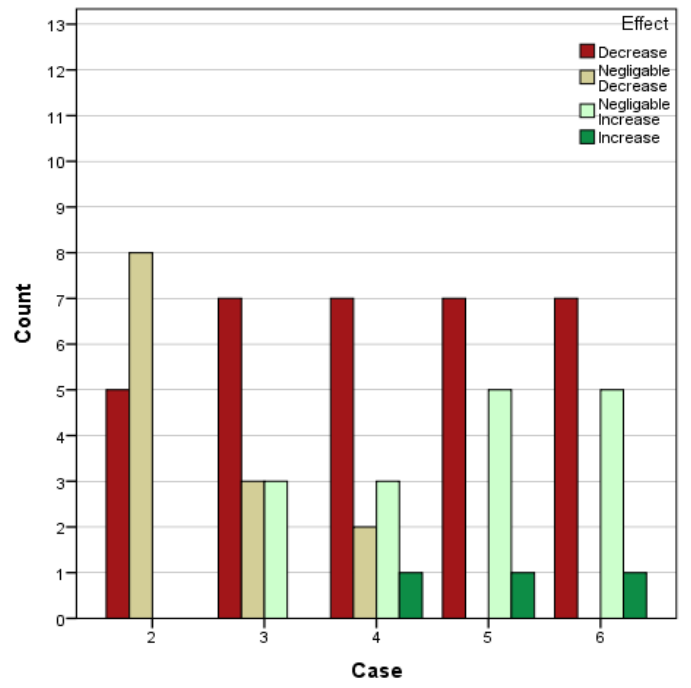

Figure 64 Hamilton cooling energy percentage effect type 


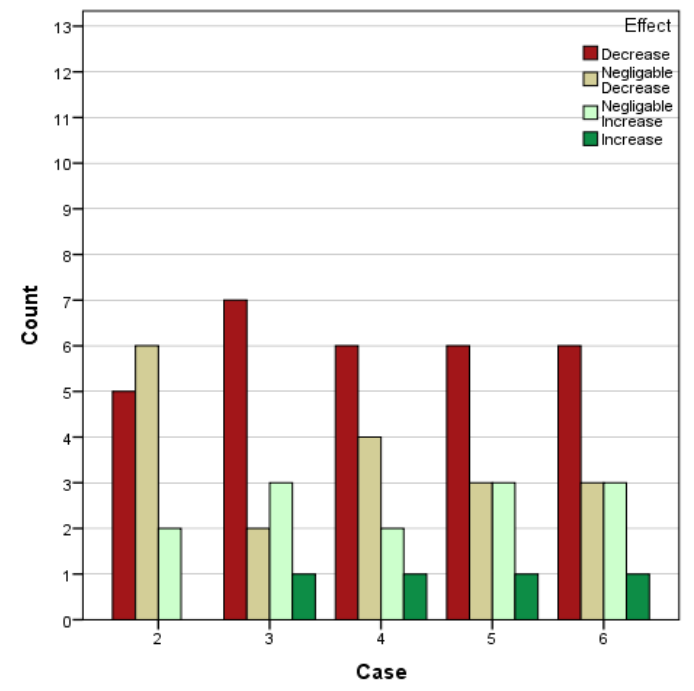

Figure 65 Napier cooling energy percentage effect type

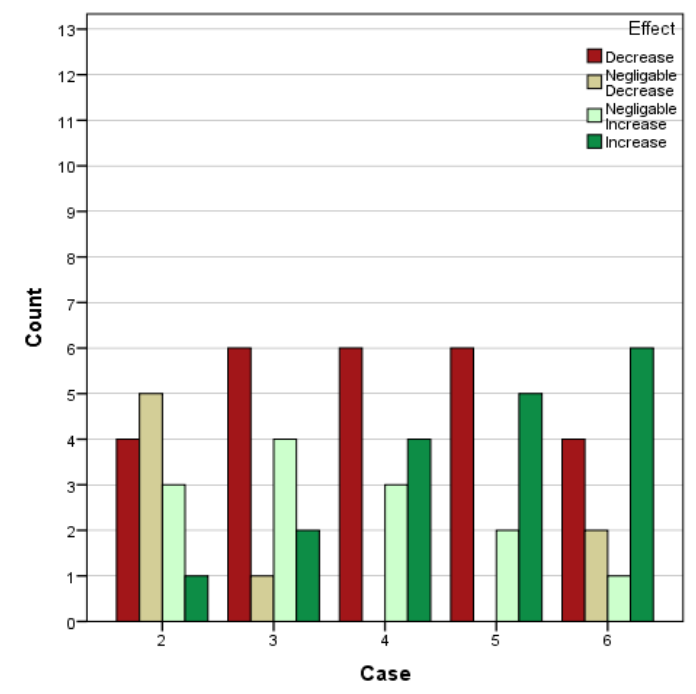

Figure 67 Wellington cooling energy percentage effect type

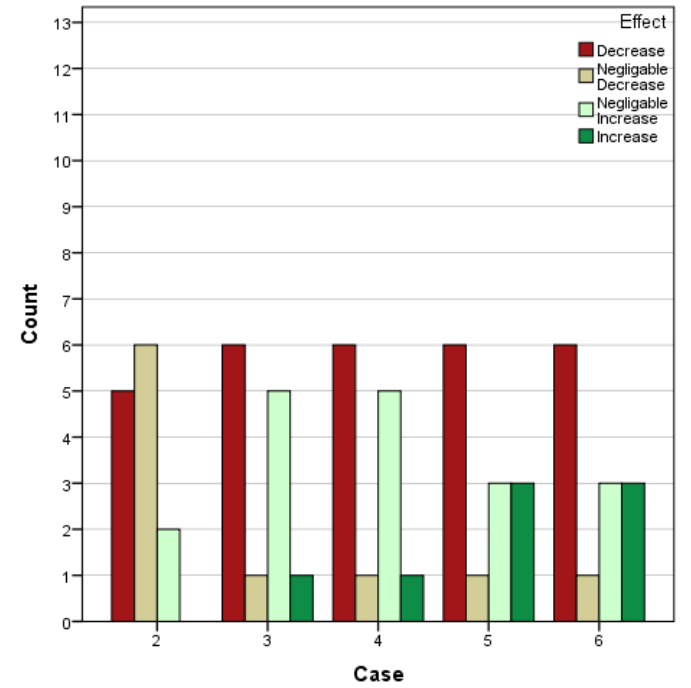

Figure 66 Paraparaumu cooling energy percentage effect type

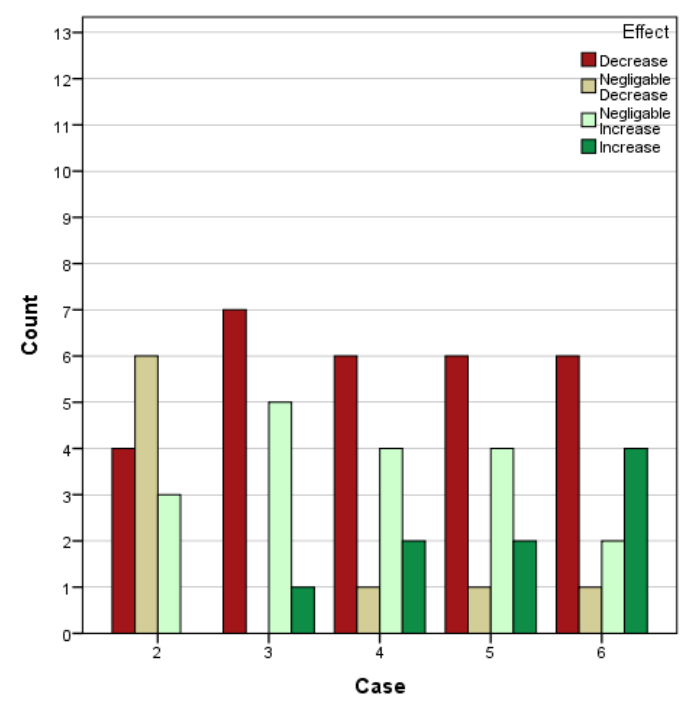

Figure 68 Christchurch cooling energy percentage effect type 


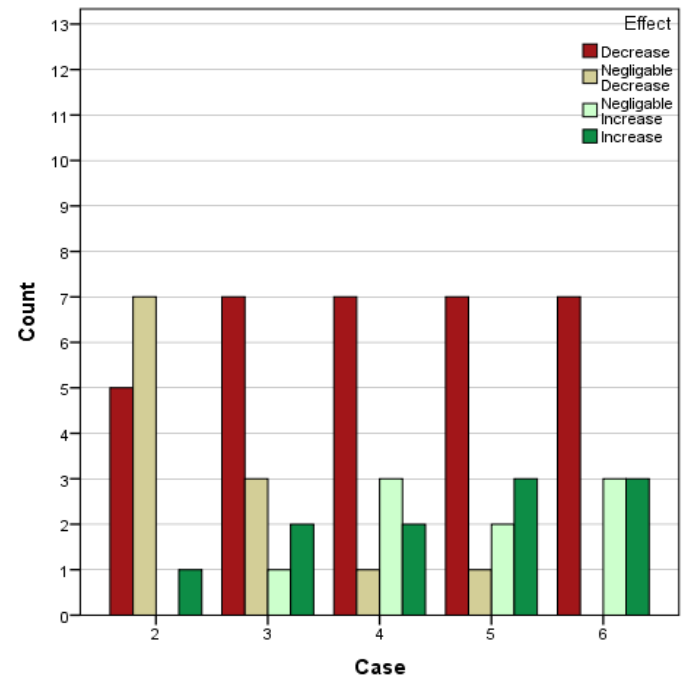

Figure 69 Queenstown cooling energy percentage effect type

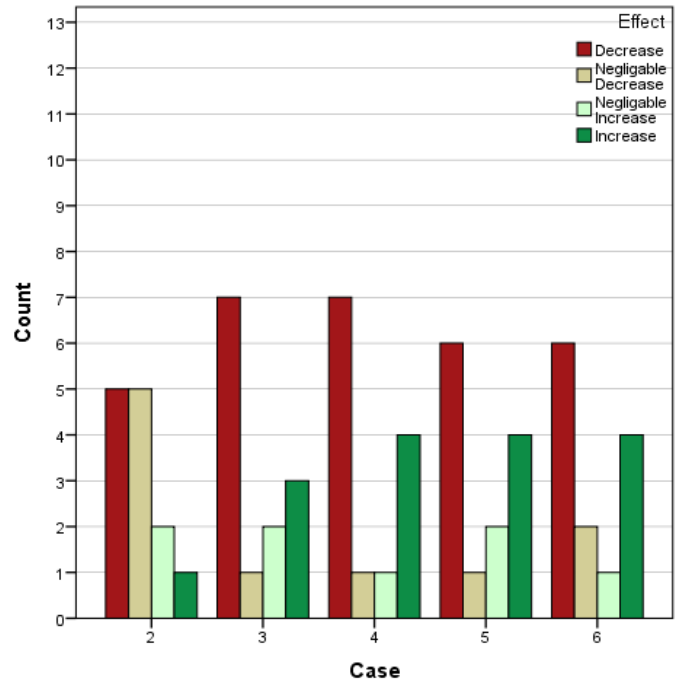

Figure 70 Dunedin cooling energy percentage effect type

\subsubsection{Comparison Attributes: Total Energy Consumption}

The buildings were grouped by their prevailing effect type on total energy consumption in each location, as shown in Table 17. The groupings were used to assess the differences in building characteristics across the groups. A comparison between groups was made for the buildings in Auckland and the performance of the buildings in other locations was discussed.

\begin{tabular}{|c|c|c|c|c|c|c|c|c|}
\hline & Auckland & Hamiltion & Napier & Paraparaumu & Wellington & Christchurch & Queenstown & Dunedin \\
\hline \multicolumn{9}{|l|}{ Negligable Increase } \\
\hline Negligable Decrease & $\begin{array}{l}\text { R0054 } \\
\text { R0738 } \\
\text { R0843 } \\
\text { R1017 } \\
\text { R1586 } \\
\text { R1663 }\end{array}$ & $\begin{array}{l}\text { R0056 } \\
\text { R1017 }\end{array}$ & \begin{tabular}{|l|}
$R 0056$ \\
$R 0843$ \\
$R 1017$ \\
$R 1586$
\end{tabular} & R1017 & R1017 & R1017 & R1017 & R1017 \\
\hline Decrease & $\begin{array}{l}\text { R0020 } \\
\text { R0198 } \\
\text { R0471 } \\
\text { R0811 } \\
\text { R0813 } \\
\text { R0831 } \\
\text { R0056 }\end{array}$ & $\begin{array}{l}\text { R0020 } \\
\text { R0198 } \\
\text { R0054 } \\
\text { R0471 } \\
\text { R0738 } \\
\text { R0811 } \\
\text { R0813 } \\
\text { R0831 } \\
\text { R0843 } \\
\text { R1586 } \\
\text { R1663 } \\
\text { R0056 }\end{array}$ & \begin{tabular}{|l|}
$R 0020$ \\
$R 0198$ \\
$R 0054$ \\
$R 0471$ \\
$R 0738$ \\
$R 0811$ \\
$R 0813$ \\
$R 0831$ \\
$R 1663$ \\
$R 0056$
\end{tabular} & $\begin{array}{l}\text { R0020 } \\
\text { R0054 } \\
\text { R0198 } \\
\text { R0738 } \\
\text { R0813 } \\
\text { R0831 } \\
\text { R0843 } \\
\text { R1586 } \\
\text { R1663 }\end{array}$ & $\begin{array}{l}\text { R0020 } \\
\text { R0054 } \\
\text { R0198 } \\
\text { R0738 } \\
\text { R0813 } \\
\text { R0831 } \\
\text { R0843 } \\
\text { R1586 } \\
\text { R1663 }\end{array}$ & $\begin{array}{l}\text { R0054 } \\
\text { R0198 } \\
\text { R0738 } \\
\text { R0843 } \\
\text { R1586 } \\
\text { R1663 }\end{array}$ & $\begin{array}{l}\text { R0198 } \\
\text { R0738 } \\
\text { R0843 } \\
\text { R1663 }\end{array}$ & $\begin{array}{l}\text { R0198 } \\
\text { R0738 } \\
\text { R0843 } \\
\text { R1663 }\end{array}$ \\
\hline Greatest Decrease & & & & $\begin{array}{l}\text { R0471 } \\
\text { R0811 } \\
\text { R0056 }\end{array}$ & $\begin{array}{l}\text { R0471 } \\
\text { R0811 } \\
\text { R0056 }\end{array}$ & $\begin{array}{l}\text { R0020 } \\
\text { R0471 } \\
\text { R0811 } \\
\text { R0813 } \\
\text { R0831 } \\
\text { R0056 }\end{array}$ & $\begin{array}{l}\text { R0020 } \\
\text { R0054 } \\
\text { R0471 } \\
\text { R0811 } \\
\text { R0813 } \\
\text { R0831 } \\
\text { R1586 } \\
\text { R0056 }\end{array}$ & $\begin{array}{l}\text { R0020 } \\
\text { R0054 } \\
\text { R0471 } \\
\text { R081 I } \\
\text { R0813 } \\
\text { R0831 } \\
\text { R1586 } \\
\text { R0056 }\end{array}$ \\
\hline
\end{tabular}

Table 17 Prevailing effect type of each building in each location - total energy consumption 


\section{Energy Use- Heating/Cooling Dominated}

The buildings located in Auckland fall into two categories- negligible decrease and decrease. At Case 2, all of the buildings within the negligible decrease category are either heating dominated or require similar amounts of heating and cooling. All of these buildings have an increase in cooling energy. Three of the buildings that fall within the decrease category have an increase in cooling energy at all or higher levels or thermal insulation. The buildings that fall within the Decrease category are both heating and cooling dominated.

While the building R1586 has a negligible decrease in energy consumption in northern locations, it falls within the greatest decrease in southern locations. This is expected to be due to the very large WWR of the building- it would experience greater window heat loss during winter. Building R1017 is the only building to fall within the negligible decrease category in every location. While the building has a comparatively similar reduction in $\mathrm{kWh}$ to a number of other buildings, it has the largest area of the sample of buildings by a significant amount $\left(19,843 \mathrm{~m}^{2}\right.$ compared to the second largest $12,891 \mathrm{~m}^{2}$ ). Therefore, the percentage difference is far smaller. All buildings but R1017 within the Negligible Increase category had an increase in cooling energy at certain levels of thermal insulation.

\section{Thermostat Set Point and Internal Load Level}

While the buildings are all simulated with a standardized heating and cooling set point, the amount of time that they will spend requiring heating or cooling energy will differ due to their surface to volume ratios, glazing and construction materials. This is similar to the heating and cooling set point- while the internal load level is consistent across the sample of buildings, the impact on the energy behaviour will vary for each building.

The warmer temperatures of Auckland, Hamilton and Napier would be expected to increase the buildings' ability to be internal load dominated and therefore no buildings fall within the Greatest Decrease Category. While the buildings spend a larger amount of time warmer inside than outside at the thermostat set points of 
$21^{\circ} \mathrm{C}$ and $24^{\circ} \mathrm{C}$ in the South Island locations- they require a greater amount of heating and therefore thermal insulation will be make greater savings.

\section{Surface to Volume Ratio and Glazing}

Generally buildings that fell within the Negligible Decrease category in Auckland were the buildings with low surface to volume ratios, higher glazing levels on the northern facades.

Buildings with the highest surface to volume ratios (R0020, R0831, R0471 and R0056) fell within the Greatest Decrease category in the South Island locations.

This would be expected as they are the most likely to be external load dominated. Thermal insulation would provide the largest reduction in energy use for these buildings.

\subsubsection{Cooling Energy Consumption: Comparison attributes}

Table 18 displays the prevailing cooling energy effect types that occur for each building in each location. Roughly half of the buildings in each location are split between the groups with an increase in cooling energy and a reduction in energy use.

\begin{tabular}{|c|c|c|c|c|c|c|c|c|}
\hline & Auckland & Hamiltion & Napier & Paraparaumu & Wellington & Christchurch & Queenstown & Dunedin \\
\hline Increase & R1586 & R1586 & R1586 & $\mathrm{R} 1586$ & $\begin{array}{l}\text { R1586 } \\
\text { R0054 } \\
\text { R0056 } \\
\text { R0054 }\end{array}$ & $\begin{array}{l}\text { R0056 } \\
\text { R1586 }\end{array}$ & $\mathrm{R} 1586$ & $\begin{array}{l}\text { R0054 } \\
\text { R0056 } \\
\text { R0471 } \\
\text { R1586 } \\
\text { R1663 }\end{array}$ \\
\hline Negligable Increase & $\begin{array}{l}\text { R0054 } \\
\text { R0056 } \\
\text { R0471 } \\
\text { R0738 } \\
\text { R0843 } \\
\text { R1663 }\end{array}$ & $\begin{array}{l}\text { R0054 } \\
\text { R0738 } \\
\text { R1663 }\end{array}$ & \begin{tabular}{|l} 
R0054 \\
R1663
\end{tabular} & $\begin{array}{l}\text { R0054 } \\
\text { R0056 } \\
\text { R0471 } \\
\text { R0738 } \\
\text { R1663 }\end{array}$ & $\begin{array}{l}\text { R0471 } \\
\text { R0738 } \\
\text { R0843 }\end{array}$ & $\begin{array}{l}\text { R0054 } \\
\text { R0471 } \\
\text { R0738 } \\
\text { R1663 }\end{array}$ & $\begin{array}{l}\text { R0054 } \\
\text { R0056 } \\
\text { R0471 } \\
\text { R1663 }\end{array}$ & \\
\hline Negligable Decrease & $\begin{array}{l}\text { R0198 } \\
\text { R0811 } \\
\text { R1017 }\end{array}$ & $\begin{array}{l}\text { R0056 } \\
\text { R0471 } \\
\text { R1017 }\end{array}$ & \begin{tabular}{|l} 
R0056 \\
R0471 \\
R0738 \\
R1017 \\
R0843
\end{tabular} & $\begin{array}{l}\text { R0843 } \\
\text { R1017 }\end{array}$ & R1017 & R1017 & $\begin{array}{l}\text { R1017 } \\
\text { R0738 }\end{array}$ & $\begin{array}{l}\text { R0738 } \\
\text { R1017 }\end{array}$ \\
\hline Decrease & $\begin{array}{l}\text { R0020 } \\
\text { R0813 } \\
\text { R0831 }\end{array}$ & $\begin{array}{l}\text { R0020 } \\
\text { R0198 } \\
\text { R0811 } \\
\text { R0813 } \\
\text { R0831 } \\
\text { R0843 }\end{array}$ & \begin{tabular}{|l} 
R0020 \\
R0198 \\
R0811 \\
R0813 \\
R0831
\end{tabular} & $\begin{array}{l}\text { R0020 } \\
\text { R0198 } \\
\text { R0811 } \\
\text { R0813 } \\
\text { R0831 }\end{array}$ & $\begin{array}{l}\text { R0020 } \\
\text { R0198 } \\
\text { R0811 } \\
\text { R0813 } \\
\text { R0831 }\end{array}$ & $\begin{array}{l}\text { R0020 } \\
\text { R0198 } \\
\text { R0811 } \\
\text { R0813 } \\
\text { R0831 } \\
\text { R0843 }\end{array}$ & $\begin{array}{l}\text { R0020 } \\
\text { R0198 } \\
\text { R0811 } \\
\text { R0813 } \\
\text { R0831 } \\
\text { R0843 }\end{array}$ & $\begin{array}{l}\text { R0020 } \\
\text { R0198 } \\
\text { R0811 } \\
\text { R0813 } \\
\text { R0831 } \\
\text { R0843 }\end{array}$ \\
\hline
\end{tabular}

Table 18 Prevailing effect type of each building in each location - cooling energy consumption 
A comparison of the building attributes was undertaken for the buildings in Auckland and reference to other locations was made.

\section{Energy Use- Heating/Cooling dominated}

The buildings within the groups Negligible Increase and Increase are not cooling dominated when uninsulated but at Case 2 building R 1586 has mixed heating and cooling requirements of 18.1 heating and 16.51 cooling. The buildings in the Negligible Decrease or Decrease groups were shown include both heating and cooling dominated buildings.

\section{Economiser Control}

When thermostat set points and internal load levels are standardised, the influence they have will vary between buildings. For example, a low surface to volume ratio will increase internal load domination, therefore increase the possibility of thermal insulation trapping heat within the building. Buildings with high glazing ratios on the northern facades and no or minimal shading will experience greater solar gain- also increasing the possibility of increased energy use. Buildings R0198, R081 1, R1017, R1586, R1663, R0738, R0054 all possess these characteristics, however all do not experience an increase in energy use at all or higher levels of thermal insulation. It appears that the use of economiser control in buildings R0198, R0811 and R1017 is the cause of these buildings' decrease in cooling energy consumption. Each of the buildings have the differential dry bulb economizer type with an upper limit temperature of $19^{\circ} \mathrm{C}$ and lower limit of $4^{\circ} \mathrm{C}$. The effect the economiser control had on the cooling energy of the buildings was tested for the building R0198 simulated in Wellington. When uninsulated, the building required $123.17 \mathrm{kWh} / \mathrm{m}^{2} / \mathrm{yr}$ modelled with the economiser control and $126.18 \mathrm{kWh} / \mathrm{m}^{2} / \mathrm{yr}$ when not modelled with the economiser function. Energy for cooling was reduced from 330,295 kWh/yr to 273,505 (17.2\% reduction).

The graphs below (Figure 71 and Figure 72) demonstrate the effect the economiser control has on the effectiveness of thermal insulation. The use of economiser control can prevent an increase in cooling energy from occurring. Building R1017 was modelled with and without economiser control in Wellington. The graph Figure 71 displays the heating and cooling energy required in $\mathrm{kWh}$ for 
each case. The building modelled with no economiser required more heating and cooling energy. An increase in energy use occurs for the building with no economiser while a reduction occurs for every case with the economiser modelled. However, the impact is very minimal- between Case 1 and 6 a reduction of $1.58 \%$ and $3565 \mathrm{kWh}$ occurs with economiser control applied, and without an increase of $0.35 \%$ and $947 \mathrm{kWh}$. While a greater reduction in $\mathrm{kWh}$ (51365kWh no economiser and 36356kWh with economiser) occurs for the building without economiser control between Case 1 and Case 6, the building with economiser control achieves a larger percentage reduction in energy use (24\% economiser and $17 \%$ no economiser).

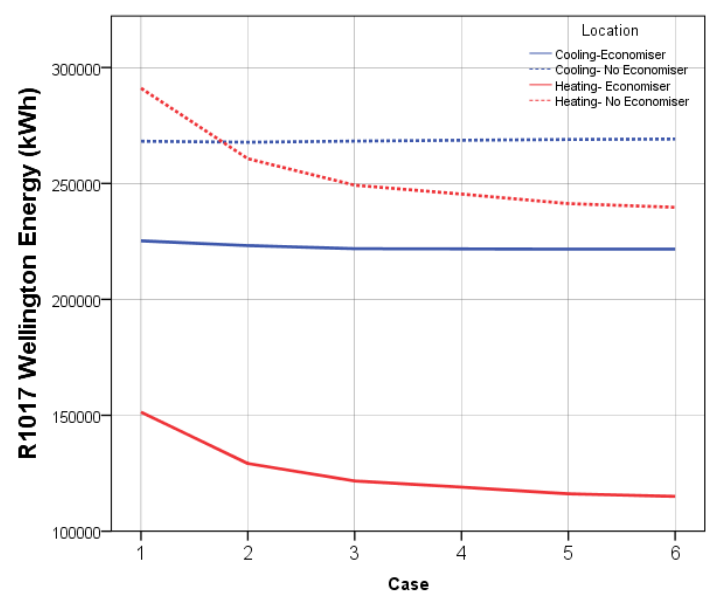

Figure 71 R1017 Wellington heating and cooling energy ( $\mathrm{kWh}$ ) at each case

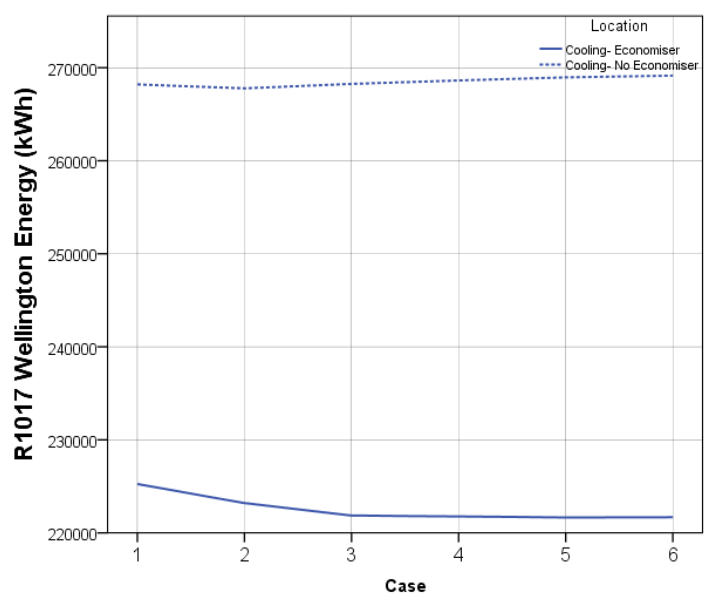

Figure 72 R1017 Cooling energy ( $\mathrm{kWh}$ ) at each case

Buildings R0020, R0813 and R0831 in Auckland do not experience an increase in cooling energy use as they have very high surface to volume ratios, small floor areas and adjacent buildings at the same height very close to the northern façade. Each of these buildings are $25 \%$ glazed or less, therefore they have a large amount of area for wall thermal insulation to be placed.

\section{Thermostat Set point}

At the set points $21^{\circ} \mathrm{C}$ and $24^{\circ} \mathrm{C}$, it would be expected that the buildings would spend a larger amount of time warmer inside than outside in the southern locations than in the northern. The average maximum January temperature is $17^{\circ} \mathrm{C}$ in Dunedin and $24^{\circ} \mathrm{C}$ in Auckland. However, the buildings also have a larger chance of being external load dominated in the cooler locations and therefore 
would require a larger amount of heating than cooling (adverse effect only occurs when building requires cooling. When the building is requiring heating, thermal insulation would be beneficial to keep the heat within the building).

\subsubsection{Summary of Findings Standardised buildings}

An increase (over 0\%) in cooling energy was observed to occur in roughly half of the buildings in each location when modelled with standardised operations. However, the decreases in heating were always great enough to outweigh the increase in cooling energy. Therefore, none of the buildings when modelled with the NZS4243 regulated and assumed values had an increase in total energy consumption for any scenario.

While no increase in total energy occurred, many buildings at Case 2 and 3 had only a Negligible Decrease in total energy use in all locations. The Case 2 level which is the minimum required level of thermal resistance for buildings located in Zone 1, was observed to negligibly decrease total energy consumption in 10 of the 13 buildings. A higher level of thermal insulation was observed to decrease the number of buildings that had a negligible decrease in energy use. However, at the highest Case, 5 of the buildings had a negligible decrease in energy use.

The characteristics of the buildings that an increase in cooling energy occurred can be summarised as buildings with low surface to volume ratios, high glazing area on the northern façade and minimal or no shading. However, buildings that are characterised by these attributes and utilise economiser control were observed to not have increase in cooling energy use. Exploration of the use of economiser control revealed that without economiser control applied, an increase in cooling energy could occur.

\subsection{Exploration of Building Attributes}

\subsubsection{Cooling Set Point: Effect on cooling energy}

This section explores the influence of the cooling set point temperature on the effectiveness of thermal insulation. This was tested on the sample of buildings in three locations (Auckland, Wellington and Dunedin) as the thermal insulation 
level is increased (6 Cases explored). As mentioned previously, an increase in cooling energy and the amount of the increase is dependent on how long a building spends warmer inside and cooler outside. Therefore, the cooling set point can determine whether a building will have an increase in cooling energy and to what extent. In the previous standardized section, it was observed that an increase in cooling energy occurred in all explored locations. However, it only occurred in certain buildings and not necessarily in all locations for each building.

The following graphs (Figure 73-Figure 85) display the cooling energy ( $\mathrm{kWh} / \mathrm{m}^{2} / \mathrm{yr}$.) for each building and each cooling set point at each thermal insulation Case. The graphs demonstrate that the cooling thermostat set point limits the energy savings from increasing thermal insulation. A higher cooling set point leads to a reduced requirement for cooling energy for all buildings in each location. A lower cooling set point is shown to cause or exacerbate an increase in cooling energy or reduce the decrease in cooling energy as the thermal insulation level is increased. While the greatest reduction in cooling energy, or the least amount of increased cooling energy, generally occurs for all buildings at the highest set point. The relationship between required cooling energy and set point in each location is different for each building. Generally, the cooling energy at the lowest set point is two to three times greater than at the highest set point for any location.

The lowest set point for each building located in Auckland always requires the highest amount of cooling energy. This would be expected given the higher temperatures of Auckland. A reduction in cooling energy use occurs at all set points and Cases for only two buildings (R0198 and R0811).

Many of the buildings had an increase in energy use when any level of insulation was added or after Case 2. For buildings R0020, R0813, R0843, R0831, R00471, and $\mathrm{R} 1663$, a lower thermal insulation level at any set point is shown to reduce the cooling energy required, while any set point at a higher thermal insulation level causes an increase. 
Buildings R0054, R0056, and R1586 have an increase in energy use at all insulation levels, locations and set points. The increase in energy use is always larger for the lower set points in each location. Conversely, a higher set point is shown to cause an increase in energy use for building R1017 in Wellington and Dunedin. This is expected to be due to the buildings use of economiser control. Although the increase in EUI appears negligible, the total increase in $\mathrm{kWh}$ is very large due to the buildings floor area of $19,000 \mathrm{~m}^{2}$.

The cooling energy behaviours among the sample at different set points as the thermal insulation level is increased include:

- Decrease in cooling energy for all insulation levels and set points but greater decrease at higher levels of thermal insulation

- Increase in energy use at higher levels of insulation and all set points

- Increase in energy use at all levels of thermal insulation and all set points

- Increase in energy use at all levels of thermal insulation at certain set points

- Negligible impact (increase or decrease)

To demonstrate the influence of the cooling set point on the effectiveness of thermal insulation on the cooling energy performance, the difference between the Case 1 and 6 energy use ( $\mathrm{kwh} / \mathrm{m}^{2} / \mathrm{yr}$ ) was analysed for two buildings (Figure 74 and Figure 82). Each of the buildings selected had a different behaviour in energy use. For building R081 1 (always decrease), between Case 1 and 6, the greatest reduction in energy use occurred for the buildings at the highest set point in each location. Note that the buildings required the least amount of energy at the highest set points. Between Case 1 and 6, the lowest set point $\left(22^{\circ} \mathrm{C}\right)$ resulted in a reduction of $1.33 \mathrm{kWh} / \mathrm{m}^{2}$, while a reduction of $2.28 \mathrm{kWh} / \mathrm{m}^{2}$ and $4.00 \mathrm{kWh} / \mathrm{m}^{2}$ occurred for the set points of $24^{\circ} \mathrm{C}$ and $26^{\circ} \mathrm{C}$. For Wellington the difference between Case 1 and 6 was $-0.83 \mathrm{kWh} / \mathrm{m}^{2},-3.59 \mathrm{kWh} / \mathrm{m}^{2}$ and -3.27 $\mathrm{kWh} / \mathrm{m}^{2}$ for the set points of $22^{\circ} \mathrm{C}, 24^{\circ} \mathrm{C}$ and $26^{\circ} \mathrm{C}$ respectively. For Dunedin, the difference between Case 1 and 6 was $-2.05 \mathrm{kWh} / \mathrm{m}^{2},-2.91 \mathrm{kWh} / \mathrm{m}^{2},-3.60 \mathrm{kWh} / \mathrm{m}^{2}$.

Conversely, for a building that had an increase in energy use at each insulation level and set point, the lowest set point in each location resulted in the highest 
increase in energy use between Case 1 and 6. For building R0056 which has an increase in energy use at each insulation level and set point- the difference in energy consumption between Cases 1 and 6 in Auckland is $-1.40 \mathrm{kWh} / \mathrm{m}^{2}, 1.20$ $\mathrm{kWh} / \mathrm{m}^{2}$, and $0.87 \mathrm{kWh} / \mathrm{m}^{2}$ for the set points $22^{\circ} \mathrm{C}, 24^{\circ} \mathrm{C}$ and $26^{\circ} \mathrm{C}$ respectively. For Wellington the difference is $1.27 \mathrm{kWh} / \mathrm{m}^{2}, 1.08 \mathrm{kWh} / \mathrm{m}^{2}$ and $0.56 \mathrm{kWh} / \mathrm{m}^{2}$ and Dunedin- $0.92 \mathrm{kWh} / \mathrm{m}^{2}, 0.47 \mathrm{kWh} / \mathrm{m}^{2}, 0.11 \mathrm{kWh} / \mathrm{m}^{2}$.

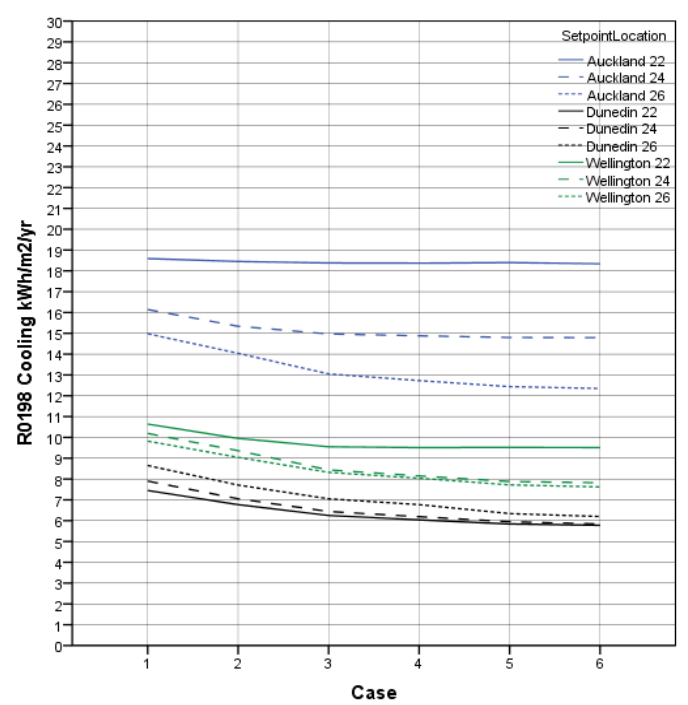

Figure 73 R0198 cooling energy

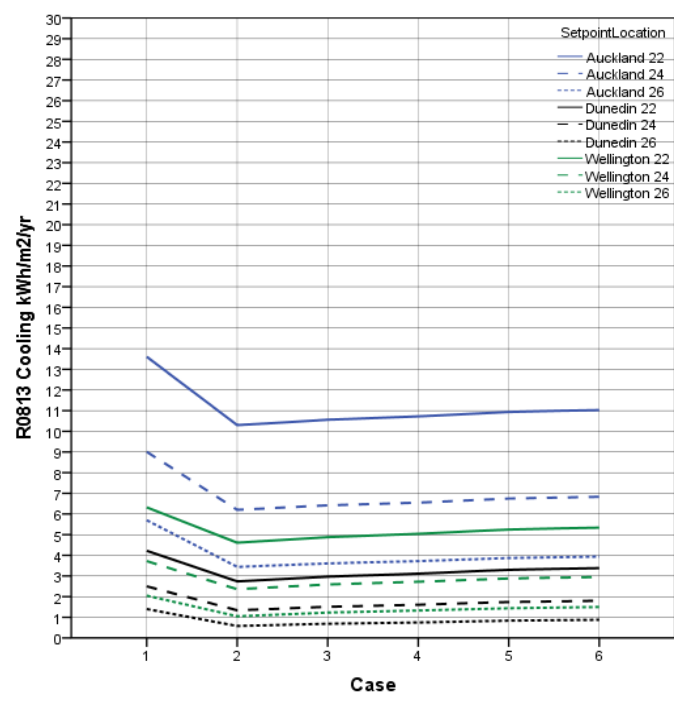

Figure 75 R0813 cooling energy

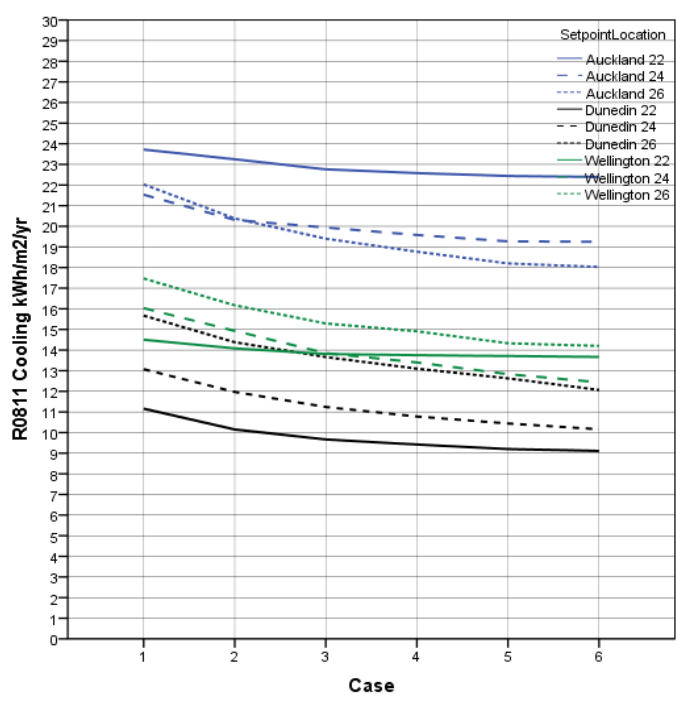

Figure 74 R08 11 cooling energy

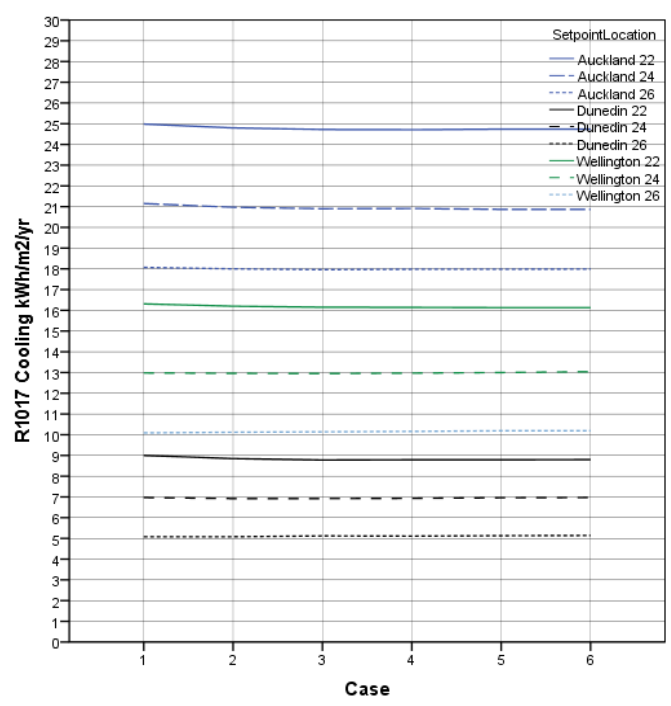

Figure 76 R 1017 cooling energy 


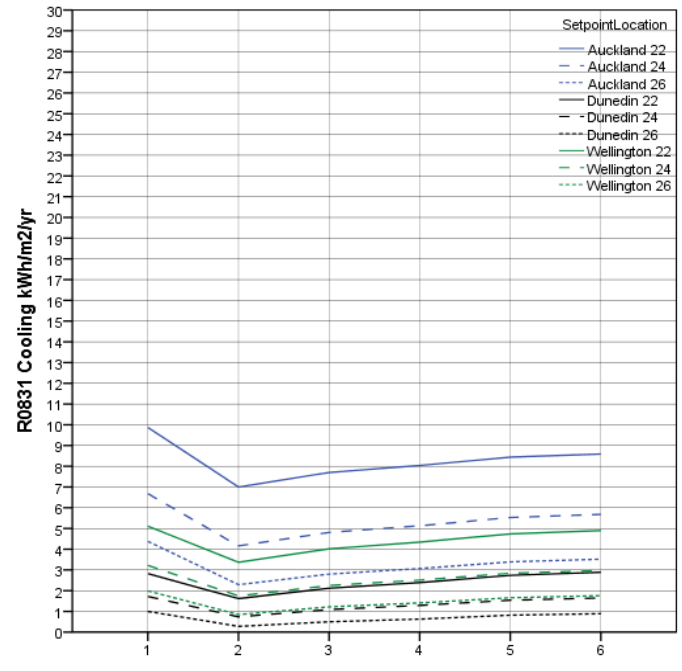

Case

Figure 77 R083 1 cooling energy

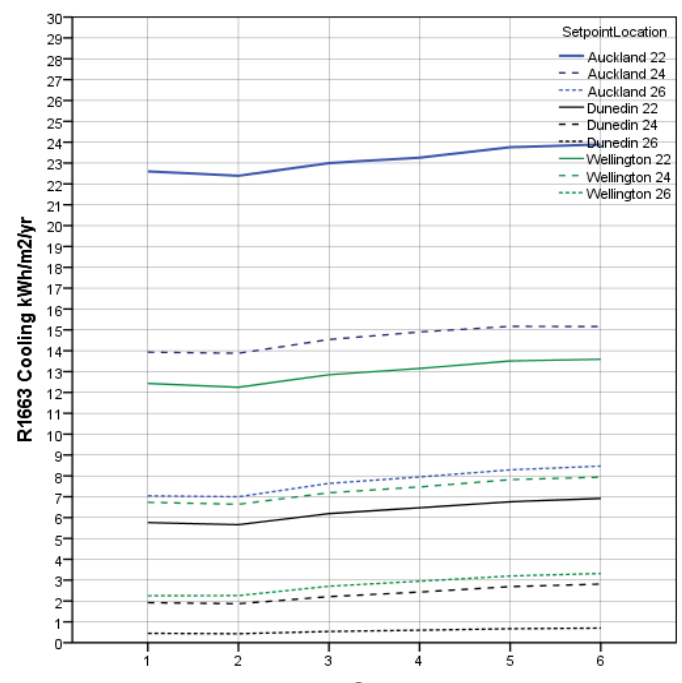

Figure 79 R 1663 cooling energy

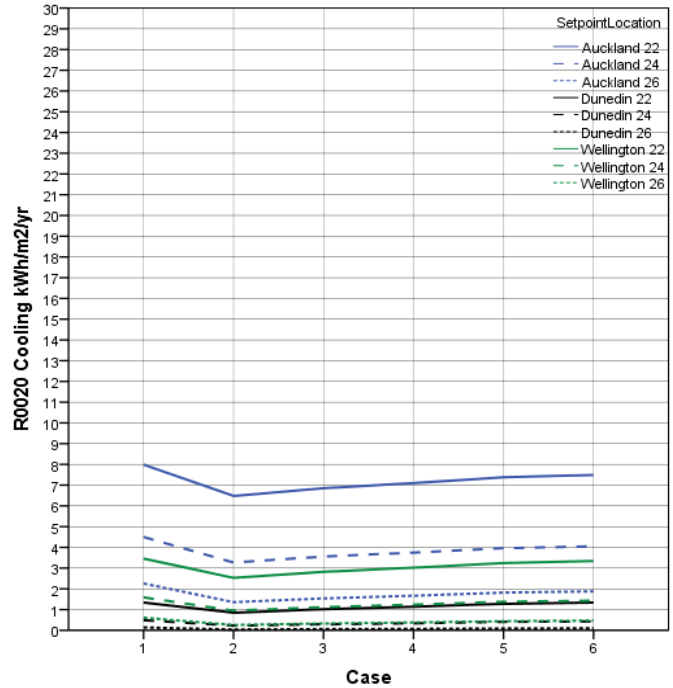

Figure 78 R0020 cooling energy

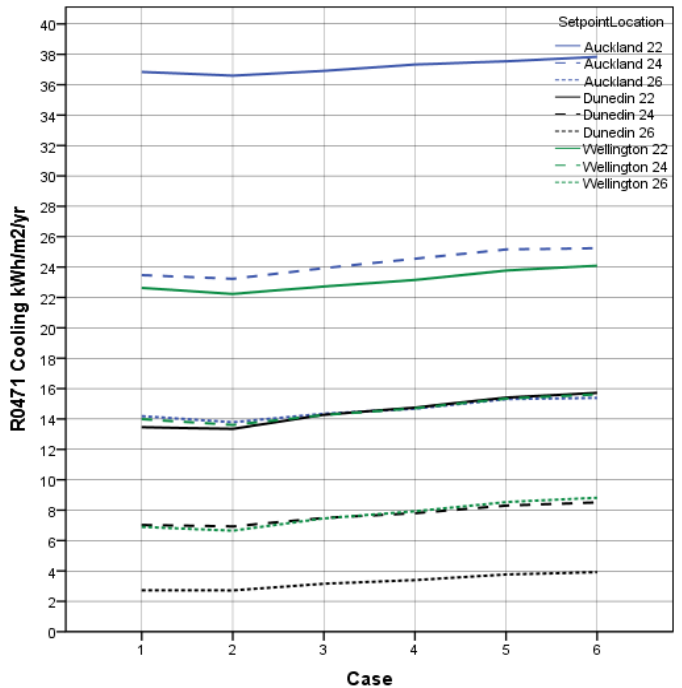

Figure 80 R047 1 cooling energy 


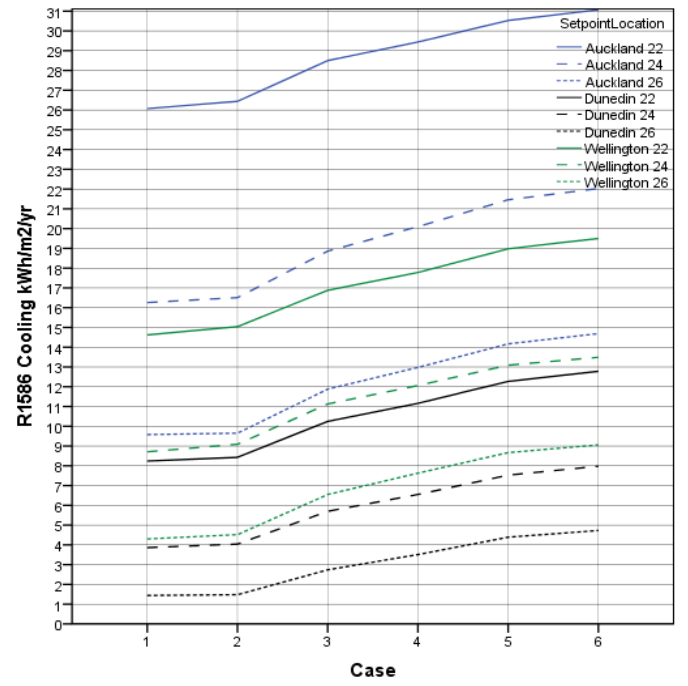

Figure 81 R1586 cooling energy

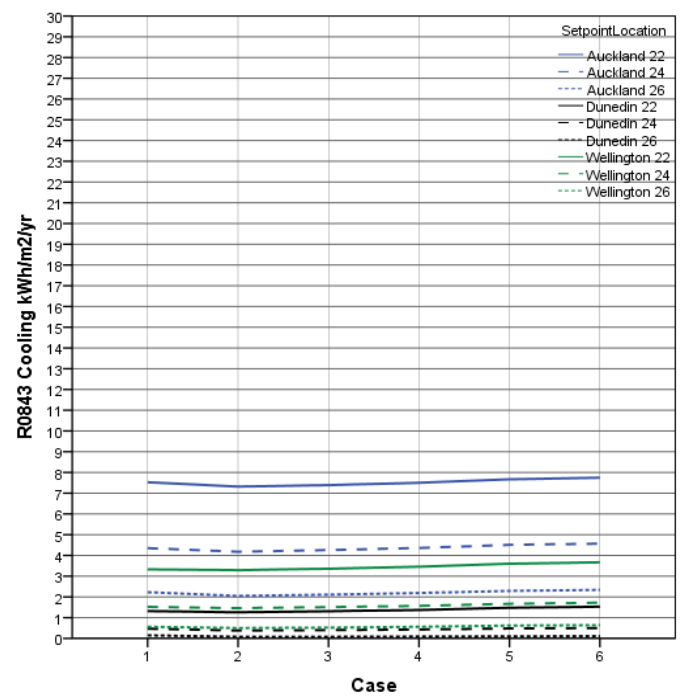

Figure 83 R0843 cooling energy

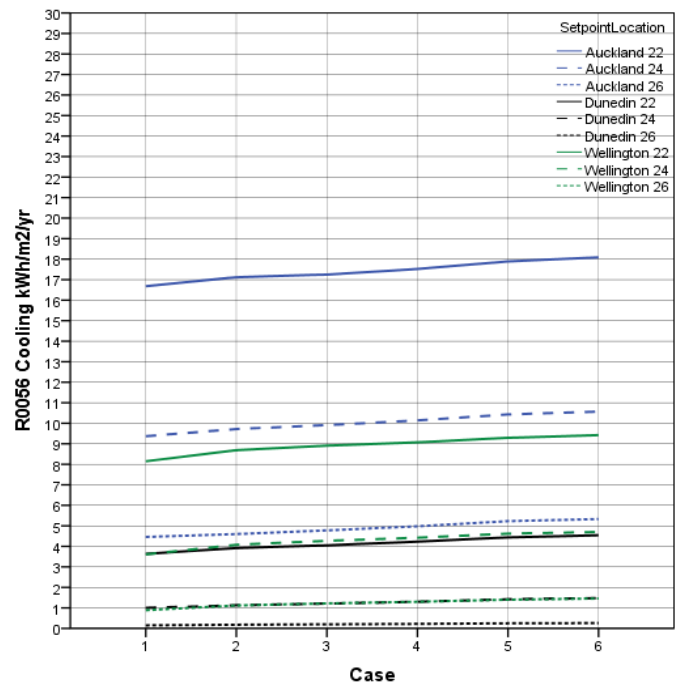

Figure 82 R0056 cooling energy

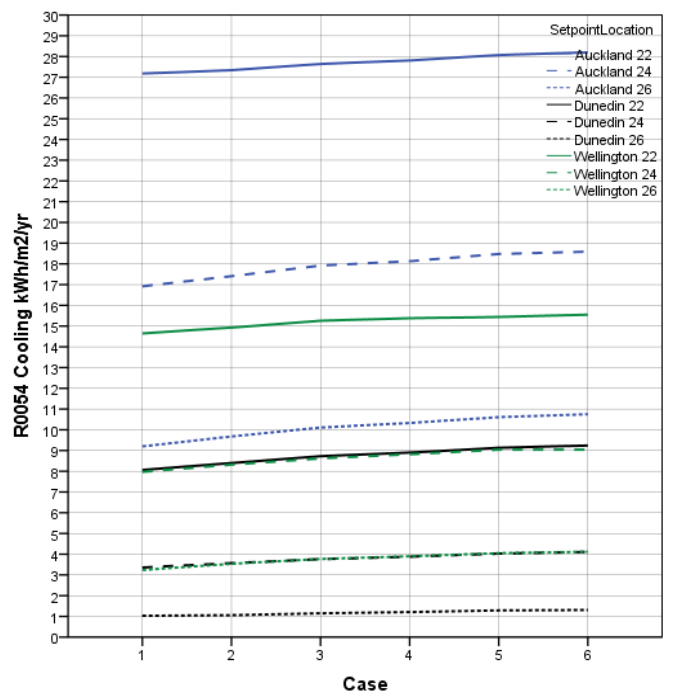

Figure 84 R0054 cooling energy 


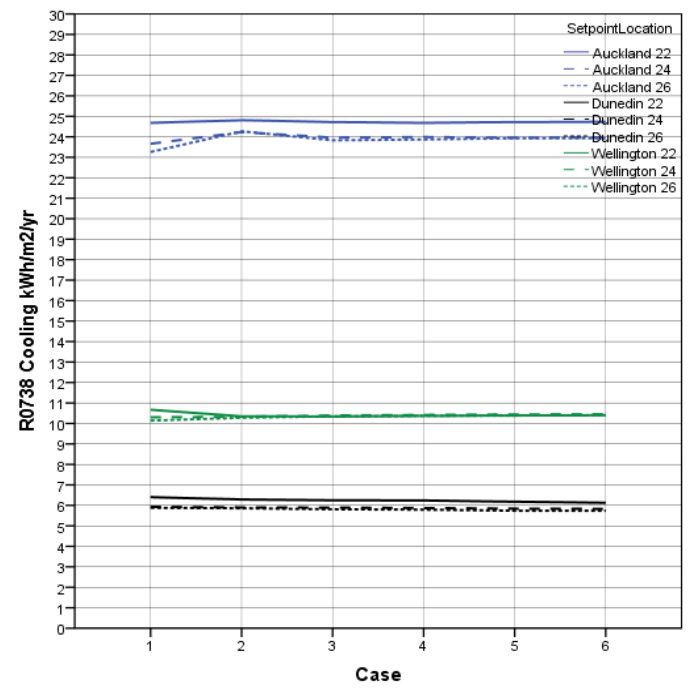

Figure 85 R0738 cooling energy

\subsubsection{Cooling Set Point: effect on heating and cooling energy}

While the adverse energy behaviour only occurs to the cooling energy of a building- it is equally as important to consider the effect different cooling set points have on the heating energy use of a building. The following graphs display the buildings heating and cooling energy combined at each of the set points, locations and thermal insulation levels.

While the lowest cooling set point for each building was shown to require the highest amount of cooling energy and causes or exacerbates an increase in energy use- this is not true for the heating and cooling energy of all the buildings. Building R0054, R0843, R0056, R1586, R0471 and R1663 had an increase in energy use at all thermal insulation levels and locations. However, it can be seen that except for building R1586, the heating and cooling energy use of these buildings is always decreased.

For buildings that did not have an increase in cooling energy for all or most set points, a higher cooling set point generally resulted in higher energy use. This can be seen in the graphs below (Figure 86-Figure 98)While a lower set point results in the highest amount of energy use for buildings that have an increase in cooling energy- as would be expected given that cooling energy is the highest and the counterintuitive effect is exacerbated at the lowest set point. 
The influence of the cooling set point temperature on the energy performance of the buildings R0811 and R0056 was discussed in the previous section. The difference in cooling energy between Case 1 and 6 at each set point in each location was discussed for each building. It was found that a higher cooling set point (requires least amount of energy use) resulted in the greatest reduction in energy use for building R0811, while a lower set point resulted in the highest increase in energy use for the building R0056. When considering the effect on both the heating and cooling energy combined, the highest cooling set point resulted in the greatest decrease in energy consumption for both building R0811 and R0056. However, unlike for the cooling energy for building R081 1, the highest cooling set point resulted in the highest amount of heating and cooling energy required for building R0811. The lowest cooling set point resulted in the highest amount of energy required for building R0056 in each location.

The difference (decrease) in energy use between Case 1 and 6 for building R0811 in Auckland was $5.57 \mathrm{kWh} / \mathrm{m}^{2}, 6.51 \mathrm{kWh} / \mathrm{m}^{2}$ and $7.79 \mathrm{kWh} / \mathrm{m}^{2}$, for the set points $22^{\circ} \mathrm{C}, 24^{\circ} \mathrm{C}$ and $26^{\circ} \mathrm{C}$ respectively. In Wellington, the difference in energy use was $11.66 \mathrm{kWh} / \mathrm{m}^{2}, 13.20 \mathrm{kWh} / \mathrm{m}^{2}$ and $12.52 \mathrm{kWh} / \mathrm{m}^{2}$ and for Dunedin the difference in energy use was $17.20 \mathrm{kWh} / \mathrm{m}^{2}, 17.24 \mathrm{kWh} / \mathrm{m}^{2}$ and $17.93 \mathrm{kWh} / \mathrm{m}^{2}$. For building R0056 the difference in energy use between Case 1 and 6 in Auckland was $6.11 \mathrm{kWh} / \mathrm{m}^{2}, 6.39 \mathrm{kWh} / \mathrm{m}^{2}$ and $6.73 \mathrm{kWh} / \mathrm{m}^{2}$, for the set points $22^{\circ} \mathrm{C}, 24^{\circ} \mathrm{C}$ and $26^{\circ} \mathrm{C}$ respectively. In Wellington, the difference in energy use was $13.40 \mathrm{kWh} / \mathrm{m}^{2}$, $13.63 \mathrm{kWh} / \mathrm{m}^{2}$ and $14.06 \mathrm{kWh} / \mathrm{m}^{2}$ and for Dunedin the difference in energy use was $20.48 \mathrm{kWh} / \mathrm{m}^{2}, 20.95 \mathrm{kWh} / \mathrm{m}^{2}$ and $21.04 \mathrm{kWh} / \mathrm{m}^{2}$. 


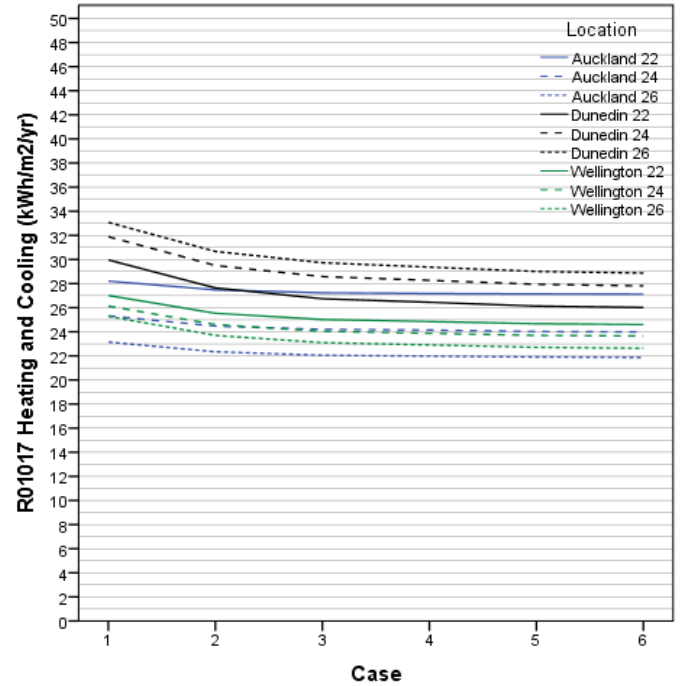

Figure 86 R 1017 heating and cooling energy

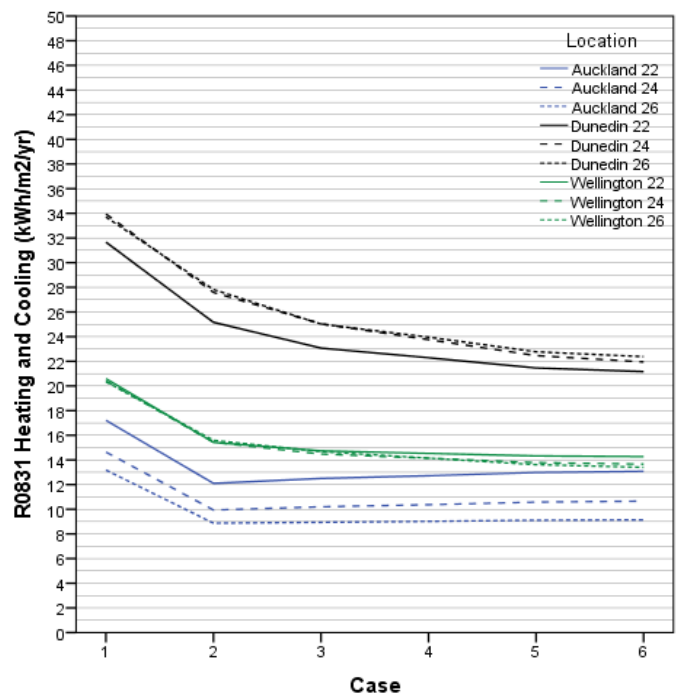

Figure 88 R0831 heating and cooling energy

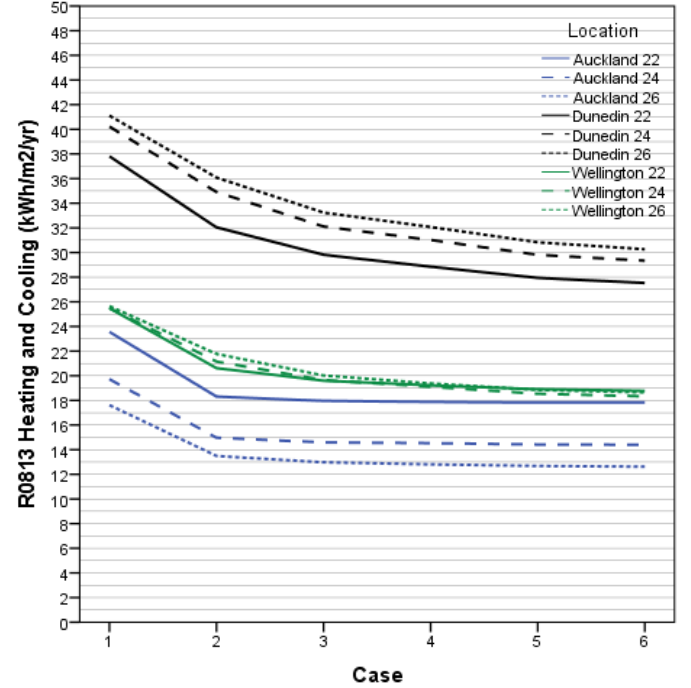

Figure 87 R0813 heating and cooling energy

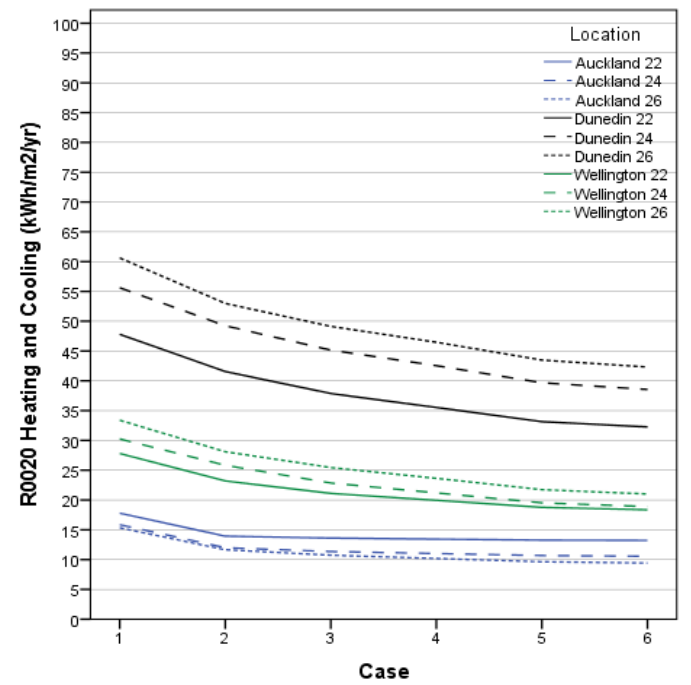

Figure 89 R0020 heating and cooling energy 


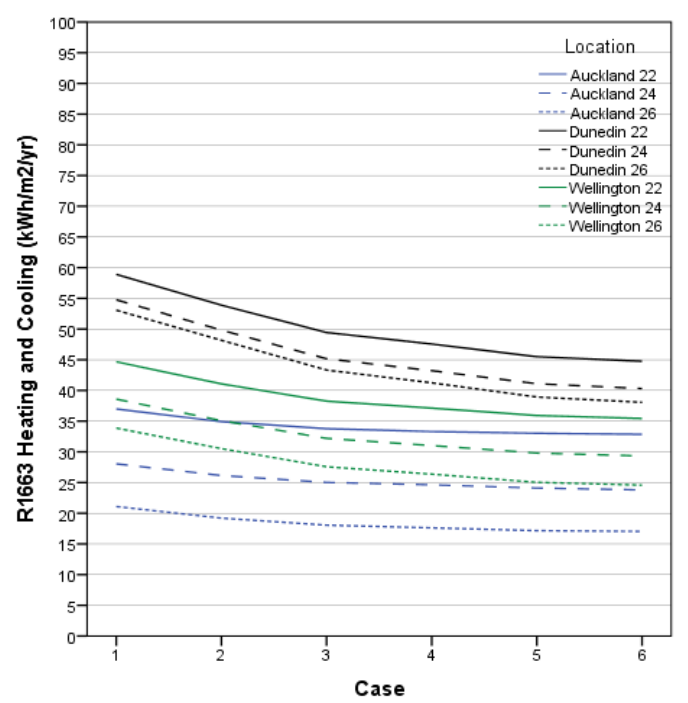

Figure 90 Building R 1663 heating and cooling energy

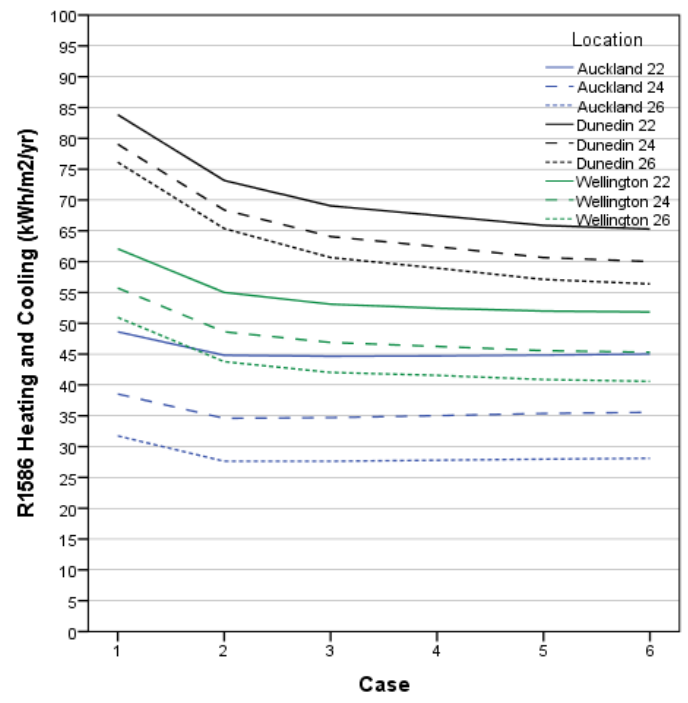

Figure 92 R 1586 heating and cooling energy

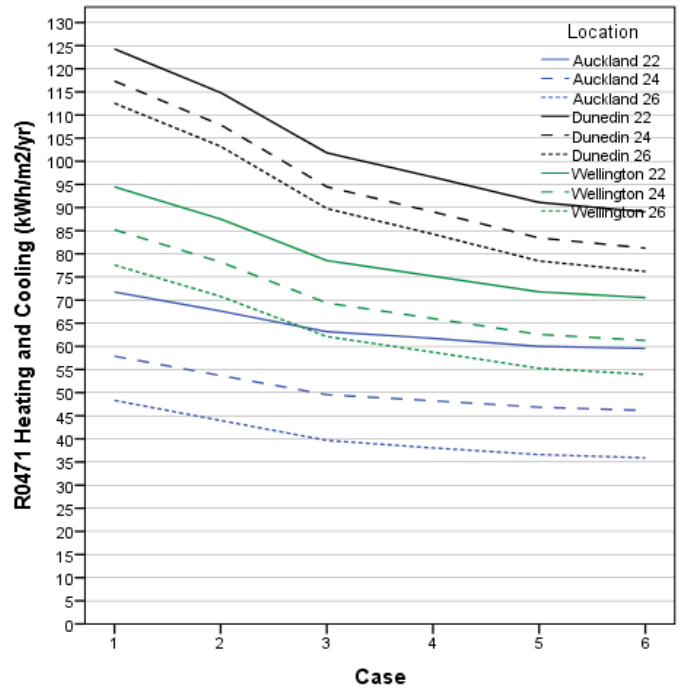

Figure 91 R047 I heating and cooling energy

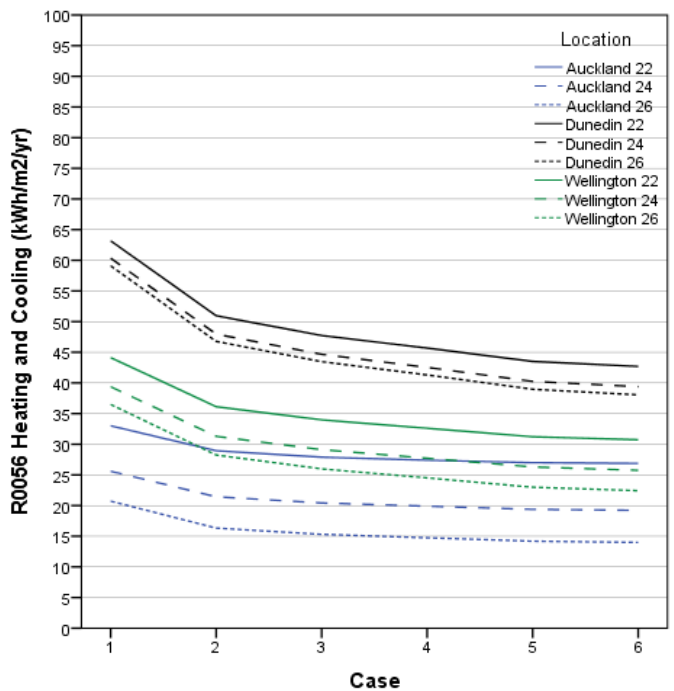

Figure 93 R0056 heating and cooling energy 


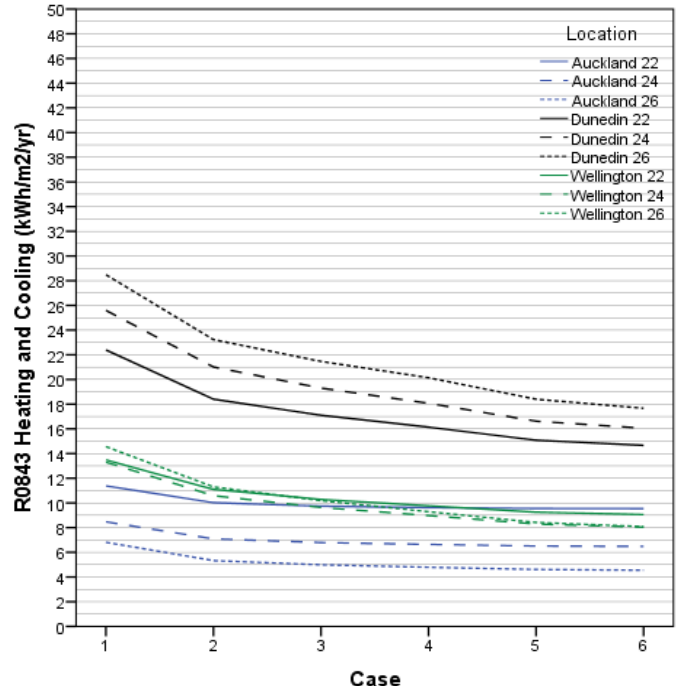

Figure 94 R0843 heating and cooling energy

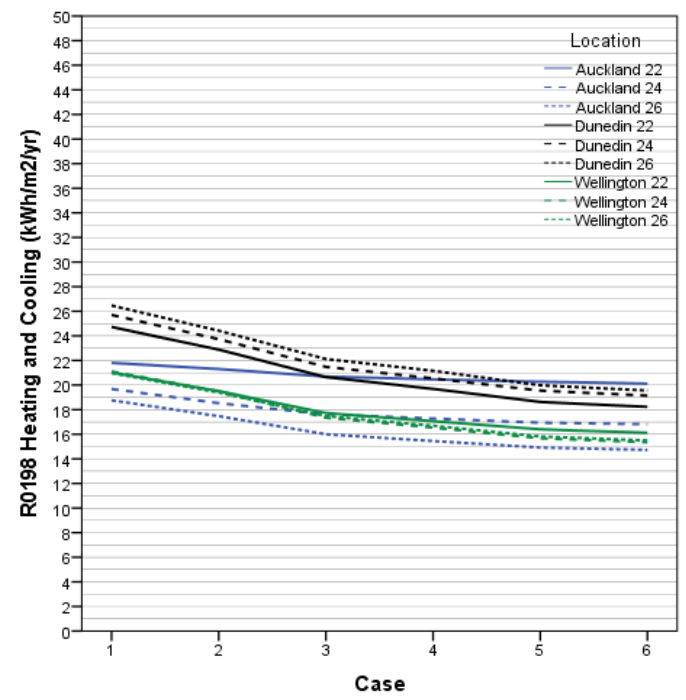

Figure 96 R0198 heating and cooling energy

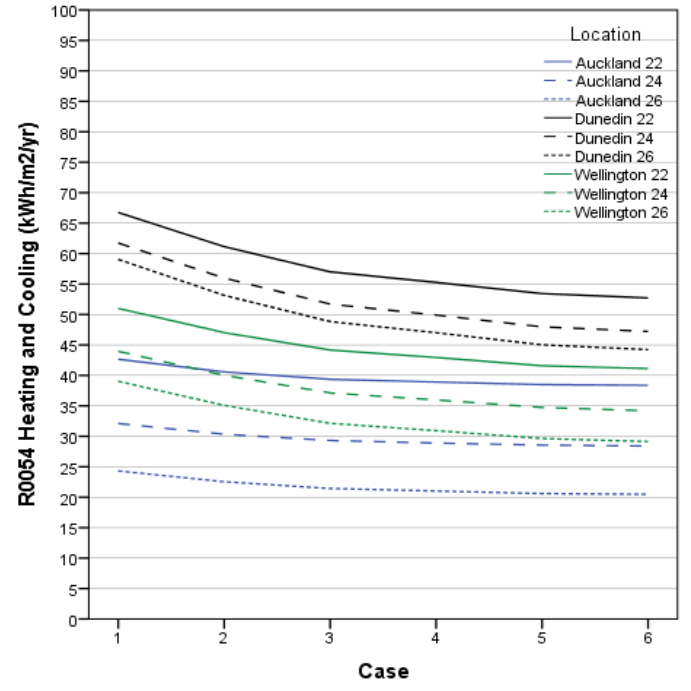

Figure 95 R0054 heating and cooling energy

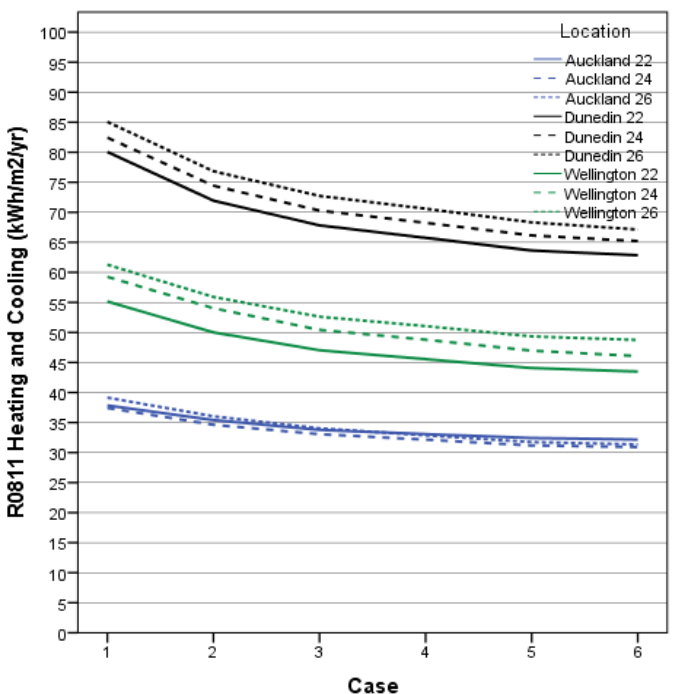

Figure 97 R0811 heating and cooling energy 


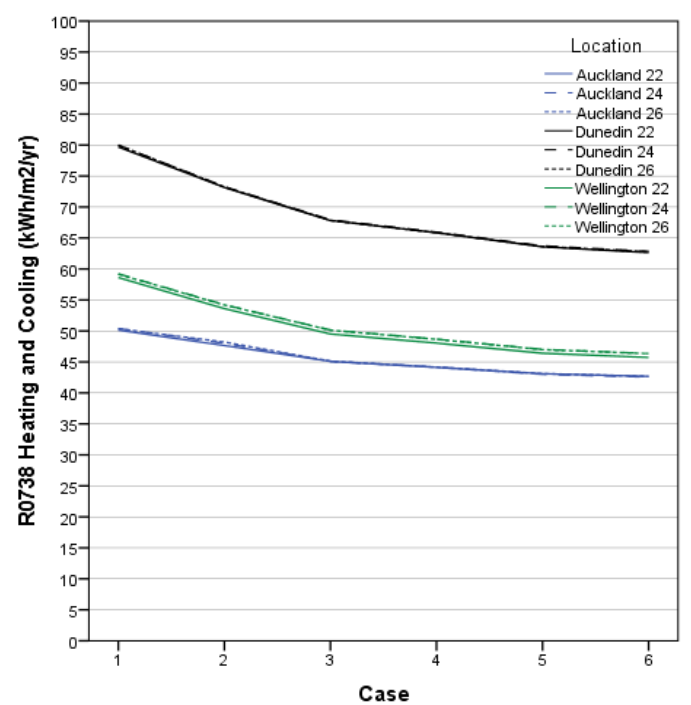

Figure 98 R0738 heating and cooling energy 


\section{Discussion and Conclusions}

\subsection{Thermal insulation in New Zealand Office Buildings}

This research explored the effects of thermal insulation levels on the energy performance of commercial office buildings in New Zealand. The research was motivated by the known condition that the addition of thermal insulation in certain buildings under certain climates could cause the space conditioning (heating and cooling) energy consumption to increase.

It is known that the adverse effect is predominantly caused by the imbalance between the envelope thermal transmission and the contribution of internal loads (when the internal loads are dominant during HVAC operation). However, no detailed investigation had been undertaken to identify the specific climates or the key drivers that can contribute to the adverse effect occurring in New Zealand office buildings.

Chapter 1 introduced the thesis topic, aim of the research and the research questions. The questions the research sought to establish included - Can insulation have a negative impact on total energy consumption in New Zealand office buildings? Secondly- what are the characteristics of New Zealand office buildings that may lead to insulation resulting in increased energy use? While the adverse energy behaviour has been established to occur in temperate climates, the locations within New Zealand where an increase in total energy consumption could occur remained ambiguous.

NZS4243.1:2007 (superseded NZS4243:1996, however the thermal resistance requirements were unchanged) currently specifies the performance requirements for large buildings to achieve an adequate level of energy efficiency in respect of their building envelope. Due to changes in the use of buildings since 1997, it was expected that the resulting energy performance of thermal insulation would be different. 
Chapter 2 provided a detailed literature review. It identified the drivers for thermal insulation causing increased energy use in office buildings and how the drivers may apply to New Zealand office buildings. A number of factors were identified to contribute to the probability of increased energy use occurring due to the addition of thermal insulation to office buildings. These include climate, constructive and operational factors. Constructive factors include high internal load levels, fixed heating and cooling temperature set points and large envelope to volume ratios. Buildings located in climates with mild winters and hot or dry warm summers (Mediterranean and Temperate climates) were identified to be at the highest risk of the adverse effect occurring.

Chapter 3 provided details of the design of the study. A parametric investigation using building energy simulation was selected as the method to assess how thermal insulation levels effect the energy performance of New Zealand office buildings. Details of the programs and processes used to undertake the parametric method of analysis were discussed. To ensure the energy results obtained in the thesis were reliable and valid, a number of measures were undertaken. This included using a sample of 13 real New Zealand office building calibrated energy models. The energy modelling was carried out in three separate groups. For each set, the buildings were modelled with varying fixed parameters- either with the models as built parameters or the NZ4243:2007 recommended, assumed and required values. When modelled with the as built and NZSZ4243 values, the buildings were modelled with the same insulation levels (6 Cases) and number of locations (8). The last set of modelling assessed how the cooling thermostat set point temperature affects the sample of buildings energy performance as the thermal insulation level was increased. To evaluate the impact each thermal insulation level had on the energy performance of the buildings, the percentage difference relative to the building uninsulated was used as an indicator. For each set of modelling, the buildings were grouped into categories that reflected their overall energy performance as the thermal insulation level increased. The attributes of the buildings between categories were then assessed to identify any trends that were present. 
Chapter 4 assessed the results of the simulations. The interrelation between the design of New Zealand office buildings and energy behaviour as the thermal insulation level was increased and locations changed was discussed.

Chapter 5 discusses the findings and conclusions.

\subsection{Discussion and Conclusions}

The hypothesis tested in this thesis was that the addition of thermal insulation will increase energy use in New Zealand office buildings. The following sections discuss the findings of the study in relation to the two research questions.

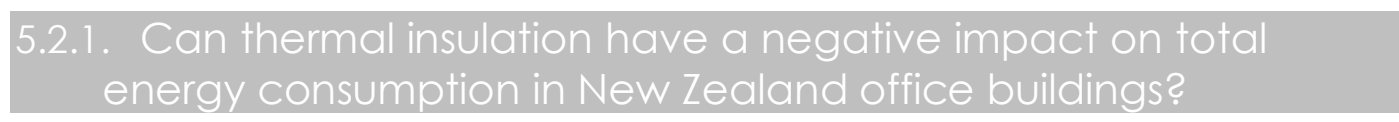

It was established that New Zealand's temperate climate provides an environment for office buildings to have a high risk of being susceptible to the adverse effect. It has previously been established that wall insulation in buildings located in Auckland and northward may lead to a significant increase in cooling energy that results in increased total energy use. While an increase in cooling energy was thought to occur in locations south of Auckland, the reduction in heating energy was expected to significantly outweigh any increase.

The results produced in this research found that an increase in total energy consumption occurred for two buildings across all sets of modelling. The increase occurred for both buildings when modelled with their as-built parameters only. For one of these buildings an increase in total energy consumption occurred in all north island locations- at all levels in Auckland and at higher levels than Cases 2 and 3 for the remaining locations. The greatest increase in energy use relative to the building uninsulated was $3 \%$. This occurred for the building when modelled in Auckland at the highest insulation Case. The other building had an increase in total energy consumption only in Auckland, for all added insulation levels except the minimum. At the highest Case, this resulted in a $0.5 \%$ increase in total energy use. 
No increase in total energy consumption occurred for any of the buildings in any location or at any thermal insulation level when modelled with the current regulated and assumed NZS4243.2 lighting and NZS4243.1 internal load values. Likewise, with the buildings when modelled with varying cooling thermostat set point temperatures.

This finding suggests that for office buildings that are susceptible to the adverse effect, added thermal insulation even at high levels is unlikely to have a great enough impact that the total energy use of a building is increased. However, an increase in cooling energy relative to the buildings uninsulated was found to occur in many of the buildings. The energy savings these buildings could achieve were often significantly impacted by the requirement for increased cooling. Across all thermal insulation levels and locations, 9 of the buildings had an increase in cooling energy when modelled as built. 8 buildings had an increase in cooling energy use for any thermal insulation level or location when modelled with the standardised NZS4243 values. The following section summarises the findings of the two sets of modelling by location and discuss the effect on energy performance of different levels of thermal insulation.

The current NZS4243.1 building envelope minimum thermal resistance requirements are provided for three climates zones. Separate requirements are set for buildings located in Zone 1 (Auckland and northward) while buildings in Zone 2 and 3 (south of Auckland) have the same levels. The background work for this standard suggested that higher levels of thermal insulation are beneficial for buildings located in the cool temperate oceanic climates of southern New Zealand locations (e.g. Dunedin and Invercargill). For buildings located in Auckland or northward (temperate climate), it was suggested that any reduction in energy use the presence of any level of wall thermal insulation caused, would be counteracted by increased cooling energy.

The two sets of modelling undertaken in this research produced different results. An increase in cooling energy was observed to occur in all locations across both sets of modelling. The impact of the increase in cooling energy was more noticeable for the northern locations. This was evident as the number of buildings 
that had a negligible decrease in energy use was greater the more northern the location was.

In comparison to the buildings uninsulated, the Zone 1 thermal insulation requirements for both sets of modelling were observed to negligibly decrease (reduction of up to 5\%) the total energy consumption of the majority of buildings when located in Auckland (Z1). An increase in total energy occurred for only one building when modelled as-built. When modelled standardised, it was found that the addition of wall insulation at a higher level decreased the number of buildings that had a negligible decrease in energy use. However, even at the highest case, 5 buildings energy consumption was still decreased up to $5 \%$. For the buildings that had negligibly decreased energy use, they either had a significant increase in cooling energy, or no or very small change in heating energy requirements.

To make a recommendation for change to the NZBC Clause $\mathrm{Hl}$ for office buildings would require a cost analysis to determine the economic benefit. However, given the very small energy benefits, the current level is unlikely to be adequate. Wall insulation (current requirements require no wall insulation in Zone 1) and at higher levels appears to provide better energy savings for the majority of buildings. As a higher level of insulation is not sufficient for all buildings, further investigation is required to determine what the most suitable minimum requirements would be.

The same minimum thermal resistance (Case 4) requirements apply to buildings located in both Zone 2 and Zone 3. Hamilton, Napier, Paraparaumu and Wellington are all located within Zone 2, while Christchurch, Queenstown and Dunedin are located in Zone 3. For Zone 2, the minimum required level of thermal insulation resulted in a reduction of total energy consumption of over $5 \%$ for most buildings. When modelled with the standardised loads, a reduction of over $5 \%$ occurred in 12 of the 13 buildings in Hamilton, Paraparaumu and Wellington, and 11 buildings in Napier. When modelled as built, 8 and 7 buildings achieved a decrease of over $5 \%$ in total energy use in Hamilton and Napier respectively. Nine buildings achieved a decrease over $5 \%$ in both Paraparaumu and 
Wellington. When modelled standardised and as-built, a lower level of thermal insulation decreased the number of buildings that achieved a reduction in energy use over $5 \%$. The number of buildings that had a decrease over $5 \%$ in energy use remained the same at higher levels of thermal insulation in all locations when modelled standardised. Any level of thermal insulation appeared to not provide significant energy savings for a number of buildings at any level when modelled as-built. The number of buildings that did not have a significant decrease in energy use was greatest for Hamilton and Napier. This suggests that separate requirements may be suitable for buildings located in these regions.

Further investigation is required to determine what level of thermal insulation would be most suitable. It appears that the most suitable level of thermal insulation would be dependent on the specific attributes of a building, therefore requiring one level for all types of buildings may not be suitable.

For Zone 3 locations (Christchurch, Queenstown and Dunedin), the minimum required level of thermal insulation reduces the energy consumption over $5 \%$ for the majority of buildings. When modelled as built in Christchurch, Queenstown and Dunedin- 10 to 11 of the sample buildings achieve a reduction of over $5 \%$. When modelled standardised, 12 buildings in each location have a reduction in energy use over $5 \%$. A higher level of thermal insulation increases the number of buildings that have a reduction in energy use over $5 \%$ for one or two buildings when modelled as built. The number is unchanged for the buildings when modelled standardised. These findings suggest that the current levels of thermal insulation are sufficient in most cases and a higher level of thermal insulation would achieve better energy efficiency for buildings located in southern locations.

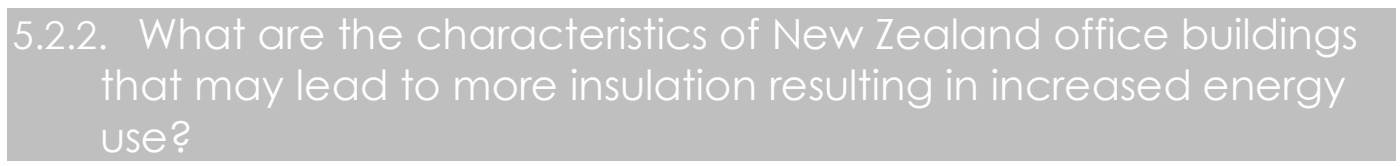

To comply with NZS4243.1:2007 using the Schedule Method of compliance, buildings must have a floor area of over $300 \mathrm{~m}^{2}$ and a window to wall ratio of 0.5 or less. Chapter 2 identified the established drivers for thermal insulation resulting 
in increased energy use. The drivers were both construction and operational characteristics of buildings. Operational factors included high internal load levels, cooling thermostat set points above the outdoor temperature for a large period of time and not utilising free-cooling. Construction factors included low surface to volume ratios, large areas of low thermal performance windows and heavyweight construction. These parameters all increase the importance of internal heat gains.

For both sets of modelling, buildings with the highest surface to volume ratios or those that utilised economiser control generally did not have an increase in cooling energy use. The exceptions were for a few buildings with high levels of thermal insulation in Auckland and Napier. The cooling energy was found to never increase (relative to the building uninsulated) for the smaller commercial office buildings of less than $1,000 \mathrm{~m}^{2}$ (two buildings) under any scenario. Buildings characterised with these attributes make up just under half of the sample of buildings (6). Among the 6 buildings, some buildings were characterised by attributes that would suggest they would be the most susceptible to the adverse effect. However, the use of economiser control appears to have stopped any increase in energy use. These attributes included large low surface to volume ratios, low performance windows with high window to wall ratios and higher internal loads.

Some buildings were observed to have an increase in cooling energy at either higher levels of thermal insulation or all levels in certain locations. A total of nine and eight buildings had an increase in cooling energy for any number of locations or thermal insulation levels when modelled as-built and with the regulated and assumed NZS4243 values respectively. For both sets of modelling it was observed that an increase in cooling energy could occur in both heating and cooling dominated buildings- at lower and higher levels of thermal insulation. Buildings that had the very highest internal load levels among the sample (when modelled as-built) had an increase in cooling energy use at all or the higher thermal insulation levels. 
When modelled as built, buildings that had high internal load levels had an increase in cooling energy use. Buildings that did not have high internal load levels were found to have an increase in energy use. This was thought to be largely due to the building's cooling set point temperatures, which resulted in the building spending a large amount of time warmer inside than outside.

Buildings that had the highest surface to volume ratios did not have an increase in cooling energy with increasing thermal insulation. Aside from the very highest ratios, the surface to volume ratio did not appear to have a large influence on whether a building had an increase in energy use when the buildings were modelled as-built. However, when the internal load levels of the buildings were standardised, a clear trend existed between the groups. Buildings with low surface to volume ratios had increased energy use, unless they utilised economiser control as previously mentioned.

All the modelled buildings were single glazed. Whether they had an increase or decrease in cooling energy was found to not be limited to buildings with certain window to wall ratios. When modelled both as-built and standardised, a number of buildings with a WWR less than 0.5 were susceptible to the adverse effect. Although the heating energy use decreased, the increase in cooling energy use was large enough to cause the total energy consumption to be only negligibly decreased (under $5 \%$ reduction). Buildings with greater window to wall ratios than 0.5 did not have an increase in energy use in all locations.

The exploration of the impact of thermal insulation on sensitivity to thermostat cooling set point temperatures demonstrated that, in most buildings, the operation of the building has a far greater effect on energy demand than thermal insulation. Changing to a lower cooling thermostat set point was demonstrated to always require the largest amount of cooling for each building. For buildings that were susceptible to the adverse effect, the increase was exacerbated at lower cooling set points. Therefore, it is recommended that the re-evaluation of NZS4243 considers including operational parameter of buildings under the energy efficiency requirements. 
The results and analysis undertaken support the following recommendations.

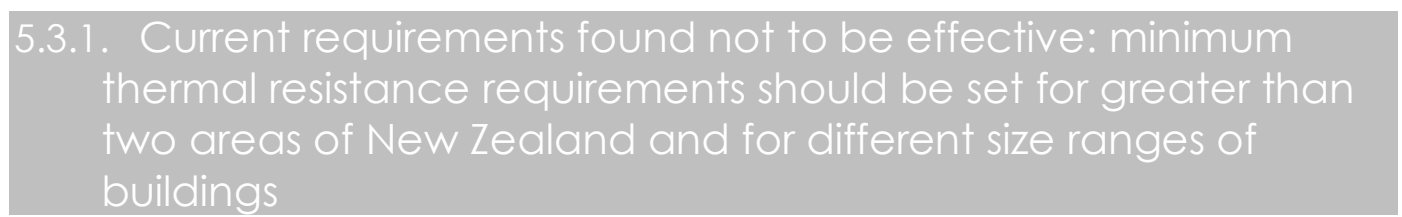

This study has demonstrated that the current NZS4243.1:2009 Schedule Method minimum required thermal resistance values may not always be effective to reduce energy consumption. This was found for both the as built and NZS4243 based modelling. It is recommended that the future re-evaluation of NZS4243:1 considers extending the number of climate zones and setting different requirements based on the size of buildings. It should also consider including building operation, as it has been shown that the cooling set point temperature can have a larger impact on energy use than envelope thermal performance.

\subsubsection{Use of Building Energy Modelling should be mandatory to demonstrate compliance with the minimum requirements}

The findings of this study demonstrate that the effectiveness of thermal insulation (even at the minimum thermal resistance level for buildings with window to wall ratios less than 0.5 ) is very dependent on the specific attributes of a building. Therefore, it is recommended that the use of building energy modelling is a mandatory requirement to demonstrate that the addition of thermal insulation achieves the desired level of energy efficiency.

\subsubsection{Re-evaluation should use a larger sample of real buildings and explore greater number of climates}

It is recommended that a larger sample of New Zealand office building energy models are used to confirm and determine the circumstances in which thermal insulation is not beneficial- so that requirements can be better set for the varying types of office buildings. 


\subsection{Future Research}

The work undertaken in this thesis explored the energy implications of thermal insulation in New Zealand office buildings. Through the use of building energy simulations, the relationship between the energy performance of the sample of office buildings and their attributes has been assessed. It was identified whether thermal insulation and at what level could lead to an increase in cooling energy use or total energy use. The characteristics of New Zealand office buildings that were susceptible to the adverse effect were also identified.

Future research should include the following three broad areas:

1) Mitigation techniques: exploration of whether passive or active overnight management strategies (such as night purge ventilation) could be used to improve the energy performance of buildings that are susceptible to the adverse effect

2) Sensitivity studies: exploration of how thermal insulations effectiveness in office and other commercial buildings, is influenced by a greater range of building parameters

3) Cost analysis: exploration of the cost implications of varying levels of thermal insulation in the roof, wall and floor of commercial office buildings. This would also determine the most cost effective minimum thermal resistance values for office buildings within different New Zealand regions. 


\section{References}

Ali-Toudert, F., \& Mayer, H. (2006). Numerical study on the effects of aspect ratio and orientation of an urban street canyon on outdoor thermal comfort in hot and dry climate. Building and Environment, 41 (2), 94-108.

https://doi.org/10.1016/j.buildenv.2005.01.013

Amitrano, L., Isaacs, N., Saville-Smith, K., Donn, M., Camilleri, M., Pollard, A., ... Cory, S. (2014). BEES - Part 1 Final Report Building Energy End-Use Study.

Anthony Gates. (2013). Determining the modelling input parameters for Heating, Ventilation, and Air Conditioning systems in New Zealand commercial buildings. Victoria University of Wellington, Wellington. Retrieved from http://researcharchive.vuw.ac.nz/bitstream/handle/10063/2642/thesis.pdf?se quence $=2$

ASHRAE. (2002). ASHRAE Guideline 14-2002 measurement of energy and demand savings. The American Society of Heating, Refrigerating and Air-Conditioning Engineers.

Baird, G., \& Prins, H. (2013, September). The attibutes of Wellington's Green Star rated buildings. Victoria University of Wellington.

Ballarini, I., \& Corrado, V. (2012). Analysis of the building energy balance to investigate the effect of thermal insulation in summer conditions. Energy and Buildings, 52, 168-180. https://doi.org/10.1016/j.enbuild.2012.06.004

Bannister, P., \& Guan, L. (1995). Basic Energy Efficiency Measures for New Zealand Office Buildings. Dunedin: Energy Group Limited.

Bannister, P., \& Guan, L. (1996). The Development of Acceptable Solutions for Office Building Energy Efficiency. IPENZ Annual Conference 1996, 2, 51. 
Bannister, P., \& Guan, L. (1997). Building Envelope Correlations for New Zealand Office Buildings. In Engineering our nation's future (Vol. 2). Wellington. Retrieved from http://search.informit.com.au/fullText;dn=759387724776300;res=IELENG Bannister, P., Guan, L., Page, I., \& Isaacs, N. (1996). The Application of Energy Efficiency Measures to Commercial Buildings. Dunedin: Energy Group Limited. Boyano, A., Hernandez, P., \& Wolf, O. (2013). Energy demands and potential savings in European office buildings: Case studies based on EnergyPlus simulations. Energy and Buildings, 65, 19-28. https://doi.org/10.1016/j.enbuild.2013.05.039

CIBSE. (2012). CIBSE Guide F. Chartered Institute of Building Services Engineers. CIBSE. (2015). CIBSE Guide A: Environmental Design. CIBSE.

Cory, S. (2016). An Exploration Of The Feasibility of Converting The New Zealand Commercial Buildings Stock To Be Net Zero Energy. Victoria University of Wellington, Wellington.

Cory, S., Donn, M., \& Pollard, A. (2015a). Comparison of NZ's Energy Efficiency Regulation and Verification Assumptions to Real Building Loads and Operation. Buildings, 5(1), 116-129. https://doi.org/10.3390/buildings5010116

Cory, S., Donn, M., \& Pollard, A. (2015b). Comparison of NZ's Energy Efficiency Regulation and Verification Assumptions to Real Building Loads and Operation. Buildings, 115-129.

Creswell-Wells, T. (2014). Urban Form and Passive Design for High Performance Buildings in the Christchruch Rebuild. Victoria University of Wellington.

de' Rossi, F., Marigliano, M., Marino, C., \& Minichiello, F. (2016, October). A Technical and Economic Analysis on Thermal Insulation Thickness for Existing Office Building in Meditteranean Climates.

EECA. (2017, December). Commercial Building Lighting Standards NZS4243 revision. 
Elink, E. (2012). Building Basics Insulation. Porirua: BRANZ.

EnergyPlus. (2015). EnergyPlus Documentation Input Output Reference. US

Department of Energy. Retrieved from

https://energyplus.net/sites/default/files/pdfs/pdfs_v8.3.0/InputOutputReferen ce.pdf

Friess, W. A., Rakhshan, K., \& Davis, M. P. (2017). A global survey of adverse energetic effects of increased wall insulation in office buildings: degree day and climate zone indicators. Energy Efficiency, 10(1), 97-116. https://doi.org/10.1007/s12053-016-9441-z

Grynning, S., Time, B., \& Matusiak, B. (2014). Solar shading control strategies in cold climates - Heating, cooling demand and daylight availability in office spaces. Solar Energy, 107, 182-194. https://doi.org/10.1016/j.solener.2014.06.007

Guan, L. (2006). The Implications of Global Warming on the Energy Performance and Indoor Thermal Environment of Air Conditioned Office Buildings In Australia (Doctor of Philosophy). Queensland University of Technology, Queensland.

Guan, L. (2010). Will Insulation Always Bring Benefits in energy Saving and Thermal Comfort? School of Engineering, Queensland University of Technology, Brisbane, Australia.

Guan, L. (2011). The influence of glass types on the performance of air-conditioned office buildings in Australia. Advanced Materials Research, 34-39.

Guan, L. (2015). The influence of internal load density on the energy and thermal performance of air-conditioned office buildings in the face of global warming. Architectural Science Review, 58(2), 162-173. https://doi.org/10.1080/00038628.2014.979395

Guang Yang, Zhengwei Li, \& Godfried Augenbroe. (n.d.). Development of prototypical buildings for urban scale building energy modeling: A reduced 
order energy model approach. Science and Technology for the Built Environment. Retrieved from http://www-tandfonlinecom.helicon.vuw.ac.nz/doi/abs/10.1080/23744731.2017.1328943

Idris, Y. M., \& Mae, M. (2017). Anti-insulation mitigation by altering the envelope layers' configuration. Energy and Buildings, 141, 186-204. https://doi.org/10.1016/j.enbuild.2017.02.025 International Energy Agency. (2008). Energy Efficiency Requirements in Building codes, Energy Efficiency Policies for New Buildings (IEA Information Paper) (p. 85). France. Retrieved from https://www.iea.org/publications/freepublications/publication/Building_Cod es.pdf

Isaacs, N. (1999). Performance-based Building Energy Efficiency Code. Presented at the Building Control Commision International Convention, Melbourne: BRANZ. Retrieved from http://www.branz.co.nz/cms_show_download.php?id=4d523bd153e72d9930 9 bce 46 eb00bddeee $468 f 32$

Isaacs, N., Donn, M., \& Baird, G. (1994). Energy efficiency and the New Zealand Building Code (Vol. 21, pp. 10-14). Presented at the IPENZ Annual Conference, Wellington. Retrieved from http://search.informit.com.au/fullText;dn=676739125331576;res=IELENG Isaacs, N., Lee, J., \& Donn, M. (1995). Energy Efficiency in The N.Z Building Code- A New Structure. Wellington: Centre for Building Performance Research. Korolija, I., Marjanovic-Halburd, L., Zhang, Y., \& Hanby, V. I. (2011). Influence of building parameters and HVAC systems coupling on building energy performance. Energy and Buildings, 43(6), 1247-1253. https://doi.org/10.1016/j.enbuild.201 1.01.003 
Marion Camelin, \& Adrien Destrez. (2011). Impacts of increased outdoor air flow rates on annual HVAC energy coosts in office environments (p. 61). Lyon: Insa Lyon. Retrieved from http://publications.lib.chalmers.se/records/fulltext/153751.pdf

Masoso, O. T., \& Grobler, L. J. (2008). A new and innovative look at anti-insulation behaviour in building energy consumption. Energy and Buildings, 40(10), 1889-1894. https://doi.org/10.1016/j.enbuild.2008.04.013

Menezes, A. C., Cripps, A., Buswell, R. A., Wright, J., \& Bouchlaghem, D. (2014). Estimating the energy consumption and power demand of small power equipment in office buildings. Energy and Buildings, 75, 199-209. https://doi.org/10.1016/j.enbuild.2014.02.011

Ministry for the Environment. (2017). Overview of likely climate change impacts in New Zealand | Ministry for the Environment. Retrieved 25 January 2018, from http://www.mfe.govt.nz/climate-change/likely-impacts-of-climatechange/overview-of-likely-climate-change-impacts NIWA. (2017). Mean monthly temperatures.

Ourghi, R., Al-Anzi, A., \& Krarti, M. (2007). A simplified analysis method to predict the impact of shape on annual energy use for office buildings. Energy Conversion and Management, 48(1), 300-305. https://doi.org/10.1016/j.enconman.2006.04.011

Pan, D., Chan, M., Deng, S., \& Lin, Z. (2012). The effects of external wall insulation thickness on annual cooling and heating energy uses under different climates. Applied Energy, 97, 313-318. https://doi.org/10.1016/j.apenergy.2011.12.009

Paul Bannister, \& Lisa Guan. (1995). Insulation in Low Energy Office Buildings. Energy Research Otago Limited. 
Pérez-Lombard, L., Ortiz, J., \& Pout, C. (2008). A review on buildings energy consumption information. Energy and Buildings, 40 (3), 394-398. https://doi.org/10.1016/j.enbuild.2007.03.007

Reilly, A., \& Kinnane, O. (2017). The impact of thermal mass on building energy consumption. Applied Energy, 198, 108-121. https://doi.org/10.1016/j.apenergy.2017.04.024

Samson Corporation. (2017). Geyser Parnell.

Shaan Cory. (2013). The reduction from 18 to 8 New Zealand locations for the purpose of post stratifying by climate for the extrapolation of presenting the energy consumption of the entire New Zealand commerical building stock.

Shaan Cory, Anothony Gates, \& Michael Donn. (2011). The Creation of Generic Simulation Models Which Represent Typical Commerical Buildings and Their Calibration Against Energy Data. Presented at the Conference of the International Building Performance Simulation Asociation, Sydney. Retrieved from http://www.ibpsa.org/proceedings/BS2011/P_1492.pdf

Standards New Zealand. (2007). NZS 4243-1: Energy efficiency - Large buildings Building thermal envelope. Retrieved 18 April 2017, from

Stazi, F., Bonfigli, C., Tomassoni, E., Di Perna, C., \& Munafò, P. (2015). The effect of high thermal insulation on high thermal mass: Is the dynamic behaviour of traditional envelopes in Mediterranean climates still possible? Energy and Buildings, 88, 367-383. https://doi.org/10.1016/j.enbuild.2014.11.056

Strømann-Andersen, J., \& Sattrup, P. A. (2011). The urban canyon and building energy use: Urban density versus daylight and passive solar gains. Energy and Buildings, 43(8), 2011-2020. https://doi.org/10.1016/j.enbuild.2011.04.007 Szokolay, S. V. (2014). Introduction to Architectural Science The Basis Of Sustainable Design (3rd ed.). Routledge. 
Wetter, M. (2004, January 1). Simulation-based building energy optimization. ProQuest Dissertations Publishing. Retrieved from http://search.proquest.com/docview/305211143/ 


\section{Appendix}

\subsection{Update of Building Energy Models: Difference in Energy Consumption Between Versions}

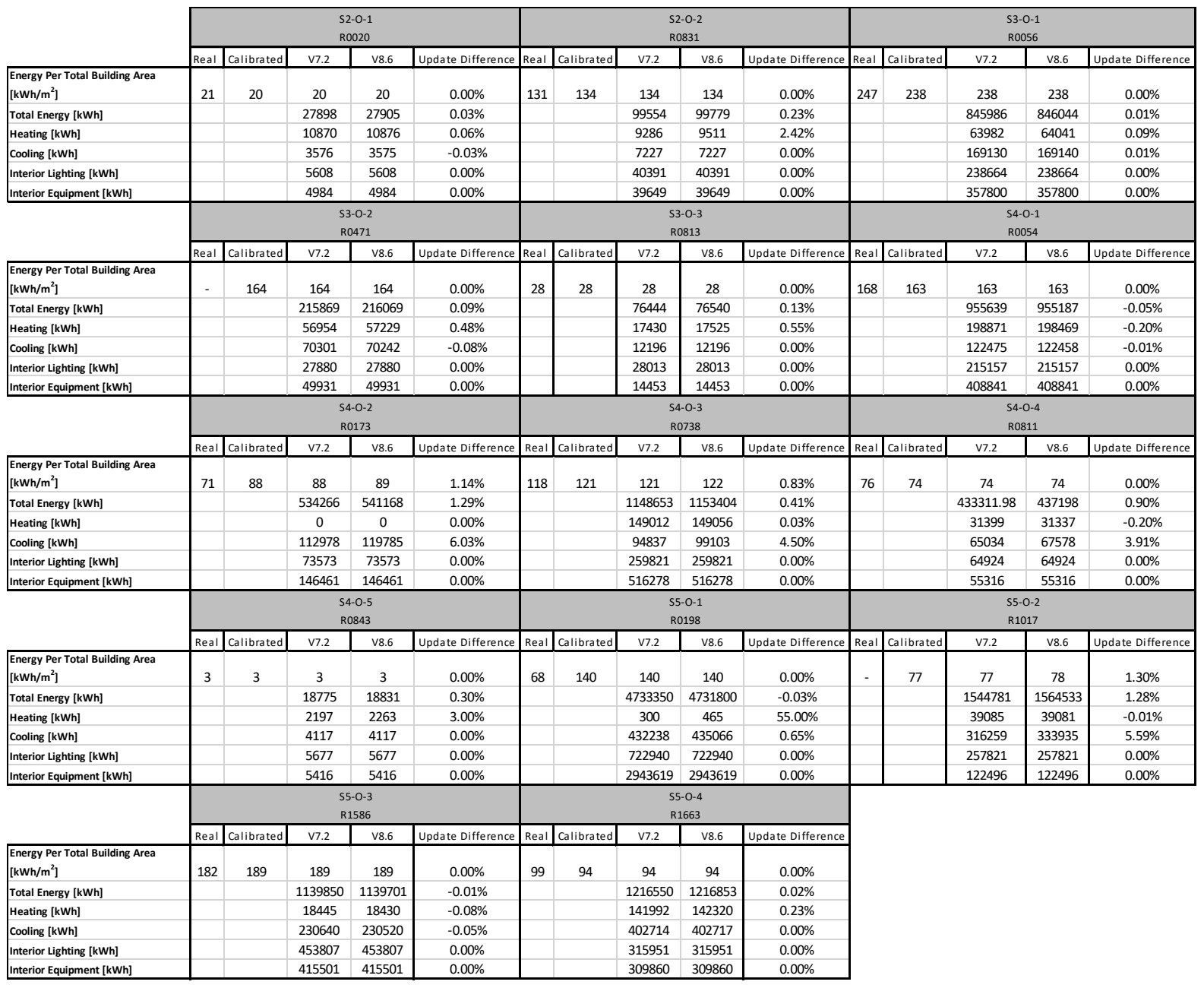

Table 19 Difference in energy consumption between version 7.2 and 8.6 

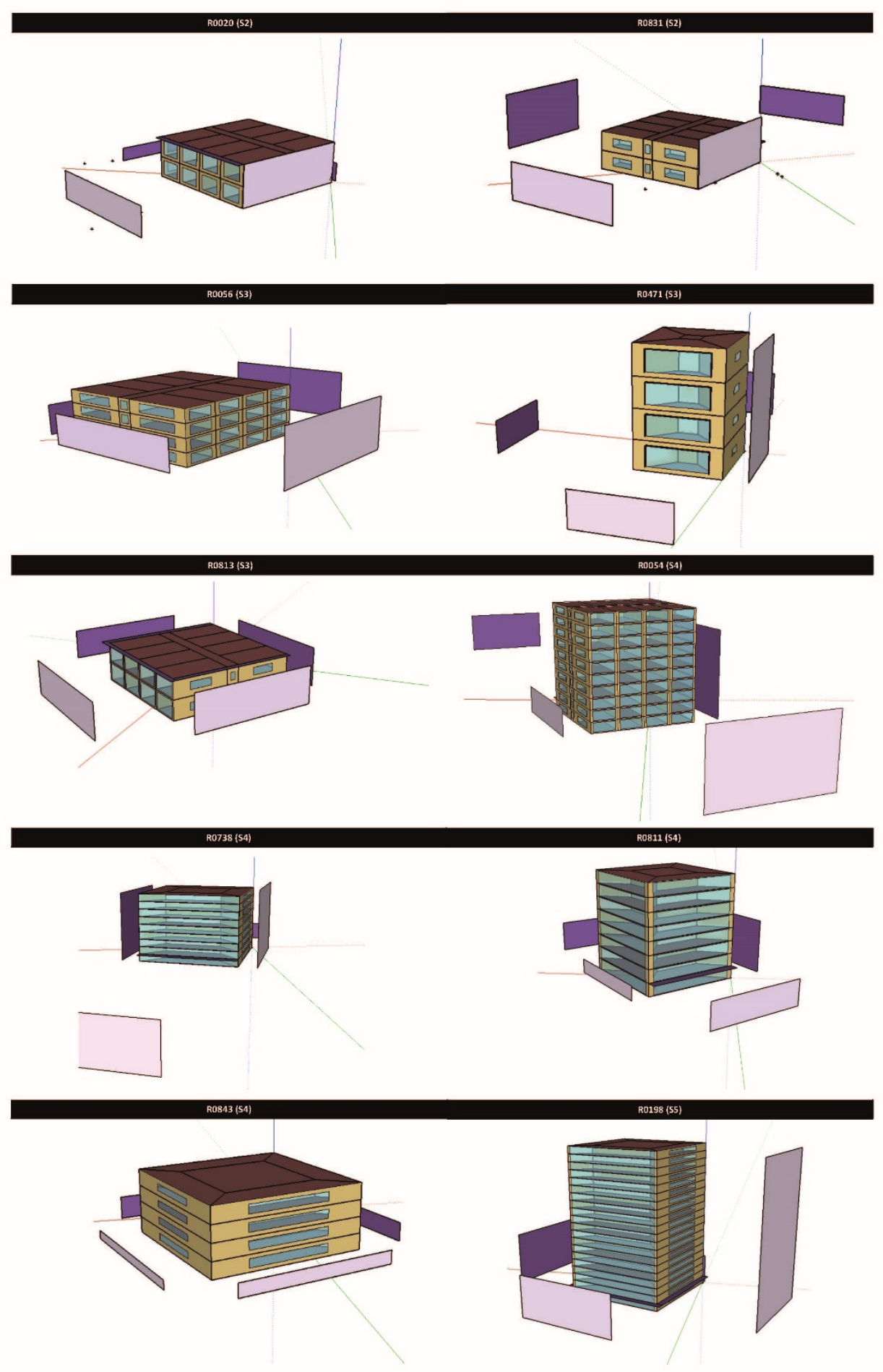


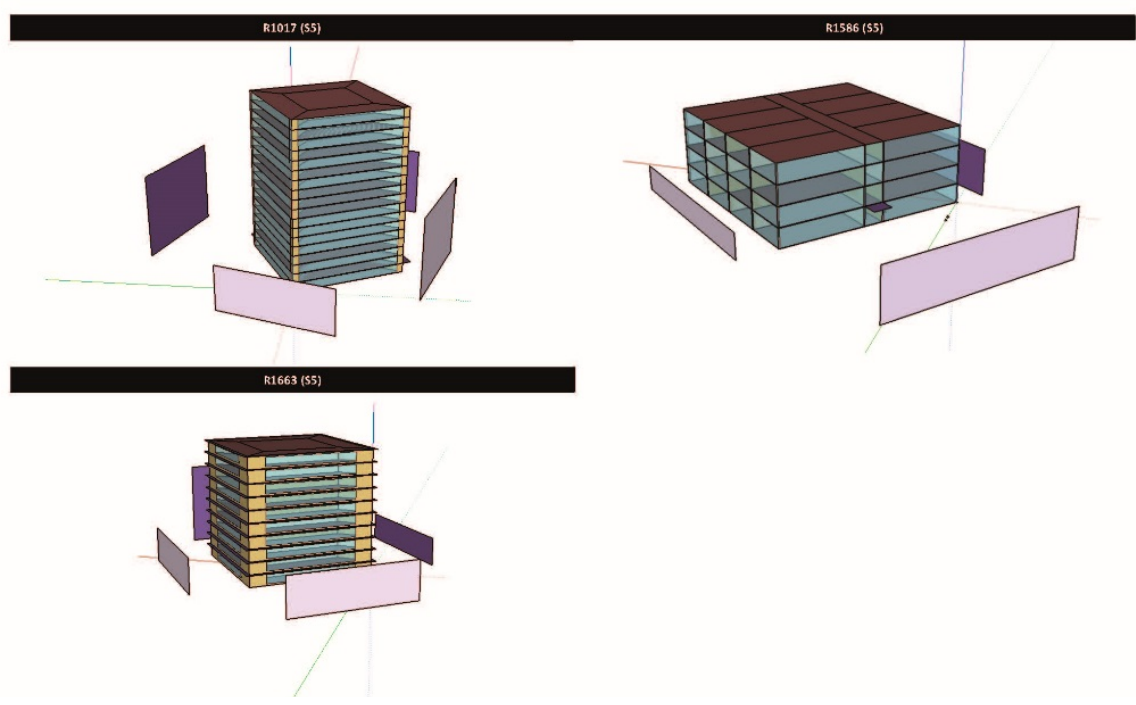

Figure 99 Illustrations obtained through Sketchup. North is represented by the green axis line and shading from adjacent buildings is represented by the purple 
The tables below give information on each of the buildings attributes

\begin{tabular}{|c|c|c|c|c|c|}
\hline \multicolumn{2}{|l|}{ 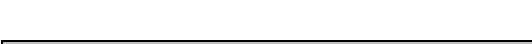 } & R0020 (S2) & R0831 (S2) & R0056 (S3) & R0471 (S3) \\
\hline \multicolumn{6}{|l|}{ Fuel Type } \\
\hline Elec/Gas & & electricity & electricity & elec+gas & elec+gas \\
\hline \multicolumn{6}{|l|}{ Geometary } \\
\hline \multicolumn{6}{|c|}{ Building Orientation (Degrees - } \\
\hline Clockwise from North, $0=N$ & & 40 & 53 & 44 & 0 \\
\hline Total Building Floor Area $n$ & & 1356 & 742.49 & 3555 & 1311 \\
\hline Total Number of Storeys \# & & 2 & 2 & 4 & 4 \\
\hline Building Height $\mathrm{m}$ & & 9 & 6.5 & 10 & 25 \\
\hline Glazing Percentage \% & $\mathbf{N}$ & $50 \%$ & $20 \%$ & $40 \%$ & $50 \%$ \\
\hline$\%$ & E & $50 \%$ & $0 \%$ & $10 \%$ & $50 \%$ \\
\hline$\%$ & s & $10 \%$ & $30 \%$ & $50 \%$ & $40 \%$ \\
\hline$\%$ & w & $0 \%$ & $0 \%$ & $50 \%$ & $5 \%$ \\
\hline \multicolumn{6}{|l|}{ Constructions } \\
\hline Primary Building Fabric & Façade material & Concrete & Concrete & Concrete & Concrete \\
\hline \multirow[t]{2}{*}{ Secondary Building Fabric } & Façade material & N/A & Weatherboard & Fibre Cement & Glass \\
\hline & Insulated & Don't Know & & Don't Know & No \\
\hline \multirow[t]{2}{*}{ Roof Construction } & Material & Suspended Concrete & Steel/G-Iron & Concrete & Concrete \\
\hline & Insulated & Don't Know & No & Yes & No \\
\hline \multicolumn{2}{|c|}{ Foundation / Ground / Basement floc Material } & Suspended Concrete & Slab on ground & Suspended concrete & Slab on ground \\
\hline & Insulated & Don't Know & Don't Know & No & No \\
\hline \multirow[t]{4}{*}{ Glazing Type } & $\mathbf{N}$ & Single & Single & Single & Single \\
\hline & E & Single & No Glazing & Single & Single \\
\hline & s & single & Single & Single & Single \\
\hline & w & No Glazing & No Glazing & Single & No Glazing \\
\hline \multirow[t]{4}{*}{ Glazing Framing Material } & $\mathbf{N}$ & Aluminium & Aluminium & Aluminium & No Glazing \\
\hline & E & Aluminium & No Glazing & Aluminium & No Glazing \\
\hline & $\mathbf{s}$ & Wood or PVC & Aluminium & Aluminium & No Glazing \\
\hline & w & No Glazing & No Glazing & Aluminium & No Glazing \\
\hline \multirow[t]{4}{*}{ Glazing Tint } & $\mathbf{N}$ & Light & Heavy & Heavy & Heavy \\
\hline & E & Light & No Glazing & Heavy & Light \\
\hline & $s$ & None & Light & Heavy & None \\
\hline & w & No Glazing & No Glazing & Heavy & No Glazing \\
\hline \multirow[t]{4}{*}{ Glazing Reflective Tint } & $\mathbf{N}$ & None & None & No Glazing & None \\
\hline & $E$ & None & No Glazing & None & None \\
\hline & $\mathbf{S}$ & None & None & No Glazing & None \\
\hline & $\mathbf{w}$ & No Glazng & No Glazing & No Glazing & No Glazing \\
\hline \multicolumn{6}{|l|}{ Loads } \\
\hline \multicolumn{2}{|l|}{ Electrical Equipment } & 5.5 & 8.13 & 8.35 & 2.04 \\
\hline \multicolumn{2}{|l|}{ Lights } & 4.9 & 18.34 & 14.5 & 6.78 \\
\hline \multicolumn{2}{|l|}{ DHW } & & 0.700 & & 1.840 \\
\hline Lifts & & & & 2.280 & \\
\hline Misc Loads & & 0.06 & 3.15 & 9.6 & 7.06 \\
\hline Occupant Density & & 0.2706 & 0.0545 & 0.066 & \\
\hline Temperature Setpoints & & & & & \\
\hline & & $13,18,18,19,17,18.7$ & & & \\
\hline Heating & & $\begin{array}{c}, 20.5,19,15 \\
28,26,22.5,30,30,24\end{array}$ & $21,23,21,21,23$ & $21.3,26.21 .3$ & 18.00 \\
\hline Cooling & & $26,23,24.5$ & $24,26,25,24,26$ & $23,26.5,23$ & 21.00 \\
\hline HVAC & & & & & \\
\hline Primary/Central system & & Heat Pump & Heat Pump & FCU & \\
\hline Additional Systems & & & & & \\
\hline Secondary system & & & & Heat Pump & Heat Pump \\
\hline Fixed electric heater & & & & & \\
\hline Gas Heater & & & & & \\
\hline Ventilation & & & & & \\
\hline Open-able Windows & $\mathbf{N}$ & & & No & No \\
\hline & E & & & No & No \\
\hline & s & & & No & No \\
\hline & w & & & No & No \\
\hline Maximum fresh air ventila & $\mathrm{n} 3 / \mathrm{s}$ & autocalculate & 0.01 & 0.01 & 0.01 \\
\hline ACH & & 0.5 & 0.1 & 0.10 & 0.1 \\
\hline
\end{tabular}

Table 20 Details of buildings R0020, R0831, R0056 and R0471 construction 


\begin{tabular}{|c|c|c|c|c|c|}
\hline \multicolumn{6}{|l|}{ Fuel Type } \\
\hline \multicolumn{2}{|l|}{ Elec/Gas } & elec & elec+gas & elec+gas & elec+gas \\
\hline \multicolumn{6}{|l|}{ Geometary } \\
\hline \multicolumn{6}{|c|}{ Building Orientation (Degrees - } \\
\hline \multicolumn{2}{|c|}{ Clockwise from North, $0=$ North) } & 35 & 333 & 20 & 52 \\
\hline \multicolumn{2}{|l|}{ Total Building Floor Area m2 } & 2674.5 & 5861 & 9439 & 5839.56 \\
\hline \multicolumn{2}{|l|}{ Total Number of Storeys \# } & 2 & 10 & 9 & 8 \\
\hline \multicolumn{2}{|l|}{ Building Height m } & 11.5 & 25 & 22 & 29 \\
\hline Glazing Percentage \% & $\mathbf{N}$ & $15 \%$ & $70 \%$ & $100 \%$ & $80 \%$ \\
\hline$\%$ & $\mathbf{E}$ & $73 \%$ & $30 \%$ & $10 \%$ & $80 \%$ \\
\hline$\%$ & $\mathbf{S}$ & $15 \%$ & $50 \%$ & $20 \%$ & $30 \%$ \\
\hline$\%$ & $\mathbf{w}$ & $5 \%$ & $70 \%$ & $30 \%$ & $80 \%$ \\
\hline \multicolumn{6}{|l|}{ Constructions } \\
\hline \multirow{3}{*}{$\begin{array}{l}\text { Primary Building Fabric } \\
\text { Secondary Building Fabric }\end{array}$} & Façade material & Concrete & Concrete & Concrete & Glass \\
\hline & Façade material & Glass & Glass & Glass & Concrete \\
\hline & Insulated & Yes & Don't Know & Don't Know & \\
\hline \multirow[t]{2}{*}{ Roof Construction } & Material & Steel/G-Iron & Concrete & Concrete & \\
\hline & Insulated & Don't Know & Don't Know & Don't Know & Yes \\
\hline \multicolumn{2}{|c|}{ Foundation / Ground / Basement floc Material } & Suspended timber & Suspended concrete & Slab on ground & Slab on ground \\
\hline & Insulated & Don't Know & Don't Know & No & Don't Know \\
\hline \multirow[t]{4}{*}{ Glazing Type } & $\mathbf{N}$ & Single & Double & Single & Single \\
\hline & E & Single & Double & Single & Single \\
\hline & $\mathbf{S}$ & Single & Double & Single & Single \\
\hline & $\mathbf{w}$ & Single & Double & Single & Single \\
\hline \multirow[t]{4}{*}{ Glazing Framing Material } & $\mathbf{N}$ & Aluminium & Aluminium & Aluminium & Aluminium \\
\hline & $\mathbf{E}$ & Aluminium & Aluminium & Steel & Aluminium \\
\hline & S & Aluminium & Aluminium & Aluminium & Aluminium \\
\hline & $\mathbf{w}$ & Aluminium & Aluminium & Aluminium & Aluminium \\
\hline \multirow{4}{*}{ Glazing Tint } & $\mathbf{N}$ & Light & Dark & Heavy & Light \\
\hline & E & Light & Dark & None & Light \\
\hline & $\mathbf{s}$ & Light & Dark & None & Light \\
\hline & $\mathbf{w}$ & Light & Dark & Light & Light \\
\hline \multirow[t]{4}{*}{ Glazing Reflective Tint } & $\mathbf{N}$ & No Glazing & None & No Glazing & None \\
\hline & $\mathbf{E}$ & No Glazing & None & None & None \\
\hline & S & No Glazing & None & None & None \\
\hline & $\mathbf{w}$ & No Glazing & None & None & None \\
\hline Loads & & & & & \\
\hline Electrical Equipment & & 1.46 & 6.98 & 7.42 & 1.35 \\
\hline Lights & & 3.17 & 10 & 8.5 & 3.04 \\
\hline DHW & & & & & \\
\hline Lifts & & & 10.990 & & \\
\hline Misc Loads & & 0 & 7.56 & 11.41 & 0.17 \\
\hline Occupant Density & & 0.014 & 0.160 & 0.047 & 0.094 \\
\hline Temperature Setpoints & & & & & \\
\hline & & & 22.3,22.3,26.5,26.5, & & \\
\hline Heating & & $20,20,18,20,20$ & 22 & $18,19.6,23,19.6,18$ & 15.7 \\
\hline & & $26,23.9,23.9,23.9,2$ & & $24,22.2,23.5,22.2,2$ & \\
\hline Cooling & & 6 & $25,24.7,27,27,24.7$ & 5 & 26.0 \\
\hline HVAC & & & & & \\
\hline Primary/Central system & & SplitSystem & $\mathrm{FCU}$ & VAV ElectricHeat & \\
\hline Additional Systems & & & & & \\
\hline Secondary system & & & Heat Pump & Heat Pump & Heat Pump \\
\hline Fixed electric heater & & & $\mathrm{N} / \mathrm{A}$ & & \\
\hline Gas Heater & & & $N / A$ & & \\
\hline Ventilation & & & & & \\
\hline Open-able Windows & $\mathbf{N}$ & No & No & No & No \\
\hline & $\mathbf{E}$ & No & No & No & No \\
\hline & S & No & No & No & No \\
\hline & w & No & No & No & No \\
\hline Maximum fresh air ventila & $\mathrm{m} 3 / \mathrm{s}$ & 0.01 & 0.01 & 0.03 & autosize \\
\hline ACH & & 0.1 & 0.1 & 0.10 & 0.10 \\
\hline
\end{tabular}

Table 21 Details of buildings R0813, R0054, R0738 and R0811 construction 


\begin{tabular}{|c|c|c|c|c|c|c|}
\hline \multicolumn{7}{|c|}{ (n) } \\
\hline Elec/Gas & & electricity & electgas & electricity & elec+gas & electgas \\
\hline Geometary & & & & & & \\
\hline \multicolumn{7}{|c|}{ Building Orientation (Degrees - } \\
\hline Clockwise from North, $0=\mathrm{N}$ & & 342 & 18 & 62 & 38 & 53 \\
\hline Total Building Floor Area $\mathrm{m}$ & & 5127 & 33628 & 19843.2 & 6029.305 & 12891 \\
\hline Total Number of Storeys \# & & 4 & 20 & 18 & 4 & 10 \\
\hline Building Height $\mathrm{m}$ & & 15 & 62.1 & 48 & 15.5 & 35 \\
\hline Glazing Percentage \% & $\mathbf{N}$ & $28 \%$ & $90 \%$ & $96 \%$ & $90 \%$ & $38 \%$ \\
\hline$\%$ & E & $17 \%$ & $30 \%$ & $95 \%$ & $90 \%$ & $52 \%$ \\
\hline$\%$ & $s$ & $17 \%$ & $70 \%$ & $80 \%$ & $90 \%$ & $40 \%$ \\
\hline$\%$ & w & $35 \%$ & $30 \%$ & $83 \%$ & $95 \%$ & $53 \%$ \\
\hline \multicolumn{7}{|l|}{ Constructions } \\
\hline Primary Building Fabric & Façade material & Fibre Cement & Concrete & Concrete & Concrete & Concrete \\
\hline \multirow[t]{2}{*}{ Secondary Building Fabric } & Façade material & 0 & N/A & Glass & Glass & N/A \\
\hline & Insulated & Yes & No & No & Don't Know & No \\
\hline \multirow[t]{2}{*}{ Roof Construction } & Material & Steel/G-Iron & & & & Concrete \\
\hline & Insulated & Yes & No & & Don't Know & No \\
\hline \multicolumn{2}{|c|}{ Foundation / Ground / Basement floc Material } & Slab on Ground & Slab on ground & Slab on ground & Slab on ground & Slab on ground \\
\hline & Insulated & No & No & No & No & No \\
\hline \multirow{4}{*}{ Glazing Type } & $\mathbf{N}$ & Single & Single & Single & Single & Single \\
\hline & E & Single & Single & Single & Single & Single \\
\hline & s & Single & Single & Single & Single & Single \\
\hline & w & Single & Single & Single & Single & Single \\
\hline \multirow[t]{4}{*}{ Glazing Framing Material } & $\mathbf{N}$ & Aluminium & Aluminium & Aluminium & Aluminium & Aluminium \\
\hline & E & Wood or PVC & Aluminium & Aluminium & Aluminium & Aluminium \\
\hline & $\mathrm{s}$ & Wood or PVC & Aluminium & Aluminium & Aluminium & Aluminium \\
\hline & w & Aluminium & Aluminium & Aluminium & Aluminium & Aluminium \\
\hline \multirow[t]{4}{*}{ Glazing Tint } & $\mathbf{N}$ & Light & None & Light & Light & None \\
\hline & E & Light & None & Light & Light & None \\
\hline & $s$ & Light & None & Light & Light & None \\
\hline & w & Light & None & Light & Light & None \\
\hline \multirow[t]{4}{*}{ Glazing Reflective Tint } & $\mathbf{N}$ & None & No Glazing & No Glazing & No Glazing & None \\
\hline & E & Light & No Glazing & No Glazing & No Glazing & None \\
\hline & $\mathrm{s}$ & Light & No Glazing & No Glazing & No Glazing & None \\
\hline & w & None & No Glazing & No Glazing & No Glazing & None \\
\hline \multicolumn{7}{|l|}{ Loads } \\
\hline \multicolumn{2}{|l|}{ Electrical Equipment } & 0.15 & 2.6 & 3.15 & 12.91 & 2.86 \\
\hline \multicolumn{2}{|l|}{ Lights } & 0.48 & 5.56 & 5.85 & 18.45 & 5.95 \\
\hline \multicolumn{2}{|l|}{ DHW } & 0.110 & & 0.860 & 1.270 & 0.630 \\
\hline \multicolumn{2}{|l|}{ Lifts } & & & 14.390 & & 3.040 \\
\hline Misc Loads & & 0.13 & 0.0 & & 1.08 & 0.0046 \\
\hline Occupant Density & & 0.003 & 0.012 & 0.028 & 0.056 & 0.007 \\
\hline Temperature Setpoints & & & & & & \\
\hline & & $16,16,14,11,14,14,1$ & & & & \\
\hline Heating & & 4 & 14.00 & 19.8 & 6.67 & $20,20,21,20$ \\
\hline Cooling & & $25.5,24,25,28,24,27$ & 28.00 & 21.8 & 23.00 & $20,21 \cdot 7,21 \cdot 7,20$ \\
\hline HVAC & & & & & & \\
\hline Primary/Central system & & SplitSystem & VAV & VAV ElectricHeat & FCU & FCU \\
\hline Additional Systems & & & & & & \\
\hline Secondary system & & & Heat Pump & & & \\
\hline Fixed electric heater & & & & & & \\
\hline Gas Heater & & & & & & \\
\hline Ventilation & & & & & & \\
\hline Open-able Windows & $\mathbf{N}$ & No & No & No & No & No \\
\hline & $\mathbf{E}$ & No & No & No & No & No \\
\hline & $s$ & No & No & No & No & No \\
\hline & w & No & No & No & No & No \\
\hline Maximum fresh air ventilat & $\mathrm{n} 3 / \mathrm{s}$ & Autosize & autosize & 0.01 & 0.01 & 0.01 \\
\hline $\mathrm{ACH}$ & & 0.1 & 1.00 & 0.10 & 0.10 & 0.10 \\
\hline
\end{tabular}

Table 22 Details of buildings R0843, R0198, R1017, R1586 and R1663 construction 


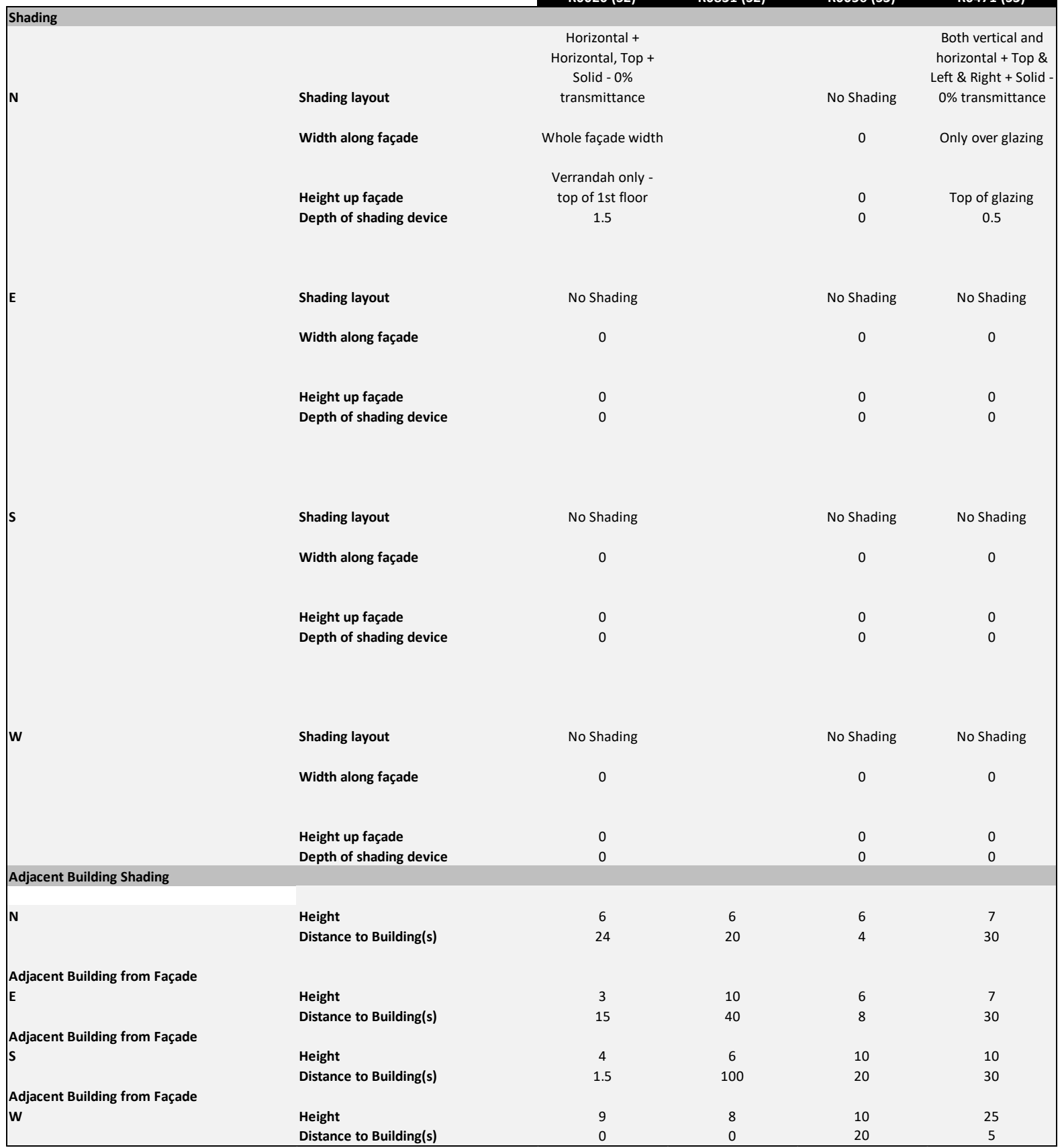

Table 23 Details of buildings R0020, R0831, R0056 and R0471 shading 


\begin{tabular}{|c|c|c|c|c|c|}
\hline \multicolumn{6}{|c|}{ 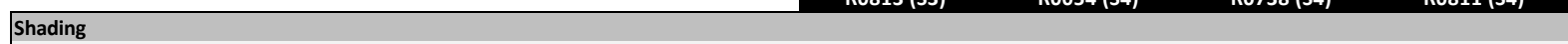 } \\
\hline \multirow[t]{4}{*}{$\mathbf{N}$} & Shading layout & $\begin{array}{l}\text { Horizontal + } \\
\text { Horizontal, Top + } \\
\text { Solid - } 0 \% \\
\text { transmittance }\end{array}$ & $\begin{array}{l}\text { Horizontal + } \\
\text { Horizontal, Top + } \\
\text { Solid - } 0 \% \\
\text { transmittance }\end{array}$ & $\begin{array}{c}\text { Horizontal + } \\
\text { Horizontal, Top + } \\
\text { Clear - } 90 \% \\
\text { transmittance }\end{array}$ & No Shading \\
\hline & Width along façade & Whole façade width & Whole façade width & Whole façade width & 0 \\
\hline & Height up façade & $\begin{array}{l}\text { Verrandah only - } \\
\text { top of 1st floor }\end{array}$ & $\begin{array}{c}\text { Whole façade } \\
\text { height }\end{array}$ & $\begin{array}{l}\text { Verrandah only - } \\
\text { top of ground storey }\end{array}$ & 0 \\
\hline & Depth of shading device & $\begin{array}{c}1.5 \\
\text { Horizontal + } \\
\text { Horizontal, Top + } \\
\text { Solid - 0\% } \\
\text { transmittance }\end{array}$ & $\begin{array}{c}1 \\
\text { Horizontal + } \\
\text { Horizontal, Top + } \\
\text { Solid - 0\% } \\
\text { transmittance }\end{array}$ & 2.5 & No Shading \\
\hline \multirow{3}{*}{ E } & Width along façade & Whole façade width & Whole façade width & 0 & 0 \\
\hline & Height up façade & $\begin{array}{l}\text { Verrandah only - } \\
\text { top of 1st floor }\end{array}$ & $\begin{array}{c}\text { Whole façade } \\
\text { height }\end{array}$ & 0 & 0 \\
\hline & Depth of shading device & 1.5 & 1 & 0 & 0 \\
\hline \multirow{8}{*}{ w } & Shading layout & $\begin{array}{l}\text { Horizontal + } \\
\text { Horizontal, Top + } \\
\text { Solid - } 0 \% \\
\text { transmittance }\end{array}$ & No Shading & No Shading & No Shading \\
\hline & Width along façade & Whole façade width & 0 & 0 & 0 \\
\hline & Height up façade & $\begin{array}{l}\text { Verrandah only - } \\
\text { top of 1st floor }\end{array}$ & 0 & 0 & 0 \\
\hline & Depth of shading device & 2 & 0 & 0 & 0 \\
\hline & Shading layout & No Shading & No Shading & No Shading & $\begin{array}{l}\text { Horizontal + } \\
\text { Horizontal, Top + } \\
\text { Solid - } 0 \% \\
\text { transmittance }\end{array}$ \\
\hline & Width along façade & 0 & 0 & 0 & Whole façade width \\
\hline & Height up façade & 0 & 0 & 0 & $\begin{array}{l}\text { Verrandah only - } \\
\text { top of ground storey }\end{array}$ \\
\hline & Depth of shading device & 0 & 1.5 & 0 & 2.5 \\
\hline \multicolumn{6}{|c|}{ Adjacent Building Shading } \\
\hline \multirow[t]{2}{*}{$\mathbf{N}$} & Height & 11 & 14 & 10 & 4 \\
\hline & Distance to Building(s) & 10 & 50 & 80 & 5 \\
\hline \multicolumn{6}{|c|}{ Adjacent Building from Façade } \\
\hline \multirow[t]{2}{*}{ E } & Height & 10 & 6 & 22 & 9 \\
\hline & Distance to Building(s) & 21.67 & 6 & 6 & 25 \\
\hline \multicolumn{6}{|c|}{ Adjacent Building from Façade } \\
\hline \multirow[t]{2}{*}{ s } & Height & 9 & 12 & 6 & 15 \\
\hline & Distance to Building(s) & 25 & 100 & 19 & 10 \\
\hline \multicolumn{6}{|c|}{ Adjacent Building from Façade } \\
\hline \multirow[t]{2}{*}{ W } & Height & 11.5 & 20 & 24 & 7 \\
\hline & Distance to Building(s) & 10 & 6 & 6 & 25 \\
\hline
\end{tabular}

Table 24 Details of buildings R0813, R0054, R0738 and R0811 shading 


\begin{tabular}{|c|c|c|c|c|c|c|}
\hline & & R0843 (S4) & R0198 (S5) & R1017 (S5) & R1586 (S5) & R1663 (S5) \\
\hline \multicolumn{7}{|c|}{ Shading } \\
\hline \multirow[t]{5}{*}{$\mathbf{N}$} & Shading layout & No Shading & $\begin{array}{l}\text { Horizontal + } \\
\text { Horizontal, Top + } \\
\text { Solid - 0\% } \\
\text { transmittance }\end{array}$ & $\begin{array}{l}\text { Horizontal + } \\
\text { Horizontal, Top + } \\
\text { Solid - 0\% } \\
\text { transmittance }\end{array}$ & No Shading & $\begin{array}{c}\text { Horizontal + } \\
\text { Horizontal, Top + } \\
\text { Solid - } 0 \% \\
\text { transmittance }\end{array}$ \\
\hline & Width along façade & 0 & Whole façade width & Whole façade width & 0 & Whole façade width \\
\hline & Height up façade & 0 & $\begin{array}{l}\text { Verrandah only - } \\
\text { top of ground storey }\end{array}$ & $\begin{array}{l}\text { Verrandah only - } \\
\text { top of ground storey }\end{array}$ & y & Top of each level \\
\hline & Depth of shading device & 0 & 2.5 & 2.5 & 0 & 1 \\
\hline & Shading layout & No Shading & $\begin{array}{l}\text { Horizontal + } \\
\text { Horizontal, Top + } \\
\text { Solid - 0\% } \\
\text { transmittance }\end{array}$ & $\begin{array}{l}\text { Horizontal + } \\
\text { Horizontal, Top + } \\
\text { Solid - } 0 \% \\
\text { transmittance }\end{array}$ & No Shading & $\begin{array}{l}\text { Horizontal + } \\
\text { Horizontal, Top + } \\
\text { Solid - } 0 \% \\
\text { transmittance }\end{array}$ \\
\hline \multirow{4}{*}{ E } & Width along façade & 0 & Whole façade width & Whole façade width & 0 & Whole façade width \\
\hline & Height up façade & 0 & $\begin{array}{l}\text { Verrandah only - } \\
\text { top of ground storey }\end{array}$ & $\begin{array}{l}\text { Verrandah only - } \\
\text { top of ground storey }\end{array}$ & y & Top of each level \\
\hline & Depth of shading device & 0 & 2.5 & 2.5 & 0 & 1 \\
\hline & Shading layout & $\begin{array}{c}\text { Horizontal + } \\
\text { Horizontal, Top + } \\
\text { Perforated solid } \\
\text { material - 30\% } \\
\text { transmittance }\end{array}$ & No Shading & No Shading & No Shading & $\begin{array}{l}\text { Horizontal + } \\
\text { Horizontal, Top + } \\
\text { Solid - } 0 \% \\
\text { transmittance }\end{array}$ \\
\hline \multirow{4}{*}{$s$} & Width along façade & Only over glazing & 0 & 0 & 0 & Whole façade width \\
\hline & Height up façade & $\begin{array}{l}\text { Verrandah only - } \\
\text { top of ground storey }\end{array}$ & 0 & 0 & 0 & Top of each level \\
\hline & Depth of shading device & 2.5 & 0 & 0 & 0 & 1 \\
\hline & Shading layout & $\begin{array}{c}\text { Horizontal + } \\
\text { Horizontal, Top + } \\
\text { Perforated solid } \\
\text { material - 30\% } \\
\text { transmittance }\end{array}$ & $\begin{array}{c}\text { Horizontal + } \\
\text { Horizontal, Top + } \\
\text { Solid - } 0 \% \\
\text { transmittance }\end{array}$ & No Shading & $\begin{array}{c}\text { Horizontal + } \\
\text { Horizontal, Top + } \\
\text { Solid - 0\% } \\
\text { transmittance } \\
\text { Quarter glazing }\end{array}$ & $\begin{array}{l}\text { Horizontal + } \\
\text { Horizontal, Top + } \\
\text { Solid - } 0 \% \\
\text { transmittance }\end{array}$ \\
\hline \multirow{3}{*}{ w } & Width along façade & Only over glazing & Whole façade width & 0 & width & Whole façade width \\
\hline & Height up façade & $\begin{array}{l}\text { Verrandah only - } \\
\text { top of ground storey }\end{array}$ & $\begin{array}{l}\text { Verrandah only - } \\
\text { top of ground storey }\end{array}$ & 0 & $\begin{array}{l}\text { Verrandah only - } \\
\text { top of ground storey }\end{array}$ & Top of each level \\
\hline & Depth of shading device & 2.5 & 2.5 & 0 & 3 & 1 \\
\hline \multicolumn{7}{|c|}{ Adjacent Building Shading } \\
\hline \multirow[t]{2}{*}{$\mathbf{N}$} & Height & 3.03 & 17 & 24.8 & 5 & 10 \\
\hline & Distance to Building(s) & 10.67 & 31 & 24 & 8 & 16.25 \\
\hline \multicolumn{7}{|c|}{ Adjacent Building from Façade } \\
\hline \multirow[t]{2}{*}{ E } & Height & 2 & 22 & 21.25 & 0 & 24 \\
\hline & Distance to Building(s) & 10 & 29.5 & 21.25 & 0 & 20 \\
\hline \multicolumn{7}{|c|}{ Adjacent Building from Façade } \\
\hline \multirow[t]{2}{*}{ s } & Height & 5.33 & 12 & 23.6 & 9.5 & 8 \\
\hline & Distance to Building(s) & 13.00 & 2 & 9.6 & 6.5 & 20 \\
\hline \multicolumn{7}{|c|}{ Adjacent Building from Façade } \\
\hline \multirow[t]{2}{*}{ w } & Height & 4.3 & 62.1 & 12.83 & 9.5 & 10.83 \\
\hline & Distance to Building(s) & 11.25 & 41 & 16.67 & 30 & 26.67 \\
\hline
\end{tabular}

Table 25 Details of buildings R0843, R0198, R1017, R1586, R1663 shading 


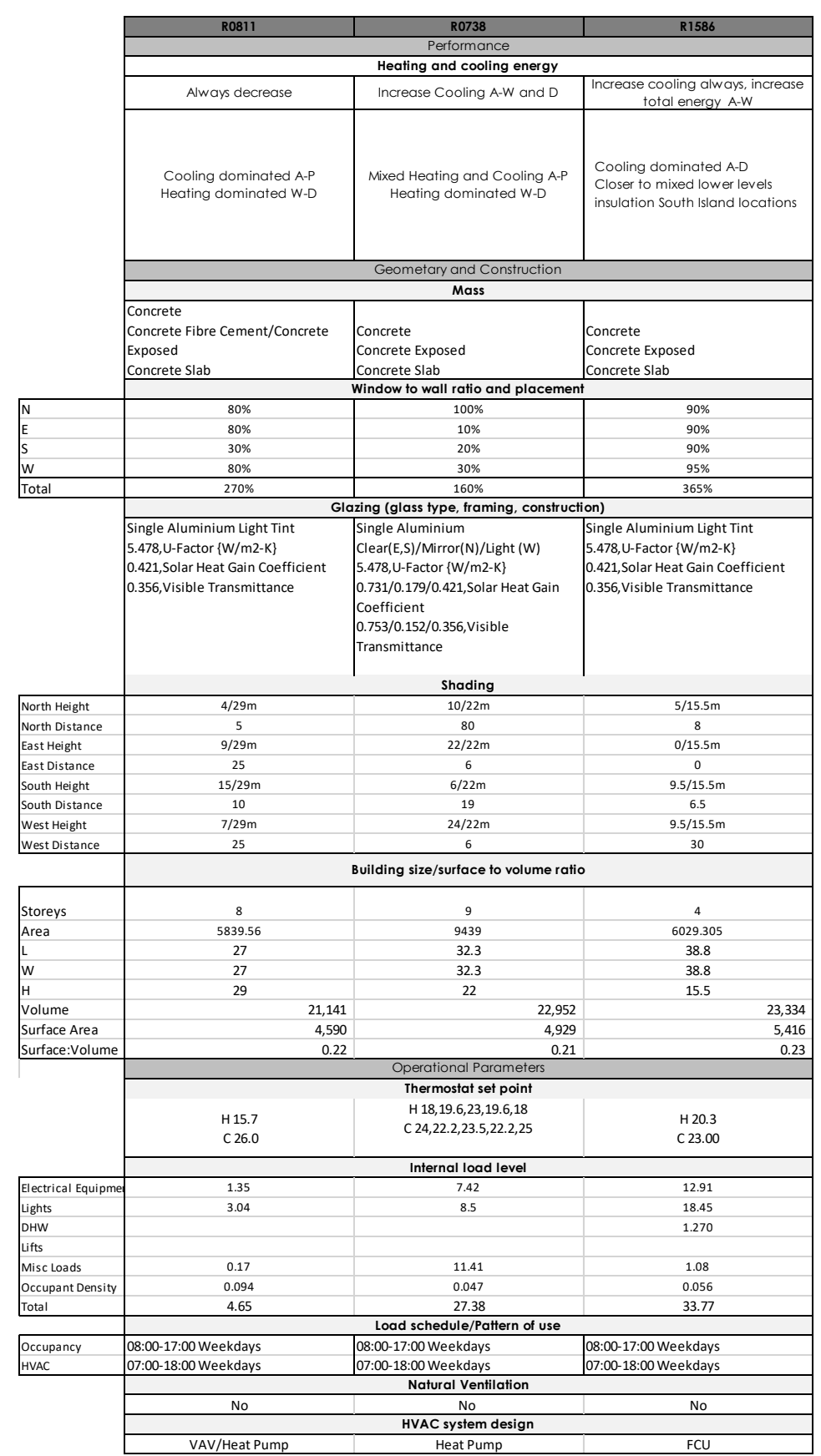

Table 26 Selected Buildings Comparison building attributes 


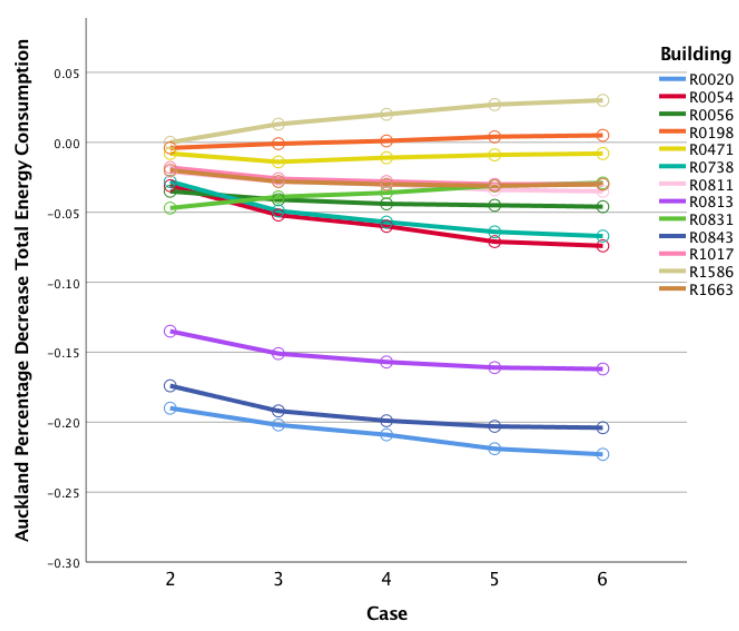

Figure 100 Percentage Reduction Total Energy Consumption of all buildings at each insulation case- Auckland

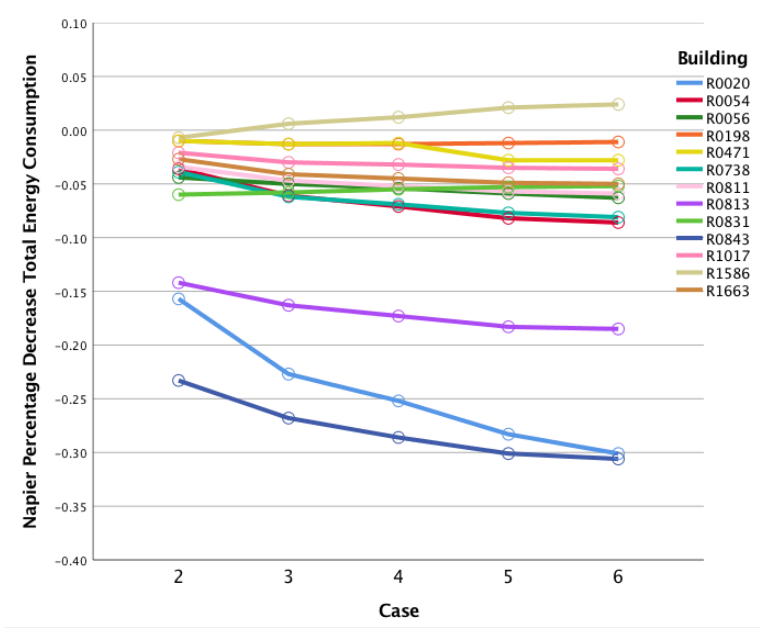

Figure 102 Percentage Reduction Total Energy Consumption of all buildings at each insulation case- Napier

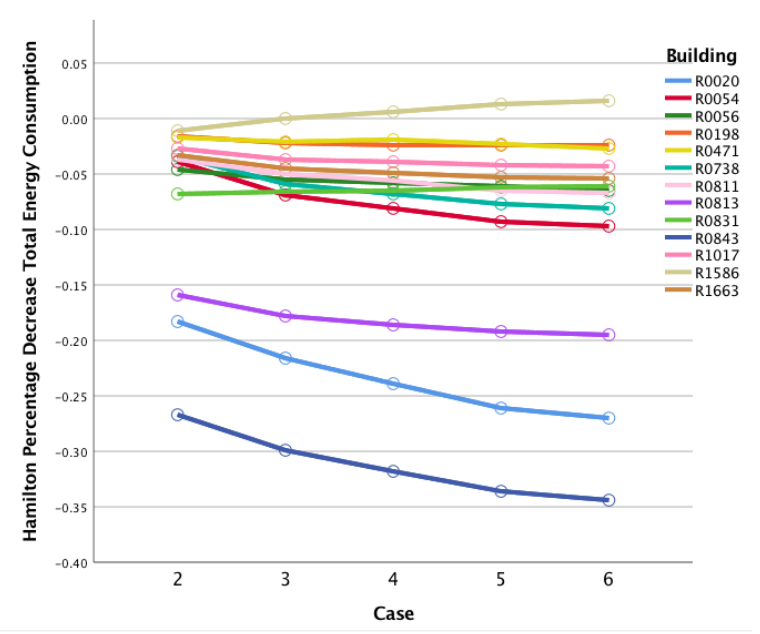

Figure 101 Percentage Reduction Total Energy Consumption of all buildings at each insulation case- Hamilton

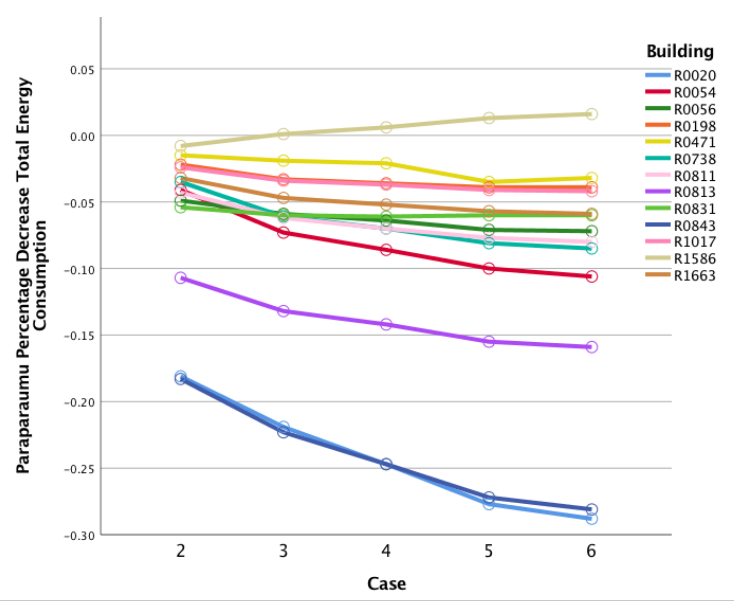

Figure 103 Percentage Reduction Total Energy Consumption of all buildings at each insulation case- Paraparaumu 


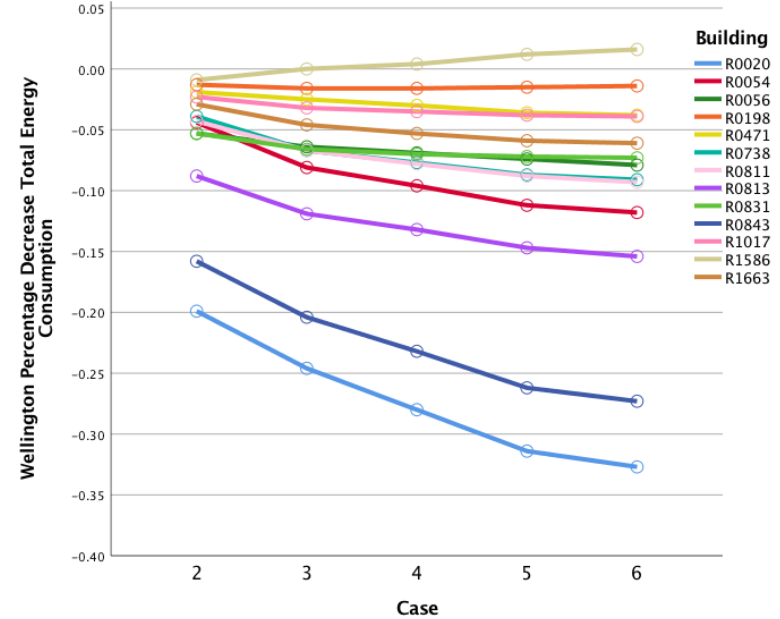

Figure 104 Percentage Reduction Total Energy Consumption of all buildings at each insulation case- Wellington

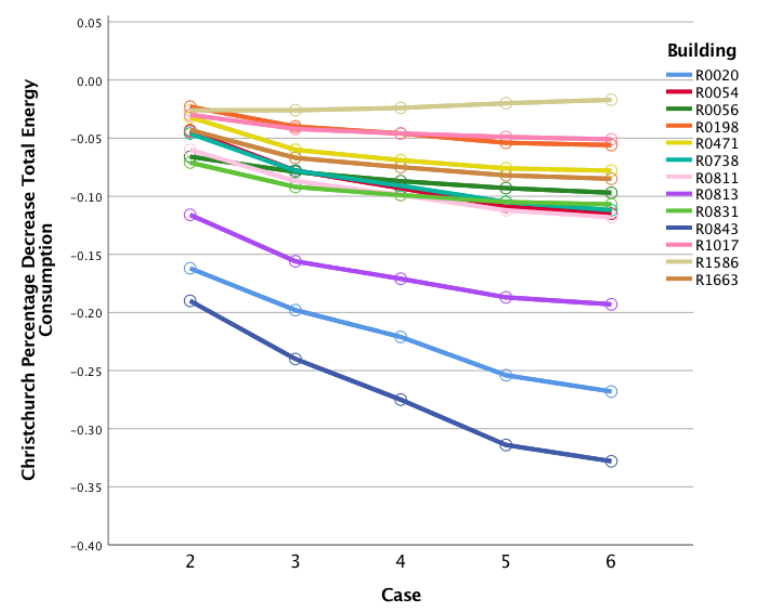

Figure 105 Percentage Reduction Total Energy Consumption of all buildings at each insulation caseChristchurch

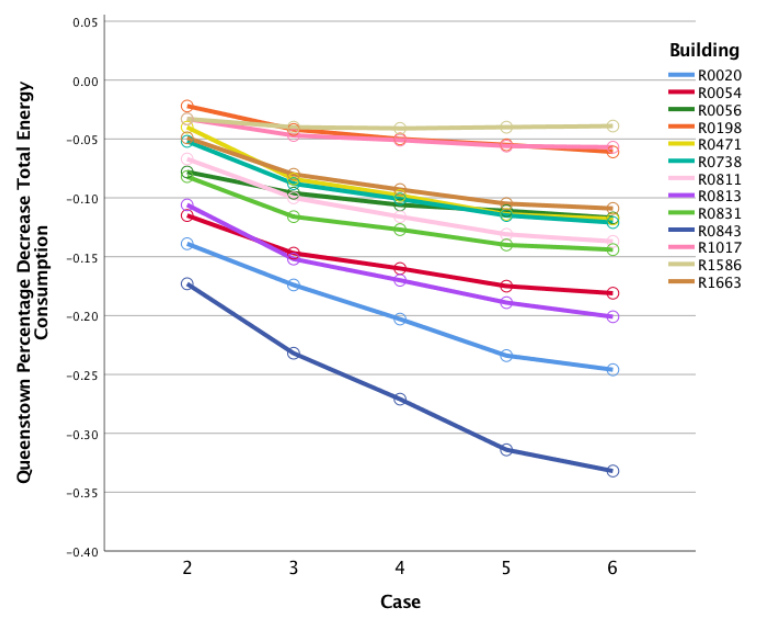

Figure 106- Percentage Reduction Total Energy Consumption of all buildings at each insulation case- Queenstown

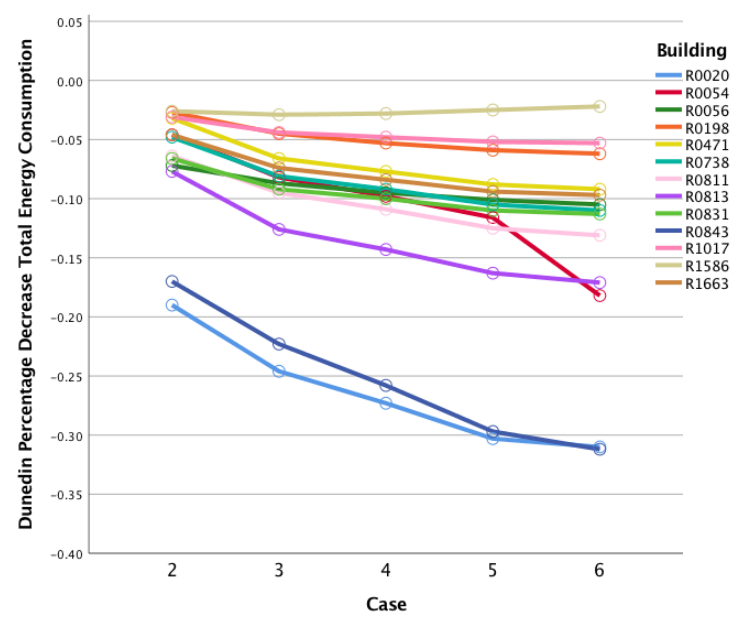

Figure 107 Percentage Reduction Total Energy Consumption of all buildings at each insulation case- Dunedin 


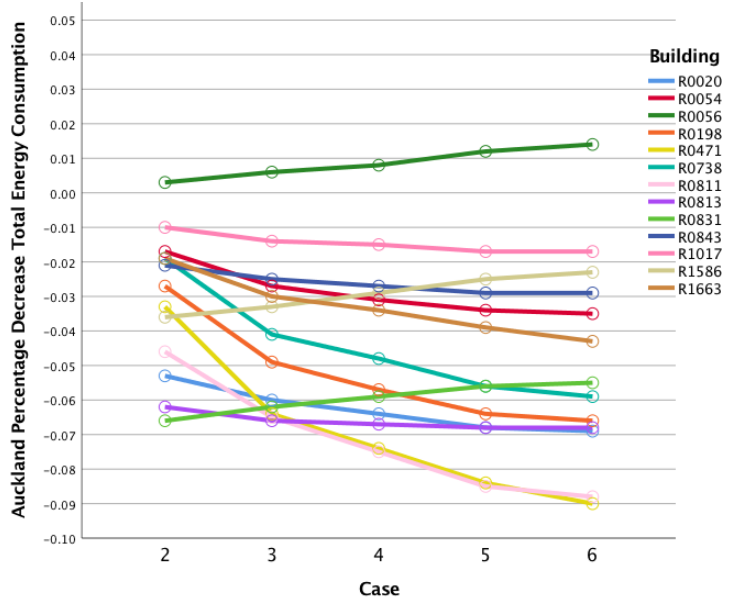

Figure 108 Percentage Reduction Total Energy Consumption of all buildings at each insulation case- Auckland

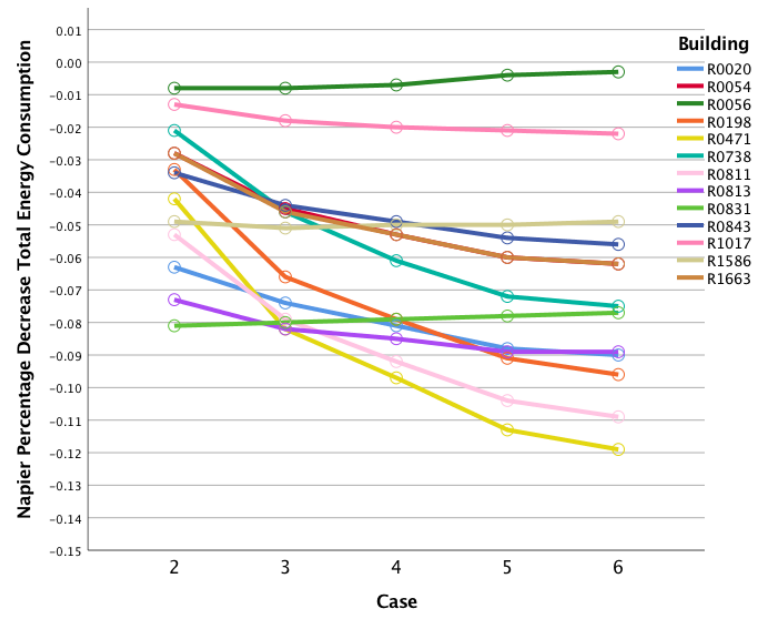

Figure 110 Percentage Reduction Total Energy Consumption of all buildings at each insulation case- Napier

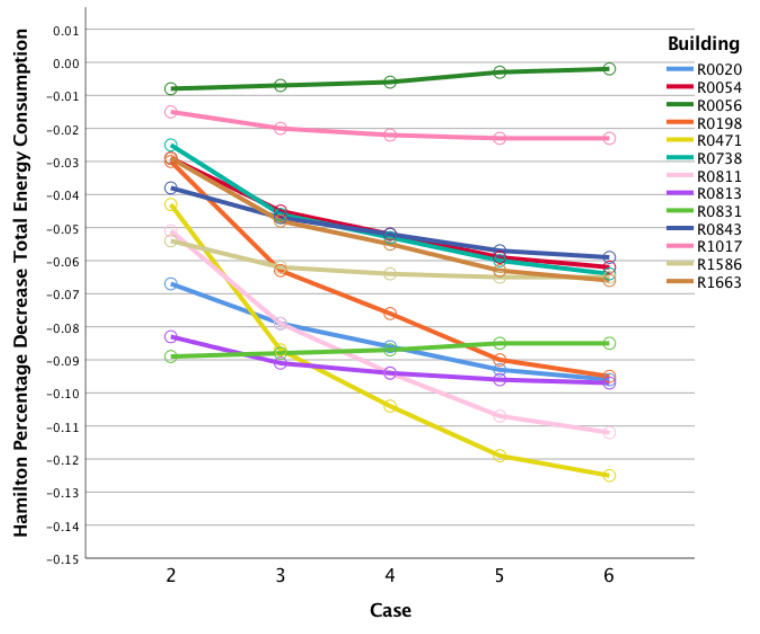

Figure 109 Percentage Reduction Total Energy Consumption of all buildings at each insulation case- Hamilton

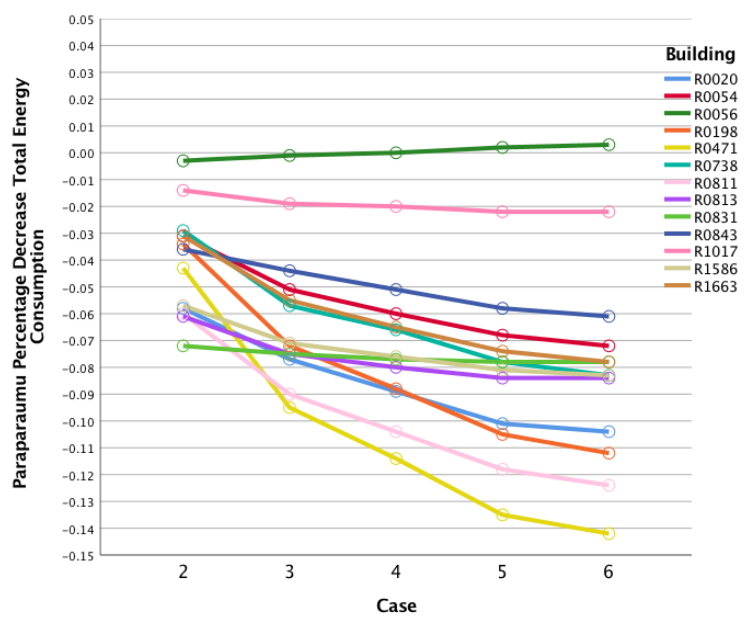

Figure 111 Percentage Reduction Total Energy Consumption of all buildings at each insulation case- Paraparaumu 


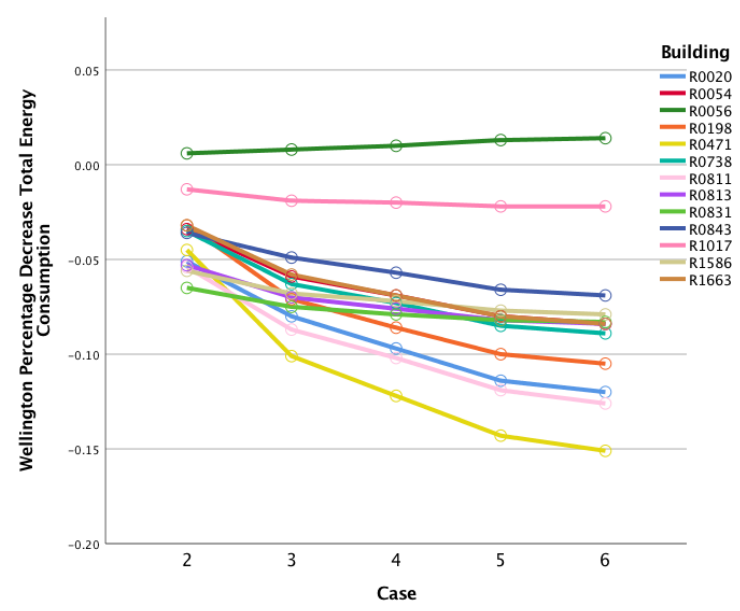

Figure 112 Percentage Reduction Total Energy Consumption of all buildings at each insulation case- Wellington

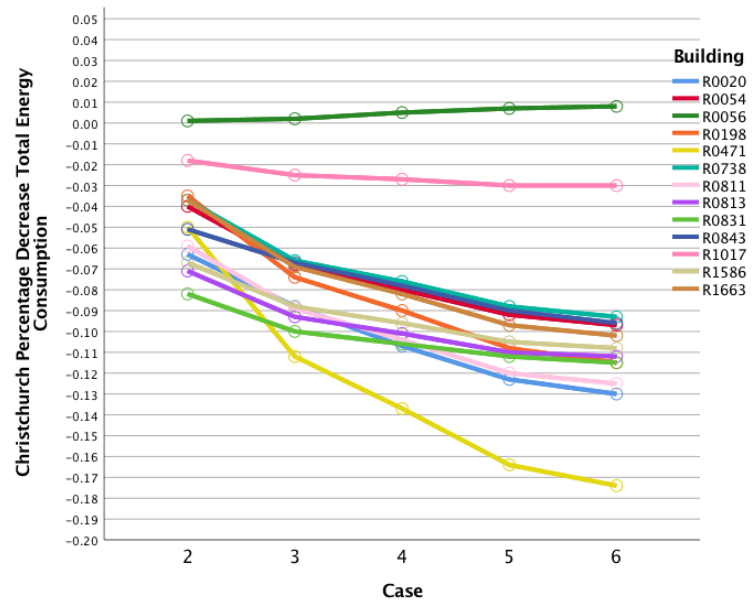

Figure 113 Percentage Reduction Total Energy Consumption of all buildings at each insulation caseChristchurch

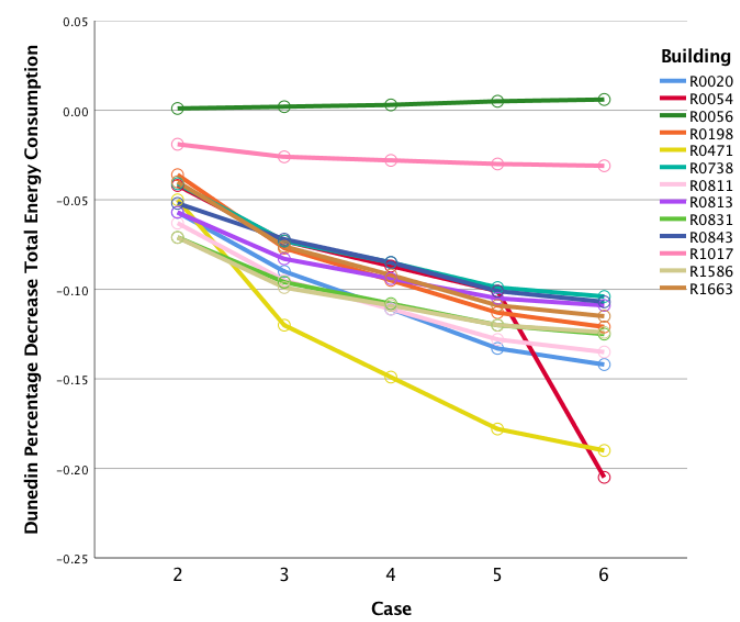

Figure 115 Percentage Reduction Total Energy Consumption of all buildings at each insulation case- Dunedin 


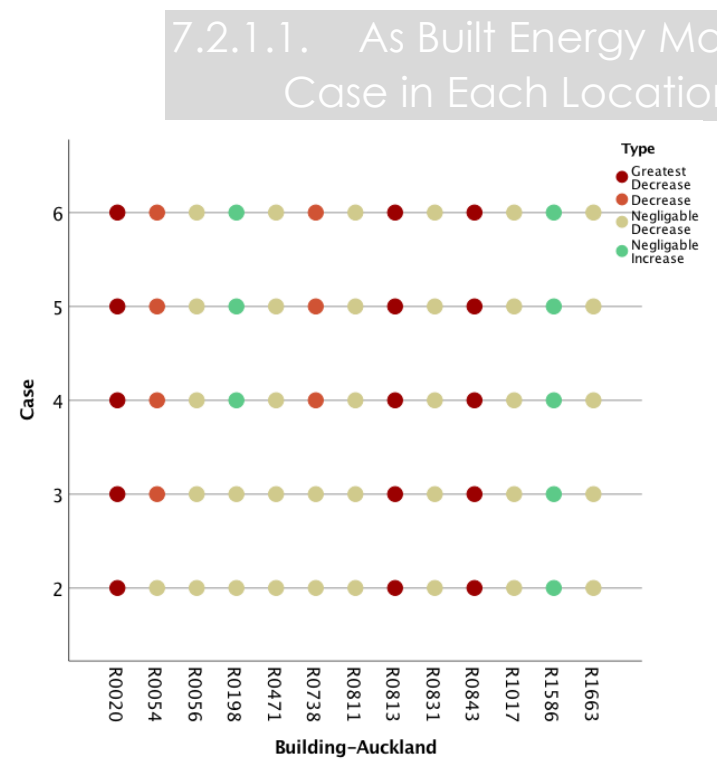

Figure 116 Effect on total energy consumption for building and case- Auckland

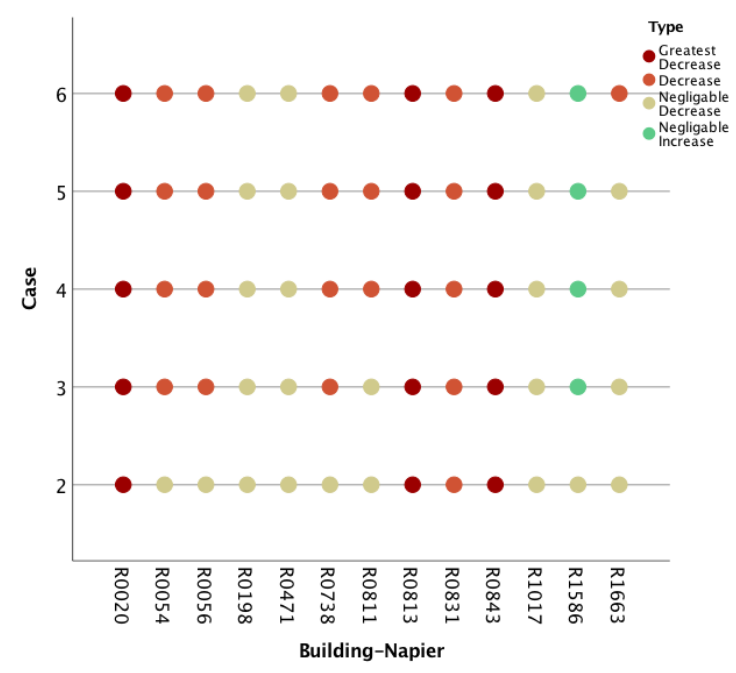

Figure 118 Effect on total energy consumption for building and case- Napier

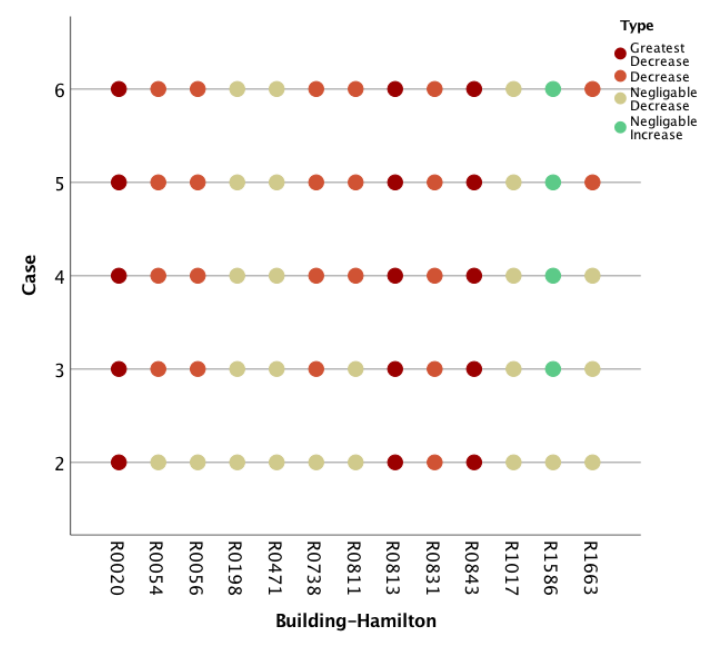

Figure 117 Effect on total energy consumption for building and case- Hamilton

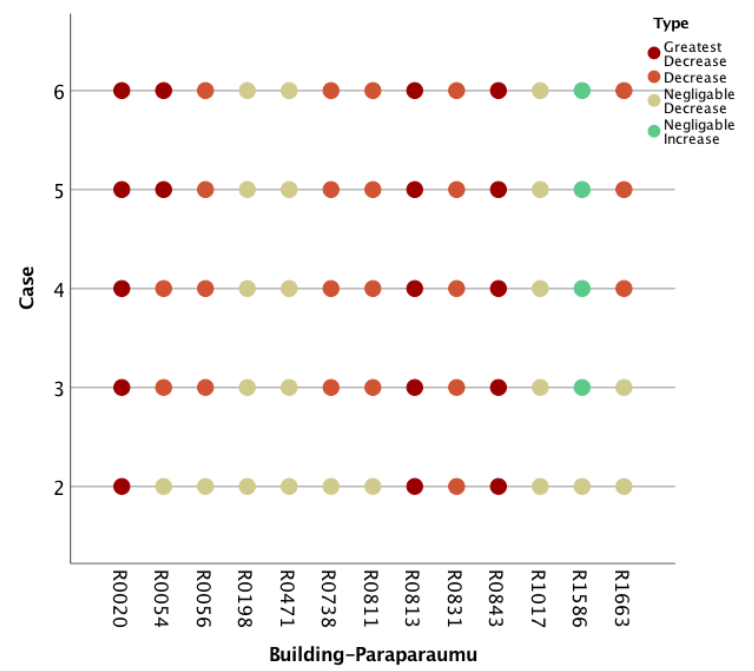

Figure 119 Effect on total energy consumption for building and case- Paraparaumu 


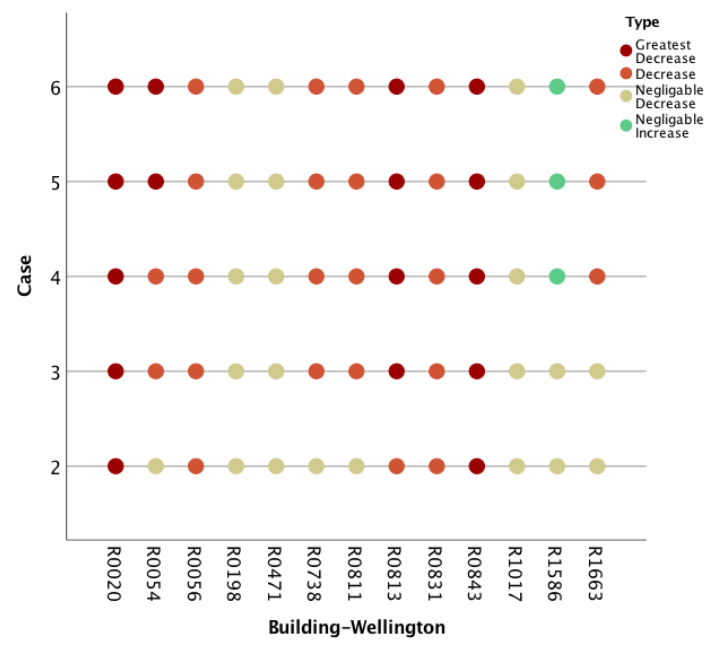

Figure 120 Effect on total energy consumption for building and case- Wellington

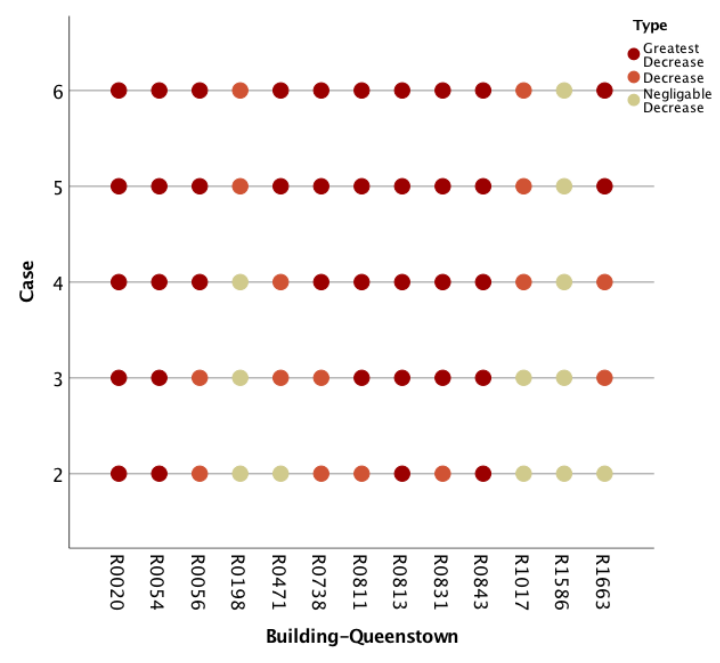

Figure 122 Effect on total energy consumption for building and case- Queenstown

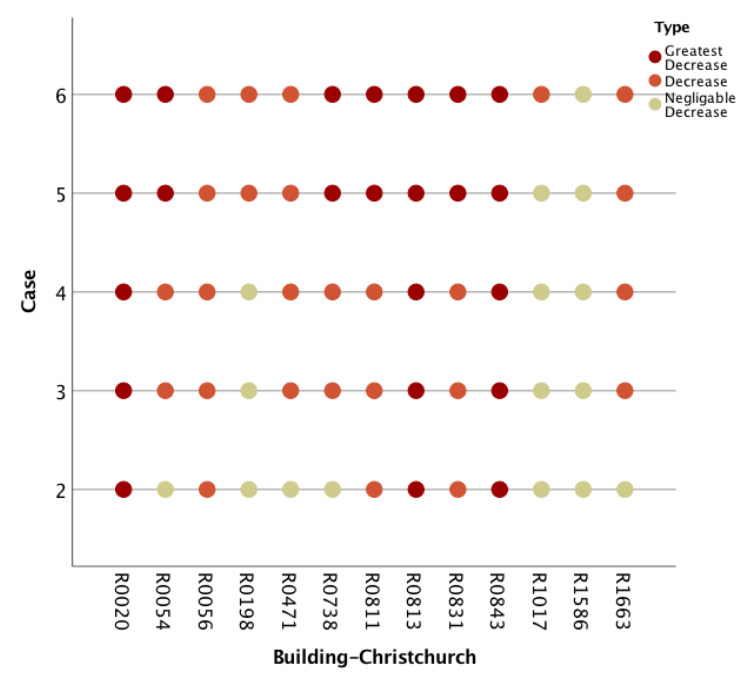

Figure 121 Effect on total energy consumption for building and case- Christchurch

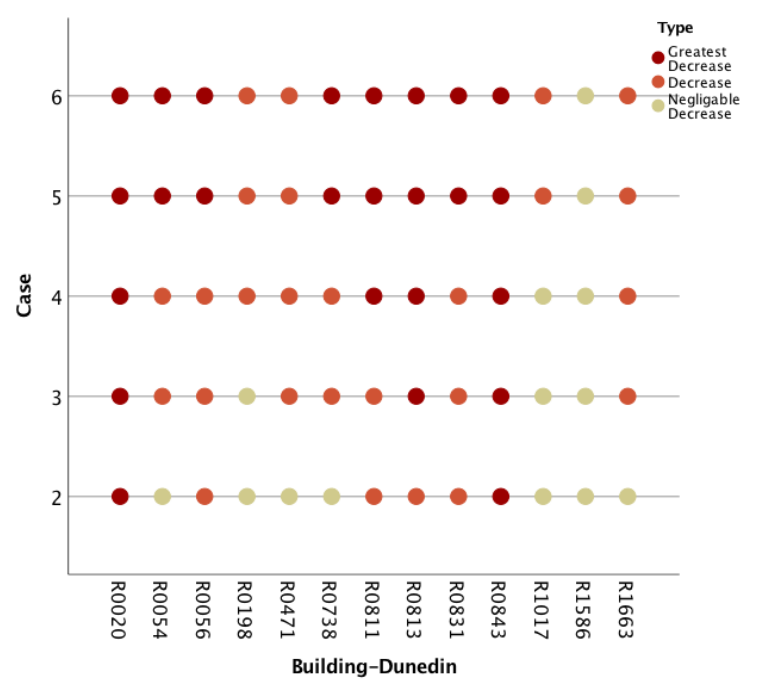

Figure 123 Effect on total energy consumption for building and case- Dunedin 


\begin{tabular}{|c|c|c|c|c|c|c|c|c|c|c|c|c|c|c|c|c|c|c|c|}
\hline & \multicolumn{3}{|c|}{1} & \multicolumn{3}{|c|}{2} & \multicolumn{3}{|c|}{3} & \multicolumn{3}{|c|}{4} & \multicolumn{3}{|c|}{5} & \multicolumn{3}{|c|}{6} \\
\hline & & Total & Heating & Cooling & \begin{tabular}{|l|} 
Total \\
\end{tabular} & Heating & Cooling & Total & Heating & Cooling & \begin{tabular}{|l|} 
Total \\
\end{tabular} & Heating & Cooling & \begin{tabular}{|l|} 
Total \\
\end{tabular} & Heating & Cooling & Total & Heating & Cooling \\
\hline \multirow{3}{*}{ Auckland } & $\min$ & 3.2 & 0.0 & 0.7 & 2.6 & 0.0 & 0.4 & 2.6 & 0.0 & 0.3 & 2.5 & 0.0 & 0.3 & 2.5 & 0.0 & 0.3 & 2.5 & 0.0 & 0.3 \\
\hline & $\max$ & 232.0 & 38.4 & 66.2 & 223.9 & 32.3 & 66.3 & 222.6 & 27.3 & 66.5 & 221.9 & 25.1 & 67.2 & 221.6 & 22.7 & 67.8 & 221.4 & 21.8 & 68.2 \\
\hline & average & 105.6 & 8.5 & 19.9 & 102.9 & 6.3 & 19.7 & 102.3 & 5.2 & 20.3 & 102.2 & 4.7 & 20.7 & 102.1 & 4.2 & 21.1 & 102.1 & 4.0 & 21.2 \\
\hline \multirow{3}{*}{ Hamilton } & $\min$ & 4.3 & 0.2 & 0.9 & 3.2 & 0.1 & 0.3 & 3.0 & 0.1 & 0.3 & 2.9 & 0.1 & 0.3 & 2.9 & 0.1 & 0.2 & 2.8 & 0.0 & 0.2 \\
\hline & $\max$ & 242.1 & 50.2 & 60.6 & 231.1 & 43.9 & 60.5 & 228.9 & 38.5 & 62.0 & 228.0 & 36.1 & 63.0 & 226.6 & 33.4 & 63.3 & 226.4 & 32.3 & 63.1 \\
\hline & average & 111.9 & 14.1 & 19.3 & \begin{tabular}{|l|}
107.4 \\
\end{tabular} & 11.1 & 18.6 & 106.3 & 9.5 & 19.2 & 105.9 & 8.8 & 19.6 & 105.5 & 8.0 & 19.9 & 105.3 & 7.7 & 20.0 \\
\hline \multirow{3}{*}{ Napier } & $\min$ & 3.7 & 0.0 & 0.8 & 2.9 & 0.0 & 0.3 & 2.7 & 0.0 & 0.3 & 2.7 & 0.0 & 0.3 & 2.6 & 0.0 & 0.2 & 2.6 & 0.0 & 0.2 \\
\hline & max & 240.5 & 49.1 & 67.1 & 230.0 & 42.5 & 67.5 & 228.4 & 37.0 & 69.0 & 227.4 & 34.6 & 69.8 & 225.6 & 31.9 & 68.5 & 225.3 & 30.9 & 68.7 \\
\hline & average & 111.6 & 12.6 & 20.0 & \begin{tabular}{|l|}
107.8 \\
\end{tabular} & 9.7 & 19.7 & 106.9 & 8.2 & 20.4 & \begin{tabular}{|l|l|}
106.6 \\
\end{tabular} & 7.5 & 20.8 & \begin{tabular}{|l|}
106.1 \\
\end{tabular} & 6.8 & 21.0 & 106.0 & 6.6 & 21.2 \\
\hline \multirow{3}{*}{ Paraparaumu } & $\min$ & 3.7 & 0.1 & 0.3 & 3.0 & 0.1 & 0.1 & 2.9 & 0.0 & 0.1 & 2.8 & 0.0 & 0.1 & 2.7 & 0.0 & 0.1 & 2.7 & 0.0 & 0.1 \\
\hline & $\max$ & 237.8 & 59.8 & 48.6 & 226.1 & 52.3 & 49.2 & 223.7 & 45.9 & 51.1 & 222.7 & 43.0 & 51.8 & 221.1 & 39.8 & 51.1 & 220.7 & 38.5 & 51.9 \\
\hline & average & 109.0 & 16.6 & 14.6 & \begin{tabular}{|l|l|}
104.8 \\
\end{tabular} & 13.0 & 14.6 & 103.4 & 11.1 & 15.3 & \begin{tabular}{|l|}
102.9 \\
\end{tabular} & 10.2 & 15.6 & \begin{tabular}{|l|}
102.2 \\
\end{tabular} & 9.3 & 15.9 & 102.0 & 8.9 & 16.1 \\
\hline \multirow{3}{*}{ Wellington } & $\min$ & 3.7 & 0.1 & 0.1 & 3.1 & 0.1 & 0.0 & 2.9 & 0.0 & 0.0 & 2.8 & 0.0 & 0.0 & 2.7 & 0.0 & 0.0 & 2.7 & 0.0 & 0.0 \\
\hline & $\max$ & 239.0 & 66.1 & 46.4 & 226.2 & 57.8 & 46.9 & 223.6 & 50.8 & 49.5 & 222.4 & 47.7 & 50.1 & 220.4 & 44.4 & 50.8 & 220.0 & 43.0 & 51.0 \\
\hline & average & 109.1 & 19.2 & 12.8 & 104.8 & 15.0 & 13.1 & 103.2 & 12.7 & 13.9 & 102.5 & 11.7 & 14.3 & 101.8 & 10.6 & 14.7 & 101.6 & 10.2 & 14.8 \\
\hline \multirow{3}{*}{ Christchurch } & $\min$ & 7.7 & 0.8 & 0.2 & 6.2 & 0.6 & 0.1 & 5.9 & 0.5 & 0.1 & 5.6 & 0.4 & 0.1 & 5.3 & 0.4 & 0.1 & 5.2 & 0.4 & 0.1 \\
\hline & $\max$ & 255.3 & 82.5 & 43.5 & 238.6 & 73.4 & 43.9 & 235.3 & 66.0 & 45.8 & 233.2 & 62.7 & 46.7 & 231.6 & 59.1 & 48.0 & 230.6 & 57.6 & 48.6 \\
\hline & average & 123.4 & 30.2 & 13.5 & 116.9 & 24.5 & 13.5 & 114.3 & 21.5 & 14.1 & 113.2 & 20.1 & 14.5 & 112.1 & 18.6 & 15.0 & 111.6 & 18.0 & 15.2 \\
\hline \multirow{3}{*}{ Queenstown } & $\min$ & 11.9 & 1.9 & 0.3 & 9.8 & 1.6 & 0.1 & \begin{tabular}{|l|}
9.1 \\
\end{tabular} & 1.3 & 0.1 & 8.7 & 1.1 & 0.1 & 8.1 & 1.0 & 0.1 & 7.9 & 0.9 & 0.1 \\
\hline & $\max$ & 267.6 & 101.5 & 41.8 & 246.7 & 84.1 & 41.7 & 241.9 & 80.3 & 42.6 & 239.3 & 77.0 & 43.4 & 237.0 & 73.7 & 44.1 & 236.3 & 72.4 & 44.8 \\
\hline & average & 136.0 & 42.9 & 12.0 & \begin{tabular}{|l|}
126.8 \\
\end{tabular} & 34.5 & 12.0 & 123.0 & 30.5 & 12.6 & \begin{tabular}{|l|}
121.4 \\
\end{tabular} & 28.6 & 12.9 & \begin{tabular}{|l|}
119.8 \\
\end{tabular} & 26.6 & 13.4 & 119.2 & 25.9 & 13.6 \\
\hline \multirow{3}{*}{ Dunedin } & $\min$ & 7.2 & 0.6 & 0.0 & 5.9 & 0.5 & 0.0 & 5.6 & 0.3 & 0.0 & 5.3 & 0.3 & 0.0 & 5.0 & 0.3 & 0.0 & 4.9 & 0.2 & 0.0 \\
\hline & $\max$ & 251.5 & 101.5 & 32.1 & 233.5 & 91.5 & 33.0 & 229.7 & 83.1 & 34.6 & 227.6 & 79.4 & 35.7 & 225.7 & 75.3 & 36.8 & 225.0 & 63.9 & 37.2 \\
\hline & average & 119.9 & 33.2 & 9.1 & 113.3 & 27.0 & 9.3 & 110.3 & 23.5 & 10.0 & 109.1 & 22.0 & 10.3 & $\mid 107.9$ & 20.3 & 10.8 & 106.4 & 19.0 & 10.8 \\
\hline
\end{tabular}

Table 27 Calibrated energy models- minimum, maximum and average $\mathrm{kWh} / \mathrm{m}^{2} / \mathrm{yr}$ for each location and Case

\begin{tabular}{|c|c|c|c|c|c|c|c|c|c|c|c|c|c|c|c|c|c|c|c|}
\hline & \multicolumn{3}{|c|}{1} & \multicolumn{3}{|c|}{2} & \multicolumn{3}{|c|}{3} & \multicolumn{3}{|c|}{4} & \multicolumn{3}{|c|}{5} & \multicolumn{3}{|c|}{6} \\
\hline & & Total & Heating & Cooling & Total & Heating & Cooling & Total & Heating & Cooling & Total & Heating & Cooling & Total & Heating & Cooling & Total & Heating & Cooling \\
\hline \multirow{3}{*}{ Auckland } & $\min$ & 79.9 & 3.5 & 4.4 & \begin{tabular}{|l|}
78.2 \\
\end{tabular} & 2.9 & 3.3 & 77.9 & 2.5 & 3.6 & \begin{tabular}{|l|}
77.7 \\
\end{tabular} & 2.3 & 3.7 & \begin{tabular}{|l|}
77.6 \\
\end{tabular} & 2.0 & 4.0 & 77.6 & 1.9 & 4.1 \\
\hline & $\max$ & 166.9 & 34.4 & 23.7 & $\mid 159.2$ & 30.4 & 24.2 & 156.0 & 25.6 & 24.0 & 154.3 & 23.7 & 24.5 & 152.7 & 21.7 & 25.2 & 152.2 & 20.9 & 25.2 \\
\hline & average & 110.4 & 14.4 & 14.4 & 107.0 & 12.0 & 13.8 & 105.7 & 10.6 & 14.2 & 105.3 & 10.0 & 14.4 & 104.9 & 9.3 & 14.6 & 104.7 & 9.1 & 14.7 \\
\hline \multirow{3}{*}{ Hamilton } & $\min$ & 81.2 & 7.0 & 4.1 & 80.5 & 6.5 & 2.9 & 80.6 & 5.8 & 3.2 & \begin{tabular}{|l|}
80.7 \\
\end{tabular} & 5.5 & 3.4 & 80.9 & 5.2 & 3.6 & 80.8 & 5.0 & 3.7 \\
\hline & $\max$ & 200.8 & 55.6 & 25.5 & 190.5 & 50.4 & 24.0 & 184.9 & 43.3 & 22.8 & 182.0 & 40.5 & 22.5 & $\mid 179.3$ & 37.4 & 23.1 & 178.3 & 36.3 & 23.4 \\
\hline & average & 122.9 & 25.3 & 14.3 & 117.6 & 22.0 & 13.1 & 115.5 & 20.0 & 13.3 & 114.6 & 19.1 & 13.4 & 113.7 & 18.1 & 13.7 & 113.4 & 17.7 & 13.7 \\
\hline \multirow{3}{*}{ Napier } & $\min$ & 81.5 & 6.1 & 4.1 & 80.9 & 5.7 & 3.0 & 80.6 & 5.0 & 3.2 & 75.6 & 5.1 & 1.5 & 75.8 & 4.8 & 1.6 & 75.8 & 4.7 & 1.7 \\
\hline & $\max$ & 194.6 & 50.6 & 27.1 & $\mid 184.4$ & 45.5 & 26.0 & 179.2 & 38.9 & 26.5 & 182.4 & 45.6 & 18.5 & $\mid 179.4$ & 42.0 & 18.1 & 178.2 & 40.6 & 17.9 \\
\hline & average & 121.0 & 22.8 & 14.6 & 116.1 & 19.5 & 13.6 & 114.1 & 17.6 & 13.8 & 113.2 & 16.8 & 13.9 & 112.3 & 15.8 & 14.1 & 112.0 & 15.5 & 14.2 \\
\hline \multirow{3}{*}{ Paraparaumu } & $\min$ & 75.6 & 6.7 & 2.0 & \begin{tabular}{|l|}
74.8 \\
\end{tabular} & 9.1 & 1.0 & 75.0 & 8.1 & 1.1 & 75.1 & 7.4 & 1.2 & \begin{tabular}{|l|}
75.4 \\
\end{tabular} & 6.6 & 1.4 & \begin{tabular}{|l|l|}
75.4 \\
\end{tabular} & 6.3 & 1.4 \\
\hline & $\max$ & 203.5 & 63.4 & 21.6 & 184.3 & 64.6 & 14.9 & 177.9 & 55.1 & 14.3 & 174.9 & 51.3 & 14.7 & $\mid 171.7$ & 47.2 & 15.3 & 170.3 & 45.7 & 15.6 \\
\hline & average & 120.5 & 28.0 & 9.5 & 115.5 & 24.3 & 8.9 & 112.8 & 21.8 & 9.1 & 111.7 & 20.7 & 9.2 & 110.5 & 19.5 & 9.4 & 110.1 & 19.1 & 9.4 \\
\hline \multirow{3}{*}{ Wellington } & $\min$ & 74.4 & 10.9 & 1.5 & 75.3 & 14.6 & 1.1 & 75.4 & 13.2 & 1.3 & 75.6 & 12.7 & 1.4 & 75.8 & 12.1 & 1.5 & 75.9 & 11.8 & 1.6 \\
\hline & $\max$ & 194.8 & 71.2 & 16.0 & 229.8 & 94.5 & 18.1 & 222.5 & 82.0 & 17.3 & 218.7 & 76.8 & 16.9 & 214.9 & 71.3 & 16.6 & 213.5 & 69.1 & 16.4 \\
\hline & average & 120.5 & 28.0 & 9.5 & 115.4 & 27.9 & 7.4 & 112.4 & 25.0 & 7.6 & 111.2 & 23.7 & 7.7 & 109.9 & 22.3 & 7.9 & 109.4 & 21.7 & 8.0 \\
\hline \multirow{3}{*}{ Christchurch } & $\min$ & 75.2 & 15.5 & 1.8 & \begin{tabular}{|l|}
75.3 \\
\end{tabular} & 14.6 & 1.1 & 75.4 & 13.2 & 1.3 & \begin{tabular}{|l|}
75.6 \\
\end{tabular} & 12.7 & 1.4 & \begin{tabular}{|l|}
75.8 \\
\end{tabular} & 12.1 & 1.5 & \begin{tabular}{|l|l|}
75.9 \\
\end{tabular} & 11.8 & 1.6 \\
\hline & $\max$ & 244.1 & 103.3 & 19.4 & \begin{tabular}{|l|}
229.8 \\
\end{tabular} & 94.5 & 18.1 & 222.5 & 82.0 & 17.3 & 218.7 & 76.8 & 16.9 & 214.9 & 71.3 & 16.6 & 213.5 & 69.1 & 16.4 \\
\hline & average & 141.1 & 48.9 & 8.6 & 134.3 & 43.2 & 8.0 & 130.4 & 39.5 & 8.2 & 128.7 & 37.8 & 8.3 & 126.9 & 35.9 & 8.5 & 126.2 & 35.2 & 8.6 \\
\hline \multirow{3}{*}{ Queenstown } & $\min$ & 74.7 & 21.3 & 1.7 & 74.5 & 20.2 & 0.9 & 74.5 & 18.6 & 1.0 & 74.6 & 17.9 & 1.1 & \begin{tabular}{|l|}
74.7 \\
\end{tabular} & 17.1 & 1.2 & \begin{tabular}{|l|}
74.7 \\
\end{tabular} & 16.8 & 1.3 \\
\hline & $\max$ & 266.0 & 124.4 & 15.6 & 251.6 & 114.6 & 14.4 & 243.0 & 99.3 & 13.7 & 238.6 & 93.1 & 13.9 & 234.0 & 86.3 & 14.4 & 232.3 & 83.7 & 14.7 \\
\hline & average & 154.8 & 64.0 & 7.0 & 146.0 & 56.2 & 6.4 & 141.1 & 51.5 & 6.7 & 138.9 & 49.3 & 6.8 & 136.5 & 47.0 & 7.0 & 135.6 & 46.0 & 7.1 \\
\hline \multirow{3}{*}{ Dunedin } & $\min$ & 71.6 & 17.8 & 0.5 & \begin{tabular}{|l|}
71.6 \\
\end{tabular} & 16.7 & 0.2 & \begin{tabular}{|l|l|}
71.7 \\
\end{tabular} & 15.0 & 0.3 & \begin{tabular}{|l|}
71.8 \\
\end{tabular} & 14.4 & 0.3 & \begin{tabular}{|l|}
71.9 \\
\end{tabular} & 13.6 & 0.4 & 72.0 & 13.3 & 0.4 \\
\hline & $\max$ & 234.9 & 110.3 & 13.1 & 220.1 & 100.9 & 12.0 & 212.5 & 87.0 & 11.2 & 208.7 & 81.3 & 10.8 & 204.8 & 75.1 & 10.4 & 203.1 & 72.7 & 10.2 \\
\hline & average & 139.4 & 54.2 & 4.6 & 132.7 & 47.9 & 4.3 & 128.2 & 43.6 & 4.5 & 126.2 & 41.6 & 4.5 & 124.1 & 39.4 & 4.7 & 122.1 & 37.8 & 4.5 \\
\hline
\end{tabular}

Table 28 NZS4243 Standardised energy models- minimum, maximum and average $\mathrm{kWh} / \mathrm{m}^{2} / \mathrm{yr}$ for each location and Case 